\title{
REVESTIMIENTO PARA EDIFICACIÓN CON PROPIEDADES BIO-RECEPTIVAS MEJORADAS: MORTERO MPC CON SUBPRODUCTOS INDUSTRIALES Y BRIÓFITO COMO ESPECIE COLONIZADORA PIONERA
}





\section{Agradecimientos}

Quiero expresar mi más sincero agradecimiento, en primer lugar a mis directores de Tesis, D. Eduardo Montero García y D. Javier Garabito López. Sin su ayuda y dedicación no podría haber terminado esta empresa.

A Dani por embarcarse conmigo en esta "marcianada" que nos llevaba a puerto desconocido y que nos ha proporcionado muy buenas experiencias en estos largos años.

A Javier Martínez. Contigo empezó todo y sin tu experiencia no se habría llevado a cabo. Gracias por tu ayuda y apoyo incondicional.

Al departamento de Materiales de Contrucción, en especial a Ángel, Verónica, Pablo y José Luis. Gracias por haberme abierto el laboratorio de par en par, por vuestra dedicación y haberme ayudado en todo momento.

A Carlos Rad por su interés en la investigación y aportación de ideas interesantes en un campo tan desconocido.

A Jorge Miñón: los resultados positivos finales son gracias a tu investigación.

A Magnesitas Navarras, en especial a Presen y Maitane. Sin vuestra aportación de conocimientos esto se hubiera ido al traste.

A Javi y Carlos. Profesionalmente por todo. Personalmente, no cabría en estas pocas líneas. Gracias por permitirme compaginar la tesis con el estudio y por darme ese empujoncillo para llevarla a cabo.

A mis padres por aguantarme y comprenderme. 


\section{Resumen}

El aumento del interés por el urbanismo y la arquitectura sostenible y ecológica ha marcado un cambio significativo en la conciencia de las naciones y de las directrices políticas. La búsqueda de formas naturales es simplemente la ejemplización de un modelo de urbanismo que cada vez pretende ser menos invasivo con su entorno. La existencia de cubiertas vegetales y/o ajardinadas es una de las primeras expresiones de esta mayor amabilidad del "asfalto" con la "tierra".

La utilización de fachadas vegetales es una idea clásica, empleándose desde hace siglos son, principalmente, las plantas trepadoras. Esta idea de "ambientación" ha ido evolucionando a lo largo de los años, si bien, básicamente se ha seguido centrando en las cubiertas o tejados verdes y bien poco en fachadas, hasta que, ya en los años ochenta Patrick Blanc, patentó su sistema de jardín vertical.

Sin embargo este tipo de conjuntos requiriere de un mantenimiento continuado a parte de la necesidad de riego y reposición constante de los plantas, lo cual lo hace caro.

El planteamiento de esta investigación es proponer una versión tan simplificada de este concepto de jardín vertical que fuera viable su implantación a gran escala.

Para ello es necesario explorar la capacidad bio-receptiva de los materiales, es decir, la propensión que tienen a ser colonizados por plantas criptógamas. De este modo se puede conseguir que el mismo material sirva de revestimiento y sustrato para el crecimiento biológico, consiguiendo un menor coste de mantenimiento y la auto-regeneración de la envolvente verde.

De este modo se investiga un mortero para envolventes, cuyas propiedades bio-receptivas han sido mejoradas empleando como base los cementos de magnesio fosfato. Este, a su vez, incorpora subproductos procedentes de distintas industrias con el fin de mejorar la sostenibilidad del conjunto e implementar el concepto de economía circular.

Sobre dicho soporte se cultiva una especie de briófito, que actua como especie pionera, fomentando, de este modo, la colonización de esta u otros tipos de especies la superficie.

En base a lo expuesto, se procedió a una caracterización de las principales propiedades que influyen en la bio-receptividad: $\mathrm{pH}$, conductividad eléctrica, rugosidad y capacidad de absorción, siendo la gran mayoría de resultados óptimos para conseguir el desarrollo de vida vegetal. Posteriormente se caracterizaron otras propiedades físicas y mecánicas.

En el proceso de evaluación del crecimiento biológico, las muestras fueron expuestas a condiciones ambientales, no obteniéndose los resultados óptimos buscados. Finalmente se evaluó la capacidad colonizadora del material mediante su exposición a micro-algas, logrando buenos resultados. 


\section{Índice}

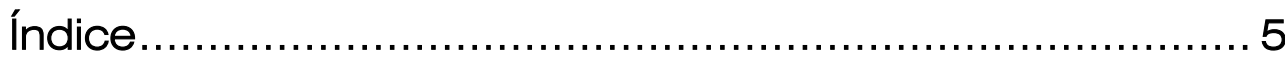

Capítulo 1. Introducción ............................................ 9

1. Justificación del tema elegido ........................................... 9

2. Sostenibilidad y desarrollo ............................................... 11

3. Contexto histórico......................................................... 12

4. Situación actual ........................................................ 19

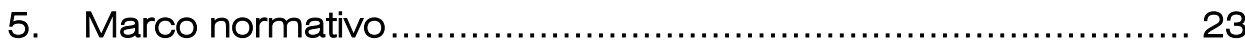

5.1. El marco normativo de la Unión Europea .................................. 23

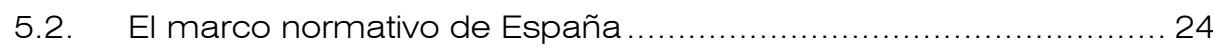

Capítulo 2.Objetivos .............................................. 28

1. Objetivos generales............................................................ 28

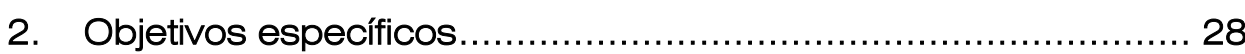

Capítulo 3. Revisión estado del arte .............................. 31

1. Los sistemas de fachadas vegetales.................................. 31

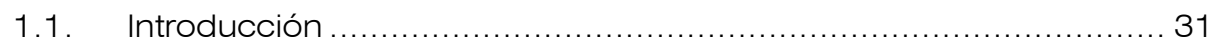

1.2. Sistema con plantas trepadoras o colgantes. ........................... 32

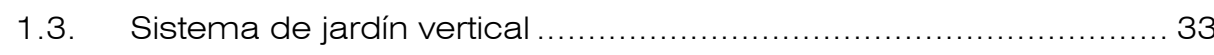

2. Sistemas que incorporan briófitos ................................... 35

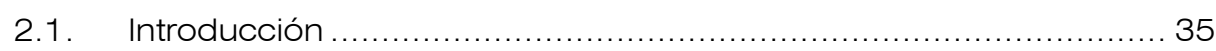

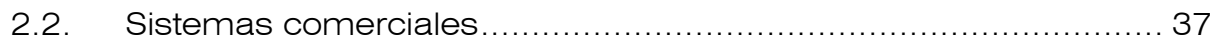

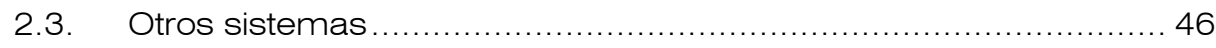

2.4. Otros sistemas en investigación ............................................ 47

3. Sistemas que exploran la bio-receptividad de los materiales ... 48

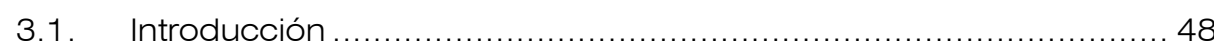

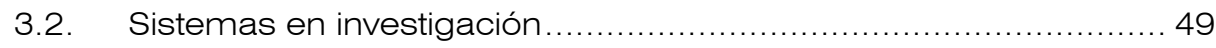

3.3. Proyectos desarrollados en BiotA Lab...................................... 55 


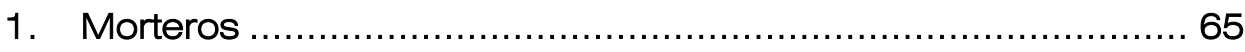

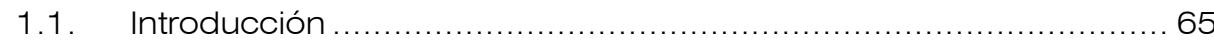

1.2. Breve revisión de la historia de los morteros ........................... 65

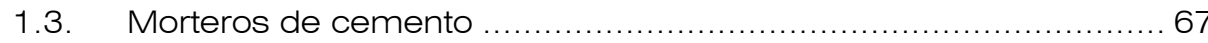

1.4. Propiedades de los morteros de cemento ............................ 70

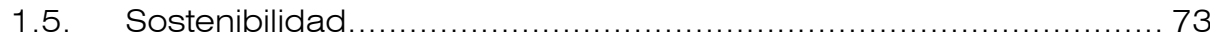

1.6. Bio-receptividad de los morteros .................................... 73

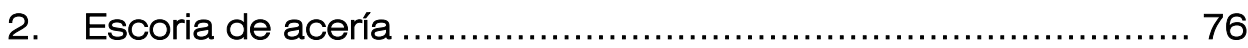

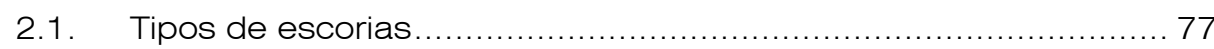

2.2. Producción de escorias de horno eléctrico (EAFS) ................... 79

2.3. Propiedades de las escorias negras de horno eléctrico (EAFS) ... 81

2.4. Valorización de las escorias negras de horno eléctrico (EAFS) ..... 82

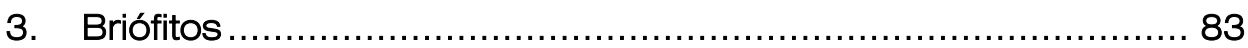

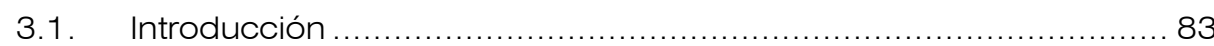

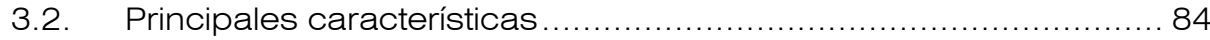

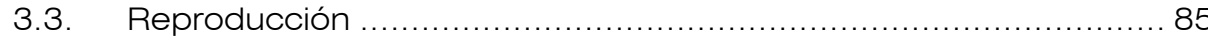

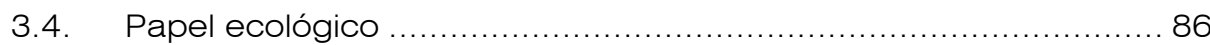

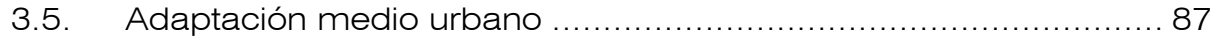

3.6. Requerimientos de la especie de briófito ......................... 87

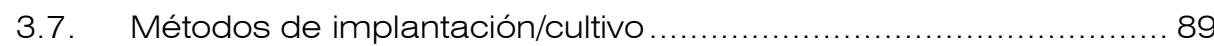

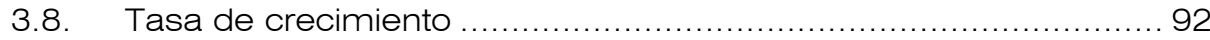

Capítulo 5. Metodología experimental ........................... 97

1. Caracterización del mortero MPC................................... 97

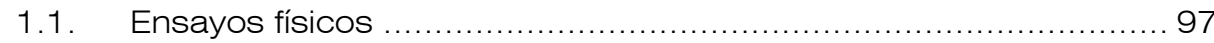

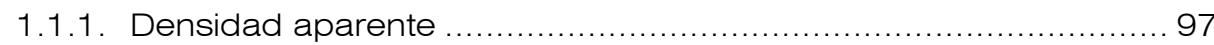

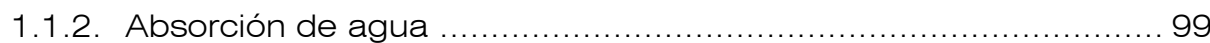

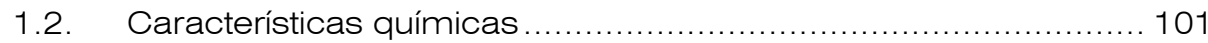

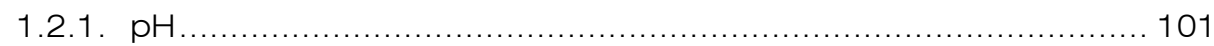

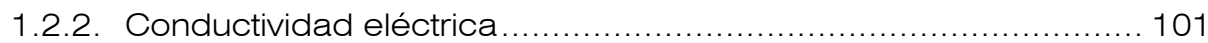

1.3. Características mecánicas ........................................ 102

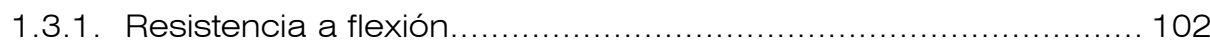

1.3.2. Resistencia a compresión ....................................... 104 


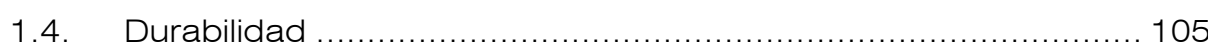

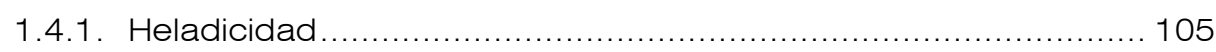

2. Caracterización conjunto soporte + briófito ........................ 107

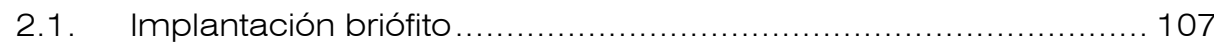

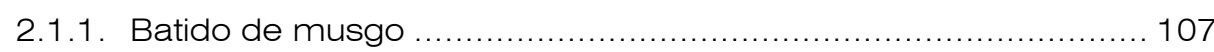

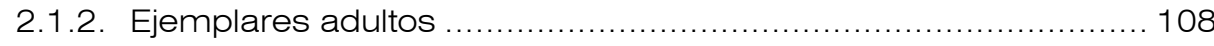

2.2. Evaluación bio-receptividad con mico-algas........................ 109

Capítulo 6. Caracterización del mortero ........................ 115

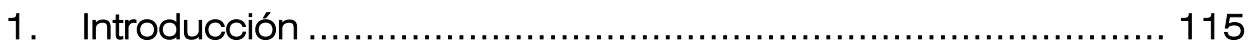

1.1. Criterios de referencia ................................................. 115

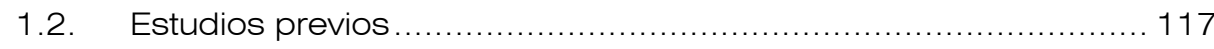

1.3. Elaboración del mortero propuesto ............................... 119

1.4. Adición de áridos a partir de residuos ................................. 120

2. Caracterización de las materias primas ........................ 122

2.1. Óxido de magnesio, MgO ....................................... 123

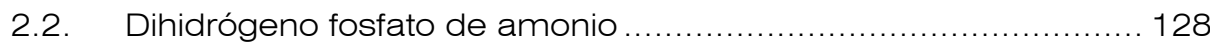

2.3. Tetraborato de sodio ........................................... 129

2.4. Escoria negra de alto horno (EAFS) ............................. 130

2.4.1. Caracterización química y mineralógica.......................... 131

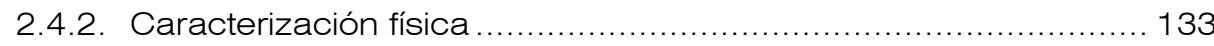

3. Fabricación y caracterización del mortero ........................ 135

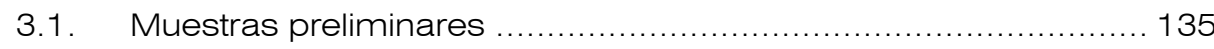

3.1.1. Justificación de las dosificaciones empleadas ..................... 135

3.1.2. Fabricación de las muestras preliminares....................... 137

3.2. Dosificación y fabricación del mortero de referencia................ 145

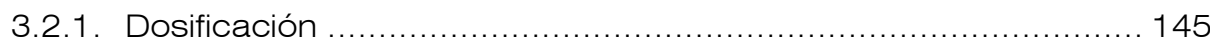

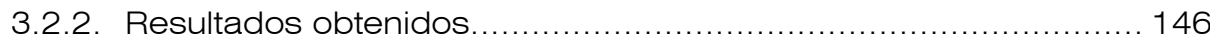

3.3. Dosificación y fabricación del mortero con adición de EAFS ....... 153

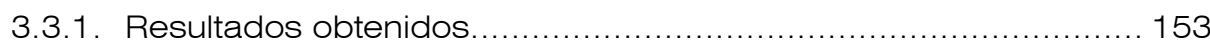

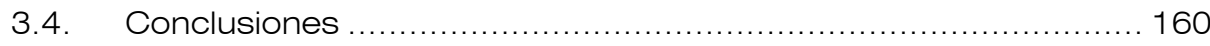

Capítulo 7. Caracterización conjunto mortero + briófito .. 167

1. Especie vegetal escogida........................................ 167

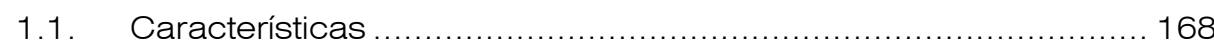


2. Estudios previos ......................................................... 171

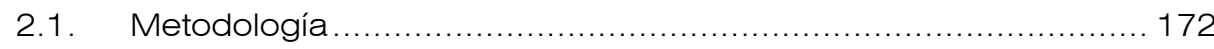

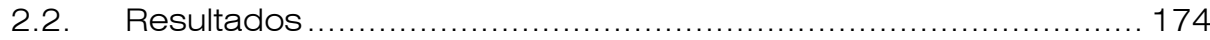

3. Colonización vegetal del mortero ................................. 175

3.1. Cuantificación de la bio-receptividad ................................... 175

3.2. Fase experimental 1. Batido de musgo. ............................... 176

3.3. Fase experimental 2. Ejemplares adultos .............................. 187

3.4. Fase experimental 3. Utilización otros briófitos .......................... 188

3.5. Fase experimental 4. Utilización de microalgas ........................ 194

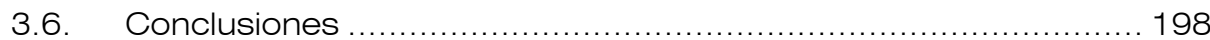

Capítulo 8. Conclusiones y líneas de investigación .......... 201

1. Conclusiones generales .................................................... 201

2. Conclusiones específicas .............................................. 202

2.1. Mortero MPC ................................................................... 202

2.2. Colonización vegetal ........................................................ 203

3. Futuras líneas de investigación....................................... 204

Anexo. Producción científica ...................................... 205

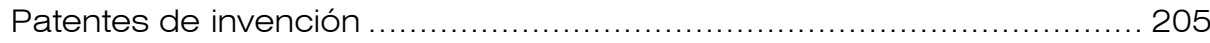

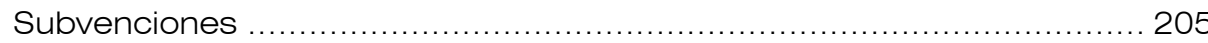

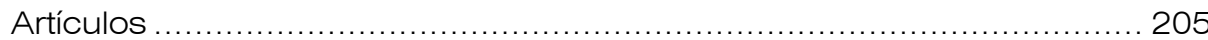

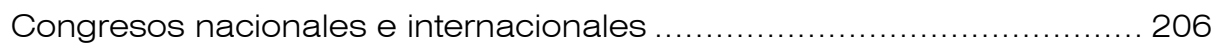




\section{Capítulo 1. Introducción}

\section{Justificación del tema elegido}

La investigación sobre la utilización de vegetación en las envolventes de los edificios en los últimos años se ha reducido a dos variantes: el uso ornamental de plantas en fachadas y las cubiertas vegetales.

El primer sistema viene utilizándose desde tiempo inmemorial, pero su empleo se ha centrado más el cariz ornamental o de "piel" superpuesta al edificio, no llegándose a integrar en los mismos.

Las cubiertas vegetales vienen siendo el sistema más investigado con vegetación de la envolvente del edificio. Su uso secular ha permitido la elaboración de innumerables investigaciones que han permitido el avance y la comercialización de sistemas, con sus consecuentes ventajas, destacando la capacidad de retención de agua, la mejora del clima urbano, evitando el efecto "isla de calor", la reducción de la contaminación, la mejora en la protección contra el ruido o la creación de espacios verdes.

Sin embargo no se ha llegado a explorar una veta viable de la transposición de ese tipo de ventajas que confieren las cubiertas vegetales a las fachadas del mismo, como parte integrante.

En este sentido, la nueva reformulación de las políticas ambientales de la Unión Europea, requieren una revisión de los tipos de ciudades de los estados miembro, demandándose unos entornos más amables, donde los propios edificios, elementos más visuales de la antropización, asuman las funciones del medio que han transformado.

A su vez, se requiere cada vez una mejora del impacto que el propio ser humano causa sobre el medio ambiente y sobre la salud de la población. Un impulso claro en favor del empleo de materiales reciclados, que reduzcan a su vez el consumo energético norenovable.

Por ello actuar sobre las envolventes de los edificios, que llegan a consumir el $40 \%$ del total de la energía del país [1], es clave. El incremento en número de las edificaciones, los hábitos de consumo y una mejora del nivel de vida, hacen prever unas tendencias futuras al alza en cuanto al impacto del parque edificatorio y residencial en la demanda energética.

Se ha optado por estudiar un sistema constructivo sobre la premisa de que una especie vegetal y que el conjunto simplifique en gran medida la escasa oferta comercial que actualmente existe. Dicho panel se debería componer básicamente de dos capas: una vegetal y un soporte sobre el que crece. Este sistema deberá integrarse en la propia 
fachada, formando parte de ella, gracias a lo cual se beneficiará la envolvente de varias de las propiedades que se aportarían si se trasladara una cubierta vegetal al plano vertical.

Pero para que dicho sistema sea viable se deberá componer de elementos que de por sí aporten un plus al desarrollo sostenible, reutilizando subproductos de procesos industriales o incluso productos de desecho, para conseguir un plus ecológico del propio sistema.

El sistema se basa en la utilización combinada de tres productos: Mortero bio-receptivo, escoria siderúrgica de alto horno y cobertura vegetal a base de un briófito tapizante.

La utilización de cada elemento por separado, no justifica su uso per se, sino que forma un conjunto en el que cada elemento tiene una función razonada.

La elección de un briófito tapizante como elemento vegetal, y única capa vista del sistema, tiene diversas justificaciones. Por un lado, la puramente estética. La utilización de envolventes verdes en edificio, confiere al mismo una apariencia más amigable. Recientemente Francia ha comenzado a obligar a todas las nuevas edificaciones para que dispongan de una cubierta verde, en caso de no colocar paneles solares. La visual aérea de una ciudad como Copenhague o Toronto las hace más atractivas a la vista.

Por otro lado y desde un punto de vista científico los briófitos utilizados en el panel ayudarían frente a la contaminación ambiental, ya que realizan la fotosíntesis, contribuyendo a fijar CO2. También ayudarían a eliminar el efecto "isla de calor". Los briófitos retienen gran cantidad de agua, evitando su rápida pérdida y los problemas derivados de la erosión hídrica.

También ejercerían como un aislante térmico del edificio. Al acumular grandes cantidades de agua, esta ejerce de "colchón térmico" evitando tanto la pérdida de calor muy rápida, como la contraria.

Respecto a la idoneidad de este tipo de especie, se ha elegido debido a que son especies resistentes a la contaminación ambiental (unas más que otras), y requieren un menor aporte hídrico en comparación con las plantas superiores, existiendo algunas que incluso viven en localizaciones desérticas. También tienen una tolerancia estacional muy interesante, permitiendo que en los periodos de más calor y menor aporte hídrico, este se seque, pero reviva en cuanto vuelva a regarse. Finalmente, los tapices de briófitos no son como los de otras especies que requieren siega o poda, ya que el musgo crece sobre sí mismo superponiéndose las capas exteriores que reciben radicación directa sobre las interiores, que van secándose.

El soporte en sí se va a realizar mediante un mortero bio-receptivo con adición de escoria negra (EAFS).

En cuanto a la elección del mortero el criterio ha sido el siguiente. El mortero a base cemento Portland es el más utilizado en construcción, gracias a su resistencia, durabilidad y trabajabilidad. Sin embargo dicho mortero tiene dos problemas esenciales en el presente estudio: no es sostenible y tiene un $\mathrm{pH}$ agresivo con respecto a la especie vegetal que pretende plantarse.

Por este motivo usaremos un mortero bio-receptivo, el cual se obtiene a partir de la reacción química ácido-base entre un metal catiónico y una fuente de anión oxoácido, mayoritariamente fosfato. Dado que el tiempo de fraguado que presentan es muy rápido también se utilizará un retardante a base de Borax. Las materias primas requeridas para la 
elaboración de la presente mezcla son de alta pureza, por ello se intentará utilizar una fuente de magnesio (MgO) procedente de un subproducto, denominado polvo de ciclón.

Además se añadirá a la mezcla, como adición en sustitución de árido, escoria de acería. Las escorias proceden del proceso de fabricación del acero en horno de arco eléctrico. Es un modo de valorizar estos residuos, aprovechando los conocimientos de una línea de investigación que desarrolla el grupo de Investigación en Ingeniería de la Edificación de la Universidad de Burgos. Dentro de esta línea de investigación se enmarcan anteriores trabajos de estudio de diferentes materiales aprovechando materiales reciclados.

La principal materia prima empleada para la fabricación de acero en horno de arco eléctrico es la chatarra de hierro o acero. También se suelen añadir otros elementos con el fin de refinar la mezcla como pueden ser pequeñas cantidades de fundición, de mineral de hierro y de ferroaleaciones. La primera etapa en el proceso de fabricación del acero, incluyo una serie de fases como la oxidación, dirigida a eliminar impurezas de manganeso y silicio, la defosforación y la formación de escoria espumante en la que se acumulan todas las impurezas. Al solidificar se extraen las escorias negras.

Estas se tratan de materiales duraderos y resistentes al paso del tiempo, como se entiende por tratarse hoy en día de un elemento arqueológico.

\section{Sostenibilidad y desarrollo}

Según la RAE, sostenible, "dicho de un proceso: Que puede mantenerse por si mismo, como lo hace, p. ej., un desarrollo económico sin ayuda exterior ni merma de los recursos existentes" [2].

La Sostenibilidad consiste en la capacidad de los seres humanos de adaptarse a su entorno sin que esta degrade de manera irreversible los recursos naturales de ese entorno.

Esta capacidad instintiva de lógico equilibrio con el hábitat natural que les rodea, no se ha trasladado al ser humano. El hombre, que se encuentra en el pico de la cima de la pirámide trófica, se ha convertido en un voraz destructor de la fuente natural de su propia vida. En vez de querer formar parte de una rueda de la vida en la que cada especie tiene un rol, juega a que todo gire en torno a él.

Si nos atenemos al informe Brundtland [3], al que haremos referencia más adelante, Desarrollo Sostenible es "Satisfacer las necesidades de las generaciones presentes sin comprometer las posibilidades de las del futuro para atender sus propias necesidades". No sólo haciendo referencia a su alcance ecológico sino que también social y económico.

Este desarrollo, deberá estar basado en los principios formulados por el economista Herman Daly, que deben basar el desarrollo sostenible:

Todo recurso renovable, no deberá ser consumido a una velocidad superior a la de su renovación natural.

Toda fuente no renovable, no deberá ser consumida sin dedicar parte de la energía resultante en desarrollar una nueva fuente que, una vez agotada la primera, nos permita continuar disfrutando de las mismas prestaciones. 
No se deberán generar más residuos que el que pueda ser absorbido o inertizado por la propia naturaleza.

También es conocido por las ideas de crecimiento antieconómico " $E /$ deterioro medioambiental es una enfermedad iatrogénica inducida por la economía física (que aboga a favor del crecimiento) que intenta recompensar la enfermedad de los deseos ilimitados mediante la prescripción de una producción ilimitada. No se cura una enfermedad inducida por un tratamiento incrementando sus dosis". Esta afirmación resalta la imposibilidad de que el futuro desarrollo, ante la escasez de fuentes de energía no renovables, se base en la búsqueda de este mismo tipo de recursos, si bien considera que "(...) el crecimiento económico actual se ha desacoplado del mundo (...) se ha convertido en una guía ciega" abogando así por lo que sería el crecimiento sostenible.

\section{Contexto histórico}

El concepto de Sostenibilidad y Desarrollo Sostenible comienza a acuñarse a mitad de los años ochenta del pasado siglo con la creación de la Comisión Mundial sobre Medio Ambiente y Desarrollo de las Naciones Unidas (ONU) en Diciembre de 1983. Dicha resolución [4] recoge el guante de otras tantas resoluciones de la ONU que venían apuntando en el mismo sentido.

Sin embargo la preservación del medio ambiente venía practicándose desde los orígenes de la humanidad. Durante siglos el ser humano se ha abastecido de manera local, intentando buscar un equilibrio entre él y su ecosistema. No obstante, ya desde hace más de dos mil años el hombre comenzó a colonizar su entorno. A modo de ejemplo, durante la época romana, en Las Médulas (León), unas minas de oro a cielo abierto, se esquilmó por completo el entorno en pro de la consecución del metal.

Por aquel entonces la escasa capacidad de la sociedad para gastar los recursos hacía que fuese casi imposible sobrepasar la capacidad de la naturaleza para regenerarlos y asimilar sus residuos. A su vez, esa imposibilidad o incapacidad de usar o trasformar parte de las reservas de la naturaleza, hizo de la humanidad más bioclimática, asentándose en los entornos más adecuados, casi siempre con ríos y/o zona de cultivo cercanas.

No es hasta la revolución industrial, especialmente desde el siglo XX, cuando se produce un aumento generalizado del consumo energético. El progreso, el transporte y, sobretodo, el abaratamiento de la energía, promueven el crecimiento exponencial en el consumo de recursos norenovables y en la generación de residuos.

No fue hasta mediados del siglo XX cuando se inicia la preocupación por el medio ambiente. El 30 de Julio de 1968, durante el $45^{\circ}$ periodo de sesiones, el Consejo Económico y Social de la ONU advierte que "Observando la deterioración constante y acelerada de la calidad del medio humano causada por factores como la contaminación del aire y de las aguas, la erosión, y otras formas de deterioración del suelo, (...)" [5] y añade "(...) Convencido también de que, para un buen desarrollo económico y social, es de importancia esencial prestar la debida atención a los problemas del medio humano". Esta resolución, que insta a la Asamblea General a una conferencia sobre "los problemas del medio humano", es quizá donde por primera vez se acuña, en documento público, lo que posteriormente se conocería como desarrollo sostenible. 
Sin mucha dilación, en Diciembre de 1968, la Asamblea General de la ONU convoca la citada conferencia para 1972, haciendo hincapié en su resolución [6] de los graves peligros que conlleva un progreso científico y tecnológico si no se controla debidamente.

La Conferencia de las Naciones Unidas sobre Medio Humano tiene lugar en Estocolmo del 5 al 16 de Junio de 1972. Esta supone la primera cita a nivel mundial que aborda la problemática sobre el crecimiento sostenible.

La conferencia vino precedida por un controvertido informe para la época editado por el "Club de Roma", una asociación informal de altas personalidades independientes de la política, los negocios y la ciencia. Fundada en 1968, cuyos miembro son "pensadores a largo plazo interesados en contribuir de manera interdisciplinaria y holística a un mundo mejor. (...) comparten una preocupación común para el futuro de la humanidad y el planeta" [7]. Su primer informe, publicado en 1972, se titula "Los límites del crecimiento" (The limits to growth) fue encargado al Massachusetts Institute of Technology (MIT) y se basa en la simulación informática del programa World3.

Para dicho análisis se recopilaron datos sobre la evolución del planeta en los primeros setenta años del siglo $X X$. Se utilizaron un conjunto de cinco factores básicos que determinan, y en último término limitan, el crecimiento en el planeta: población, producción agrícola, recursos naturales, producción industrial y contaminación. Dichas variables se interrelacionaron entre sí y los resultados de las ecuaciones se interpolaron mediante simulación informática para obtener los valores futuros de dichas variables.

Los resultados obtenido con el programa World3 dieron una perspectiva bastante negativa [8]. Siguiendo el patrón obtenido, tal y como se puede observar en la (Figura 1), como consecuencia de la disminución de los recursos naturales, y el aumento continuado de la población, a partir del año 2000 se produciría una grave crisis industrial y agrícola que a su colapso y decrecimiento. A mitad del siglo XXI la población alcanzaría el máximo histórico, pero comenzaría a disminuir bruscamente. Desde ese momento las producciones industrial y agrícola se estancarían, con un crecimiento muy inferior al de principios del siglo XX, con la población humana en contracción y los recursos naturales casi esquilmados.

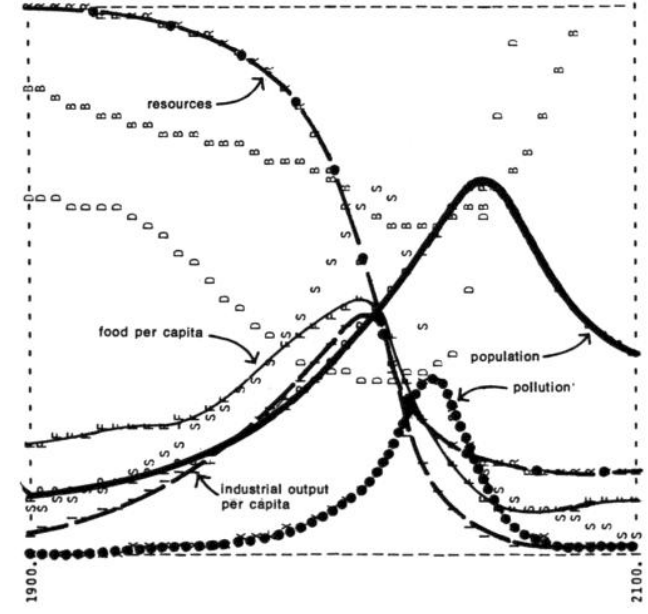

Figura 1. Diagrama evolución actual Fuente: The Limits to Growth, 1972

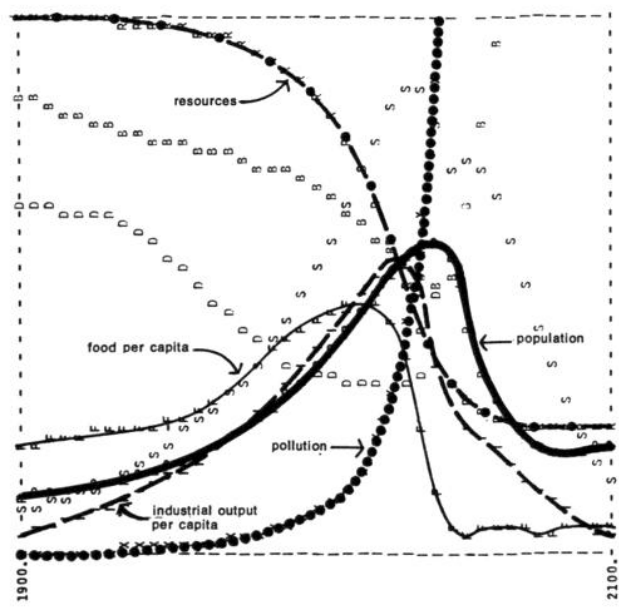

Figura 2. Evolución con doble de recursos. Fuente: The Limits to Growth, 1972 


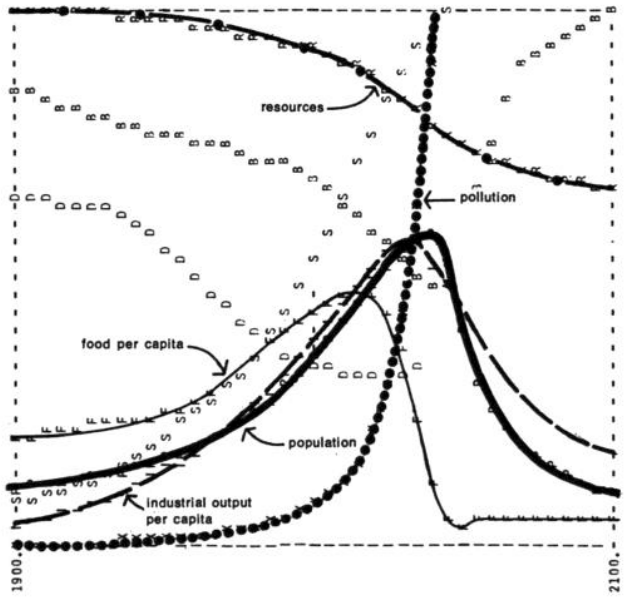

Figura 3. Evolución con recursos ilimitados Fuente: The Limits to Growth, 1972

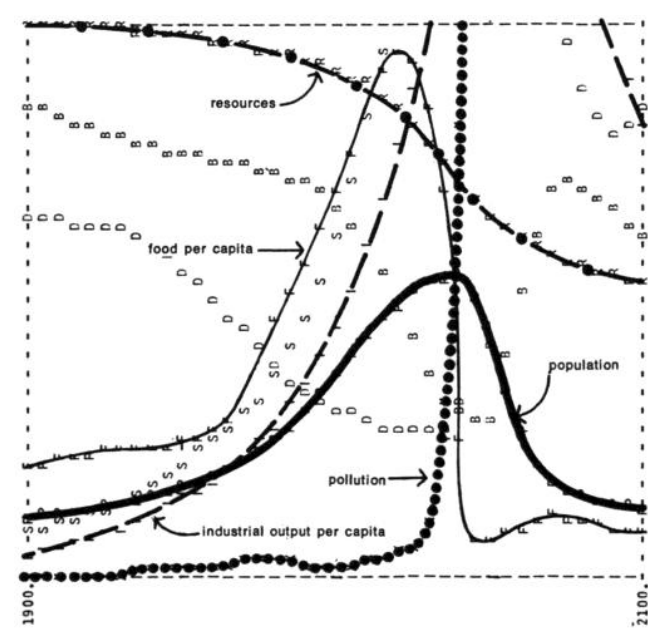

Figura 5. Evolución con recursos ilimitados, control de polución y mejora productividad agrícola. Fuente: The Limits to Growth, 1972

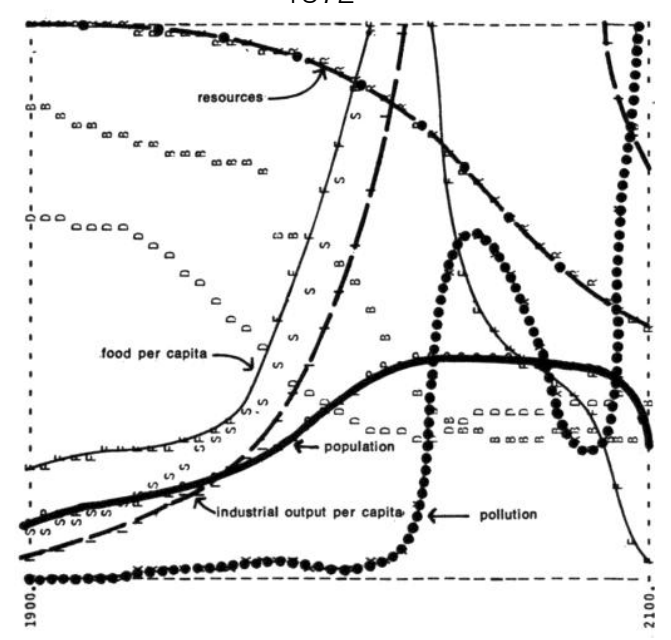

Figura 7. Evolución con recursos ilimitados, control de la polución, mejora productividad agrícola y control "perfecto" de la natalidad. Fuente: The Limits to Growth, 1972

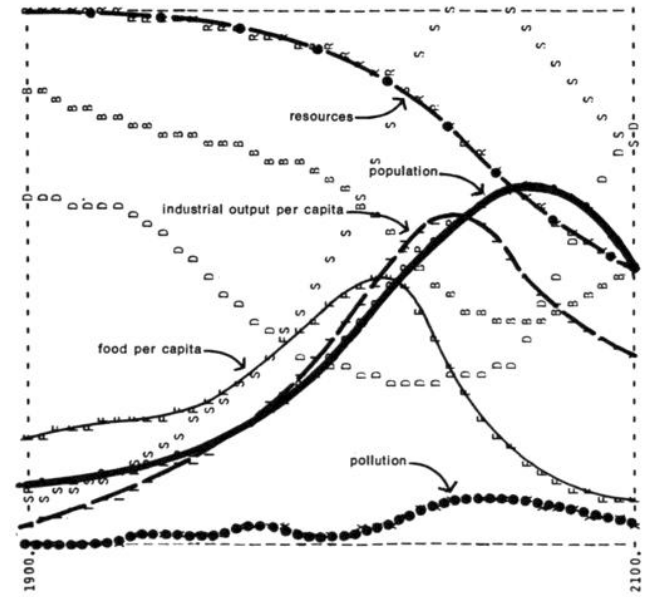

Figura 4. Evolución con recursos ilimitados y control de la polución Fuente: The Limits to Growth, 1972

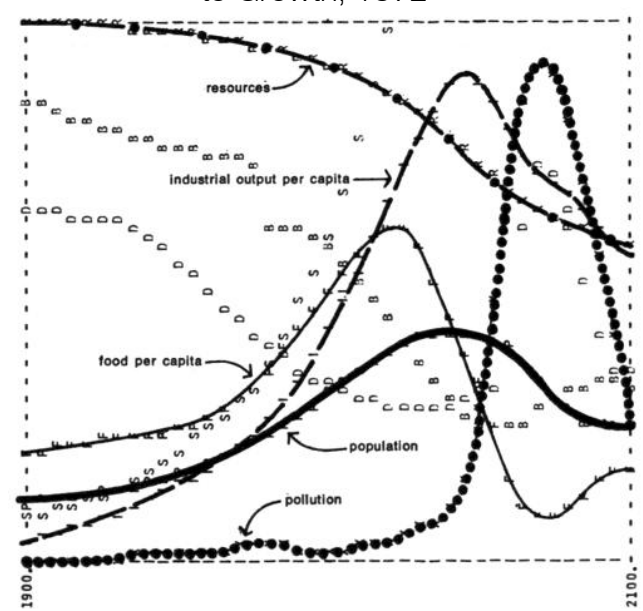

Figura 6. Evolución con recursos ilimitados, control de la polución y control "perfecto" de la natalidad. Fuente: The Limits to Growth, 1972

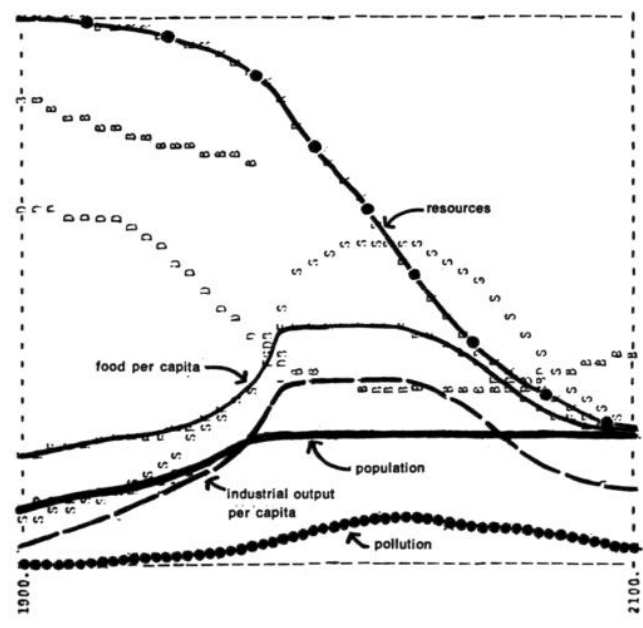

Figura 8. Evolución con población y capital estabilizados Fuente: The Limits to Growth, 1972 


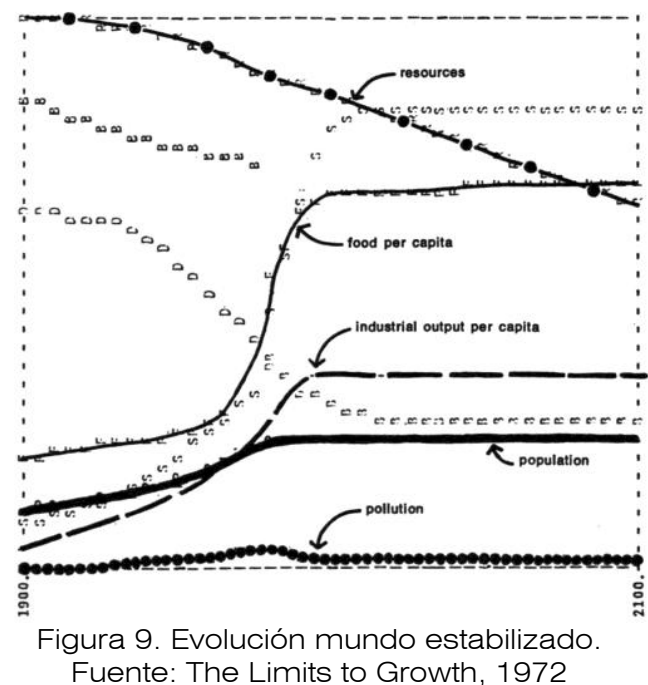

En el informe también se reflejan otros modelos, modificando los supuestos iniciales y evaluando cómo estos podían modificar la evolución o el resultado final. Se establecen distintos supuestos, desde que las reservas y recursos mundiales se multiplicasen por dos (Figura 2. Evolución con doble de recursos. o ilimitadas (Figura 3) tan sólo significaba un retraso de diez $O$ veinticinco años en el desencadenamiento final del colapso. Además, este aumento de los recursos vendría acompañado de incremento de las tasas de contaminación, inasumibles, cuya que influencia en la población haría que la mortalidad se dispare, reduciéndose la población del año 2100 a niveles críticos, por debajo de los estándares.

La introducción de controles sobre producción de contaminantes (Figura 4), mejora de la eficiencia de la producción agrícola (Figura 5), de la natalidad (Figura 6 y Figura 7), tampoco conseguirían impedir el colapso final.

Las únicas variables que consiguen evitar la situación de postración mundial se fundamentan la paralización del proceso de crecimiento exponencial de la economía y la población (crecimiento vegetativo igual a cero (Figura 8), no mermando los recursos naturales que quedan, sino que se destinen, en exclusiva a la renovación y modernización del capital para un uso más ahorrador de recursos y menos contaminante (Figura 9).

El informe concluye con la premisa que "si se mantienen las tendencias actuales de crecimiento de la población mundial, industrialización, contaminación ambiental, producción de alimentos y agotamiento de los recursos, este planeta alcanzará los límites de su crecimiento en el curso de los próximos cien años. El resultado más probable sería un súbito e incontrolable descenso tanto de la población como de la capacidad industrial."

No obstante finaliza el informe postulando que es posible modificar estas tendencias de crecimiento y establecer condiciones de equilibrio ecológico y económico de tal modo que se pueda mantener un crecimiento de forma sostenible en el futuro. Esta situación de equilibrio global permitiría la satisfacción de las necesidades materiales básicas de cada persona en la Tierra y que todas tendrían igual oportunidad de desarrollar su potencial humano individual. Sin embargo también establece un punto de no-retorno para la aplicación de estas 
condiciones de equilibrio que se deberían de aplicar no más tarde del año 1985.

El informe fue ampliamente criticado poco después de su publicación, tanto por sus conclusiones como por su metodología, ya que, según algunos, el informe se basada en el crecimiento exponencial de población, capital y contaminación, pero sin embargo, no se había considerado el crecimiento de las tecnologías para ampliar los recursos y el control de la contaminación. [9]

Por ello, posteriormente, las previsiones fueron revisadas:

- 1993: Más allá de los límites. [10] Esta revisión revisan las previsiones recogidas en el estudio original con veinte años de perspectiva. Esta nueva revisión prevé, con si se sigue con el mismo crecimiento exponencial de la población y consumo de recursos, el colapso global comenzará en 2020. Además se incide que el cambio de los recursos no-renovables por renovables no es suficientemente rápido para compensar la capacidad de la naturaleza para regenerarse y absorber la contaminación.

- 2004: Los límites del crecimiento 30 años después. [11] Esta actualización del estudio, vuelve a simular el crecimiento, pero teniendo en cuenta el avance de la tecnología o la influencia de diferentes políticas, éticas o metas. En la mayoría de los escenarios contemplados los límites se rebasan en exceso y se sufre un colapso por agotamiento de recursos, escasez de alimentos, declive industrial o alguna combinación de estos.

Este escenario final (Imagen 12) es el que denomina como sociedad sostenible. La introducción de políticas sostenibles con 20 años de antelación hubiera supuesto menos contaminación, más recursos no renovables y un bienestar promedio ligeramente superior. Al final, el estudio aboga, de nuevo, por una transición global hacia una sociedad sostenible.

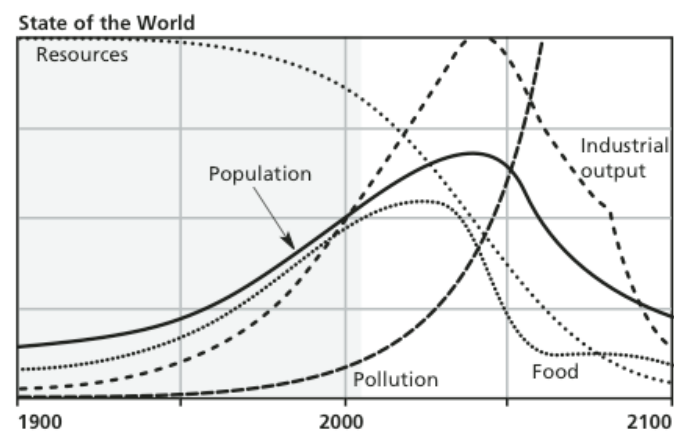

Imagen 10. Evolución con aumento de los recursos no-renovables

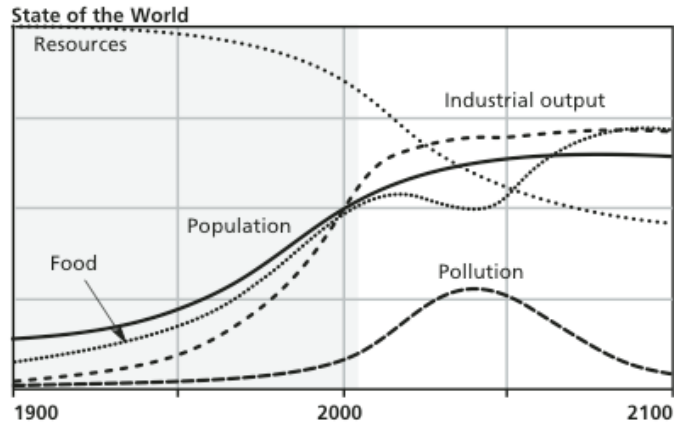

Imagen 11. Evolución con estabilidad poblacional e industrial 


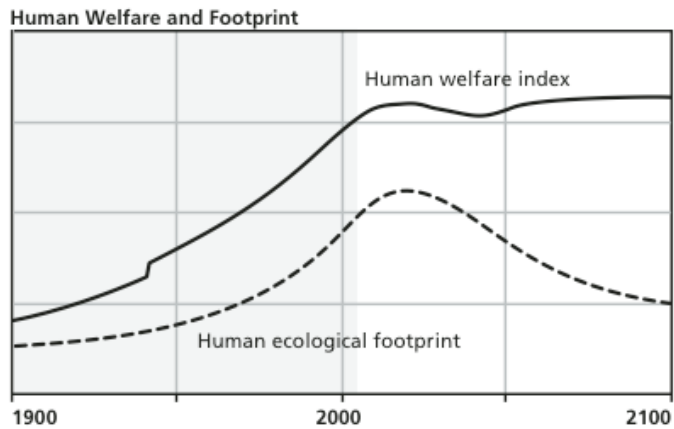

Imagen 12. Evolución con estabilidad poblacional e industrial y mejoras tecnológicas

- 2012: Los límites del crecimiento. Esta última actualización fue elaborada por Jorgen Randers haciendo una proyección para los siguientes 40 años. En esta ocasión se datos fiables del estado actual de varias variables, según los cuales, ya habríamos sobrepasados varios límites físicos.

El estudio, confirma varias de las previsiones del informe original conviniendo por una transición global hacia una sociedad sostenible que reduzca la huella ecológica.

El texto se convirtió en una clara referencia durante la Conferencia de Estocolmo sobre Medio Humano. La cita, supone una primera punta de lanza de lo que será a partir de entonces, la conciencia sobre los problemas ambientales.

Una de las consecuencias de dicha conferencia fue la creación del Programa de las Naciones Unidas para el Medio Ambiente (PNUMA), cuya misión consiste en la preservación del medio ambiente, mejorando la vida de las naciones y sin comprometer la de las futuras generaciones.

Aunque lo realmente importante de la cita fue la conocida como Declaración de Estocolmo [12], compuesta por veintiséis principios y un plan de acción de diez recomendaciones. Esta declaración desarrolló el primer cuerpo de una «legislación blanda» para cuestiones internacionales relativas al medio ambiente. Pero la principal consecuencia es la ferviente acogida por parte de los países pertenecientes a la Organización de Cooperación y Desarrollo Económicos (OCDE), que promulgaron 31 importantes leyes nacionales ambientales en el periodo 1971-1975, basadas en los principios de la Declaración.

El medio ambiente obtuvo una relevancia en las agendas políticas: antes de la conferencia existían únicamente diez gobiernos que disponían de ministerio de medio ambiente, en 1982, ya unos ciento diez países contaban con un ministerio o secretaría específico para la materia. [13]

También se articuló por primera vez el derecho de las personas a vivir en un medio ambiente de calidad que les permita llevar una vida digna y gozar de bienestar.

Prácticamente un año después todas las tesis contenidas en el informe "Ios límites del crecimiento" parecieron tomar forma a finales de 1973 con la denominada "primera crisis del petróleo". En esas fechas la Organización de Países Árabes Exportadores de Petróleo (OPEP) 
decide no exportar más petróleo a los países que habían apoyado a Israel en la guerra del Yom Kippur, que enfrentaba a Israel con Siria y Egipto; castigando así a Estados Unidos y a sus aliados de Europa Occidental.

Esto conduce a que el precio del petróleo crudo se llegue a cuadriplicar. La escasez de recursos parecía haberse adelantado en el tiempo y por primera vez se ve claro la imposibilidad de la dependencia de los recursos no renovables. Rápidamente, los gobiernos buscan fuentes de energía más seguras para reducir la dependencia de combustibles importados. Como ejemplo, en este periodo es cuando se reduce drásticamente la velocidad en las carreteras de Estados Unidos, para disminuir el consumo de carburante, a $55 \mathrm{Mph}$.

Sin embargo, y pese a la multitud de normativas creadas, la grave dependencia mundial de una fuente no renovable como es el petróleo volvió a quedar retratada tras la segunda crisis que tuvo lugar entre mediados de 1978 a finales de 1981. En ella, las revueltas de Oriente Próximo, principalmente la revolución iraní y posteriormente la guerra entre Irán e Irak, provocan que el precio del petróleo vuelva a subir con fuerza, multiplicando su precio casi por tres, sobre un precio ya inflado por la crisis de 1973. Sin embargo, la posterior caída brusca del precio, no refutaron, a los ojos de muchos, el problema de la escasez de crudo sino consideraron que el suceso había tenido mucho más de especulación.

Es por ello que había gran expectación ante el siguiente paso de las Naciones Unidas y, sobretodo, frente al recién creado programa PNUMA. Dicho programa aprueba una resolución [14] en mayo de 1982 en la que se solicita a la Asamblea General que elabore la perspectiva ambiental hasta el año 2000 y más adelante. Sin embargo, no es hasta un año después cuando, de nuevo, el Consejo de Administración del PNUMA, aprueba la decisión 11/3, en la que se adjunta un proyecto de resolución, para su aprobación en la Asamblea General que será ratificado en 19 de diciembre de 1983. Dicha resolución emplaza a la creación de una comisión especial intergubernamental que elabore un programa de estrategias ambientales a largo plazo y que, básicamente, sirva de "think-tank" entre estados.

Ya en 1987 la Comisión Mundial sobre el Medio Ambiente y el Desarrollo (CMMAD), creada en base a la resolución antes citada, presentó un informe del trabajo realizado durante los cuatro años precedentes. Éste trabajo denominado "Our common future" o también "Informe Brundtland", es el primero que define el desarrollo sostenible como aquel que "satisface las necesidades de la generación actual sin comprometer la capacidad de las generaciones futuras para satisfacer sus propias necesidades". A su vez se establece un principio de acuerdo entre países en la visión de la problemática sobre el medio ambiente, en medio de un desarrollo económico y social que debe orientarse hacia un crecimiento menos agresivo.

En 1990, la entonces Comunidad Europea, emite el "Libro Verde sobre el medio ambiente urbano" [15], primer documento de rango europeo en el que la Comisión Europea analiza la problemática ambiental en el medio urbano y los posibles campos de acción. Sin embargo al no tener rango de directiva, no compromete a los estados miembros a adoptarlas.

En Diciembre de 1988 se convoca en la ONU una conferencia sobre el medio ambiente y desarrollo debido a la profunda preocupación "por el continuo deterioro de la situación del medio ambiente y la grave 
degradación de los sistemas mundiales necesarios para la vida (...) si se permite que continúen podrían perturbar el equilibrio ecológico mundial." y continúa haciendo un guiño al crecimiento sostenible postulado en el informe Brundtland "(...) la causa principal del continuo deterioro del medio ambiente mundial son las modalidades insostenibles de la producción y el consumo, en particular en los países industrializados". Así mismo se promulga que dicha conferencia deberá elaborar las estrategias y medidas para detener los efectos de la degradación del cambio climático.

Entre el 3 y el 14 de Julio de 1992 tuvo lugar en Río de Janeiro la conferencia de la ONU sobre el Medio Ambiente y el Desarrollo. La denominada "Cumbre de Río" aclara el término de desarrollo sostenible estableciendo varios principios como que todo ser humano tiene derecho a una vida saludable y productiva en armonía con la naturaleza y que "para alcanzar el desarrollo sostenible, la protección del medio ambiente debe ser parte del proceso de desarrollo y no puede ser considerado por separado".

Aunque quizá el acuerdo más importante de la cumbre sea la denominada "Agenda 21", un ambicioso programa de acciones que deberían desarrollarse por los estados miembros, a todos los niveles. Este plan ha sido estrechamente seguido por la comisión. Es por ello que se van convocando cumbres como la de 1997, denominada "Río+5", en la que se evalúan el nivel de incidencia de la Agenda 21 y la revisión de los objetivos.

A partir de ese momento, los países comienzan a llevar a cabo el plan propuesto en la Agenda 21. La Comunidad Europea (CE) desarrolla planes para impulsar las políticas ambientales y se van sucediendo sucesivas ediciones de Conferencias de Ciudades Europeas en Aalborg, Hannover, Lisboa... con el lema "piensa globalmente, actúa localmente (Think globlal, act local)", acuñado ya en la cumbre de 1972.

La cumbre de Johannesburgo o de "Río+10" no estaba dirigida únicamente a gobiernos, sino también a ONG's y empresas. Esta se enfoca en la evaluación de los años desde la conferencia de Río y la aprobación de un Plan de Acción de desarrollo sostenible, ya que se estima que los objetivos aún quedan lejos.

Previamente la Convención Marco de las Naciones Unidas sobre el Cambio Climático (CMNUCC) aprueba el 11 de Diciembre de 1997 el "Protocolo de Kioto", que tiene por objetivo reducir las emisiones de los gases de efecto invernadero causantes del calentamiento global en un porcentaje de al menos un $5 \%$ en el periodo 2008 a 2012, en comparación a las emisiones que tuvieran en 1990. La Unión Europea se ha comprometido a reducir un $8 \%$ sus emisiones.

\section{Situación actual}

A la fecha de redacción del presente texto, 21 de Noviembre de 2016, la población mundial rebasa los 7.353 millones de personas [16], y una tasa demográfica de crecimiento de un 10\% anual [17]. Esto supondrá que antes de mediados de siglo la población mundial pueda duplicarse y que este fenómeno vuelva a reproducirse cada 30 o 40 años. Sin embargo, atendiendo a la Figura 13, esta evolución no parece haber sido progresiva. Si bien hasta el siglo XVIII, coincidiendo con la Revolución Industrial, la población mundial había experimentado un crecimiento paulatino y sostenido, es a partir de esta fecha cuando la población comienza a dispararse, duplicándose en menos de 200 años. 
Esta grave superpoblación y sobretodo la tasa de crecimiento vegetativo ha incidido de forma diversa según el grado de desarrollo del país, incidiendo de forma más acusada en las zonas más deprimidas. Esto implica, en la práctica, una grave disminución de los recursos naturales que a su vez va asociado a una degradación del medio ambiente. Este desequilibrio, se ha visto acuciado con el desarrollo de los países emergentes, como China o India, que tradicionalmente, debido a su atraso tecnológico, tenían un consumo de recursos relativamente bajo.

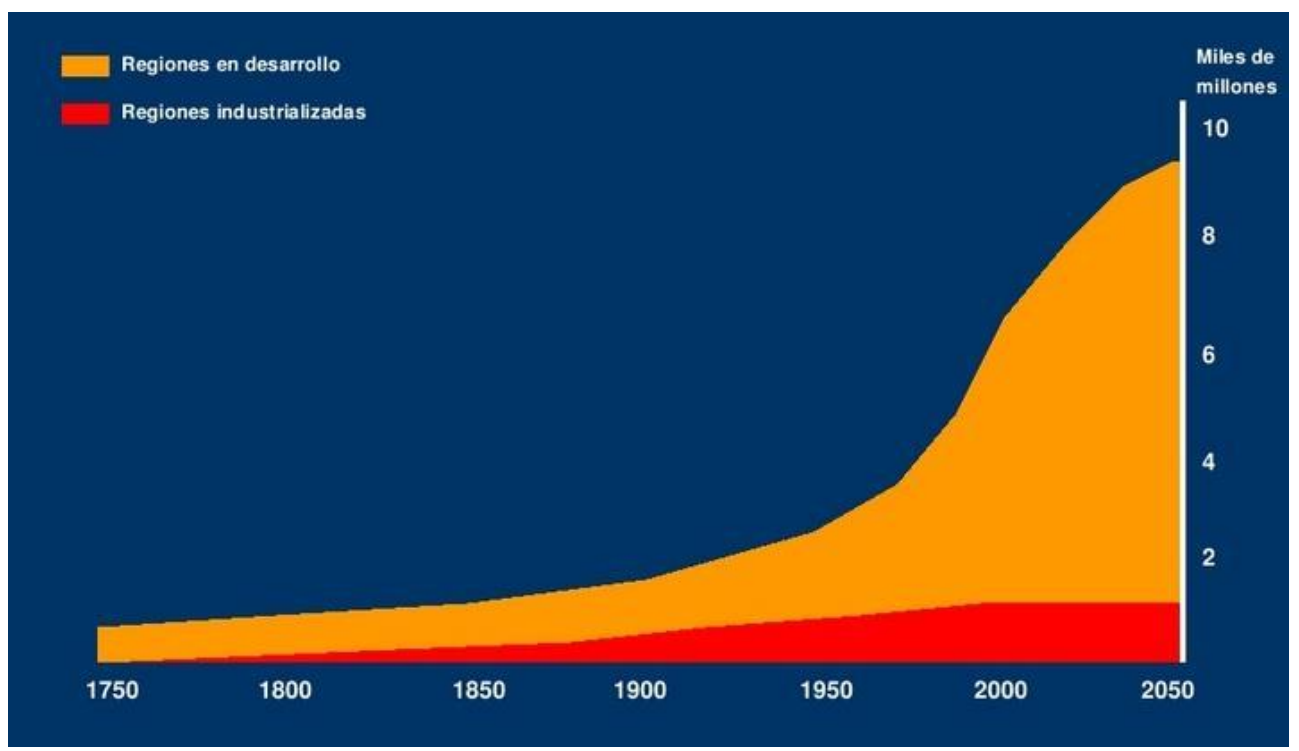

Figura 13. Diagrama de crecimiento poblacional mundial y previsión hasta 2050

Esta evolución poblacional, que en sí misma es preocupante, viene acompañada de datos como la de evolución de las emisiones de $\mathrm{CO} 2$ a la atmósfera. El desarrollo de los países emergente ha disparado esta tasa (Figura 14) y no compensa los esfuerzos de los países miembros de la OCDE en su reducción (Figura 15). Según datos oficiales, sólo en 2011 las emisiones de CO2 en China subieron un 9,3\%, mientras que bajaron en USA un 2\%, un 3\% en la UE y un 2\% en Japón.

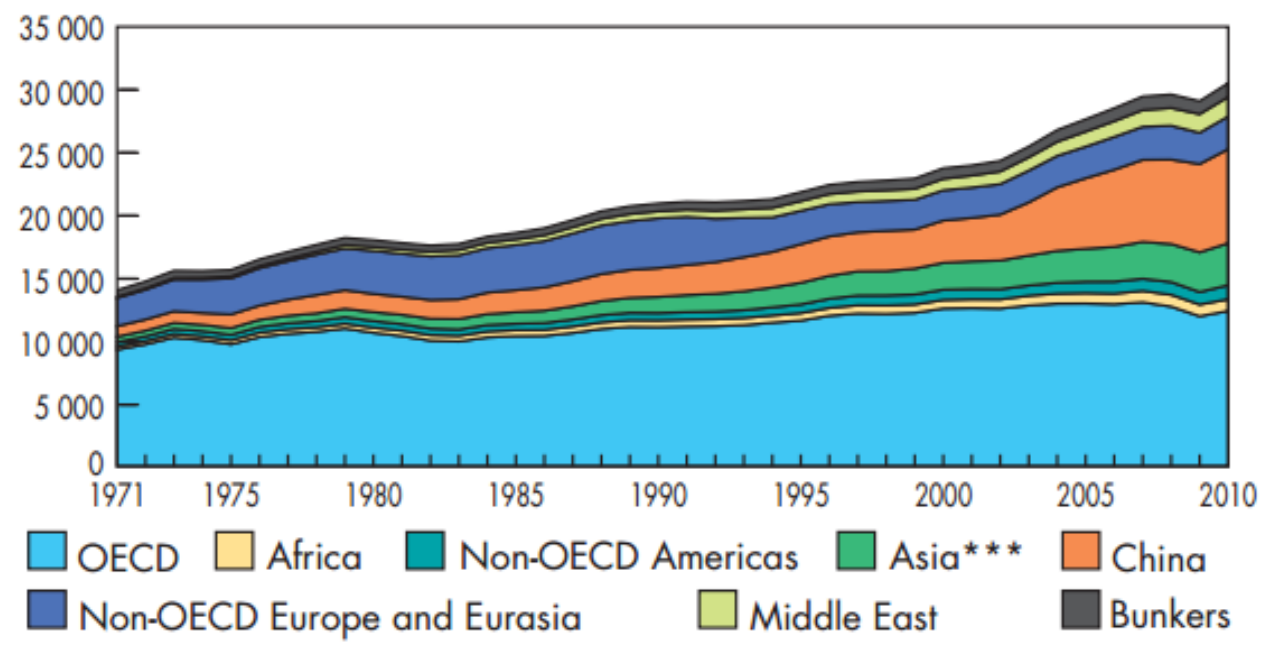

Figura 14. Emisiones CO2 mundiales de 1971 a 2010 por regiones. 


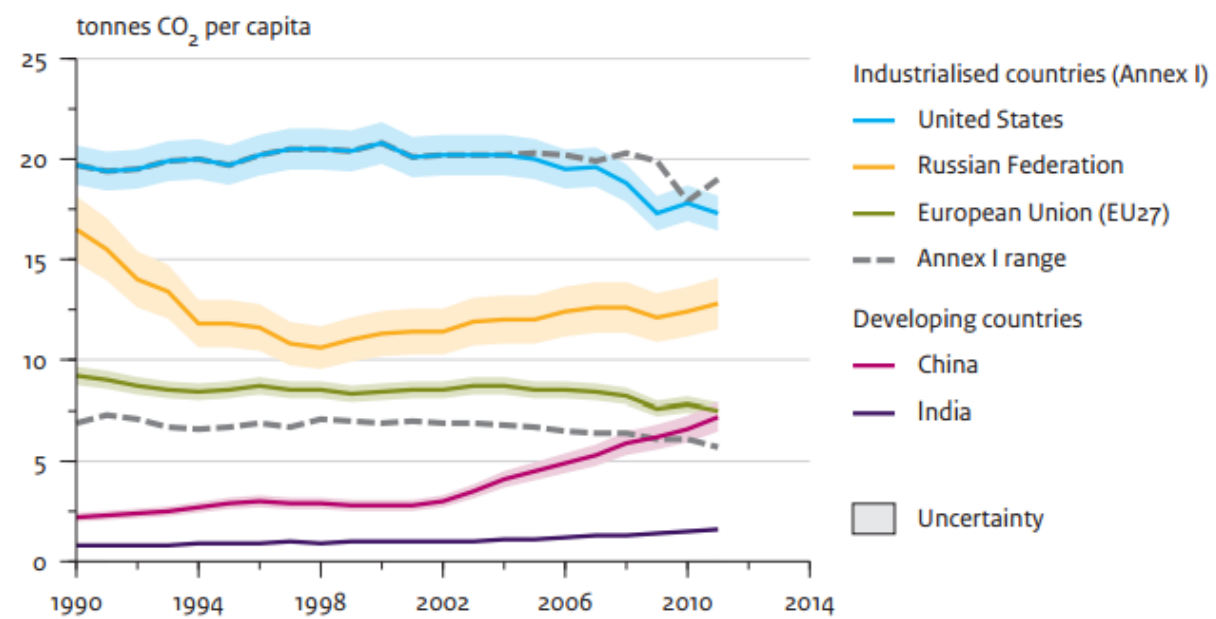

Figura 15. Emisiones de CO2 per cápita procedentes de combustibles fósiles.

No obstante es más conveniente para valorar el nivel de impacto medio-ambiental al que se está sometiendo al planeta recurrir al concepto de huella ecológica. Este concepto evalúa el impacto de un determinado modo o forma de vida sobre una determinada región, estimando la bio-capacidad de dicha región para generar los recursos necesarios, así como absorber los residuos creados. La metodología de cálculo está basada en la estimación de la superficie necesaria para satisfacer los consumos asociados a la alimentación, al consumo energético y a la ocupación del terreno.

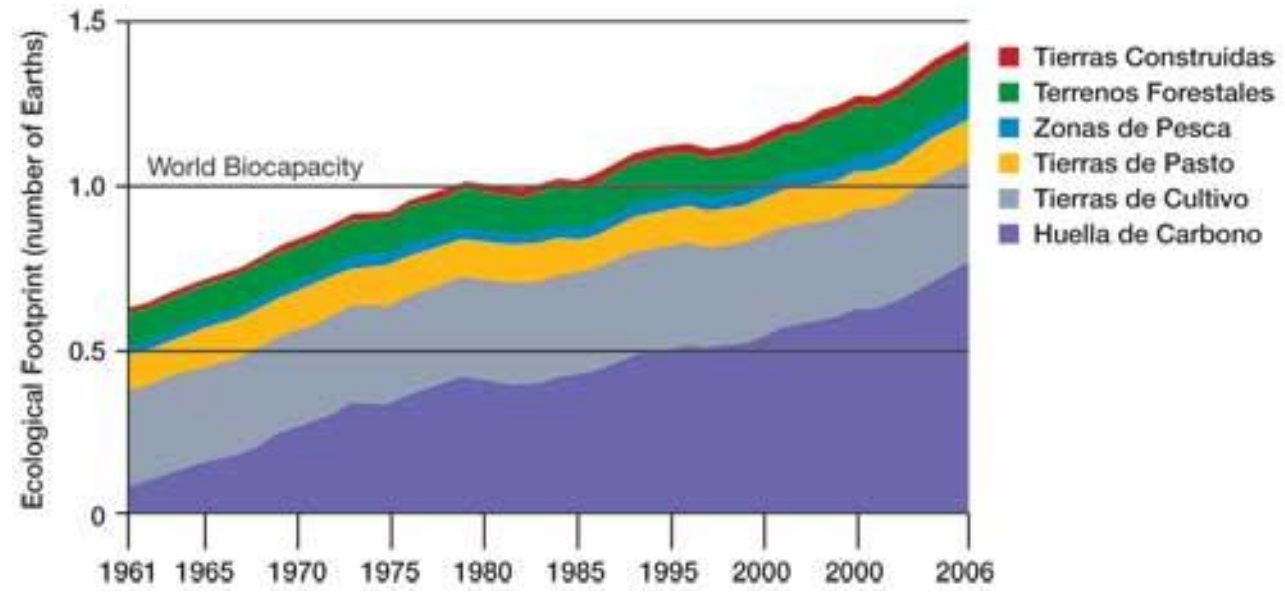

Figura 16. Huella ecológica de la humanidad por componente. Fuente Red de la Huella Global

Actualmente la demanda de la humanidad sobre los recursos naturales, representados en la huella ecológica, ha aumentado de forma continua. El ser humano, que en 1961 demandaba en torno al $50 \%$ de la capacidad regenerativa del planeta, en 2010 demanda el $144 \%$ de esa capacidad [18]. Se estima que si continúan los escenarios modelados por la ONU, "con el actual crecimiento y consumo, en la década de 2030 de necesitará el equivalente a dos planetas Tierra para mantenernos" [19].

Estos valores (Figura 16) diferenciados de forma regional, arrojan unas diferencias importantes entre países desarrollados y no-desarrollados. Por ejemplo el consumo per cápita de Norteamérica es de 8,7 Ha 
globales/persona, de 4,5 en Europa y en contraposición de 1,4 en África.

Quizá con estos mimbres no son extraños hoy fenómenos como pueden ser el cambio climático, la deforestación, la lluvia ácida, crecimiento del agujero en la capa de ozono... que están directamente causados por el fervor industrial de la actividad económica.

Sin embargo sería un error centrarnos exclusivamente en la industria y el transporte como principales causantes de la contaminación y la degradación del medio ambiente. El entorno urbano-residencial consume del orden del $24 \%$ de energía final, situándose como el segundo más importante por detrás del sector transporte [20]. Así mismo, no hay que olvidar el gran consumo que supone la construcción del inmueble en sí, pudiéndose llegar a invertir entre un 15 y un $20 \%$ entre extracción, transporte y puesta en obra de los materiales, derribo, reciclaje y valorización de residuos.

Es por ello que hay que tener muy en cuenta el sector de la edificación, no solo por el consumo de energía durante su uso, sino también el consumo de materiales y de generación de residuos que produce. El parque inmobiliario ha evolucionado a una velocidad muy superior a la del crecimiento poblacional. Si las 6.687.200 viviendas que existían en 1950 albergaban a poco más de 28.000.000 de personas, en 2012 para casi 47.000.000 existían 25.276.303 viviendas, es decir, que mientras que la población no ha llegado a doblarse, la vivienda casi se ha cuadruplicado.

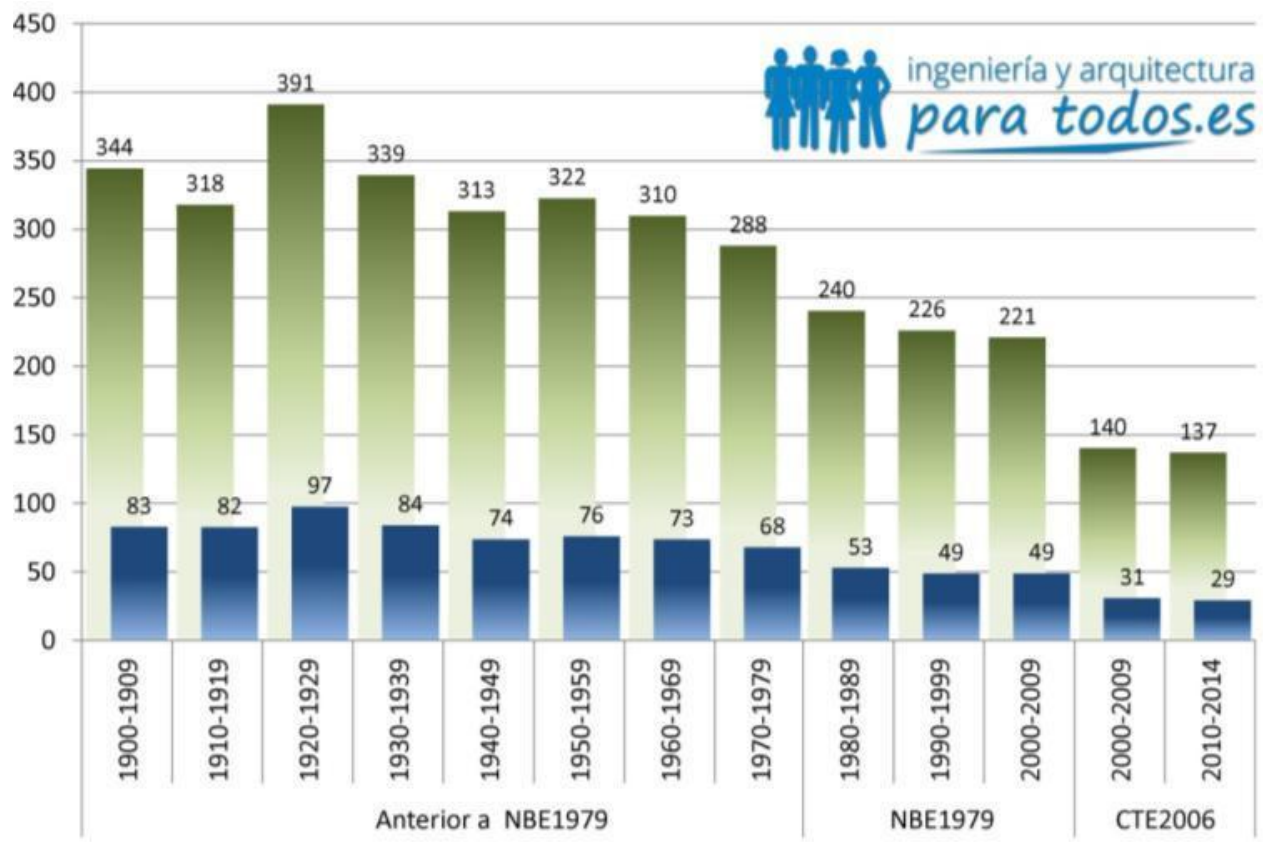

\section{- Promedio de $\mathrm{kWh} / \mathrm{año} * \mathrm{~m}^{2} \quad$ Promedio de $\mathrm{kgCO}_{2} / \mathrm{año}^{*} \mathrm{~m}^{2}$}

Figura 17. Evolución del consumo medio de energía en viviendas

Este crecimiento desmedido ha provocado, a su vez, varias consecuencias, entre las que destaca la destrucción de recursos naturales al no haberse procurado su consumo sostenible. Esto lleva aparejado el coste ecológico de la desaparición de yacimientos de materias primas, así como la destrucción de un ecosistema (véase prospecciones a cielo abierto) o la proliferación de vertederos, muchos 
de ellos descontrolados, de los residuos generados, en gran parte por el sector de la construcción.

Así mismo hay que tener en cuenta la disfuncionalidad de una gran parte del parque inmobiliario. Según los datos del País Vasco [21] casi el $50 \%$ de las viviendas fueron construidas entre 1961 y 1980 , siendo la antigüedad media de 39 años. Esta situación acentúa el consumo de energía primaria, sobretodo en calefacción, donde una vivienda construida antes de 1979 demanda en torno a unas 2,8 veces más energía que una de 2007.

El grado de confort también ha provocado que el consumo de energía haya evolucionado al alza. A partir del 1979, año de la entrada en vigor de la Normativa de Condiciones Térmicas de los edificios, el consumo de energía primaria fue disminuyendo según se optimizaba los materiales e instalaciones de las viviendas. Antes de esta fecha el precio de los combustibles, principalmente del carbón y de los productos derivados del petróleo, todavía no eran altos, y el nivel de consumo eléctrico de los hogares era más bien bajo.

La entrada en vigor de la NBE CT-79, precedida de los acontecimientos ya relatados de las distintas crisis del petróleo, obligó a unos requerimientos mínimos en cuanto a aislamiento, no solo por una necesidad de aislamiento mínimo de las viviendas, sino más bien para bajar la dependencia del petróleo. Esto dio lugar a una fuerte bajada del consumo de energía, de en torno a un $15 \%$, sólo en su primera década de vigencia. La aplicación desde 2006 del Código Técnico de Edificación, ha supuesto una bajada clara del 37\% del consumo respecto a la década anterior, del $50 \%$ respecto a los años 70 y de casi 2/3 en comparación con el pico máximo de los años 20.

\section{Marco normativo}

\subsection{El marco normativo de la Unión Europea}

El origen de la Unión Europea se cimenta en 1951 con la creación de la Comunidad Europea del Carbón y del Acero (CECA). Seis años después, estos mismos países deciden, firmando el denominado Tratado de Roma, la creación de la Comunidad Económica Europea (CEE).

Pese a que en dicho tratado no se hace mención al medio ambiente, se hace una clara alusión a "tener como fin esencial de sus esfuerzos la constante mejora de las condiciones de vida y de trabajo de sus pueblos" [22], con lo cual se abre la puerta a la futura necesidad de actuación

Las raíces de la política europea relativas a medio ambiente han ido paralelas a la política de la ONU. No es hasta 1972 con la cumbre de Paris, en la que se empieza a establecer una política sostenible. En ella se llega a la conclusión que no es posible el crecimiento económico si no se traducía en la mejora de la calidad del nivel de vida de los seres humanos y de la protección del medio ambiente [23].

Sin embargo la política actual de la UE ha evolucionado desde dicha época, consiguiendo una reducción bastante significativa de la contaminación y las emisiones.

Desde 2008 los Estados miembros de la UE tienen el compromiso de alcanzar para 2020 los objetivos "20-20-20": reducir el 20\% de las emisiones de gases de efecto invernadero; reducir el $20 \%$ del consumo 
de energía primaria y aumentar al $20 \%$ la energía primaria consumida de fuentes renovables. Los datos han de estar referidos a 1990.

Para ese objetivo es necesaria la simplificación de la Directiva 2002/91 sobre el rendimiento energético de los edificios, que constituía el marco normativo.

Como resultado se dispone la Directiva 2010/31 [24], relativa a la eficiencia energética de los edificios. Las principales novedades de la directiva son:

- Establecimiento de un marco metodológico comparativo para el cálculo de los requisitos mínimos de eficiencia energética.

- Edificios de consumo energético casi nulo "(...) con un nivel de eficiencia energética muy alto [...]. La cantidad casi nula o muy baja de energía requerida debería estar cubierta, en muy amplia medida, por energía procedente de fuentes renovables, incluida energía procedente de fuentes renovables producida in situ o en el entorno". Así mismo se establece dos plazos para la implementación:

31 de Diciembre de 2018 para todos los nuevos edificios propiedad u ocupados por autoridades públicas.

31 de Diciembre de 2020, para todos los edificios nuevos.

- Ampliación del ámbito de aplicación de los Certificados de Eficiencia Energética, aparte de los recogidos en la anterior directiva, a todos los edificios ocupados por autoridades públicas mayores $500 \mathrm{~m}^{2}$ (250 a partir de Julio de 2015).

- Elaboración de los sistemas para inspección de los sistemas de climatización.

La nueva Directiva 2012/27 tiene como justificación, entre otras en "(..) la creciente dependencia de las importaciones, la escasez de recursos energéticos, asi como a la necesidad de limitar el cambio climático" . Esta directiva, más generalista que la de 2010, ya que establece un marco global para la eficiencia energética, también establece algunas concreciones respecto al sector de la construcción:

- Se deberá establecer una estrategia a largo plazo para la renovación del parque edificatorio.

- Hace hincapié en la función ejemplarizante de los edificios de los organismos públicos, estableciéndose un porcentaje de renovación en todos sus edificios.

- Se fomentarán las auditorías energéticas.

Se promoverá la eficiencia en la calefacción y la refrigeración, evaluando el potencial de cogeneración y los sistemas urbanos.

\subsection{El marco normativo de España}

España, no es ajena a las crisis energéticas y legisla la primera norma básica que regula las condiciones térmicas de la edificación (NBE-CT79) [25] coincidiendo con las sucesivas crisis del petroleo. Esta primera normativa limitaba la transmitancia de los edificios y controlaba los rendimientos y consumos de los equipos caloríficos.

El Código Técnico de Edificación (CTE) [26] en su documento básico de Ahorro de Energía (DB-HE) nace junto con el Reglamento de 
Instalaciones Térmicas (RITE) [27] como transposición de la directiva europea Directiva 2002/91.

El CTE, concretamente el DB-HE, ha supuesto un vuelco en las condiciones de habitabilidad produciendo cambios en la forma de construcción. Sus principales documentos son los siguientes:

HE-1: Limitación de demanda energética. Supone una "vuelta de tuerca" a la que existía. Supone un ahorro de en torno al 30\% sobre la normativa anterior.

HE-2: Rendimiento de las instalaciones térmicas. Este documento se remite directamente al RITE.

HE-3: Eficiencia energética de las instalaciones de iluminación.

HE-4: Contribución solar mínima de agua caliente sanitaria. Es el documento con una prescripción más novedosa, estableciendo una obligatoriedad de una contribución mínima de la producción de ACS con placas solares, o, en caso de prohibición expresa, el equivalente con medios renovables.

HE-5: Contribución fotovoltaica mínima de energía eléctrica (HE5)

El RITE es el reglamento que regula el diseño, instalación y mantenimiento de las instalaciones de climatización y de producción de ACS. Su normativa establece las exigencias mínimas de rendimiento, eficiencia y bienestar para atender la demanda de las instalaciones térmicas.

Ambas normativas han sido actualizadas en 2013 mediante el RD $238 / 2013$ y la orden FOM/1635/2013. Ambas actualizaciones son consecuencia de la transposición de la directiva europea 2010/32. La principal novedad, es la creación de un nuevo capítulo "HE-O" que limita el consumo energético con la idea de mejorar de forma sustancial la eficiencia energética de los edificios.

Paralelamente al CTE se aprobó el RD 47/2007 que regula el procedimiento básico para la certificación de eficiencia energética de edificios de nueva construcción. Este documento se ha visto actualizado y ampliado en su alcance con la aprobación del RD 235/2013 que amplía el ámbito de aplicación de su anterior a todas las viviendas, aparte de las de nueva construcción, a todas aquellas que se vayan a comprar, vender 0 alquilar. Con ella, se transpone parcialmente la directiva 2010/32.

También, en un plano similar, se aprueba del RD 105/2008 por el que se regula la producción y gestión de los residuos de construcción y demolición. Por primera vez se obliga a todo proyecto de ejecución a la redacción de un estudio de gestión de residuos de construcción y demolición, que contendrá una estimación de la cantidad de los residuos procedentes de la obra y una valoración de la gestión de los mismos. 
[1] Recomendación (UE) 2016/1318 de la Comisión, de 29 de julio de 2016, sobre las directrices para promover los edificios de consumo de energía casi nulo y las mejores prácticas para garantizar que antes de que finalice 2020 todos los edificios nuevos sean edificios de consumo de energía casi nulo. D.O.U.E., 208 pp. 46-57.

[2] Real Academia de la Lengua Española. Diccionario de la lengua española, 23. a edición. 2014 www.rae.es

[3] Asamblea General de las Naciones Unidas (ONU). Informe de la Comisión Mundial sobre Medio Ambiente y el Desarrollo (Comisión Brundtland): Nuestro Futuro Común. Nueva York, 1987.

[4] Asamblea General de las Naciones Unidas. Resolución 38/161. Proceso de elaboración de la perspectiva ambiental hasta el año 2000 y más adelante. Nueva York, 1983.

[5] Consejo Económico y Social de las Naciones Unidas (ECOSOC). Resolución 1346. Cuestión de la convocación de una conferencia internacional sobre los problemas del medio humano. Nueva York, 1968.

[6] Asamblea General de las Naciones Unidas. Resolución 2398. Problemas del medio humano. Nueva York, 1968

[7] The club of Rome (El club de Roma) www.clubofrome.org.

[8] Donella H. Meadows, Gary. Meadows, Jorgen Randers, and William

W. Behrens III. The Limits to Growth. New York, 1972.

[9] Robert Solow. Newsweek, 13 Marzo 1972, página 103.

[10] Donella H. Meadows, Gary, Dennis L. Meadows and Jørgen Randers. Beyond the Limits: Confronting Global Collapse, Envisioning a Sustainable Future. Chelsea Green Pub., 1992

[11] Donella H. Meadows, Gary, Dennis L. Meadows and Jørgen Randers. The limits to growth: the 30-year update. Chelsea Green Pub., 2004

[12] Conferencia de las Naciones Unidas sobre el Medio Humano. Declaración de la Conferencia de las Naciones Unidas sobre el Medio Humano. Estocolmo, 1972.

[13] R. Clarke y L. Timberlake. Stockholm Plus Ten. London: Earthscan, 1982.

[14] Asamblea General de las Naciones Unidas. Registros oficiales, 36 periodo de sesiones. Sup. $\mathrm{n}^{\circ} 25$ (A/37/25), parte uno, anejo 1.

[15] Comisión de las Comunidades Europeas. Libro Verde sobre el medio ambiente urbano: COM (90) 218. Bruselas, 1990.

[16] U.S. and World Population Clock. Www.census.gov/popclock/

[17] Central Inteligence Agency (CIA). The World Factbook. Datos de 2012. www.cia.gov

[18] Global Footprint network. Biodiversity indicators partnership, Ficha de indicador 2.3.1. www. footprintnetwork.org

[19] Betazeta Networks S.A. VeoVerde www.veoverde.com 
[20] Comunidad Autónoma de Madrid (CAM). Guía de Rehabilitación energética de edificios de vivienda. Madrid, 2008.

[21] Gobierno Vasco. Claves energéticas del sector doméstico en Euskadi. Vitoria-Gasteiz, 2013.

[22] Comunidad Económica Europea. Tratado constitutivo (tratado de Roma). Roma, 1957.

[23] Juan José Martín Arribas, Universidad de Burgos. La Unión Europea ante el fenómeno del cambio climático. Burgos, 2005.

[24] Directiva 2010/31/UE, Diario Oficial de la Unión Europea, L 153/1335.

[25] Real Decreto 2429/1979, de 6 de julio, por el que se aprueba la norma básica de edificación NBE-CT-79, sobre condiciones térmicas en los edificios.

[26] Real Decreto 314/2006, de 17 de marzo, por el que se aprueba el Código Técnico de la Edificación.

[27] Real Decreto 1027/2007, de 20 de julio, por el que se aprueba el Reglamento de Instalaciones Térmicas en los Edificios 


\section{Capítulo 2.Objetivos}

\section{Objetivos generales}

La presente Tesis Doctoral surge con un triple enfoque: generar nuevas superficies verdes en las zonas urbanas; permitir la simplificación de los sistemas de jardín vegetal actualmente existentes y favorecer la utilización de subproductos industriales que permitan acercarnos a una economía circular.

El objetivo fundamental es proporcionar una primera aproximación al uso de la bio-receptividad en los revestimientos de fachada. Para conseguir este objetivo se descarta la posibilidad de emplear morteros de revoco tradicionales debido a su alcalinidad y se opta por un mortero químico con un $\mathrm{pH}$ bajo, más compatible con la colonización vegetal de su superficie.

No obtante este mortero se modifica para que incluya residuos o subproductos industriales. Esto debiere suponer la sustitución de más de la mitad de la composición de materia prima, pudiendo implementar una economía circular, ayudando a disminuir el uso de los recursos naturales, reduciendo la producción de residuos y a limitando el consumo de energía.

Este mortero, utilizado en revestimientos de edificaciones, deberá también ser colonizado por una especie de briófito, que actúa como especie colonizadora pionera, consiguiendo a su vez, una simplificación máxima de los sistemas de jardín vegetal existentes actualmente.

\section{Objetivos específicos}

Para la consecución del objetivo general, se precisa definir los siguientes objetivos específicos:

- Evaluar un tipo de material que simplifique al máximo la idea de jardín vertical, consiguiendo un sistema cuyo mantenimiento sea mínimo.

- Elaborar un mortero, a través de una dosificación tal, que consiga un $\mathrm{pH}$ cercano a la neutralidad y que sirva como soporte biológico.

- Explorar la utilización de los morteros de magnesio fosfato utilizando diversos componentes y dosificaciones que abaraten el coste y reduzcan el impacto ambiental, considerando la opción de sustituirlos parcial o totalmente por sub-productos. 
- Estudiar la inclusión en las dosificaciones de residuos o subproductos agregados que supongan una reducción en el aporte de material y a su vez mejoren las propiedades del propio mortero.

- Caracterizar el mortero, definiendo un criterio de dosificación que conjugue las propiedades fisico-quimicas, mecánicas y que a su vez introduzca los sub-productos o residuos comentados.

- Evaluar si el material elaborado es bio-receptivo a la colonización vegetal utilizando una briófitos como especie pionera.

- Desarrollar un método de cultivo óptimo para el objetivo general de la tesis.

- Elegir un briófito que sirva como especie colonizadora pionera y definir su idoneidad para este uso.

- Determinar la necesidad de tratamientos adicionales que incentiven la colonización vegetal del mortero. 



\section{Capítulo 3. Revisión estado del arte}

\section{Los sistemas de fachadas vegetales}

\subsection{Introducción}

El concepto de fachadas vegetales o fachadas verdes se remonta a la antigua Babilonia. En torno al siglo IX a.C. se construyeron los "Jardines Colgantes de Babilonia", considerados una de las siete maravillas del mundo antiguo y uno de los primeros ejemplos de este tipo de arquitectura. Sin embargo este ejemplo no se entendería como una integración en la fachada, ya que su función era estética.

Otro ejemplo de la antigüedad corresponde a la época romana. Durante el Imperio, a lo largo del Mediterráneo, los romanos disponían las vides en espalderas y en las paredes de las viviendas. La idea era proporcionar sombreamiento a la par que se permitía la recolección de uvas.

Este popular sistema se fue extendiendo posteriormente con distintos tipos de plantas, del Mediterráneo al norte de Europa, más proclive al crecimiento de las plantas trepadoras. En estas zonas, la decoración vertical con flores, como rosales trepadores, llegó al punto de cubrir por completo las fachadas. Esto permitía a su vez amortiguar el choque térmico debido al agua que retenía en su interior las plantas.

Sin embargo hasta mediados del siglo $X X$ no se produzco ningún cambio sustancial en los sistemas de fachadas verdes. La utilización de hiedras en vez de otras trepadoras supuso básicamente el único cambio durante esta época.

En 1920 el movimiento de la ciudad jardín británico y americano promulgó la necesidad de modernizar los edificios a través de características tales como pérgolas o estructuras de enrejado para plantas trepadoras. Este movimiento, extendido a todo el mundo, permitió que las fachadas verdes tomaran relevancia, no sólo ornamental, sino que pasaron a aportar un plus ecológico y energético.

No obstante es a partir de los años 70 del siglo pasado cuando el aumento del interés en la "arquitectura verde" marca un cambio en la ciudad postindustrial. Una de las figuras clave de esta transformación es el botánico francés Patrick Blanc, que crea un sistema patentando de jardín vertical que permite la plantación de numerosas especies.

Desde ese momento, hasta la actualidad, se han investigado y desarrollado muchos tipos de fachadas verdes. Estos sistemas, normalmente basado en la obtener mejoras sostenibles y ecológicas de los sistemas, muchas veces se quedan muy lejos de este propósito. 
Actualmente existen multitud de sistemas constructivos con los que se puede abordar la construcción de los jardines verticales. La evolución acaecida durante los últimos años ha permitido un desarrollo muy acentuado en este tipo de sistemas, proliferando multitud de modelos patentados. Sin embargo estos se pueden agrupar en los siguientes subgrupos.

\subsection{Sistema con plantas trepadoras o colgantes.}

El acercamiento más antiguo a los sistemas de fachadas verticales consiste en este tipo de sistemas. En su simpleza, aparte de sus beneficios, radica su amplia utilización desde la antigüedad.

Debido a su uso histórico y a que se basan en la utilización de una o varias plantas que van tupiendo la superficie, agruparemos ambos tipos de plantas (trepadoras y colgantes), aunque, por definición, se tratan de dos sistemas opuestos.

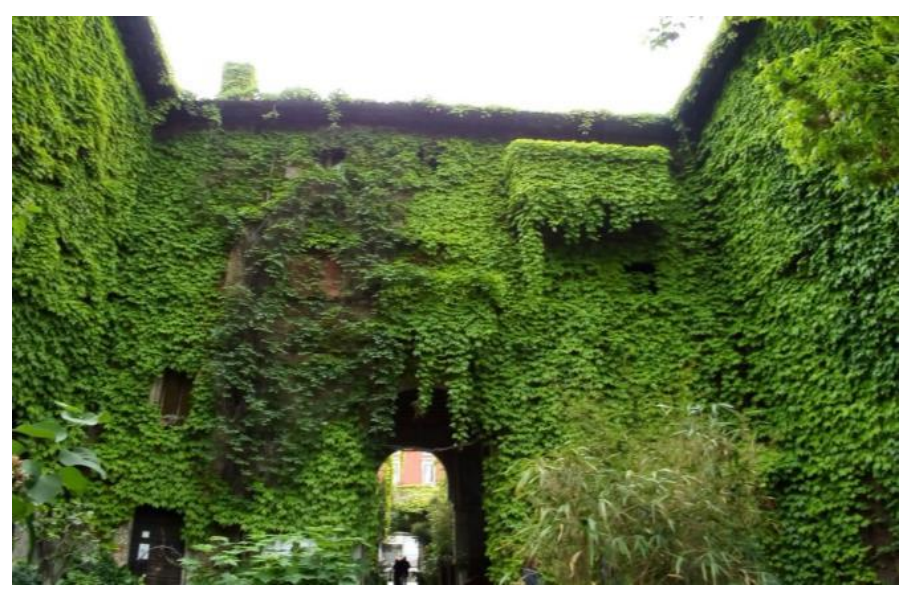

Imagen 18. Centro dell'incisione Alzaia Naviglio Grande Milano (Italia) Fuente propia

Los sistemas con plantas trepadoras permiten la cubrición de la fachada mediante el uso de este tipo de plantas que colonizan la fachada. Éstas se "adhieren" en resquicios de la propia fachada o a una sub-estructura, adherida o adosada a ella.

En una concepción más clásica (Imagen 18) estas se plantan directamente sobre el terreno, sin embargo también se pueden utilizar maceteros de los que crezcan las plantas, colocados a diversas alturas y que permitan así aumentar la superficie alcanzada por la planta.

Caben dos posibilidades, las plantas que se sustentan por si solas y las que no. Las primeras, debido al tamaño de su tronco y/o ramas, les permiten alzarse sin necesidad de estar apoyadas, ya que su propia rigidez permite su crecimiento natural.

Las segundas requieren de un soporte al cual encaramarse o enroscarse. Suelen utilizar órganos propios como los zarcillos, raíces adventicias o directamente ramas que permiten enredarse al soporte y buscar así una mayor cantidad de luz para lograr desarrollarse. Otra opción es la disposición de una subestructura, como rejas o mallas, las cuales permiten el crecimiento de la especie vegetal, manteniéndola separada del cerramiento, permitiendo así la creación de una cámara de aire, y la preservación de la propia fachada. 
Los sistemas con plantas colgantes consisten en la disposición de maceteros, colocados a una o diversas alturas y que, debido al cuelgue de la planta, se va tamizando la superficie de la fachada.

Como ya se ha indicado antes, esta es una de las técnicas de fachadas verticales más antiguas. Si bien en un principio se utilizaban únicamente como tamizadores de un espacio, sin que hubiera una fachada por su cara posterior, posteriormente se han venido utilizando como cortinas adosadas a los cerramientos gracias a cables o rejas. Con ello se consigue el mismo efecto "doble-piel" que con la planta trepadora.

\section{Ventajas}

- Gran sencillez y amplia experiencia.

- Bajo mantenimiento.

- Económico.

Inconvenientes

- Escasos beneficios de ahorro energético.

- Lento crecimiento.

Hábitat de multitud de especies animales. En zonas residenciales, puede ser un inconveniente.

\subsection{Sistema de jardín vertical}

Los jardines verticales son la disposición vertical, sobre una fachada o sobre cualquier tipo de soporte vertical, de diversas plantas que cubren la superficie tratada, dando la apariencia de ser un jardín dispuesto en sentido vertical.

Su principal objetivo es integrar completamente la vegetación en la arquitectura para lograr los máximos beneficios ambientales con el mínimo consumo de agua y energía [1]. Para ello se requiere a su vez sistemas de riego y aporte de los nutrientes adecuados, que permitan la correcta manutención del jardín.

Los principales sistemas de jardinería vertical se dividen en dos grandes grupos, pese a que dentro caben multitud de subgrupos:

\section{Jardines verticales hidropónicos.}

Se entiende por jardín vertical hidropónico al sistema en el cual las raíces de las plantas crecen en un medio inerte. Popularizado en los años 80 por el botánico francés, Patrick Blanc [2], cuya patente es la base de la mayoría de jardines verticales. Consiste en dos capas de fieltro de poliamida dispuestas sobre una estructura metálica. El sistema se basa en la gran capilaridad y capacidad de retención de agua en el fieltro, que permite un desarrollo de las raíces de las plantas. Esta doble piel posibilita la existencia de una cámara de aire que funciona a modo de colchón térmico.

El material base puede ser cualquiera de los siguientes:

- Fieltro no tejido (poliamida, polietileno, poliéster...)

- Lana de roca

- Espumas técnicas (poliuretano, poliurea...), etc. 


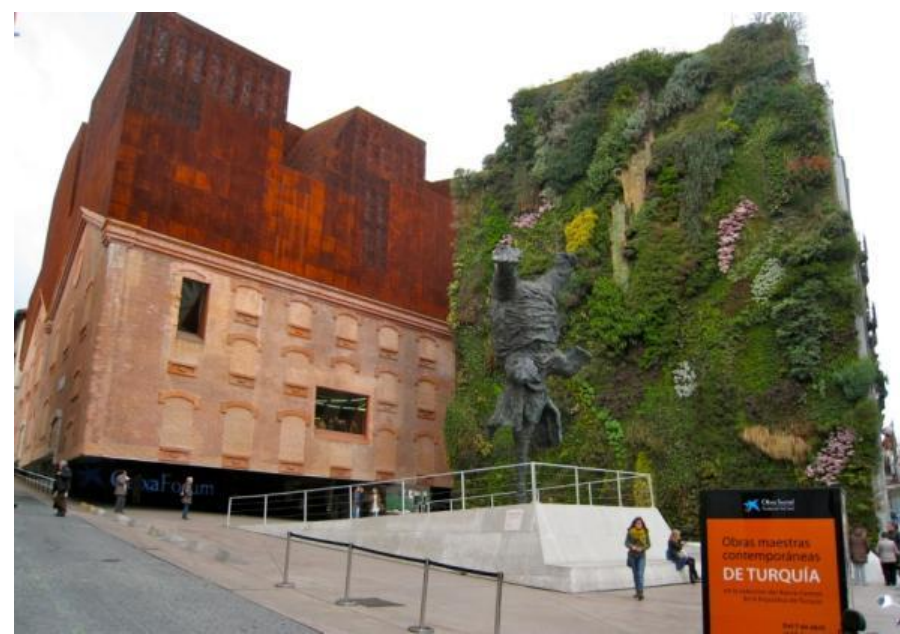

Imagen 19. CaixaForum, Madrid.

Es quizás la simpleza del sistema, su fiabilidad y su bajo coste de mantenimiento en donde radica su gran popularidad, siendo dos ejemplos de los más conocidos el CaixaForum de Madrid (Imagen 19) o el de la tienda Kulturkaufhaus Dussmann en Berlín.

\section{Jardines verticales con sustrato.}

Se entiende por este sistema aquel en el cual las raíces crecen en un medio con un sustrato granular. Básicamente consiste en la disposición de plantas sobre diversos "maceteros" de diversas formas y/o materiales, dispuestos en la superficie mediante subestructuras, y cuyo crecimiento colmata la superficie de plantas.

Estos maceteros deben contener un sustrato granular con un porcentaje orgánico más o menos elevado, pudiendo incluirse sustitución de suelo por sustrato ligero como arlita, perlita, sphagnum... que les confieren una mayor capacidad de retención de agua, aireación y drenaje.

Los nutrientes se pueden aportar vía riego pero, a diferencia de los jardines hidropónicos, no son imprescindibles para el funcionamiento a corto plazo, ya que el propio sustrato los contiene.

La principal ventaja de este tipo de jardines frente a los sistemas

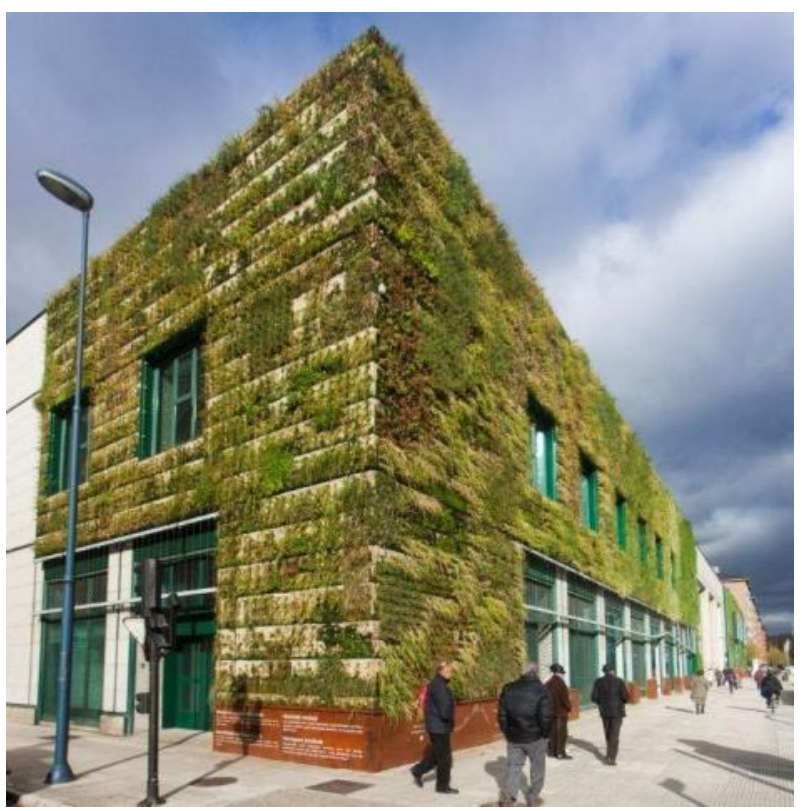
hidropónicos es la rapidez con la que se consigue un efecto de colonización vegetal de la fachada. Sin embargo pecan de ser sistemas complejos, más costosos y con un mantenimiento más caro, lo cual suele ir en su contra a la hora de elección.

Por otro lado su gran modularidad, existiendo en la actualidad numerosos formatos comerciales de diversas formas, materiales y la 
capacidad de elección de un mayor rango de plantas están haciendo de estos jardines más comunes, como el del Palacio de congresos Europa de Vitoria-Gasteiz (Imagen 20).

\section{Sistemas que incorporan briófitos}

\subsection{Introducción}

Para clasificar las plantas, estas se suelen dividir en dos grandes grupos en función de su complejidad: inferiores y superiores. Las primeras son aquellas de composición más primitiva, que carecen de tejidos y raíces y su alimentación se realiza a través del medio que le circunda. En este grupo se suelen incluir las briófitas y las hepáticas.

Las plantas superiores son aquellas que disponen de órganos diferenciados, tejidos vasculares y realizan la fotosíntesis.

Los jardines verticales se han basado tradicionalmente en la disposición de plantas denominadas superiores. Sin embargo, esta decisión añade un plus de complejidad en los sistemas propuestos, ya que requieren bases para sustrato más importantes, aparte de un mantenimiento más complejo.
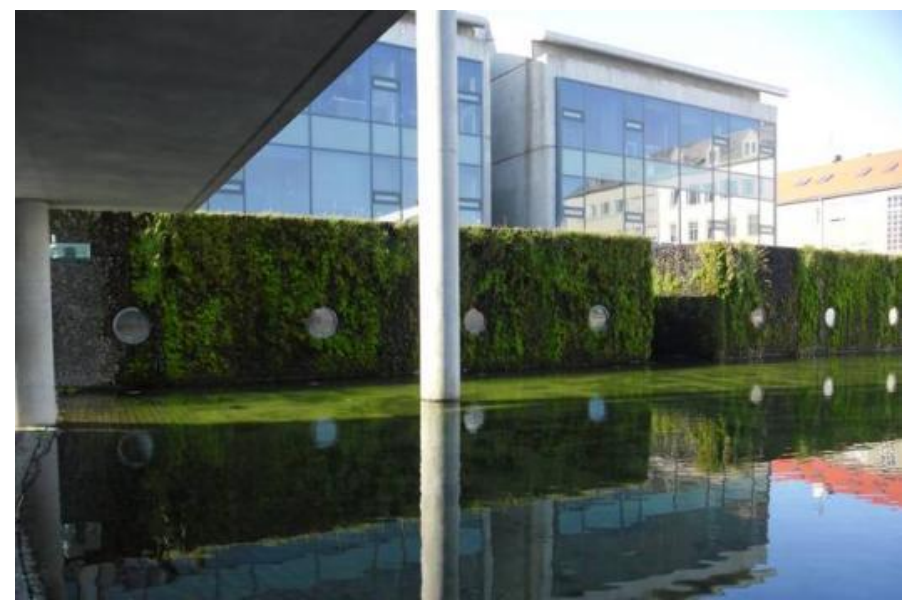

Imagen 21. Ayuntamiento de Reykjavik

La utilización de plantas inferiores no es un invento nuevo. Estas se vienen utilizando desde épocas remotas en climas duros, con alta humedad y abundancia de precipitaciones, pero no como un elemento principal de las pieles de los edificios.

Se han empleado fundamentalmente como sellantes de juntas o como aislante, gracias a su capacidad de retención de líquidos. Incluso en la actualidad, se siguen utilizando para estos fines en zonas como Alaska o Nepal.

A pesar de la dificultad que entraña el uso de briófitos y hepáticas, también se ha utilizado, eso sí recientemente, como elemento principal en revestimiento de fachadas. Un ejemplo bastante conocido es el Ayuntamiento de Reykjavik (Imagen 21). La pared de musgo suaviza el aspecto del edificio, hecho de piedra volcánica porosa, constantemente humedecida con agua bombeada desde un estanque. La idea de los diseñadores, Studio Granda, era sencilla: coger un sustrato local apropiado (la roca volcánica) y plantar sobre algo que en Islandia crece casi en cualquier lugar, musgo, y solamente añadirle agua. 
Otros ejemplos importantes del uso contemporáneo de briófitos y hepáticas en la arquitectura, es su utilización como cubiertas verdes. Este uso, mucho más prolífero que en fachadas, se basa en la disposición de las capas necesarias, sobre las que crezca posteriormente el musgo. Esto solo puede permitirse en zonas que se vean favorecidas por las condiciones atmosféricas, creando un clímax natural para el musgo.

A modo de ejemplo, en Buholmen, Noruega, Skaara Arkitekter [3] ha diseñado una cabaña cuya cubierta se colmata con una capa de musgo. Esta proporciona aislamiento térmico y la captura de la escorrentía del agua de lluvia.

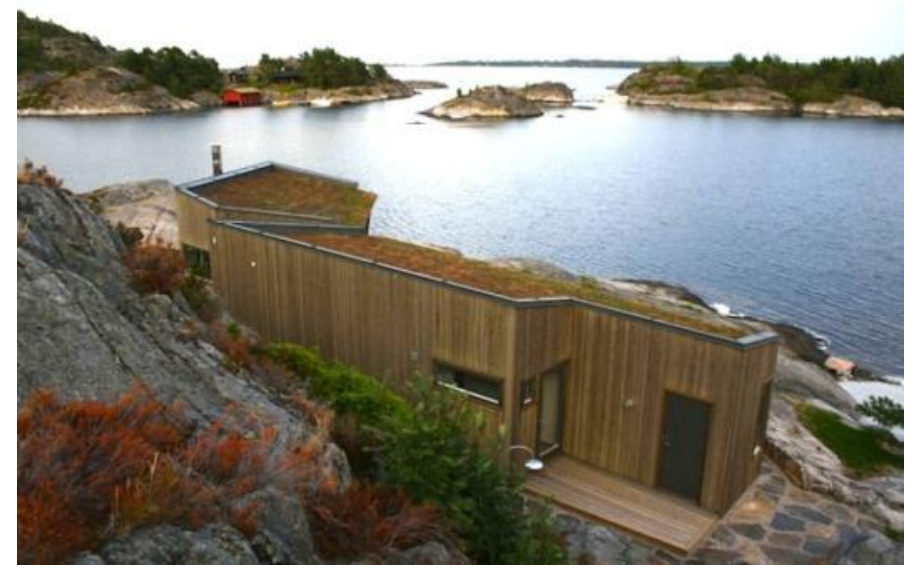

Imagen 22. Bulholmen cottage. Noruega. Fuente: Skaara Arkitekter

Ampliando el ámbito de empleo de la arquitectura al paisajismo, existen también ejemplos de utilización de musgos (briófitos) en el urbanismo. Dicho uso, de forma controlada y no accidental, viene llevándose a cabo en oriente.Los jardines de musgos de los templos budistas han sido cuidados durante siglos por los monjes, para mantener estos espacios de meditación tranquila. También existen evidencias de su existencia en Corea y China [4].

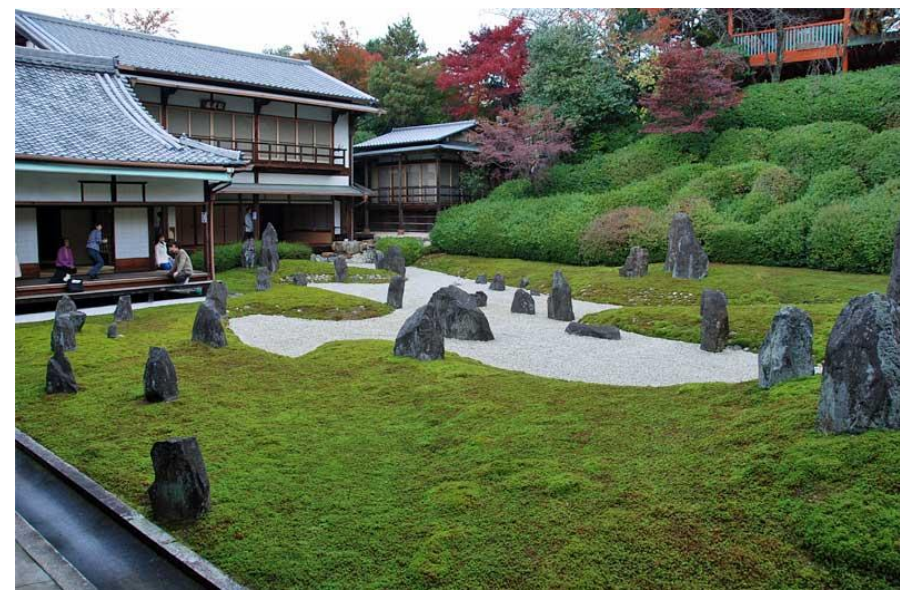

Imagen 23. Templo de Kōmyō-in, Tokio, Japón.

Sin embargo, este aparente axioma de capacidad del musgo para su proliferación no tiene reflejos en otros casos, como sucedió en Munich (Alemania), según explica Jannice Glime [5], donde se cubrió un edificio con un panel de toba volcánica con musgos. 
El desarrollo de estos paneles se llevó a cabo en un ambiente controlado en un laboratorio. Los problemas comenzaron una vez puesto en obra, ya que el musgo nunca se llegó a adaptar correctamente al ambiente menos controlado.

En un primer momento se procedió a regar los musgos con el agua procedente de las precipitaciones atmosféricas, recogidas en el tejado del propio edificio. Sin embargo este fue el gran problema que asoló la fachada verde. La lluvia, al disolver la contaminación atmosférica, y en especial las partículas pesadas, arrastraba con ella toda esta contaminación, que a su vez se transmitía directamente al briófito.

Debido a este fracaso, se optó por la sustitución de esta forma de riego y de los musgos perdidos, instalando un sistema que mantenía húmeda la roca. Sin embargo, esto provocó la disolución de los carbonatos de la roca, provocando de nuevo la muerte de los musgos.

\subsection{Sistemas comerciales}

En este apartado se describen los sistemas comerciales que han incorporado briófitos en su composición. Sus características hacen que cuenten con una gran potencial y es por ello que se han desarrollado una serie de sistemas comerciales.

No obstante, la mayororía de estos sistemas ha adolecido de diversos problemas y han llevado a que muchos de los productos que se relacionan no hayan llegado a salir a la luz o simplemente se hayan dejado de comercializar.

En general, los briófitos son plantas de complicado cultivo y reproducción, de ahí vienten parte de los pobres resultados obtenidos a la hora de utilizarlos. También de el escaso conocimiento desde la ingeniería a la hora que conseguir su adaptación a la envolvente de edificios, frente a otras plantas.

\section{Géomoss ${ }^{\circledR}$.}

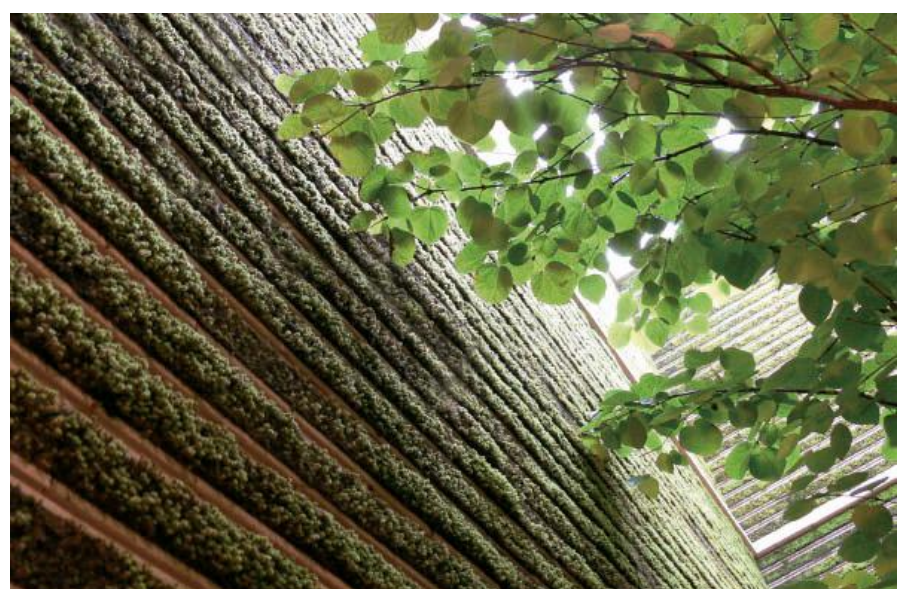

Imagen 24. Sistema Géomoss. Fuente Geobois

- Empresa comercializadora:

Géobois / Géolam

- Denominación comercial: Géomoss

\section{Web no disponible}

Géomoss es un sistema prefabricado que consiste en la disposición de briquetas de cerámica cóncava sobre las que se un revestimiento de 
espuma celular con una estructura tipo nido de abeja, que sirve de sustrato para el crecimiento de musgo.

Estos módulos se disponen sobre un sistema de raíles de aluminio en los que se instalan con un sistema tipo clip de acero inoxidable.

La instalación de riego está asegurada por un sistema de goteo dispuesto sobre las piezas cerámicas, e integrado en los raíles de aluminio, por las que resbala (son inertes y no porosas) hasta que es trasmitida al briófito.

\section{Componentes del sistema}

- Base de cerámica

- Espuma cerámica

- Briófito (Racomitrium)

- Anclaje: Perfiles de aluminio anclados a fachada

- Sistema de riego: Goteo integrado en sub-estructura.

\section{Principales ventajas}

La enumeración de las ventajas se basa en el catálogo de la empresa, al no tener constancia de estudios o fichas técnicas que avalen los datos que la empresa promulga.

- Bajo consumo de agua (0-400 litros/ m²)

- No necesita mantenimiento.

- Mejora del aislamiento térmico y acústico de la fachada

- Mejora la calidad del ambiente mediante la absorción de gases de efecto invernadero.

- El sistema se está instalando mayoritariamente en Japón, pero existen ejemplos en otras partes del mundo.

\section{Principales desventajas}

- Sistema de relativa complejidad.

- Escasa implantación y por lo tanto, imposibilidad de contrastar resultados.

- Escasa aportación de documentos que acrediten las ventajas vendidas por la empresa.

- Escasa sostenibilidad del sistema.

- Aparentemente el sistema ha dejado de comercializarse, al desaparecer la página web específica y no aparecer en la del distribuidor.

CODRA system.

- Empresa comercializadora: Ilsong

- Denominación comercial: CODRA system

http://ilsong99. cafe24.com/?page id $=617$ 


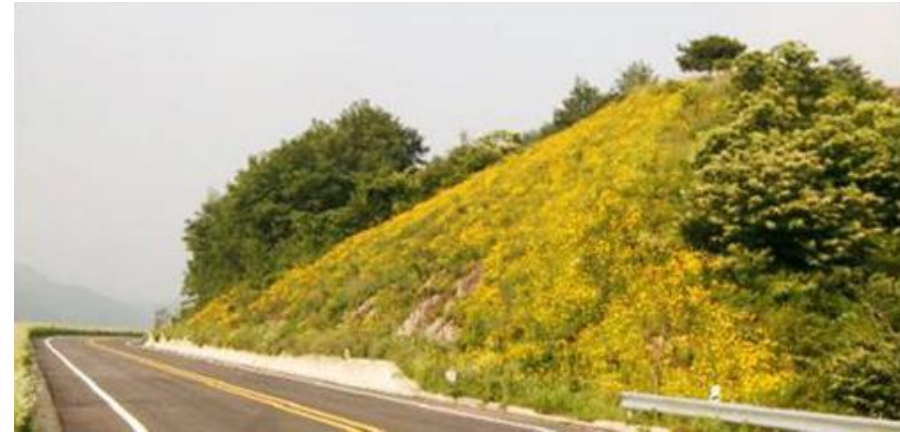

Imagen 25. Sistema Codra (Codra System) Fuente: Ilsong

CODRA es un sistema que se utiliza para la estabilización de taludes basados en la idea de una reconstrucción amable con el medio ambiente que logre una regeneración ambiental reteniendo a su vez agua y actuando como pantalla acústica.

El sistema propone la utilización de una variedad de musgos que actúan como especie pionera y generando las condiciones de bioreceptividad necesarias para el asentamiento de un mayor número de plantas de diversas especies.

\section{Componentes del sistema}

- Lámina geotextil

- Musgo autóctono

- Resinas de polímeros

El sistema se compone básicamente de una red estructural (Imagen 25) dispuesta directamente sobre el talud. Esta red se compone por una lámina geotextil dispuesta bajo una serie de musgos autóctonos.

Para la estabilización se impregna una serie de resinas con polímeros para evitar el desmoronamiento del talud resultante y que favorece el crecimiento de nueva vegetación, al tratarse de materiales biodegradables y permitir una gran retención de líquidos.

\section{Principales ventajas}

Estas afirmaciones se basan en el catálogo de la empresa, al no tener constancia de estudios o fichas técnicas que avalen los datos que la empresa promulga.

- Sistema sencillo.

- No necesita mantenimiento.

- Regeneración ambiental.

- Sistemas biodegradables.

\section{Principales desventajas}

- Sistema descontrolado.

- Escasa aportación de documentos que acrediten las ventajas vendidas por la empresa.

- Escasa compatibilidad en implantación en edificios. 
Moss Catch system.

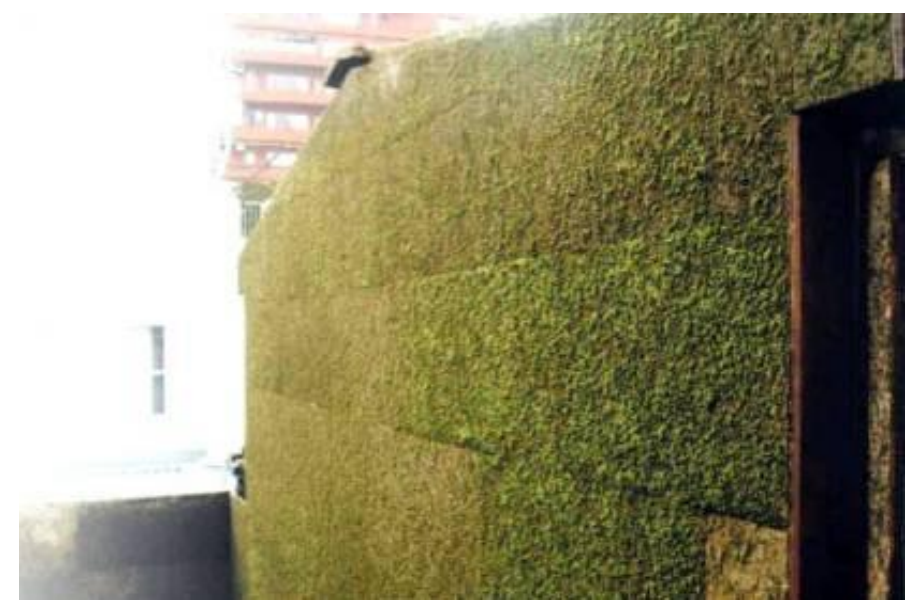

Imagen 26. Moss catch system. Fuente: Ilsong

- Empresa comercializadora:

Ilsong

- Denominación comercial:

Moss catch system

\section{Web no disponible}

Moss catch es un sistema de paneles de fachada (Imagen 26 e Imagen 27) que se basa en la disposición de paneles o rollos, sobre los que se plantan diferentes tipos de musgos en edad temprana, con el fin de crear las condiciones necesarias para la implantación de otras especies.

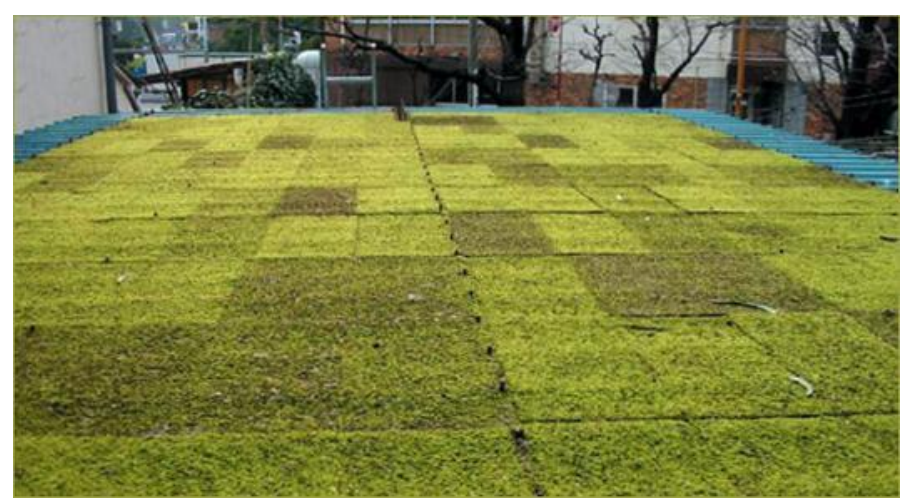

Imagen 27. Moss catch system en rollos. Fuente: Ilsong

Deberíamos diferenciar entre los sistemas compuestos por rollos y los de paneles (Imagen 28), ya que su fin condiciona la utilización de un sustrato $u$ otro. Por ello se utilizará los paneles como recubrimiento horizontal y vertical de muros, fachadas, cubiertas, etc... Sin embargo se destinan los rollos cuando se pretenda la creación de jardines de musgos o cubiertas ajardinadas, aunque también permite su implantación en fachadas.

\section{Componentes del sistema}

- Panel o rollo

- Musgo 


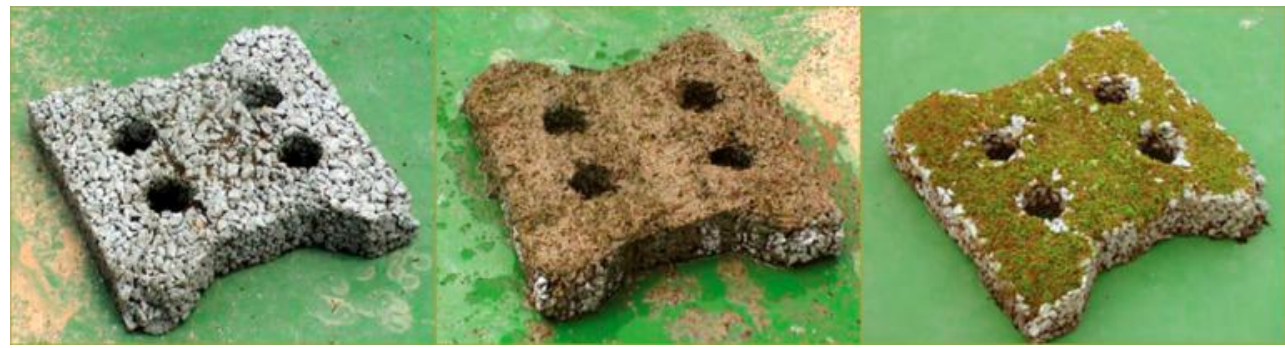

Imagen 28. Implantación musgo en panel. Fuente: Ilsong

\section{Principales ventajas}

Estas afirmaciones se basan en el catálogo de la empresa, al no tener constancia de estudios o fichas técnicas que avalen los datos que la empresa promulga.

- Sistema sencillo.

- Escaso peso.

- Bio-receptividad del sistema.

- Gran capacidad de absorción de agua.

\section{Principales desventajas}

- Sistema relativamente descontrolado.

- Escasa aportación de documentos que acrediten las ventajas vendidas por la empresa.

- Aparentemente el sistema ha dejado de comercializarse, al no aparecer en la página web del distribuidor.

\section{Enka-moss.}

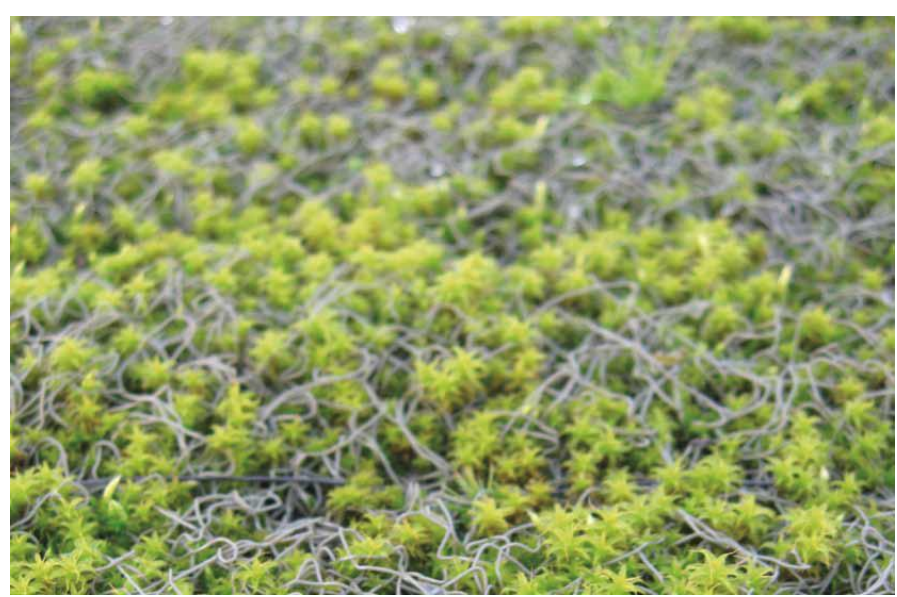

Imagen 29. Enkamoss. Fuente: Colbond.

- Empresa comercializadora:

Colbond

- Denominación comercial:

Enkamoss

Web no disponible

Enka-moss es un material, comercializado en rollos (Imagen 29), compuesto por un tejido sintético y una estructura tridimensional de nylon que contiene brotes de musgo. La principal utilidad es la 
concepción de cubiertas verdes de edificios y aislamiento acústico (aparentemente en fachadas).

Su funcionamiento se basa en la capacidad de retención de agua del tejido y del propio musgo. La adherencia del musgo se sustenta directamente en los rizoides y en la maya tridimensional que funciona a modo de arnés.

\section{Componentes del sistema}

- Sustrato

- Tejido sintético

- Estructura tridimensional de nylon

- Musgo

\section{Principales ventajas}

Estas afirmaciones se basan en el catálogo de la empresa, al no tener constancia de estudios o fichas técnicas que avalen los datos que la empresa proporciona.

- Sistema sencillo.

- Posibilidad de disposición en vertical.

- Gran capacidad de absorción de agua.

\section{Principales desventajas}

- Requiere sustrato sobre el que disponerse.

- Pese a que supuestamente está concebido como un sistema de rehabilitación de cubiertas, al requerir una cubierta verde, la estructura de estas no suelen estar dimensionadas para soportar el peso de sustrato.

- El sistema no se ha llegado a comercializar, tal y como nos ha transmitido la empresa comercializadora.

XF-321 (Pre-vegetated mats).
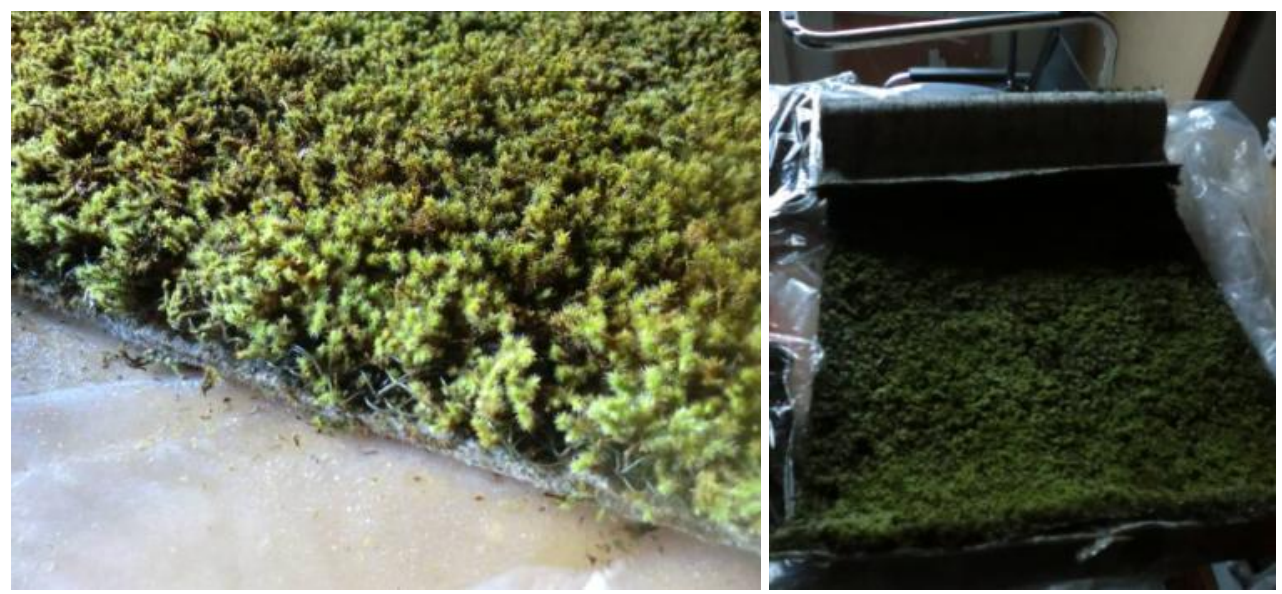

Imagen 30. XF-321. Fuente: Elaboración propia 
- Empresa comercializadora:

- Denominación comercial:

\section{Web no disponible}

El material, denominado provisionalmente como XF-321 (Imagen 30), es un producto desarrollado por la empresa Xeroflor, el cual viene a sustituir al Enkamoss anteriormente descrito, dentro de algún tipo de colaboración comercial entre ambas empresas.

Al ser un material todavía en investigación, no se ha proporcionado ficha técnica o descriptiva con la que poder saber sus características, aunque se suponen las mismas que en el Enka-moss.

De dicho material se ha proporcionado un par de muestras con las que se evaluará su evolución en hábitats más o menos controlados.

\section{M1 - Die Moosmaschine}

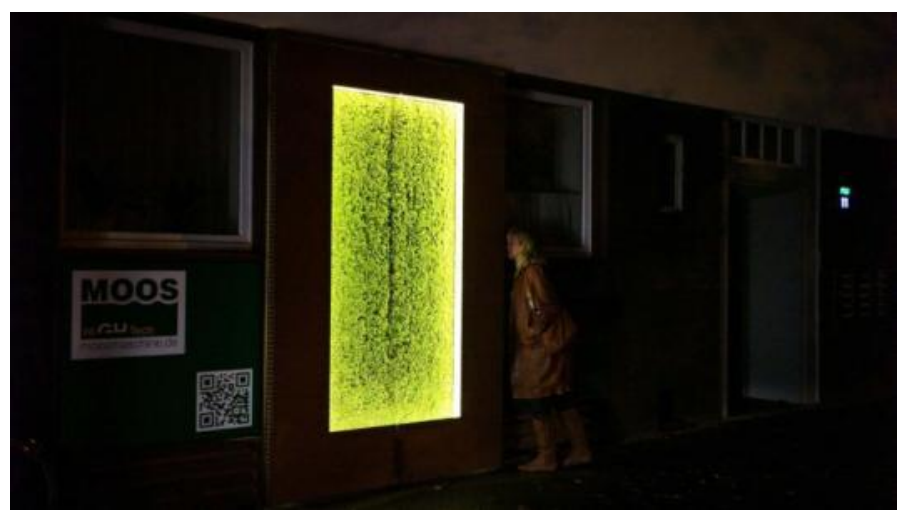

Imagen 31. Prototipo. Fuente: www.mossmaschine.de

- Empresa comercializadora:

No se comercializa

- Denominación comercial:

Moss Machine

\section{www.moosmaschine.de}

Moos Maschine (Imagen 31) se trata de un complejo sistema diseñado por el Dr. Günter Haese con la colaboración del briólogo Jan-Peter Frahm, y construido por la empresa a Gartenheim.

El sistema se basa en la disposición de un musgo en una cámara acristalada, al que se aportan riego (Imagen 32). El riego se efectúa por dos equipos diferentes, gobernados por un software específico, uno elabora la solución nutritiva adecuada para el briófito y otro se encarga de la irrigación con la periodicidad necesaria.

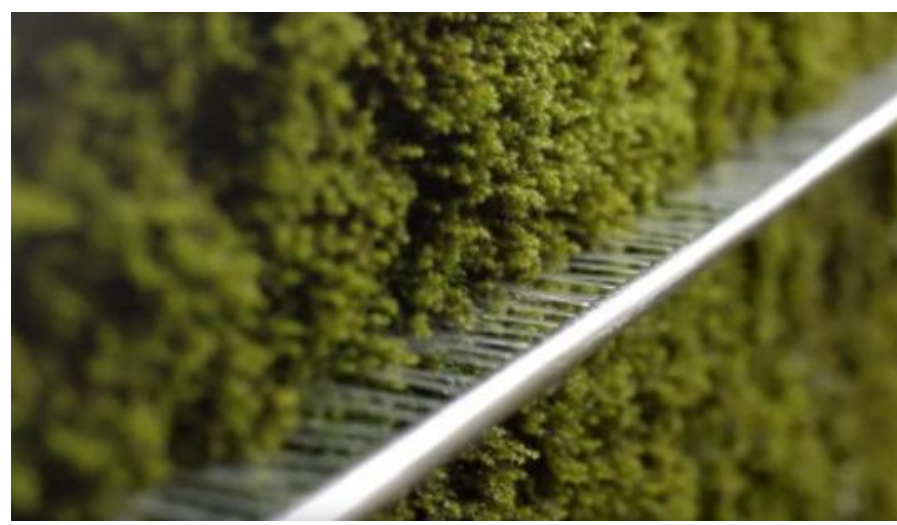

Imagen 32. Sistema de riego. Fotograma extraído video promocional. 


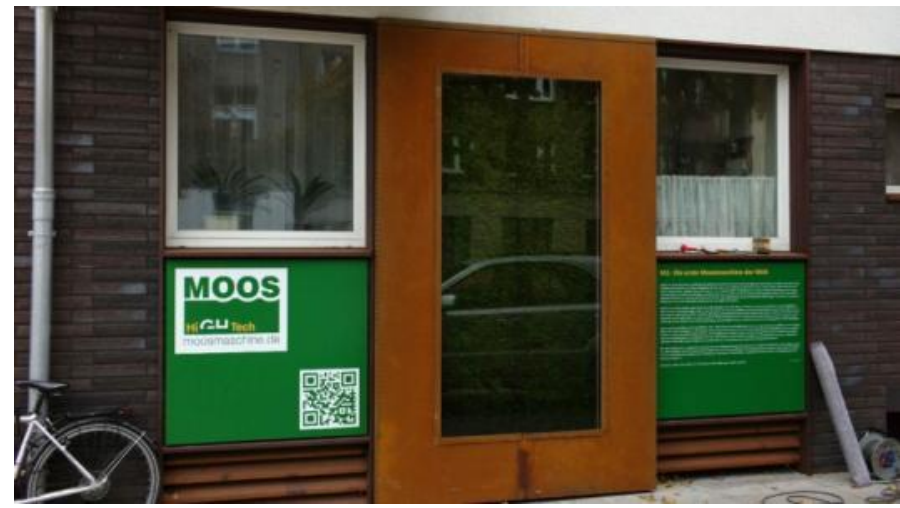

Imagen 33. Prototipo. Fuente: www.moosmaschine.de

No ha sido posible conseguir más información que la recogida en su vídeo promocional de 2013 [6], en el cual se promociona como "la primera máquina de musgo del mundo".

Realmente el sistema, debido a su gran complejidad, a su disposición casi como en una urna, sin estar en contacto con el exterior, y con un complejo equipamiento, se escapa un poco del objeto de la investigación.

\section{Moss wall}

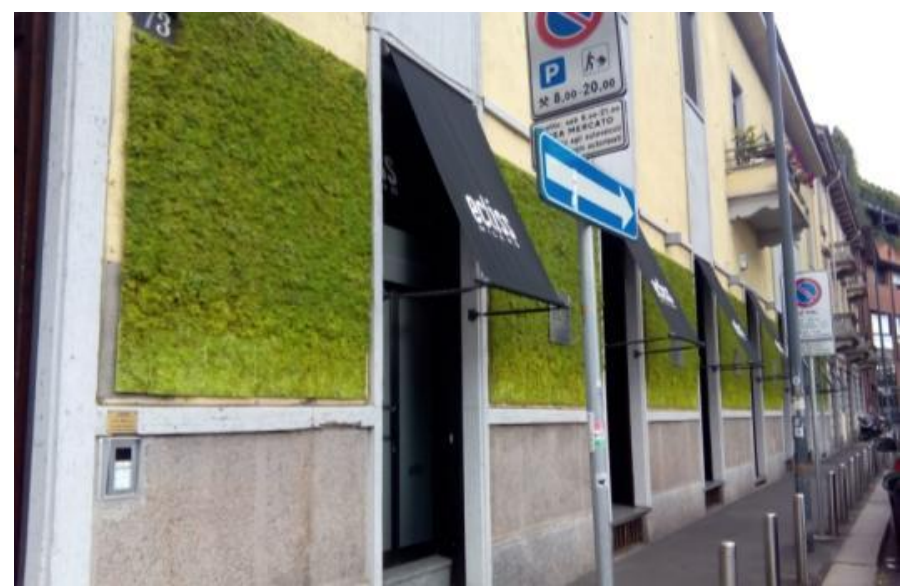

Imagen 34. Moss Wall en Ecliss Milano. Fuente propia

- Empresa comercializadora:

- Denominación comercial:

\section{www. verdeprofilo.com/es/pages/moss-wall}

La empresa italiana Verde Profilo, especializada la creación de espacios ajardinados [7] tales como jardines y prados verticales, ha desarrollado un sistema de panel que utiliza un liquen estabilizado (incluso teñido en varios colores) (Imagen 35), cuyo uso únicamente se prescribe para interiores. En principio no requiere mantenimiento, excepto garantizar una tasa de humedad siempre superior al $40 \%$, debiendo mantenerla con sistemas humidificadores. En ningún caso el panel tiene que ser expuesto a luz solar directa, fuente de calor, ni a la intemperie. 


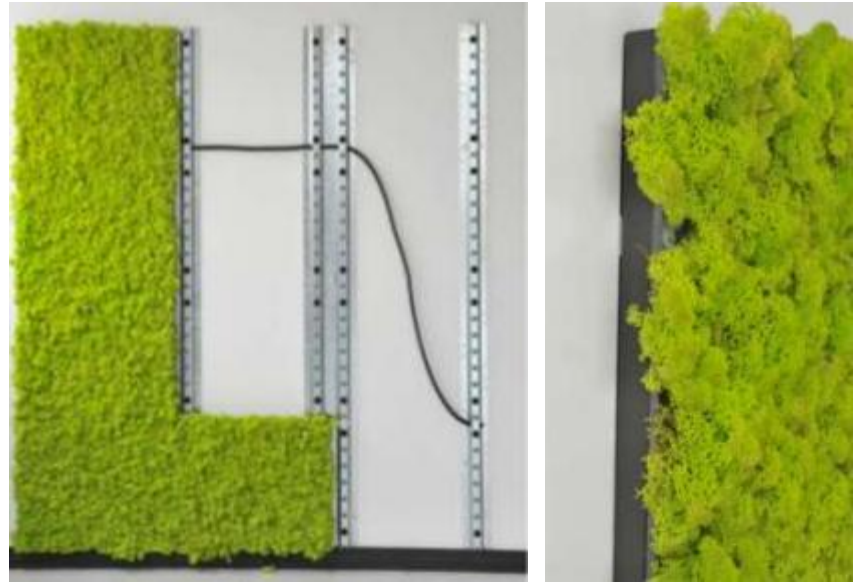

Imagen 35. Detalle Moss Wall. Fuente: Verde Profilo

La razón por la que el panel no se puede utilizar en exteriores depende básicamente del hecho de que la lluvia y el sol tienden a dispersar la sustancia que sustituye a la savia, por tanto, el liquen en ese punto se seca y se destruye [8].

Sin embargo, se ha dispuesto en el exterior, en la fachada de la empresa Ecliss Milano (Imagen 34), en un conjunto con exposiciones temporales, desde noviembre de 2013. Las condiciones temporales y la alta humedad, la tienda se sitúa junto a uno de los canales de Milán, han permitido que la fachada continúe verde.

\section{Componentes del sistema}

- Sub-estructura metálica de acero galvanizado

- Panel con liquen

\section{Principales ventajas}

Estas afirmaciones se basan en el catálogo de la empresa, al no tener constancia de estudios o fichas técnicas que avalen los datos que la empresa proporciona.

- Sistema sencillo.

- Polivalencia de acabados y colores.

- Capacidad de adaptación a distintas fachadas.

\section{Principales desventajas}

- No se puede utilizar en exteriores.

- Duda real de la resistencia de un liquen al proceso de estabilización y al teñido.

- En caso de condiciones de humedad inferiores al 40\% necesita un sistema de humidificación, no permite otro riego. 


\subsection{Otros sistemas}

\section{Prototipo en base geo-compuesto con musgo.}
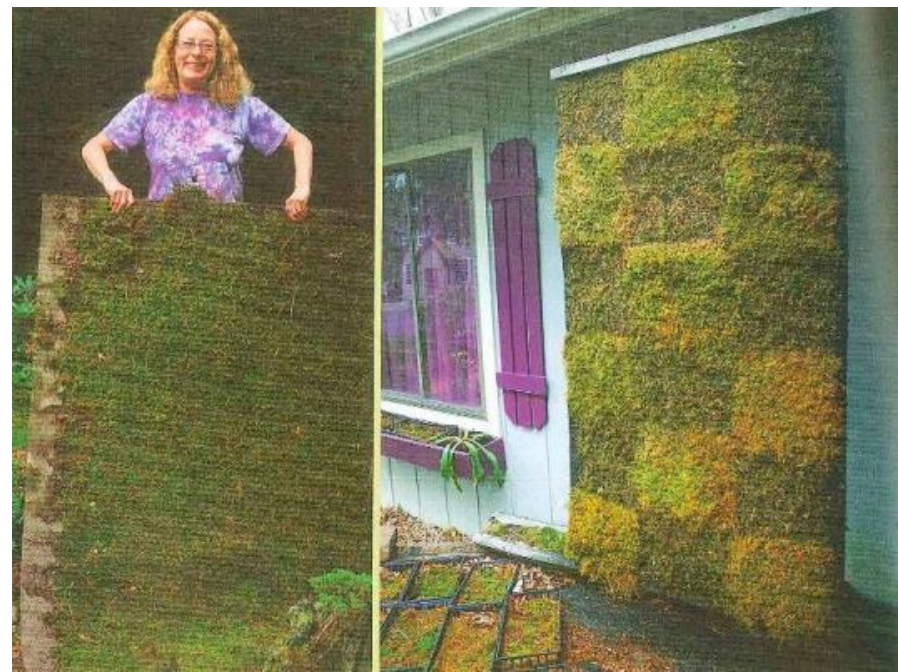

Imagen 36. Panel de musgo. Fuente: Annie Martin

Uno de los intentos en simplificar al máximo el revestimiento de una fachada con musgo es el que ha llevado a cabo la experta en jardinería con briófitos, Annie Martin. A través de su actividad divulgativa en Bryonet, un grupo de discusión de la "International Association of Bryologists" (IAB) [9], así como su empresa "Mountain Moss" [10] es reconocida como una de las mayores expertas en la materia.

Recientemente ha elaborado unos prototipos de paneles ligeros de fachadas con musgo. Su elaboración casera es bastante sencilla: ha diseminado diversos brotes de musgo sobre un geo-compuesto comercial utilizado en drenajes (Imagen 37), cultivándolo en primer momento sobre un plano horizontal.[11]

Una vez que los rizoides del musgo se han adherido al geo-compuesto y han comenzado a reproducirse, ha dispuesto el panel en el exterior, colgado en posición vertical, recibiendo un mantenimiento a base de riego por pulverización (Imagen 36).

\section{Componentes del sistema}

- Geo-compuesto Enkadrain [12].

- Musgo. Entodon seductrix.

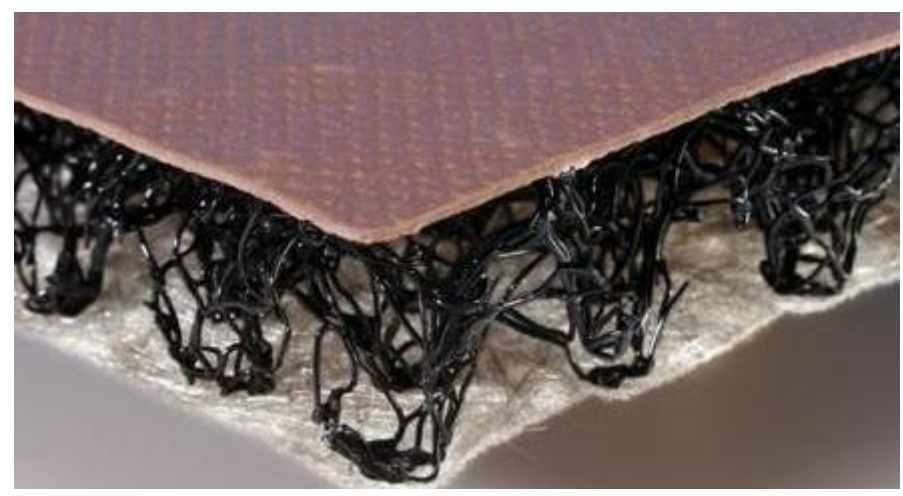

Imagen 37. Enkadrain. Fuente Coldbond 


\section{Principales ventajas}

Estas ventajas han sido descritas en una conversación mantenida con Annie Martin.

- Enorme sencillez.

- Fácil fabricación.

- Escaso mantenimiento.

- Mejorar la calidad del ambiente mediante la absorción de gases de efecto invernadero.

\section{Principales desventajas}

- No existe una implantación comercial y por lo tanto, imposibilidad de contrastar resultados.

- Requiere un continuo riego (frecuente aunque corto), que implementado en fachadas completas, requeriría de un sistema de riego.

\subsection{Otros sistemas en investigación}

\section{Briosistema}

- Denominación:

Proyecto para el desarrollo de la "envolvente briofita biosostenible" en la edificación: Briosistema

- Investigadores: Universidad Politécnica de Madrid

\section{Euroestudios, SL}

\section{http://www.euroestudios.es/}

http://upm.es/observatorio/vi/index.jsp?pageac=actividad.jsp\&id actividad $=175233$

Tal y como se indica en el observatorio de $1+\mathrm{D}+\mathrm{i}$ de la Universidad Politécnica de Madrid (UPM), "el proyecto tiene por objeto el diseño de una envolvente inteligente constituida por material vegetal (briófitas) en su parte externa apoyado en un soporte textil y una estructura metálica que soporta los elementos de mantenimiento y motorización de la envolvente vegetal (riego, sensores, etc.), con objeto de incrementar la eficiencia térmica de los edificios en cualquier época del año".

El proyecto ha sido seleccionado en el subprograma nacional INNPACTO del Programa Nacional de Cooperación Público-Privada, dentro del Plan Nacional de Investigación Científica, Desarrollo e Innovación Tecnológica 2008-2011.

Dado que se trata de un sistema aún en investigación, solamente se ha podido obtener información de dos fuentes: la web de la empresa investigadora y una video-conferencia mantenida con los investigadores.

Según la web de Euroestudios, únicamente se han podido obtener los objetivos:

- Conseguir un producto estándar de fácil cálculo y aplicación.

- Aumentar la eficiencia energética. 
- Conseguir un producto indicador de contaminación.

- La sostenibilidad.

- La utilización de materiales reciclables que no generan residuos en su obtención.

- La optimización en el consumo de recursos monitorizando en tiempo real las estructuras permitiendo mantenerlas en condiciones óptimas.

Sin embargo, según la videoconferencia, se han podido obtener más datos, debido a que el sistema se halla en fase de prototipo, habiéndolo desarrollado en un parque urbano madrileño.

\section{Componentes del sistema}

- Base textil, sobre la que "planta" directamente en musgo.

- Sistema de riego.

- Sistema de monitorización y control.

\section{Conclusiones}

Se sistema monitoriza en todo momento el estado de hidratación del briófito, aportándole humedad siempre que lo requiera con el fin de que su aspecto se siempre lo más natural posible.

Los resultados obtenidos por los investigadores difieren bastante entre el modelo en condiciones controladas de laboratorio frente a las condiciones exteriores.

El sistema presenta problemas de aclimatación al exterior. Aparentemente las condiciones climáticas, pese al control continuado, son agresivas.

\section{Sistemas que exploran la bio-receptividad de los materiales}

\subsection{Introducción}

El diseño de productos que exploran la bio-receptividad de los materiales se trata de un campo que está iniciando su andadura. Tradicionalmente se ha investigado la bio-receptividad no como una forma incentivar la generación de superficies verdes. De hecho varios estudios elaboran una metodología para evaluar la bio-receptividad de materiales [13].

En la actualidad se están investigando diversos tipos de prototipos que desarrollan materiales y sistemas constructivos con bio-receptividad mejorada. De este modo se intenta favorecer el crecimiento espontaneo de vegetación directamente sobre los soportes deseados.

Sin embargo dado que la bio-receptividad mejorada asociada a los materiales de construcción se trata de una materia innovadora, únicamente se están explorando materiales en fase de investigación y no de comercialización. Esto también es debido a la complejidad intrínseca de las investigaciones, al tratarse de materias transversales que afectan a varios campos de la investigación como son arquitectura, construcción, ingeniería (simulaciones energéticas y análisis medio- 
ambientales), biología, edafología, botánica e incluso robótica (en algunos casos de impresión 3D) [14].

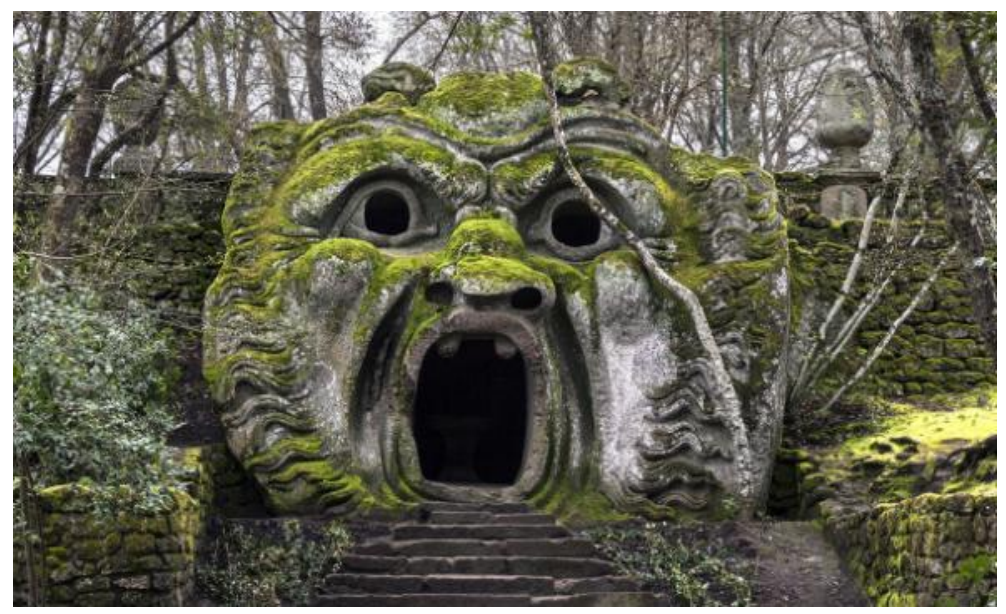

Imagen 38. Estatua bio-colonizada. Parco dei mostri. Bomarzo (Italia)

El diseño bio-receptivo está avanzando rápidamente, pasando de materiales que favorecen el crecimiento en su superficie [15] a materiales mucho más elaborados, que también juegan con sus formas y superficies [16]. Según estos últimos, estos materiales además se simulan diversas situaciones medio-ambientales y factores climáticos que, al final, permitan optimizar los prototipos, de cara a su durabilidad e implementación real en edificios.

Cruz y Beckett apuntan también a una de los problemas a la hora del desarrollo de los materiales de construcción de bio-receptividad mejorada y esto la complejidad a la hora de analizar la influencia del clima en los materiales. Según ellos mientras que para el análisis de la arquitectura sostenible / bioclimática basta con utilizar estudios que utilizan como referencia el global del edificio, para este tipo de diseños que investigan es necesario evaluar a la vez varias "escalas" de nivel de influencia: escala "macro"; escala "meso" y escala "micro".

De este modo se analizan a la vez orientaciones, superficies y exposición (escala "macro"); textura y morfología de los componentes del sistema de fachada (escala "meso") y la composición del material: $\mathrm{pH}$, porosidad, composición... (escala "micro"). Esta combinación de factores y análisis permite una caracterización correcta del material bioreceptivo.[17].

Actualmente se investigan un abanico de materiales para envolventes de fachadas, diseñados para ser bio-receptivos. Estos generan las condiciones adecuadas para la bio-colonización de algas, líquenes y briófitos jugando, principalmente, con la porosidad, rugosidad, capacidad de absorción de agua y $\mathrm{pH}$, las cuales se consideran esenciales para el desarrollo vegetal en su superficie.[18]

\subsection{Sistemas en investigación}

\section{Texturas bio-colonizables}

- Denominación: Texturas Bio-colonizables

- Diseñador: Martín Azúa

\section{http://www.martinazua.com/es/producto/texturas-} biocolonizables/ 


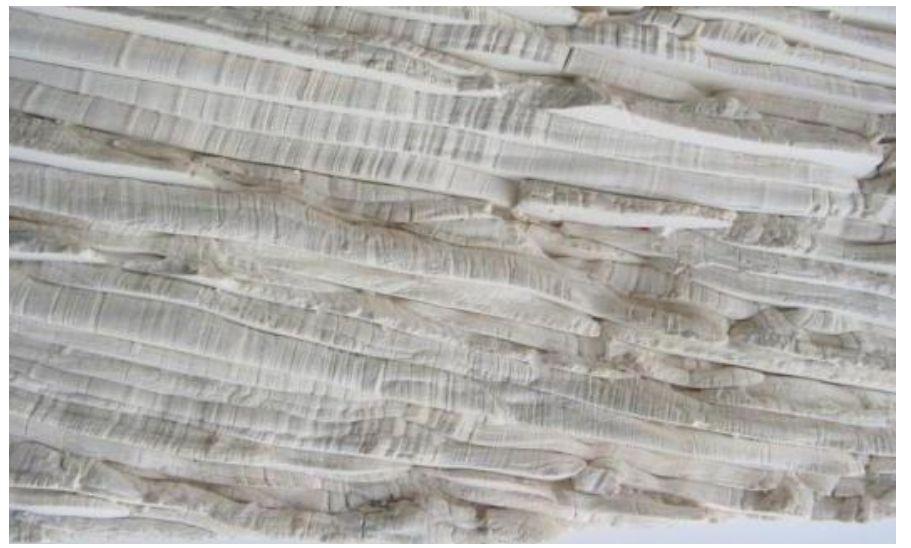

Imagen 39. Texturas bio-colonizables. Fuente: Martín Azúa.

Martín Azúa, diseñador vasco, "ha desarrollado una serie de "revestimientos arquitectónicos para suelos y fachadas capaces de acoger vida vegetal: mohos, líquenes, musgos, etc. Los edificios construidos con estos materiales se mimetizarán con el entorno artificial". (19),

Y continúa "(...) la versión que nosotros proponiamos es la colonización espontanea por especies locales que no necesita riego ni condiciones especiales para su crecimiento". "(..) consistía en una textura de huecos que acogía el polvo del aire y con la humedad ambiente forma una sustrato que permite el crecimiento de líquenes y musgo". (Imagen 39, Imagen 40 y Imagen 41).

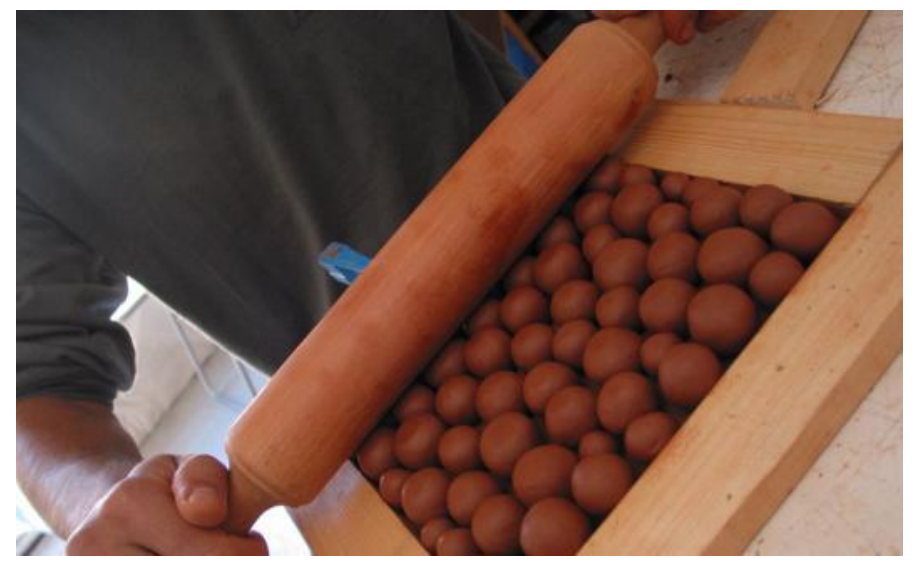

Imagen 40. Fabricación texturas bio-colonizables. Fuente: Martín Azúa

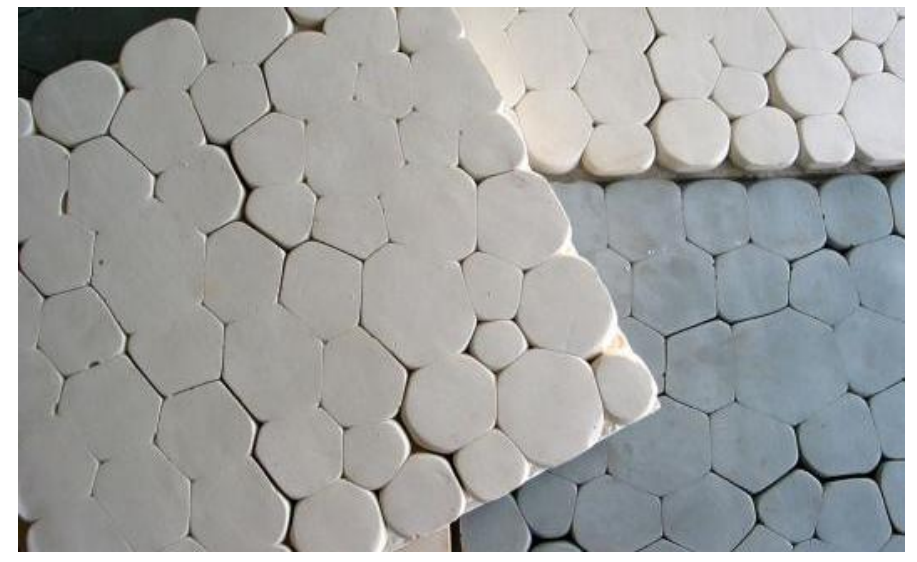

Imagen 41. Texturas bio-colonizables. Fuente: Martín Azúa 
No hay más información, a parte de la existente en la propia página web [20] donde se observa los materiales con los que se elabora (se presupone arcilla) y el método de fabricación.

\section{Bio-ceramic system (BCS) \\ - Denominación: Bio-ceramic system \\ - Investigadores: Iker Luna, Luis Fraguada. Institute for advanced architecture of Catalonia (laaC)}

https://iaac. net/research-projects/self-sufficiency/bio-ceramicsystem/

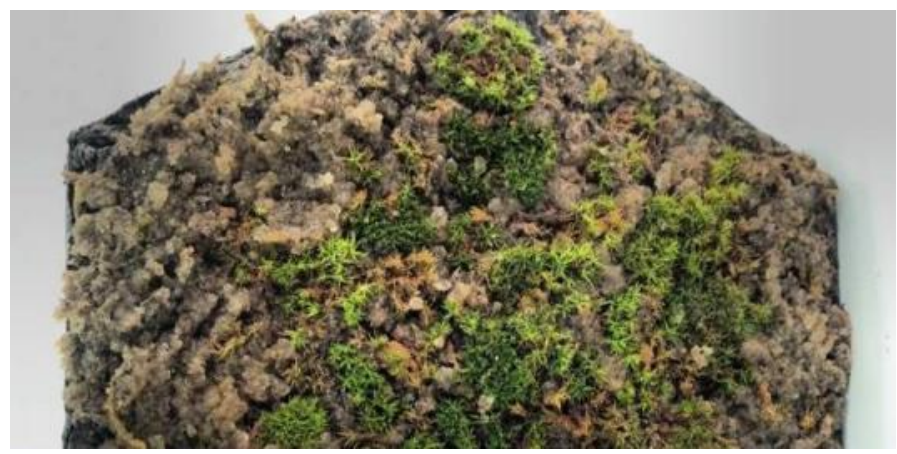

Imagen 42. Bio-ceramic system. Fuente: laaC

Bio-ceramic system (Imagen 42) es un sistema desarrollado dentro del programa Open Thesis Fabrication que desarrolla el propio Institute for advance architecture of Catalonia.

La investigación consiste en explorar la bio-receptividad de un material cerámico, aprovechando su porosidad para retener agua, en combinación con fibras naturales para mejorar otras propiedades [21].

El investigador basa su experimento en un dato: diversas especies como los musgos u otros organismos tienen la capacidad de crecer en diversas tipologías de superficies, en particular superficies con altos niveles de humedad y $\mathrm{pH}$ elevado.

Por ello utiliza un material cerámico, en concreto arcilla de bentonita, al que incorpora serrín de pino para producir un acabado rugoso que mejorara el proceso de crecimiento del musgo y chamotte (grog clay) con el que se mejora su comportamiento mecánico.

El sistema se compone de dos capas cerámicas: una primera, que acogerá el briófito, a la que se le ha incorporada lana de roca para evitar roturas. La capa interna, se encuentra esmaltada y dispone de menos porosidad, para dar rigidez al conjunto.

Sobre ambos se disponen los briófitos (no se especifica especie), que se diseminan mediante un "batido de musgo".

\section{Conclusiones}

De los prototipos investigados, el de mayor bio-receptividad es aquel con absorción de agua moderada.

A mayor capacidad de absorción de agua por los prototipos, se produce una mayor velocidad de desecación. 
El prototipo mecánicamente mejor es el que incorpora chamotte y lana de roca.

\section{Componentes del sistema}

- Capa cerámica preparada para acoger el organismo vegetal. Está diseñada con una textura geométrica para evitar roturas, con mayor porosidad, y tiene incorporada lana de roca.

- Capa cerámica esmaltada para aumentar la rigidez del sistema, aunque permite almacenamiento de agua.

\section{Principales ventajas y desventajas}

- El crecimiento del briófito sobre la cerámica origina una amortiguación de la transferencia de calor, debido al agua que retiene el briófito para mantenerse vivo.

- Los prototipos con mayor absorción de agua tienen el inconveniente de desecarse a mayor velocidad.

- Debido a las características inherentes al material cerámico, éste puede sufrir daños ocasionados por las condiciones climáticas

\section{Conjunto multicapa en base cemento}

- Denominación: Conjunto multicapa en base cemento, aplicable como soporte biológico para fachadas de edificios u otras construcciones

- Investigadores: Manso Blanco S. et al

\section{Universidad Politécnica de Cataluña}

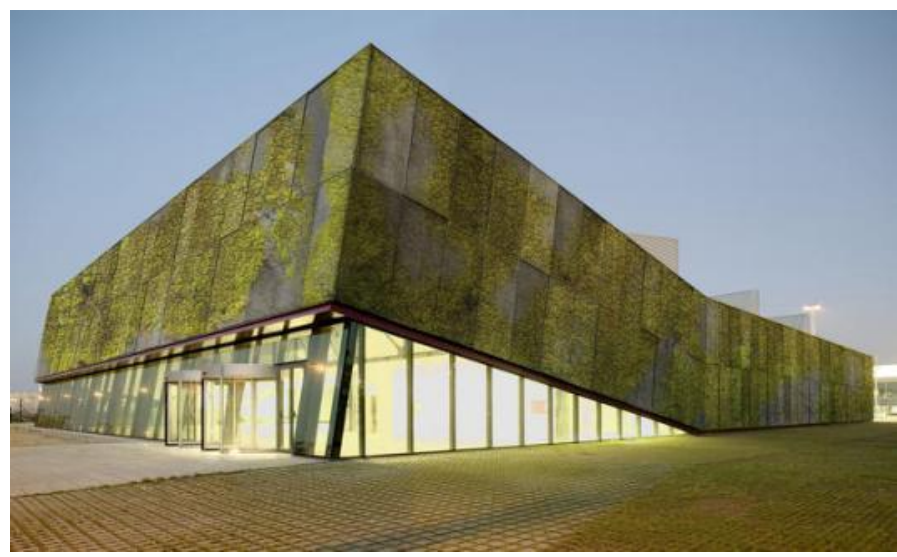

Imagen 43. Simulación Centro cultural aeronáutico del Prat de Llobregat. Fuente UPC.

La tesis que ha investigado pretende explotar la capacidad bioreceptiva de un material en base de cemento pero con un pH más bajo que sirve como sustrato para el crecimiento de ciertos organismos biológicos "permitiendo captar el agua de lluvia, almacenarla en la micro-estructura interna del material junto con el aporte nutritivo para los organismos biológicos y controlar la superficie que colonizarán y en la que crecerán dichos organismos, siendo de gran importancia el procedimiento y material empleado para evitar la pérdida de agua de la estructura y delimitar las zonas de crecimiento de los organismos" [22]. 

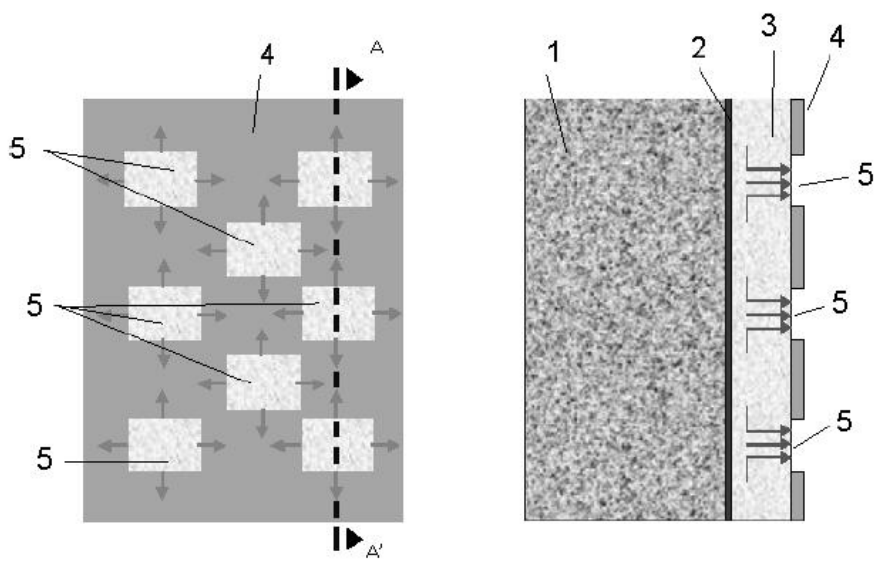

Imagen 44. Esquema sistema. Fuente: Sandra Manso

\section{Componentes del sistema (Imagen 44)}

- Capa estructural. Soporte estructural de la construcción.

- Capa de anclaje e impermeabilización. Esta interfase deberá mejorar, en caso necesario, el anclaje entre las capas estructural y biológica y, además, servir de protección frente al paso de agua hacia la capa estructural.

- Capa biológica de colonización. Tiene función de soporte biológico así como de retención hídrica, permitiendo de este modo disponer de un reservorio de agua para los organismos que se cultiven en su superficie.

- Capa de revestimiento e impermeabilización. Permite la entrada de agua al material pero no su salida. Presenta una serie de huecos que dejan al descubierto la capa inmediatamente inferior (capa biológica).

\section{Conclusiones}

El sistema en su conjunto parece algo complejo y con una estructura aparentemente difícil de implementar, debido al número de capas y los materiales pesados que las componen, en su mayoría en base cemento.

Este sistema aporta una capa biológica de colonización muy interesante, ya que es la que realmente proporciona bio-receptividad al conjunto. Si bien propone dos conglomerantes diferentes para esta capa, la innovación más relevante de este conjunto es la que se realiza con un conglomerante ácido-base de magnesio-fosfato (MPC en sus siglas en inglés).

Este es uno de los primeros acercamientos que se han realizado a la exploración de materiales con bio-receptividad mejorada. Con la disposición de esta capa de colonización, Manso evalúa la problemática de los materiales cementosos y halla otro conglomerante que aporta las condiciones de $\mathrm{pH}$, rugosidad superficial, porosidad, y absorción necesarias para conseguir el desarrollo vegetal.

Por otro lado, el sistema pretende la colonización espontánea del soporte. Sin embargo este proceder deja la colonización al libre albedrio, pudiendo no llegarse a conseguir finalmente el tapiz verde deseado, tardar un tiempo excesivo en colonizarse o requerir incluso de medidas extra. [23] 
Este sistema explora un cemento de magnesio-fosfato utilizando materias primas de muy alta pureza y por lo tanto se estima que el coste de implementación sería alto.

\section{Vidrio celular bio-receptivo}

- Denominación: Placas porosas bio-receptivas elaboradas a partir de vidrio reciclado sinterizado

Investigadores: Ferrándiz-Mas, V. et al.

\section{Imperial College London y Arborea Research,}

El estudio trata de potenciar las propiedades bio-receptivas de un material de construcción fabricado a partir de la sintetización de vidrio reciclado con el fin de que sea bio-colonizado.[24]. En el presente caso se ha estudiado la bio-colonización con microalgas, C. Vulgaris mediante la extracción de la clorofila-a.

El fin último es la obtención de paneles de vidrio reciclados. Estos se elaboran a partir de la reducción a polvo de restos machacados de vidrio, los cuales se ligan con agua y un aglutinante orgánico. Posteriormente, después de ser prensados, para conseguir la forma adecuada, se sintetizan a distintas temperaturas $\left(680-740^{\circ} \mathrm{C}\right)$.

Ese rango de temperaturas a la hora de sintetizar el vidrio, permite conseguir diferencias entre las propiedades del vidrio que afectan directamente a la bio-receptividad: porosidad, capacidad de absorción, $\mathrm{pH}$ y transmitancia lumínica.

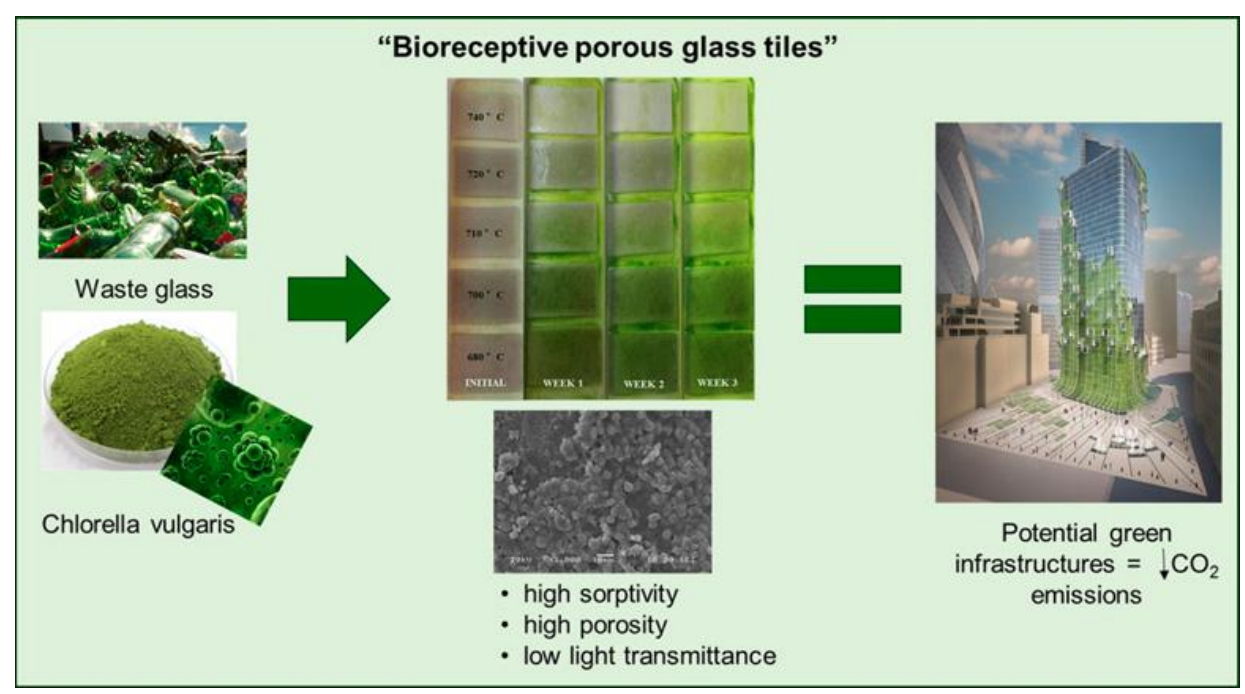

Imagen 45. Esquema de vidrio celular bio-receptivo. Fuente: Ferrándiz-Mas V. et al

El estudio que los paneles sintetizados a $700^{\circ} \mathrm{C}$ muestran un mejor comportamiento bio-receptivo, coincidiendo con los valores más altos de absorción y porosidad.

\section{Conclusiones}

El sistema parece una buena y sencilla forma de conseguir colonización vegetal en superficies vidriadas.

La transmitancia lumínica influye negativamente en la bio-receptividad del material, ya que, según el estudio, esta propiedad es inversamente proporcional a la porosidad y la absorción [25], dos de las características principales de los materiales bio-receptivos [26]. 
El proceso de sintetización del vidrio y la necesidad de tan elevadas temperaturas parece ir en contra del espíritu de los materiales sostenibles, ya que no se busca únicamente la reutilización de los residuos, si no que el coste energético del proceso no aumente desproporcionadamente la energía gris del producto.

\subsection{Proyectos desarrollados en BiotA Lab}

BiotA Lab es una plataforma de investigación de diseño que combina arquitectura, biología e ingeniería. Se desarrolla en Bartlett School of Architecture del University College London. [27]

El laboratorio explora nuevos enfoques multidisciplinares en el diseño ambiental. Actualmente tienen abierta una línea de investigación de productos bio-receptivos utilizando como base el cemento de magnesio-fosfato desarrollado por Sandra Manso.

Los directores del laboratorio Marcos Cruz y Richard Beckett han publicado una relación de los productos que actualmente investigan [28]

\section{Prototipo de panel de fachada}

Denominación: $\quad$ Façade panel prototype for buildings [29]

\section{BiotA Lab. The Bartlett School of Architecture}

Este prototipo trata de emplear la capacidad bio-colonizadora del cemento de fosfato magnesio investigado por Sandra Manso [30], utilizándolo como capa superficial.

De este modo el panel de fachada (Imagen 46) posibilita la aparición de plantas criptogamáticas que le confieren un acabado vegetal buscado.
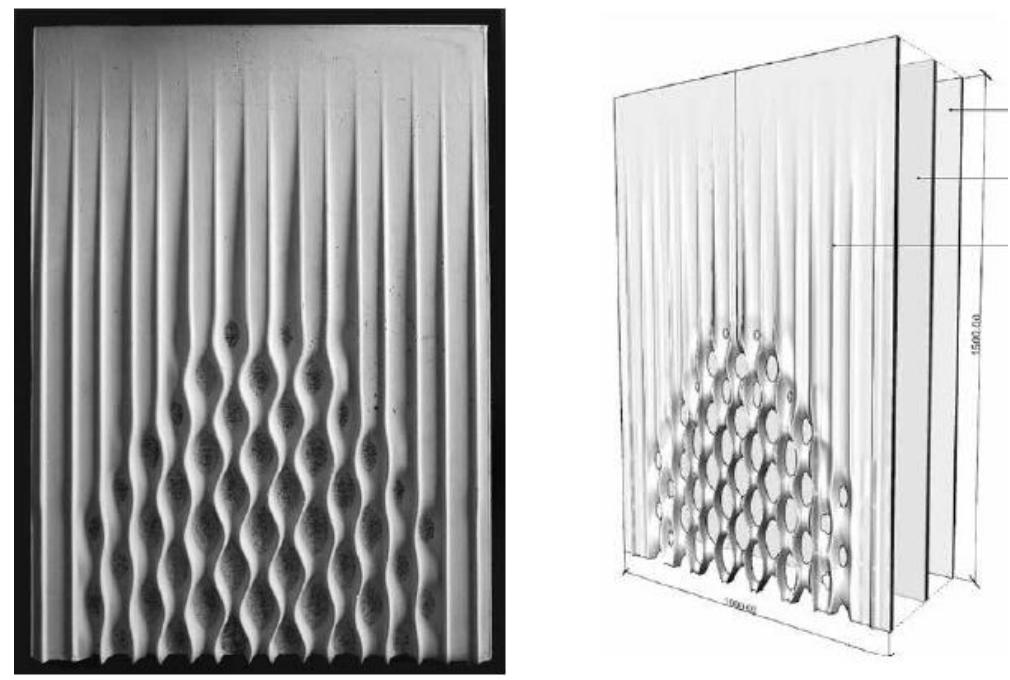

Imagen 46. Prototipo de panel de fachada. Fuente: Richard Beckett

Este objetivo se consigue mediante un diseño especial, según indican, basado en formas naturales provenientes de la visualización de la corteza arbórea, generando diversas depresiones, acanaladuras y estrías para obtener las distintas áreas de crecimiento de vegetación y, a su vez, guiar el agua procedente de las precipitaciones hacia ellas [31]. 
De este modo se crean zonas predominantemente bio-receptivas y zonas no bio-receptivas con las que generar el diseño verde deseado.

Este complicado diseño se consigue gracias al empleo de técnicas de diseño e impresión $3 \mathrm{D}$ con los que se realizan los moldes para el fraguado posterior de los cementos. Así se optimiza la morfología del panel mediante una simulación previa a su implementación.

\section{Conclusiones}

Los paneles suponen una importante evolución en materia de bioreceptividad, sin embargo aún están siendo testados evaluando su comportamiento y por lo tanto los resultados obtenidos podrían variar alguna de las conclusiones.

Tomando como referencia el sistema investigado por Sandra Manso [32], esta investigación lo materializa en forma de panel, diseñados con una acabado superficial que es proclive a la colonización vegetal.

Este prototipo soluciona el problema que presentaba el sistema de Sandra Manso referente a la colonización espontánea del soporte, ya que disemina puntualmente una mezcla de esporas de briófito y células de algas consiguiendo incentivar el crecimiento vegetal. De esto modo se crea una capa vegetal como especie pionera que permite una biocolonización más rápida y efectiva.

Queda por investigar el potencial en diversas orientaciones. Hasta el momento solo se ha conseguido el diseño efectivo con orientación noroeste.

\section{Ladrillos bio-receptivos para crecimiento de musgo}

Denominación: Bioreceptive sandstone brick for moss growth [33]

\section{BiotA Lab. The Bartlett School of Architecture}

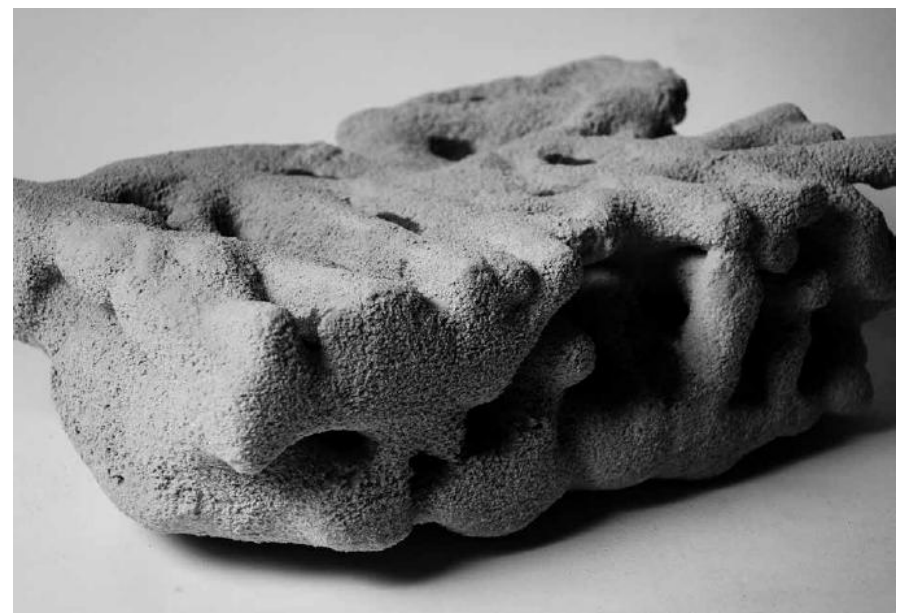

Imagen 47. Ladrillos bio-receptivos para crecimiento de musgo. Fuente: BiotA Lab et al

El prototipo (Imagen 47) trata de utilizar la capacidad bio-colonizadora del cemento de fosfato magnesio (MPC) mezclado con polvo de roca arenisca con el fin de intentar emular el pH (entre 7 y 8 ) y la composición química de algunas rocas.

Al igual que en el panel del punto anterior, los ladrillos basan su composición y su morfología en los productos existentes en la naturaleza, mediante la observación de los mismos, más exactamente en las rocas areniscas localizadas en parajes rústicos de las afueras de 
Londres. Estas están en gran parte cubiertas por musgos, líquenes y algas.

El diseño, elaborado también a través de técnicas de impresión 3D, es concebido con una geometría bastante compleja con el fin de aumentar las zonas proclives a la colonización microbiana y también a la de los briófitos deseados: Atrichum Undulatum y Hedwigia Ciliata.

El material obtenido dispone de unos valores adecuados tanto de porosidad y capacidad de retención de agua como de rugosidad superficial.

\section{Conclusiones}

Estos ladrillos suponen, al igual que los paneles anteriores, una nueva evolución en materia de bio-receptividad. Sin embargo, no ha sido testado su comportamiento sino simulado mediante programas informáticos y por lo tanto los resultados obtenidos podrían variar alguna de las conclusiones.

Al igual que el panel anterior, este sistema soluciona el problema que presentaba el sistema de Sandra Manso [34] respecto a la capacidad de colonización espontánea del soporte. En este caso, a la hora del secado de los ladrillos, se diseminan diversas clases de bacterias, con el fin de estabilizar el ladrillo y ser base para la aparición de briófitos.

Se desconocen, los comportamientos mecánicos del ladrillo, durabilidad y compatibilidad con materiales de construcción. Se da por hecho que formarán parte de un muro y por lo tanto sería interesante conocer los mismos, para comprobar la idoneidad de este producto.

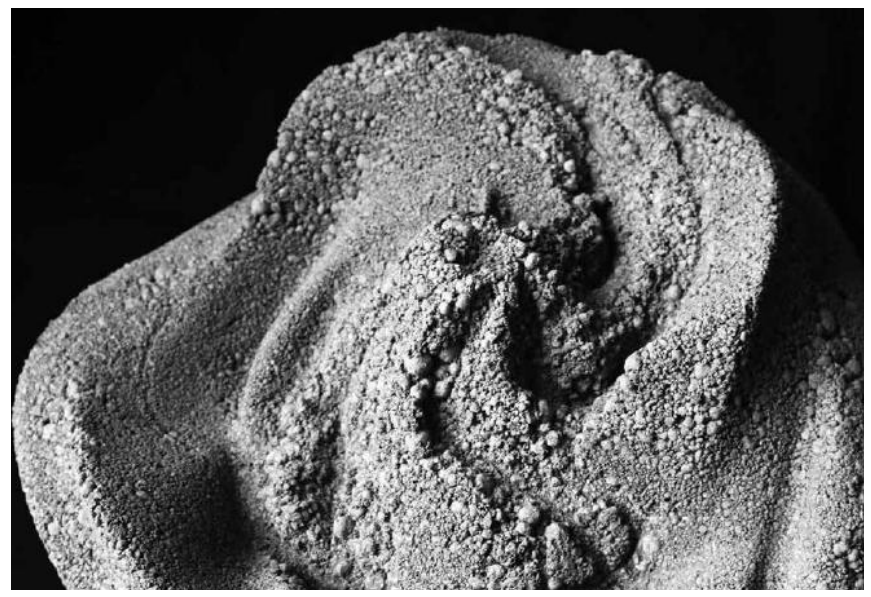

Imagen 48. Componentes de fachada de hormigón aligerado para crecimiento de criptógamas. Fuente: BiotA Lab, Sul Ah Lee y Tae Hyun Lee. Dan Lin, Wen Cheng.

Componentes de hormigón aligerado para crecimiento de criptógamas

Denominación: Lightweight concrete components for cryptogam growth [35]

\section{BiotA Lab. The Bartlett School of Architecture}

La investigación se basa en el diseño y fabricación de elementos, a partir de hormigón aligerado sobre el que se aplica una capa exterior bio-receptiva. Son elementos puntuales dispuestos en zonas concretas de la fachada, que permitan ser montados y desmontados periódicamente. 
El fin es conseguir que los elementos sean desarrollados en situaciones controladas hasta que se consiguen que prosperen las especies. Una vez dispuestos en fachada, tienen una vida y finalmente son limpiados y resembrados, comenzando de nuevo el ciclo.

El diseño, está realizado para conseguir una alta superficie bioreceptiva, cuidando bastante la estética y las zonas donde no se quiere que crezca vegetación.

\section{Conclusiones}

Se trata de un elemento decorativo, derivado de los materiales anteriormente descritos.

No explora una vegetación continua, se centra únicamente en ciclos de vida cortos.

No se ha testado en medio ambiente urbano.

Pantallas de hidrogel para crecimiento de algas

Denominación: Hydrogel screens for algae growth [36]

BiotA Lab. The Bartlett School of Architecture

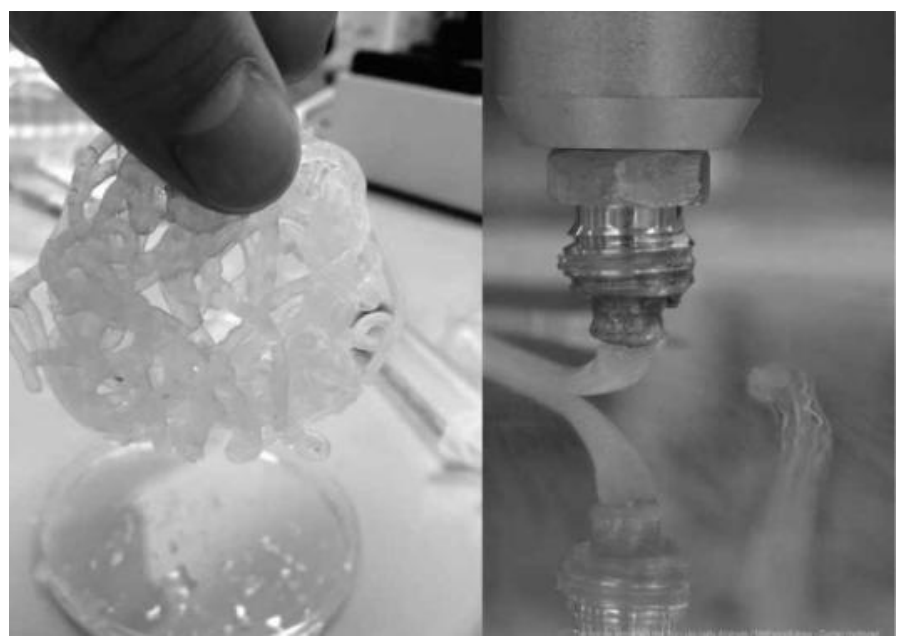

Imagen 49. Impresión 3D de pantallas de gel para el crecimiento de algas. Fuente BiotA Lab, Shneel Malik, Soo Hyung Kin, Sunbin Lee y Yuxi Lu

Este proyecto se basa en un nuevo modo de exploración de la bioreceptividad, que en esta ocasión no modifica el material en sí, sino que se trata de un añadido externo en superficie.

Para ello se busca la integración de algas en la envolvente el edificio, formando parte de ella, dando así un enfoque más sencillo en su integración en fachadas.

Para el presente proyecto se ha desarrollado un hidrogel con capacidad bio-receptiva, compuesto por diversas materias y células de algas. Se obtiene mediante la impresión 3D de una estructura semisólida. Este estado permitirá que el crecimiento de las algas se genere en la misma superficie del gel, una vez esta se hidrate, bien por la humedad ambiental, bien por las precipitaciones atmosféricas o por aporte hídrico. 
De este modo, los paneles que se pretenden emplear, podrán disponer en su superficie algas a las que el gel proveería de nutrientes, generando grandes superficies de biomasa, y que requieran poco mantenimiento

Una vez retiradas, las algas, Chlorella Sorokiniana, pueden destinarse para la producción de biomasa y el tratamiento de los residuos contenidos en el agua, por lo que su labor continua después de uso, valorizándose.

\section{Conclusiones}

La idea de generación de algas mediante la utilización de la propia envolvente del edificio supone un importante avance a la hora de generar este producto en un medio tan agresivo como el urbano.

Este gel supone una simplificación extrema de los sistemas que actualmente se utilizan en la generación de algas en las envolventes. Estos sistemas tendían a generar las algas en bio-reactores, paneles o tubos en los que dentro de un medio acuoso se producían las algas. [37].

El proyecto consiste en una idea que se encuentra en una fase muy embrionaria. Si bien, aparentemente, podría ser viable la generación de algas en una fachada, resulta muy difícil que estas aparezcan sin una aportación significativa de agua.

El potencial quedará muy condicionado por las orientaciones y la ubicación de las pantallas que contienen el gel. De ello dependerá en gran medida la posibilidad o no de que se generen algas.

También el sistema está muy limitado por la estética y mantenimiento del edificio: las pantallas quedarán expuestas cada vez que se retire la biomasa generada y se requerirá una nueva disposición del gel con cada recolección.
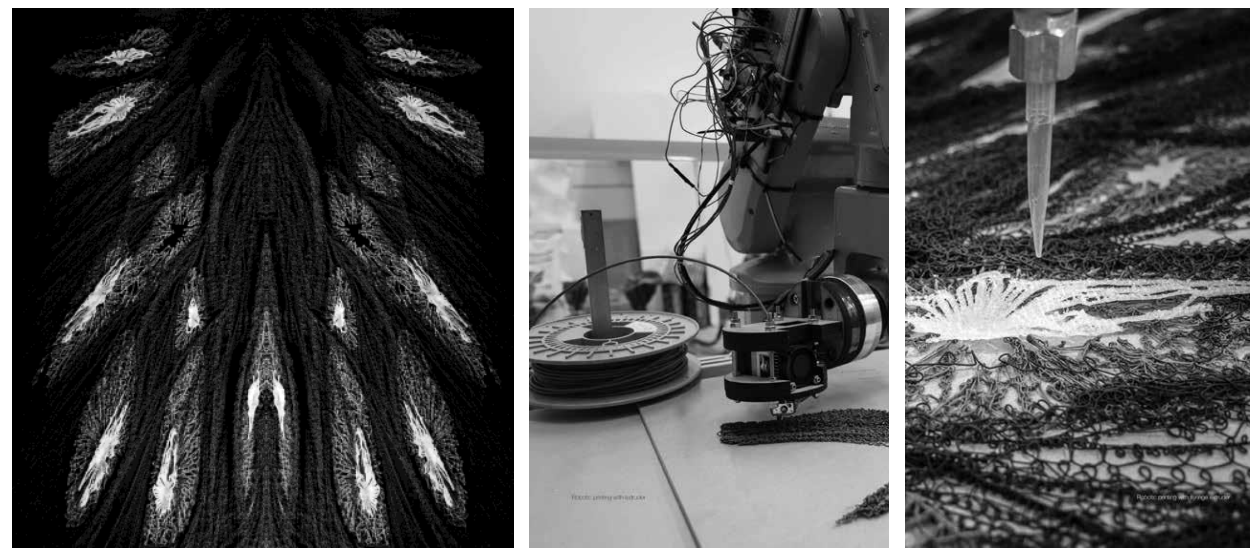

Imagen 50. Composite de celulosa para potenciar el crecimiento de micelio. Fuente BiotA Lab, Cheng-Hsiang Lew, Xia Chen Wei, You-Han Hu y Yuan Jiang

\section{Bio-andamiajes de composite de celulosa para superficies arquitectónicas}

Denominación: Bioscaffolds in architectural surfaces [38]

\section{BiotA Lab. The Bartlett School of Architecture}

Los "bio-andamiajes" son un tipo de geometrías complejas elaboradas a partir de células y tejidos, cuya función es sustituir a tejidos biológicos 
dañados cuando estos requieren restauración o sustitución debido a daños en su estructura. [39].

Este concepto que en principio parece no pertenecer al campo de la ingeniería / arquitectura, está íntimamente ligado al de material bioreceptivo, ya que la trasformación del material permite aportar el comportamiento deseado.

Cruz y Beckett engloban en dos los posibles tipos de bio-andamiajes:

- Bio-andamiaje temporal: El propio material aporte nutrientes a los tejidos en desarrollo. Esto conlleva la degradación del material según van desarrollándose los tejidos.

- Bio-andamiaje permanente: El tejido superficial estimula el desarrollo mediante sus propiedades intrínsecas, no mediante un aporte nutricional.

El material investigado se trata de un composite de celulosa cuya función es doble: generar un soporte físico y aportar nutrientes para el crecimiento de un hongo (micelio), compuesto por una serie de filamentos. El fin último es conseguir paneles donde se controle la superficie para el crecimiento de este hongo.

Hasta el momento solamente han conseguido resultados trabajando en escala microscópica mediante la diseminación gracias a un brazo robótico y una geometría determinada por un patrón algorítmico.

\section{Conclusiones}

La idea de la transformación de los propios materiales para conferir propiedades que de otra forma carecen de ellas se trata de un tema interesante en su transposición a la ingeniería.

Se desconoce el comportamiento a escala macro. Tampoco se conoce como funcionaría el hongo como colonizador primario ni la durabilidad del conjunto. 
[1] Urbanarbolismo, jardines vegetales. http://www.urbanarbolismo.es /blog/fachadas-vegetales-urbanarbolismo/

[2] Gandy, Mathew. (2010) The Ecological Facades of Patrick Blanc. Architectural Design, 80: 28-33.

[3] Skaara Arkitekter. https://skaara.no/prosjekter/buholmen/

[4] Martin, Annie (2015) The magical world of moss gardening.

[5] Glime, Jannice (2012) Bryophyte Ecology. Chapt. 5 Construcciton 5$1-2$

[6] M1 - Die erste Moosmarchine der Welt https://youtu.be/RXUzixWFzEg

[7] Verde Profilo. Azienda. www.verdeprofilo.com

[8] Comunicación personal vía e-mail. Laura Rusconi, comercial Verde profilo.

[9] International Association of Bryologists (IAB). http://iab-bryologistswebsite.blogspot.com.es/

[10] Mountain Moss Enterprises www.mountainmoss.com

[11] Martin, Annie (2015) The magical world of moss gardening. Planting an propagation. 188

[12] Colbond geosynthetics. Enkadrain. http://www.colbondgeosynthetics.com/cms/generated/pages/products/enkadrain/uses/defa ult.htm

[13] Prieto, B., Silva, B., Lantes, O. Biofilm quantification on stone surfaces: Comparison of various methods (2004) Science of the Total Environment, 333 (1-3), pp. 1-7.

[14] Cruz, M., Beckett, R. Bioreceptive design: A novel approach to biodigital materiality (2016) Architectural Research Quarterly, 20 (1), pp. 51-6

[15] Manso S, Segura I, Aguado A, Conjunto multicapa en base cemento, aplicable como soporte biológico para fachadas de edificios u otras construcciones, Patente PCT/ES2013/070438, 28 Julio 2013.

[16] Cruz, M., Beckett, R. Bioreceptive design: A novel approach to biodigital materiality (2016) Architectural Research Quarterly, 20 (1), pp. 51-6

[17] lbíd

[18] Ibíd

[19] Azúa Martín. (2012) Textural Biocolonizables. Pasajes arquitectura. Diseño e innovación, 125: 33.

[20] Martín Azúa. Trabajo. Laboratorio. Texturas biocolonizables. http://www.martinazua.com/es/producto/texturas-biocolonizables/

[21] Institute for Advanced Architecture of Catalonia (laaC). Open Thesis Fabrication Program in 2013. https://iaac.net/research-projects/selfsufficiency/bio-ceramic-system/ 
[22] Manso S, Segura I, Aguado A, Conjunto multicapa en base cemento, aplicable como soporte biológico para fachadas de edificios u otras construcciones, Patente PCT/ES2013/070438, 28 Julio 2013.

[23] Manso, S., Calvo-Torras, M.T., De Belie, N., Segura, I., Aguado, A. Evaluation of natural colonisation of cementitious materials: Effect of bioreceptivity and environmental conditions (2015) Science of the Total Environment, 512-513, pp. 444-453

[24] Ferrándiz-Mas, V., Bond, T., Zhang, Z., Melchiorri, J., Cheeseman, C.R. Optimising the bioreceptivity of porous glass tiles based on colonization by the alga Chlorella vulgaris (2016) Science of the Total Environment, 563-564, pp. 71-80

[25] Ibid

[26] Coutinho, M.L., Miller, A.Z., Macedo, M.F. Biological colonization and biodeterioration of architectural ceramic materials: an overview. (2015) J. Cult. Herit. 16 (5), 759-777

[27] BiotA Lab, Bartlett School de Architecture, University College London

http://www.biota-lab.com/

[28] Cruz, M., Beckett, R. Bioreceptive design: A novel approach to biodigital materiality (2016) Architectural Research Quarterly, 20 (1), pp. 51-64

[29] Ibid

[30] Manso S, Segura I, Aguado A, Conjunto multicapa en base cemento, aplicable como soporte biológico para fachadas de edificios u otras construcciones, Patente PCT/ES2013/070438, 28 Julio 2013.

[31] Cruz, M., Beckett, R. Bioreceptive design: A novel approach to biodigital materiality (2016) Architectural Research Quarterly, 20 (1), pp. 51-64

[32] Manso S, Segura I, Aguado A, Conjunto multicapa en base cemento, aplicable como soporte biológico para fachadas de edificios u otras construcciones, Patente PCT/ES2013/070438, 28 Julio 2013.

[33] Cruz, M., Beckett, R. Bioreceptive design: A novel approach to biodigital materiality (2016) Architectural Research Quarterly, 20 (1), pp. 51-64

[34] Manso S, Segura I, Aguado A, Conjunto multicapa en base cemento, aplicable como soporte biológico para fachadas de edificios u otras construcciones, Patente PCT/ES2013/070438, 28 Julio 2013.

[35] Cruz, M., Beckett, R. Bioreceptive design: A novel approach to biodigital materiality (2016) Architectural Research Quarterly, 20 (1), pp. $51-64$

[36] Cruz, M., Beckett, R. Bioreceptive design: A novel approach to biodigital materiality (2016) Architectural Research Quarterly, 20 (1), pp. 51-64

[37] Splitterwerk Architects, ARUP, Colt International, Strategic Science Consult (2015) Building with Bio-Intelligent Quotient (BIQ) http://www.buildup.eu/en/practices/cases/biq-house-first-algae-

powered-building-world 
[38] Cruz, M., Beckett, R. Bioreceptive design: A novel approach to biodigital materiality (2016) Architectural Research Quarterly, 20 (1), pp. 51-64

[39] Levenberg, S., Langer, R. Advance in Tissue Engineering (2004) Current Topics in Developmental Biology, PP. 61, 113 



\section{Capítulo 4. Componentes del sistema propuesto}

\section{Morteros}

\subsection{Introducción}

Se denomina mortero al conglomerado o masa constituida por arena, conglomerante y agua, que puede contener además algún aditivo. Este se amasa y coloca en obra en estado plástico y al endurecer consigue las características que permiten su utilización en albañilería.

La elección del mortero como base (o soporte) del revestimiento elaborado en la presente tesis deriva del gran conocimiento tanto científico como investigadorque existe en la actualidad en los hormigones y en los morteros con agregados de áridos reciclados. De hecho la propia Universidad de Burgos, a través del Grupo de Investigación de Ingeniería de Edificación (GIIE) dispone de un relevante número de publicaciones en la materia [1].

El mortero, en el sentido amplio del concepto, se trata de un material que dadas sus propiedades puede reunir varias de las características deseadas como material de soporte de una especie vegetal.

Por un lado, su adaptabilidad. El mortero al tratarse de una masa que se moldea en fresco y posteriormente endurece tiene esa capacidad de adaptación al molde consiguiendo el tipo de acabado deseado. Por otro lado sus propiedades mecánicas suelen ser aptas para su utilización incluso como elemento resistente.

Por otro lado su versatilidad. Se trata de un material ampliamente utilizado en la construcción desde hace miles de años. Sus propiedades se han venido modificando con la adición de sustancias o modificación de dosificaciones. Por lo tanto se trata de un material que permite jugar con sus componentes para poder adaptar sus características a las que se requiere para conseguir un material sostenible y bio-receptivo.

\subsection{Breve revisión de la historia de los morteros}

Los primeros "morteros" pueden remontarse a las primeras grandes civilizaciones como Mesopotamia [2]. Sobre el año 7.000 a.C. datan los restos hallados en las excavaciones de Jericó, donde se han encontrado casas de ladrillo y suelos realizados con una especie de mortero de cal pulido. 
En el antiguo Egipto Jacques-Joseph Champollion halló, entre los bloques calizos de la Gran Pirámide, una especie de mortero con calcinación de piedras de algez impurificadas de cal, utilizado en su construcción. Éste se utilizaba con varios fines [3]:

- Para facilitar la colocación del bloque, con una función lubricante.

- Para el asentamiento de las piezas. Una vez levantados los muros, se disponían en los huecos y llagas, taponando las irregularidades. En este caso tenía una función ligante, gracias a su rápido fraguado y buena adherencia.

- Para decoración. Como enlucido de paredes y suelos.

No obstante, puede afirmarse que el uso del mortero de cal, propiamente dicho, corresponde a los griegos y romanos. Las excavaciones realizadas de finales del siglo II y principio del siglo I a.C., (casas de Délos y de Thera) serían las primeras que atestiguarían la existencia de un mortero de cal [4]. Estos están compuestos, de forma general, por cal y arena fina, a los que se añade polvo de mármol para conseguir revestimientos estucados.

Los romanos fueron herederos directos de esta tecnología griega, a la que denominaron opus caementitium. Se tratan de morteros de alta calidad, cuyas obras han llegado hasta nuestros días.

Dignos ejemplos son el acueducto de Segovia (s. II d.C.), el Colosseo (72 - 80 d.C.) y el Pantheon de Agripa (118-125 d.C.) como máximo exponente. Este último dispone de una cúpula semiesférica de 43,3 m (Imagen 51), formada por mortero de cal, trozos de toba o tufo y escorias volcánicas. El perfecto estado de conservación deja ver la gran calidad y durabilidad de los morteros romanos.

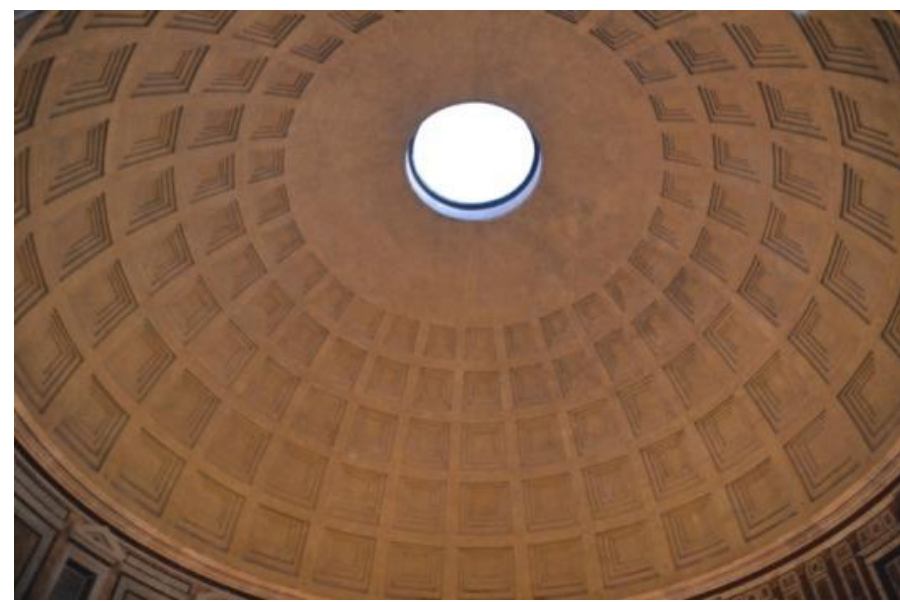

Imagen 51. Cúpula Pantheon Agripa, Roma (Italia). Fuente: Propia

La mezcla de materiales romana por excelencia era de una parte de cal por tres de arena, pero además solían emplearse aditivos como ceniza volcánica, tierra cocida o teja triturada [5]. La cal utilizada solía ser de arcilla cocida o puzolana, confiriéndole al mortero propiedades hidráulicas.

Los romanos fueron la última gran civilización que mejoró esta técnica de elaboración. Durante la época medieval y hasta más allá de la caída del antiguo régimen, no se experimentaron avances en la calidad de los morteros, sino, más bien, retrocesos en sus prestaciones. 
Los morteros empleados en esta época difieren poco de los romanos, que se modificaban añadiendo todo tipo de componentes orgánicos (animales y vegetales) para intentar conferirles mejores características con menor uso de cal.

Ya en el siglo XVIII comienzan a fabricarse morteros con ligantes hidráulicos, susceptibles de endurecer bajo el agua. Concretamente en el año 1756, en la construcción del faro Eddystone, en Plymouth (Reino Unido), se utilizaron cales procedentes de la calcinación de piedra caliza impurificada con arcillas; estos conglomerantes resistían bien el agua de mar, ya que su composición química es muy similar a la de las actuales cales hidráulicas.

Sin embargo no es hasta principios del siglo XIX cuando comienzan a elaborarse los primigenios cementos, ya que en ese momento se empiezan a fabricar mezclas que al calcinarse en horno juntas, conseguían después morteros con textura compacta, baja permeabilidad al agua y gases y con escasa porosidad. (Furlan, V. et al). De hecho descubren que la mayor o menor capacidad hidráulica depende de la cocción entre arcilla y cal. Estos primeros morteros de cemento eran de fraguado muy rápido.

En 1811 James Frost patenta un cemento artificial obtenido por calcinación lenta de caliza molida y arcilla lo que acabó desembocando en el cemento Portland, patentado en 1824 por Joseph Aspdin, el cemento hidráulico artificial que ha llegado hasta nuestros días.

\subsection{Morteros de cemento}

Pese a la diversidad de conglomerantes existentes en la actualidad, cemento, cal o bastardos, el más extendido sigue siendo el mortero de cemento.

Tanto por su mejor trabajabilidad y adaptabilidad como por su rigidez, el mortero de cemento sigue siendo un imprescindible en la construcción moderna, utilizándose en numerosas fases de la obra.

Los morteros de cal y los bastardos (cal + cemento) se han relegado a un segundo plano, dejándolos como mezclas apropiadas para restauración. Esto se debe a su mayor flexibilidad, en comparación con el cemento, que evita la rotura por los movimientos propios de la piedra. A su vez no incluye en su composición sales solubles, que pueden provocar la aparición de eflorescencias en las superficies de los materiales de construcción.

Los morteros de cemento para albañilería se clasifican, en función de su uso, de la siguiente forma:

- Morteros para revocos y enlucidos: Mezcla compuesta de uno o varios conglomerantes inorgánicos, de áridos, de agua y a veces de adiciones $\mathrm{y} / \mathrm{o}$ de aditivos, para realizar revocos exteriores o enlucidos interiores. [6]

Disponen de varias subdivisiones, según propiedades, sistemas de fabricación y concepto.

- Morteros para albañilería: Mezcla compuesta de uno o varios conglomerantes inorgánicos, de áridos, de agua y a veces de adiciones y/o aditivos para colocar, unir o rejuntar piezas de albañilería. [7] 
Estos morteros son aquellos que se utilizan de forma general en albañilería, siendo la base para el asentado de fábricas, rejuntados, etc...

Según el concepto de mortero de albañilería, se clasifican de la siguiente manera [8]:

- Mortero para albañilería diseñado: Mortero cuya composición y sistema de fabricación se han elegido por el fabricante con el fin de obtener las propiedades especificadas (concepto de prestación).

- Mortero para albañilería prescrito: Mortero de composición definida cuyas propiedades dependen de las proporciones declaradas de los componentes (concepto de receta).

Según sus propiedades y/o su utilización [9]:

- Mortero para albañilería para uso corriente (G): Mortero para albañilería sin características especiales.

- Mortero para albañilería para juntas y capas finas (T): Mortero para albañilería diseñado con un tamaño máximo de árido menor o igual a un valor especificado.

- Mortero para albañilería ligero (L): Mortero para albañilería diseñado con una densidad en estado endurecido y seco inferior a un valor que figura especificado.

Según el sistema de fabricación [10]:

- Mortero para albañilería hecho en fábrica (mortero industrial): Mortero dosificado y mezclado en una fábrica.

- Mortero para albañilería semiterminado hecho en fábrica

- Mortero para albañilería predosificado: Mortero cuyos componentes se dosifican por completo en una fábrica y se suministran al lugar de su utilización, donde se mezclan de acuerdo con las especificaciones y condiciones indicadas por el fabricante.

- Mortero para albañilería premezclado de cal y arena: Mortero cuyos componentes se dosifican y mezclan por completo en una fábrica, y se suministran al lugar de su utilización, donde se añaden otros componentes especificados o suministrados por la fábrica

- Mortero para albañilería hecho en obra: Mortero cuyos componentes son dosificados y mezclados en la obra

Los componentes obligados de un mortero son el conglomerante, el árido y el agua, siendo los aditivos y adiciones componentes esporádicos que se añaden al mortero para modificar, mejorar u obtener propiedades especiales. [11]

Es necesario diferenciar entre mortero de cemento y hormigón. Pese a que la composición, según una definición rápida, es la misma, la principal diferencia estriba en el árido empleado. Aparte de las propiedades y puesta en obra de cada uno, como norma general el mortero utiliza arena que pase por el tamiz de $4 \mathrm{~mm}$ de luz de malla [12] Por el contrario en el hormigón se requiere la presencia, aparte de arenas, de gravas que queden retenidas en el mismo tamiz de $4 \mathrm{~mm}$. 


\section{Componentes de los morteros de albañilería}

\section{Conglomerante}

Material utilizado para unir partículas sólidas de tal manera que formen una masa coherente (...) [13], es decir la parte activa capaz de aglutinar el árido y formar un bloque monolítico.

Los conglomerantes más utilizados son el cemento Portland, la cal hidratada y el yeso; pudiendo utilizarse en un mortero uno o más conglomerante mezclados, denominándose mortero bastardo.

\section{Áridos}

La Norma UNE-EN 998-2 define al árido como "material granular que no contribuye a la reacción de endurecimiento del mortero", dicho de otro modo, es aquel material inerte, de procedencia inorgánica, que sustituye parcialmente al conglomerante en la mezcla dotándole de mayores características mecánicas.

El conglomerante utilizado tiene que envolver por completo al árido para poder cohesionar el conjunto evitando el contacto entre partículas del árido entre sí, lo cual provocaría discontinuidades en el mortero. Es por ello importante la forma y tamaño del árido, para conseguir materiales con unas prestaciones mecánicas adecuadas para su uso.

La Norma UNE-EN 13139:2002, establece los requisitos de los áridos:

- Requisitos geométricos: relativos al tamaño del árido, granulometría, forma de las partículas y contenido y calidad de los finos.

- Requisitos físicos: densidad de las partículas, absorción de agua, resistencia al hielo y al deshielo.

- Requisitos químicos: contenido en cloruros, componentes que contienen azufre, o que alteran la velocidad de fraguado y el endurecimiento del mortero, reactividad álcali sílice. Para los áridos artificiales establece también un contenido máximo de sustancias solubles en agua y una pérdida por calcinación limitada.

Los agregados del árido que se han utilizado en la confección de los morteros de esta Tesis, residuos reciclados de escorias negras de horno eléctrico (EAFS) son materiales de procedencia no orgánica y no mineral.

La norma UNE de áridos establece que "el mandato M/125 "Áridos" incluye áridos reciclados y algunos materiales de origen nuevo o no habitual así como áridos naturales y manufacturados conocidos y tradicionales (...) Para materiales no habituales de origen secundario, sin embargo, el trabajo de normalización ha empezado recientemente y se necesita más tiempo para definir claramente el origen y características de estos materiales" [14].

Dado que no existe una normativa específica, la idoneidad del tipo de árido se establecerá en base a las investigaciones que se han venido llevando a cabo por el grupo de investigación de Ingeniería de Edificación de la Universidad de Burgos.

\section{Aditivos}

La Norma UNE-EN 998-2 define los aditivos como "materiales añadidos en pequeñas cantidades para obtener modificaciones especificadas de las propiedades". 
Los aditivos de uso más habitual son los retardadores de fraguado (retardantes) y los inclusores de aire (aireantes), aunque también existes algunos no normalizados como plastificantes, hidrofugantes...

\section{Adición:}

La Norma UNE-EN 998-2 lo define como material inorgánico finamente dividido (que no es árido, ni conglomerante) que se puede añadir al mortero para mejorar u obtener propiedades especiales.

\section{Agua}

El agua de los morteros se trata del componente necesario para la hidratación del conglomerante y como lubricante que permitir la trabajabilidad de la mezcla fresca.

El agua tiene que ser inocua, no debiendo contener sustancias que puedan alterar el fraguado de los conglomerantes o las propiedades del resto de componentes. En general se aceptarán todas las aguas potables sancionadas por la práctica, sin necesidad de garantizar su calidad. [15].

\subsection{Propiedades de los morteros de cemento}

El mortero se trata de un compuesto moldeado en estado plástico y que una vez endurecido resulta apto y durable para su uso. En base a su propia definición se pueden establecer dos fases con dos propiedades diferentes en cada una de ellas: estado plástico (fresco) y endurecido.

\section{Propiedades del mortero fresco}

Se conoce como "estado fresco" a la fase inmediatamente posterior a la mezcla de los componentes, caracterizada por ser una fase en la que la consistencia permite su puesta en obra, utilización y moldeado.

En esta fase los componentes pueden tener movimientos independientes, lo que puede ocasionar la pérdida de homogeneidad de la mezcla al producirse ciertas agrupaciones de una parte de sus componentes.

Es por ello que se necesita evitar esa pérdida de homogeneidad en el interior de un mortero. Ello se consigue mediante una consistencia adecuada que permita, en estado fresco, un moldeo con los medios y técnicas habituales, facilitando la adaptación a la forma final e impidiendo la aparición de poros internos que creen una estructura heterogénea y discontinua en el conglomerado.

El conjunto de todas estas propiedades es básicamente el concepto trabajabilidad, entendido como la propiedad que determina el esfuerzo requerido para manipular una cierta cantidad de material recién mezclado con la mínima pérdida de homogeneidad [16].

La evaluación de las propiedades que determinan la trabajabilidad, puesto que no es un parámetro en sí (la Norma UNE-EN 1015-9 no define el concepto de trabajabilidad) se utilizan parámetros tales como la consistencia, la densidad del mortero fresco, la retención de agua, la adherencia en fresco, etc... [17]

\section{Propiedades del mortero endurecido}

Se conoce como "estado endurecido" a la fase prestacional del propio mortero, en la que el conglomerado se encuentra en estado sólido. 
Se puede considerar el mortero como un material compuesto, en el que la parte débil es la matriz cementicia y la parte más fuerte es el árido. El cemento, constituido en su mayor parte por silicatos cálcicos, se hidrata debido a la mezcla coloidal de la fase líquida y sólida, formando un gel que cristaliza. La aparición de los cristales es la base de la resistencia del cemento endurecido y del efecto adhesivo con el árido [18].

Sus principales propiedades son la resistencia a compresión, dureza superficial, adherencia a los materiales pétreos, cierta impermeabilidad y buen comportamiento frente a los agentes atmosféricos.

\section{Características mecánicas}

Según el uso para el que se destine el mortero, este se encuentra sometido a un tipo de solicitaciones mecánicas u otras. Los morteros que se utilizan para rejuntado, asiento de fábricas, recrecidos, etc... están sometidos principalmente a compresión, cortante y flexión.

Sin embargo, en los morteros de revoco sus solicitaciones más importantes son a flexión y tracción.

Además hay que considerar las solicitaciones que transmite al mortero su soporte [19].

\section{Características físicas}

Las características físicas que condicionan sustancialmente las propiedades de los morteros de cemento son las siguientes:

- Densidad aparente Es la relación entre el volumen y el peso seco, incluyendo huecos y poros que contenga, aparentes o no.

Permite comprobar la capacidad portante del mortero, ya que esta está influida por factores como son la proporción y densidad de los componentes del mortero y de la porosidad total.

- Porosidad Es la fracción de huecos, abiertos o cerrados, que presenta un material. Se mide como porcentaje entre los huecos existentes sobre el volumen total.

Permite obtener la permeabilidad, ya que depende de la red porosa del mortero.

- Reacción al fuego. Es la capacidad de un material o conjunto de materiales de soportar durante un período de tiempo determinado la exposición al fuego sin pérdida de la estabilidad estructural y/o sin transmisión del fuego y/o sin transferencia de calor significativa.

- Capacidad aislamiento térmico, los morteros convencionales, sin propiedades agregadas, son buenos transmisores del calor, por lo que el aislamiento térmico de las edificaciones se fía a otros componentes de la envolvente edificatoria [20]

\section{Durabilidad}

Se entiende por durabilidad de un mortero "el tiempo durante el cual un mortero mantiene las prestaciones que le hacen apto para la función que cumple en la obra".

Esta capacidad depende, en gran medida, de las propias características mecánicas, y físicas. No obstante también influyen, de forma determinante, la elaboración y puesta en obra, orientación y las acciones medioambientales y atmosféricas. 
En general el mortero debe ser apto para el uso previsto respecto de las prestaciones prescritas, y que estas contemplen, aparte de las propias características del mortero, las acciones exteriores que condicionan la durabilidad del mortero:

- Heladicidad

Consiste en una acción destructiva debida a los ciclos de hielodeshielo. Esta se basa en el aumento de volumen del agua existente dentro de los poros del mortero, al pasar de estado líquido a sólido. Este cambio, en su estado habitual, se debe a las variaciones de temperatura.

El agua existente en los poros puede provenir de distintas fuentes. La más habitual es la que procede de aporte externo (véase agua de lluvia, humedad, riego, capilaridad...), no obstante también puede proceder de una sobrehidratación del mortero fresco.

- Humedades

La humedad es el agua que impregna o cubre un cuerpo. Esta propiedad está directamente ligada a la capacidad de absorción del propio mortero y la heladicidad.

La presencia de agua, tanto superficial como en los poros internos, puede provocar diversos procesos de tipo químico que disgreguen el material o provoquen fisuras o fracturas.

La humedad puede provenir de dos fuentes distintas: de las condiciones climatológicas o fuentes externas y por capilaridad.

- Fisuración

La fisuración es un fenómeno bastante común en los morteros. Este sucede debido a la retracción hidráulica debida a la rigidización que se produce en el mortero fraguado cuando no se ha evaporado por completo el agua de amasado. Esta evaporación, al producirse rápidamente, provoca una tensión superficial que provoca la aparición de fisuras en la superficie de mortero.

En esto influye un correcto curado del mortero durante su fraguado, ya que un secado rápido de la muestra fresca puede incentivar la aparición de fisuras. El curado durante el periodo de fraguado, manteniendo una humedad constante evita la evaporación rápida debido al calor que desprende el mortero fraguando.

- Eflorescencias

Estas son cristales de sales solubles procedentes del mortero fresco que se depositan en la superficie cuando el agua en el que se encuentran disueltas se evapora.

Estas sales proceden de los propios componentes del mortero o del agua de amasado. Por ello es necesario evitar la aparición de estas sales, bien utilizando agua que no contenga sales solubles o bien interponiendo una capa hidrofugante entre el mortero y los elementos sobre los que se va a disponer, siempre y cuando estos puedan disponer de sales en su composición susceptibles de disolverse con el agua del mortero. 


\section{- Atmósfera contaminada}

La acción de una atmósfera contaminada consiste en la interacción de los iones de sulfato presentes tanto en las sales solubles como en gases sulfurosos, al entrar en contacto con el aluminato del clinker del cemento Portland. Esto genera un producto altamente expansivo, denominado ettringita.

Esta expansión, provoca una sobresaturación, de los poros al cristalizar gran parte del agua, produciendo tensiones en los poros que pudieran llegar a fisurar el mortero.

Por ello es necesario controlar la concentración de aluminatos y evitar la presencia de agua en los poros internos del mortero. Con ello se consigue una menor exposición a la producción de ettringita y por tanto a su expansividad.

\subsection{Sostenibilidad}

La sostenibilidad a la hora de elaborar el material de soporte es uno de los objetivos prioritarios en la presente tesis.

Sin embargo el mortero de cemento Portland no es un material sostenible debido a la elaboración del clinker, uno de sus principales componentes. El Clinker requiere para su producción una generación de energía extremadamente elevada, lo cual lleva aparejado un consumo energético muy elevado, de tal modo que la producción de 1 $\mathrm{kg}$ de cemento tipo Portland conlleva la emisión de $1 \mathrm{~kg}$ de $\mathrm{CO} 2$ a la atmósfera y un consumo energético de 5,4-6 MJ. Las emisiones son tan elevadas que ascienden a aproximadamente el $5 \%$ del total de las emisiones CO2 a la atmósfera en todo el planeta [21].

Dada la dependencia del cemento Portland en el sector de la construcción, y que actualmente no se han desarrollado productos que puedan solventar esta insostenibilidad, se puede actuar sobre los componentes, utilizando (como ya se emplea) materias primas alternativas como escorias de alto horno, cenizas volantes, residuos de demolición...

También se puede actuar alterando las dosificaciones del mortero, intentando alterar el tipo de árido utilizado en el mortero y reutilizando tanto residuos y subproductos procedentes de procesos industriales como residuos inertes de la construcción.

En morteros especiales, que no deriven del cemento, se puede utilizar productos que no sean extremadamente puros, pero que sean lo suficientemente reactivos 0 inertes para que, no influyendo en la mezcla, permitan dotarla de un plus sostenible.

\subsection{Bio-receptividad de los morteros}

Tal y como se ha definido en el capítulo anterior, la bio-receptividad es la aptitud de un material a ser colonizado por uno o varios grupos de organismos vivos sin, necesariamente, experimentar ningún deterioro [22].

Sin embargo los morteros más comunes en la construcción, no tienden a ser bio-receptivos, debido a las características que vamos a ver a continuación. Por ello, se requiere una modificación de sus propiedades intrínsecas para conseguir que el material, al menos, no sea un medio agresivo que impida el desarrollo de vegetación. 
Los principales valores que condicionan la bio-receptividad de un mortero son los siguientes:

\section{$\mathrm{pH}$}

El pH se trata de la propiedad intrínseca más influyente en los morteros a la hora de condicionar la bio-colonización vegetal [23]. De este modo un $\mathrm{pH}$ alcalino de un mortero, que suele rondar 12, condiciona por completo la posibilidad de prosperar la mayor parte de microorganismos, algas...; no siendo suficiente con mejorar sus otras características: rugosidad, porosidad y red capilar interconectada.

El porqué de esta alcalinidad en el mortero de cemento deriva de su propia composición. El cemento Portland, como se ha explicado anteriormente, deriva de un producto industrial llamado Clinker cuya composición química es extremadamente amplia lo cual deriva en un comportamiento muy variable en función de su dosificación. [24].

Para conseguir un medio más amable para la proliferación de un briófito requerimos un $\mathrm{pH}$, como mínimo, en un rango entre $(9,5-10)$ [25] a partir del cual se considera que no es viable la colonización ya que el propio soporte inhibe la capacidad colonizadora de la especie vegetal.

Las investigaciones existentes hasta el momento, consideran varios escenarios en los que se consigue reducir el pH en los morteros. Por un lado, trabajando con cemento Portland, se ha investigado que la carbonatación de la cal apagada existente en el Clinker, consigue reducir el valor del pH hasta 8,3 [26]. Sin embargo la carbonatación supone una patología en los morteros, principalmente los que se encuentren armados con refuerzos de acero, ya que facilita la oxidación del acero.

Otro enfoque es el que ha realizado Sandra Manso et al. con el sistema patentado multicapa en base cemento. [27] Este sistema, elaborado a base de varias capas con distintos tipos de cementos, constituye un avance interesante, ya que elabora un cemento de fosfato magnesio (MPC) cuyo $\mathrm{pH}$ es de 6,7.

Dado que este enfoque parece interesante la propia investigadora compara el $\mathrm{pH}$ del mortero de fosfato magnesio (MPC) que ha elaborado con un mortero de cemento Portland, al que intenta aumentar su bio-receptividad mediante una carbonatación acelerada. El resultado obtenido consigue bajar el pH hasta 9 [28].

Puesto que la tasa reducción del pH del mortero de cemento, mediante carbonatación viene a ser un 50\% del conseguido con mortero de fosfato magnesio (MPC), se considera que el desarrollo de la especie de briófito escogida tendrá mayor viabilidad si se utiliza este tipo de mortero (MPC) frente a uno de cemento Portland, pese a que se proceda a una carbonatación acelerada.

\section{Rugosidad}

La rugosidad es un factor relevante, aunque de menor incidencia que el $\mathrm{pH}$ en la bio-receptividad general del mortero.

Existen varios factores que explican porqué condiciona la rugosidad superficial la bio-colonización. Por un lado, basándonos en la observación de los materiales presentes en la naturaleza, los vegetales suelen aparecer en zonas rugosas, con cavidades e imperfecciones que permitan la acumulación de nutrientes y humedad, así como la 
acumulación de polvo. De este modo se generan entornos que favorecen que prospere la vida vegetal.

Por otro lado, la rugosidad superficial permite que las raíces, o rizoides en el caso de esta tesis, de los briófitos se puedan anclar a su superficie. De hecho varias investigaciones determinan que la rugosidad de un mortero es un factor importante de cara a su colonización. [29] [30]

Ambas investigaciones testan como influye la porosidad en la bioreceptividad, sin embargo cada una determina un mayor o menor grado de influencia en el global de los condicionantes.

\section{Porosidad}

La porosidad del mortero, así como la existencia de una red de capilares interconectados, es una propiedad importante para conseguir una buena bio-receptividad.

Un mortero de albañilería estándar, elaborado con cemento Portland, contiene una serie de poros. Existen dos tipos de porosidad: abierta y cerrada. Los poros abiertos son aquellos que tienen acceso desde el exterior del material. La porosidad cerrada es aquella que no tiene acceso directo desde el exterior.

La bio-receptividad viene condicionada por la compacidad del material. $\mathrm{Si}$ el material dispone de una mayor porosidad y de una mayor capacidad de absorción, conseguimos un material más proclive a ser colonizado.

Esta compacidad del material se consigue actuando principalmente en su composición y el método de elaboración.

El conglomerante utilizado influye directamente en la porosidad del material endurecido. Dependiendo de si se emplea cemento Portland, cal u otro material, la porosidad varía. Sin embargo, atendiendo a la composición, son más determinantes tanto los aditivos como la relación agua-cemento. Existen numerosos aditivos aireantes que permiten aligerar el material $y$, por consiguiente, conseguir una porosidad en mayor o menor grado.

También conviene considerar que ciertos aditivos, que no influyen directamente sobre la propia porosidad, si influyen en la capacidad de absorción, inhibiendo la posibilidad de intercambio de agua y nutrientes entre la red porosa: plastificantes, hidrofugantes, nano-cristalizaciones, etc...

Por otro lado, el proceso de fabricación es igualmente influyente o incluso puede tener mayor influencia [31]. El tratamiento del mortero fresco, su fraguado y también su curado (y el mayor o menor grado de hidratación durante él), influyen sustancialmente, ya que un fraguado muy rápido provocará una porosidad cerrada interior.

También hay que tener en cuenta la vida útil del material. La dimensión de los poros aumenta según envejece el material [32], pudiendo provocar una degradación excesiva del material.

Para la presente investigación se requieren morteros con una porosidad adecuada y que esta se encuentre bien distribuida. Aparentemente a menor densidad conseguiríamos una mayor bio-receptividad, sin embargo la existencia de una porosidad exagerada con muchos macro poros abre la puerta a la proliferación de micro-organismos y bacterias, lo cual puede ser contraproducente. Tal es así que en un 
estudio comparativo de varios tipos de cementos [33], la muestra más bio-receptiva resultó ser la de menor porosidad.

\section{Aporte de nutrientes}

El aporte de nutrientes se puede realizar de diferentes modos. Por un lado, y vistos los proyectos que se desarrollan en el BiotA Lab [34] puede realizarse directamente disponiendo esporas en el propio material. Otro método puede ser mediante un aporte externo.

Las propias partículas movidas por el aire pueden servir como nutriente, sin embargo el propio mortero, dada su composición, puede aportar estos nutrientes necesarios.

\section{Escoria de acería}

Se conoce como siderurgia al proceso de extracción del mineral hierro para la obtención del metal hierro y sus aleaciones. Este proceso conlleva la utilización de varias materias primas como el mineral de hierro, o bien hierro pre-reducido o chatarra.

El proceso se compone de dos etapas diferenciadas: la metalurgia primaria o fusión y la metalurgia secundaria o afino del baño fundido. La metalurgia primaria se realiza en un horno de arco eléctrico mientras que la segunda comienza en un horno de arco y termina en una de cuchara.

Durante este proceso se generan una serie de subproductos del proceso de fabricación, si bien su incidencia depende en gran medida de su volumen residual respecto del total.

- Escorias siderúrgicas.

- Polvos de acería.

- Refractarios.

- Arenas de fundición.

- Cascarilla de laminación

Por volumen, las escorias siderúrgicas y los polvos de acería son los que aportan el mayor volumen de residuos.

Actualmente la valorización posterior no está suficientemente explorada, en gran medida por la falta de homogeneidad en la composición de estos residuos, que provoca su descarte casi por completo, en el proceso industrial.

La escoria siderúrgica surge como subproducto durante el proceso de fabricación de los productos férreos. En la fundición, cuando el caldo está expuesto a altas temperaturas y en estado líquido, estas impurezas se separan del metal fundido apareciendo como una capa flotante, gracias a su menor densidad que los materiales férreos. Esta "caldo" una vez extraído, enfriado y solidificado forma la escoria, propiamente dicha.

Existen numerosos tipos de escorias, debidas, por un lado, a los variados procesos de fabricación del hierro, acero y ferroaleaciones diversas, los cuales han variado a lo largo de la historia, gracias a la implementación de las investigaciones científicas a las técnicas industriales. Por otro a heterogeneidad en la composición de los diferentes materiales que conforman las mezclas metalúrgicas: 
diversas variantes de ferroaleaciones generan escorias de composición distinta.

Es por ello que la producción de escorias supone un gran reto para su posterior utilización, considerando esa gran diversidad en su composición.

\subsection{Tipos de escorias}

Las escorias siderúrgicas, en función del proceso de fabricación del hierro o del acero, se pueden dividir en las siguientes:

- Escoria de Horno Alto (BF Slag).

- Escoria de Convertidor de Oxigeno (LD).

- Escoria de Cubilote.

- Escoria de Horno Cuchara (LF).

- Escoria de Horno Eléctrico de Arco (EAF).

Escorias de Horno Alto. (BF slag)

El horno alto (Blast Furnace, BF) es un horno tradicionalmente utilizado en la fabricación de hierro y de acero. Está formado por un troncocilindro de acero, forrado de otro material no cerámico, con una serie de aberturas (piqueras) en la parte inferior (crisol) y en la parte superior.

Su funcionamiento es el siguiente: se introduce un gas a presión junto con la materia prima (hierro, coque y materiales fundentes), que rápidamente se separarán en dos productos: el hierro por un lado y las impurezas junto a los fundentes (escoria primaria) por otro.

Según va aumentando la temperatura, Ilegando hasta los $1500^{\circ} \mathrm{C}$, el producto llega hasta el crisol del horno, produciendo los dos materiales definitivos: arrabio y escoria. El arrabio, con mayor densidad que la escoria, fluye a través de una piquera.

Esta escoria, una vez enfriada, genera varios tipos de subproductos, en función de la técnica de enfriamiento.

El ratio de escoria producida por tonelada de acero es de $250-300 \mathrm{~kg}$.

- Escoria cristalizada.

Se obtiene por un enfriamiento lento de la escoria líquida, insuflando aire.

El material obtenido tiene forma y características similares a las rocas ígneas. Su uso más extendido es como base para estabilización de suelos.

- Escoria vitrificada (granulada o peletizada)

Se obtiene mediante un enfriamiento brusco, normalmente mediante la adición agua.

Su estructura está vitrificada, aunque presenta algunos elementos cristalizados. Posee una densidad aparente muy variable. Su utilización suele ser como adición en la fabricación de cementos. 


\section{- Escoria expandida}

Se obtiene mediante en enfriamiento controlado de la escoria líquida.

Su estructura consiste en granos angulares con porosidad mayor que la cristalizada.

\section{Escorias de convertidor de oxígeno. (LD)}

En el proceso de afinado del acero no suele bastar con el proceso propio del alto horno, sino que requiere un tratamiento en un Convertidor de Oxigeno. Éste consiste en hacer pasar una corriente de oxigeno a través del arrabio líquido.

El ratio de escoria producida por tonelada de acero es de $80-120 \mathrm{~kg}$.

El enfriamiento se realiza lentamente disponiéndolas en contacto con el aire. Su estructura está totalmente cristalizada, componiéndose por silicatos cálcicos, óxidos de hierro y magnesia.

Su uso principal suele ser como pavimentos, especialmente en la capa de rodadura de las carreteras, y como correctores de suelos agrícolas.

\section{Escorias de cubilote}

El horno de cubilote es de los sistemas más antiguos que actualmente siguen en funcionamiento, datando sus características esenciales del siglo XVIII. Consiste básicamente en un cilindro vertical que sirve de soporte al ladrillo refractario que lo recubre interiormente. Dispone de dos aberturas opuestas en la parte baja, por ellas sale el metal líquido fundido y la escoria.

Este horno tiene la peculiaridad de mantener al metal y al combustible en contacto directo por lo que logra altos grados de eficiencia térmica.

Las escorias proceden, en gran medida, de la ceniza del coque, restos del desgaste del los refractarios, de arena y tierra en los retornos, piezas defectuosas y chatarras usadas en la carga. Su composición química, al igual que propiedades y apariencia, es heterogénea, no siendo muy distintas de las escorias de los hornos eléctricos o altos hornos.

\section{Escorias de Horno Eléctrico (EAF). Escoria negra}

El horno de arco eléctrico (Electric Arc Furnace), se trata de un cilindro recubierto por un refractario, que dispone de un hogar (bóveda) por donde se introducen las materias primas, y una piquera por la que sale el acero líquido.

Este proceso se divide en dos etapas diferenciadas, que generan dos escorias diferentes: la metalurgia primaria o fusión y la metalurgia secundaria o afino.

La primera etapa, de fusión, tiene el siguiente funcionamiento: se disponen las materias primas a través de la parte superior del horno. En el interior se hacen descender unos electrodos hasta la superficie del metal. La corriente eléctrica fluye por cada uno de los electrodos, formando un arco eléctrico hasta la carga metálica. El calor producido por la resistencia del metal genera calor que, junto con el producido por el arco eléctrico, funde el metal.

Se requiere gran cantidad de electricidad para la producción de acero con horno de arco eléctrico. Para producir una tonelada, se requieren 
unos $440 \mathrm{kWh}$ de electricidad que permitan llegar al punto de fusión del acero $\left(1520^{\circ} \mathrm{C}\right)$

Esta primera etapa se divide a su vez en dos etapas diferentes: la primera fase, denominada de fusión, y la segunda que comprende las etapas de oxidación y reducción, destinadas a eliminar las impurezas del manganeso y silicio. El material cargado durante el proceso de fusión se acompaña de una cantidad de impurezas, fundentes y materiales aditivos. A partir de estos, se obtiene una escoria espumante flotando sobre el caldo de acero líquido. A estas escorias se las denomina escorias negras.

La segunda etapa, de afino, se trata de una fase reductora consistente en desoxidación, desulfuración, ajuste en la composición y control de la temperatura de la colada (previamente desescoriada) procedente de la metalurgia primaria. Esta se realiza en un horno de cuchara.

\section{Escoria de Horno Cuchara (LF). Escoria blanca}

El horno de cuchara se utiliza para el refinado del acero fundido, procedente de la metalurgia primaria.

La función básica de estos hornos es la búsqueda de un ajuste y sincronización exacta para una colada continua. Paralelamente, mediante la adición de diversas materias se consigue un ajuste en la composición, permitiendo un acero limpio y con adecuadas características mecánicas transversales.

Existen diversos hornos de cuchara accionados mediante arco eléctrico, aunque se reducen básicamente a tres sistemas diferentes: Los agitados por inducción, los agitados por gas a través de tapón poroso y los agitados por gas a través de una tobera.

El funcionamiento es sencillo. Durante la colada se añade una nueva escoria básica reactiva, denominada escoria blanca. Para la homogeneización de la temperatura y de la composición, el líquido fundido tiene que ser mezclada continuamente por medio de agitación de un gas inerte, normalmente argón, haciendo posible la operación de afino y la consecución de la calidad buscada, mejorando la reactividad de los elementos aleantes.

La escoria blanca permite la reducción de los óxidos metálicos presentes en la colada durante la fase de desoxidación y desulfuración.

\subsection{Producción de escorias de horno eléctrico (EAFS)}

La producción de acero mundial, según los daros de la World Steel Association, que agrupa a los 66 principales países productores de acero, durante el año 2015 fue de 1,622.8 MT, lo que ha supuesto un descenso en el conjunto anual del 2,8\%.

Esta caída afectó principalmente a los principales productores a nivel mundial que son los países asiáticos: China, Japón, India y Corea del sur, además Estados Unidos, Rusia y la Unión Europea.

En el año 2015 la producción de acero bruto en España fue de 14,8 millones de toneladas, lo que supuso un aumento de un $4,3 \%$. Actualmente el método de fabricación más extendido en España es el Horno de arco eléctrico abarcando el $68,5 \%$ de la producción total. 
Actualmente la producción de acero en España se encuentra en niveles de 1998, debido a la pujanza del acero de países como China, y a la crisis económica del país. Desde el año 2007, la producción de acero bruto en España ha bajado un 22,10\%.

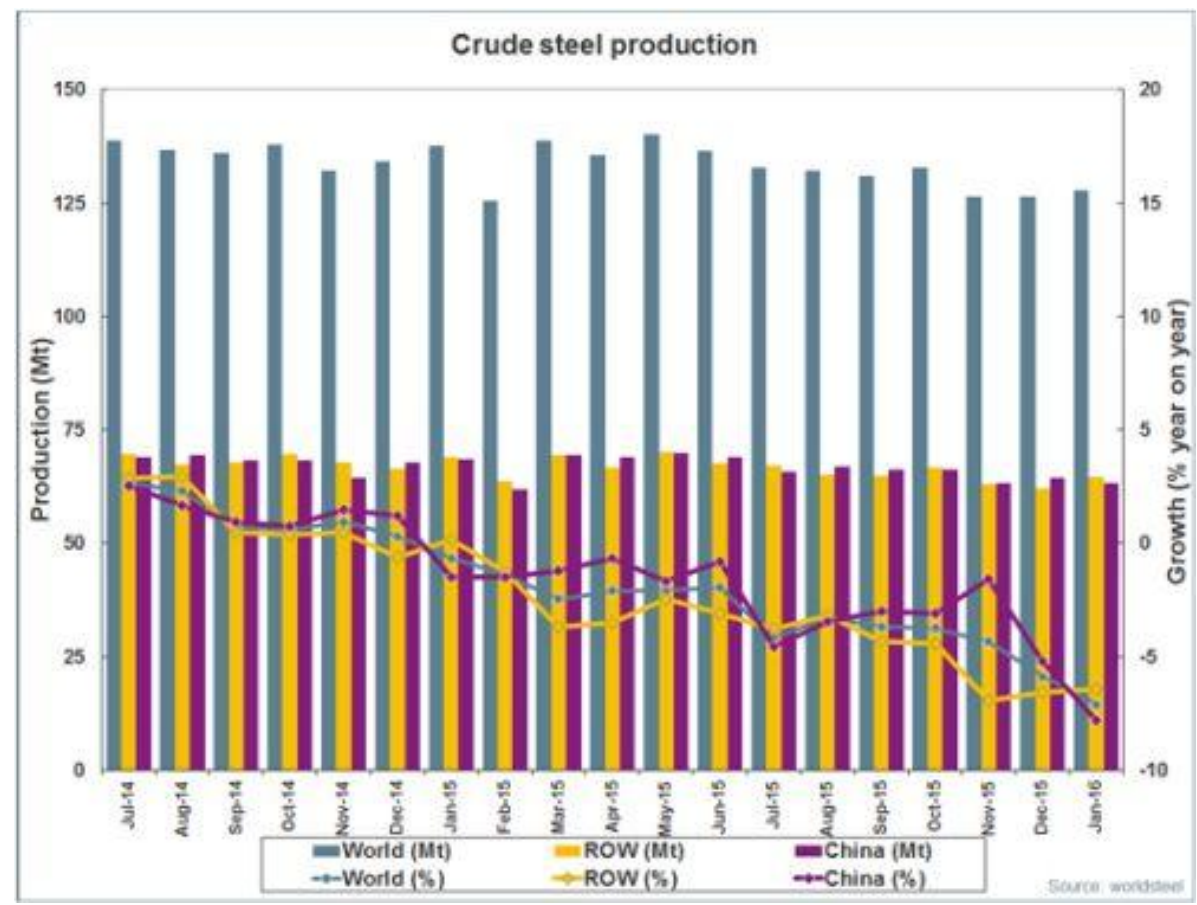

Imagen 52. Producción de acero mundial. Fuente: Worldsteel

Esta producción supone la tercera más importante de la Unión Europea, por detrás de Alemania e Italia.

Por comunidades existen actualmente un total de 22 acerías, todas de arco eléctrico excepto una integral, que se concentran en la cornisa cantábrica, especialmente en Asturias (20\%) y País Vasco (32\%).

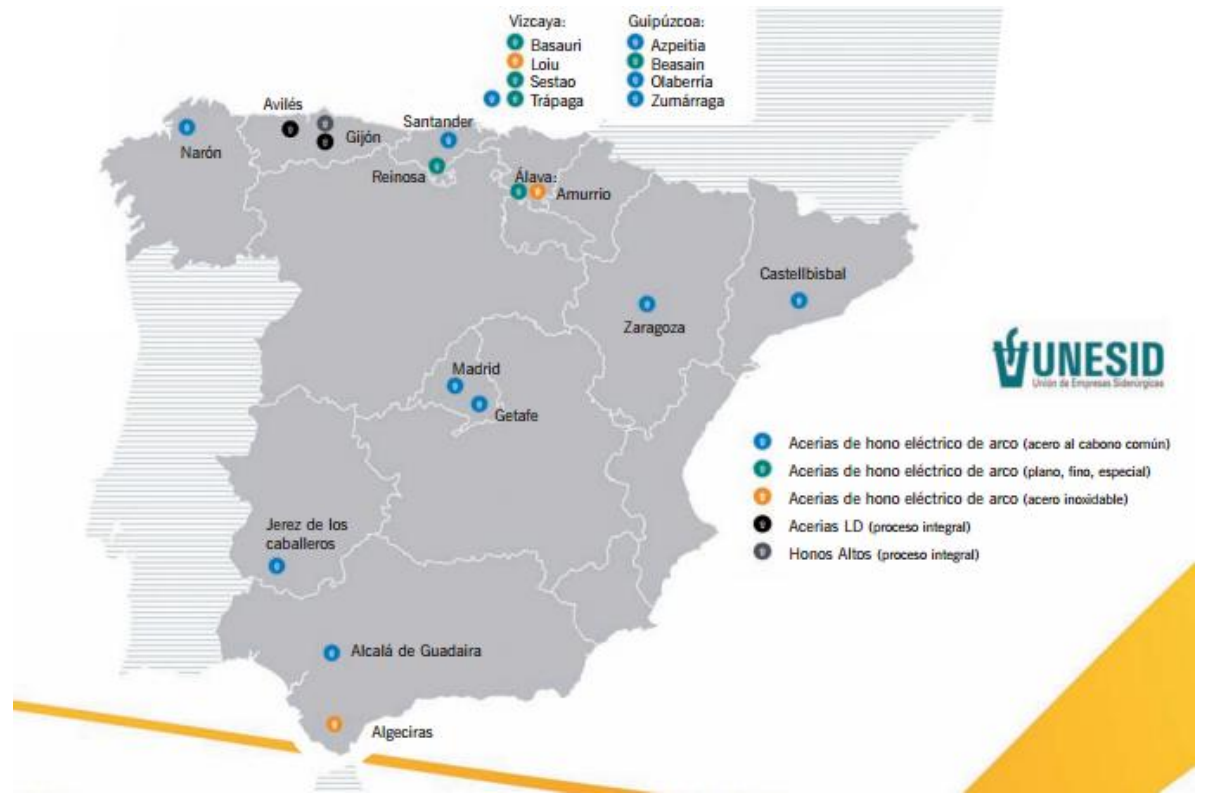

Imagen 53. Distribución de empresas siderúrgicas en España. Fuente: UNESID 
Del total de acero producido, 13,2 millones de toneladas correspondieron a acero común, 980.000 toneladas a acero inoxidable y 620.000 toneladas al resto de productos.

A partir de estos datos, y de los ratios de escoria generada por tonelada de acero común producido, para los hornos de arco eléctrico, obtenemos el total de la producción de escorias (EAFS)

\begin{tabular}{|c|c|c|}
\hline $\begin{array}{l}\text { Acero producido } 2015 \\
\text { (mill. t) }\end{array}$ & $\begin{array}{c}\text { Ratio de escoria } \\
\text { (kg/t de acero) }\end{array}$ & $\begin{array}{l}\text { Producción de } \\
\text { escorias }(t)\end{array}$ \\
\hline \multirow{2}{*}{13,20} & Escoria negra & 1.760 .000 \\
\hline & Escoria blanca & 330.000 \\
\hline
\end{tabular}

Dada que la producción de acero en horno de arco eléctrico se realiza en la casi totalidad de las industrias siderúrgicas y que la escoria negra obtenida es 5,3 veces la de la escoria blanca, la presente tesis doctoral basará su estudio en las escorias negras.

\subsection{Propiedades de las escorias negras de horno eléctrico (EAFS)}

\section{Propiedades de la escoria bruta}

La composición química de la escoria obtenida en los caldos líquidos durante la fabricación del acero está condicionada por el tipo de chatarra utilizada. Por ello la escoria obtenida en España difiere en su composición de la obtenida en otra zona, aunque siempre dentro de unos rangos.

\begin{tabular}{lll} 
& \multicolumn{1}{c}{ Rango (\%) } & Valor Medio (\%) \\
$\mathrm{FeO}$ & $7,00-35,0$ & 25 \\
$\mathrm{Fe} 2 \mathrm{O} 3$ & $11,0-40,0$ & 25 \\
$\mathrm{CaO}$ & $23,0-32,0$ & 25 \\
$\mathrm{SiO} 2$ & $8,0-15,0$ & 11 \\
$\mathrm{Al} 2 \mathrm{O} 3$ & $3,5-7,0$ & 5 \\
$\mathrm{MgO}$ & $4,8-6,6$ & 5 \\
$\mathrm{MnO}$ & $2,5-4,5$ & 4 \\
$\mathrm{CaO}$ libre & $0-4,0$ & 2
\end{tabular}

Tabla 1. Composición química EAFS acería española. Fuente: CEDEX

Las propiedades físicas dependen en gran medida del método de enfriamiento utilizado, a partir de los caldos líquidos.

- Enfriamiento rápido. La escoria vertida directamente sobre el suelo, se mezcla con agua, lo cual produce un enfriamiento muy rápido. Debido a este enfriamiento brusco, la escoria presenta mucha porosidad de tamaño pequeño. Su estructura es principalmente vítrea.

- Enfriamiento normal. La escoria se vierte en un cono de función dispuesto bajo la piquera del horno eléctrico (EAF). La escoria se vierte posteriormente en una fosa donde termina de enfriarse. La escora presenta una estructura cristalina con una porosidad menor.

- Enfriamiento lento. Al igual que en el enfriamiento normal, la escoria se vierte directamente desde el horno a un cono de 
fundición, donde se enfría lentamente. La escoria presenta una estructura totalmente cristalina, muy poco porosa y con alta dureza.

\section{Propiedades de la escoria procesada}

Para la utilización de las escorias negras de horno eléctrico (EAFS), se debe proceder a su machaqueo para la obtención del árido.

$\begin{array}{lll}\text { Propiedad } & \text { Árido grueso } & \text { Árido fino } \\ \text { Tamaño }(\mathrm{mm}) & 4,76-25,0 & 0-4,76 \\ \text { Densidad aparente }(\mathrm{Mg} / \mathrm{m} 3) & 3,35 & 3,70 \\ \text { Absorción (\%) } & 3,29 & 2,89 \\ \text { Porosidad (\%) } & 10,5 & - \\ \text { Desgaste de Los Ángeles (\%) } & \approx 20 & - \\ \text { Tabla 2. Propiedades físicas áridos EAFS. Fuente: CEDEX }\end{array}$

- Densidad relativa.

Entre 3,1 y 4,5. Muy elevada y por encima de la de los áridos naturales.

- Absorción.

Entre el 1\% y $4 \%$ del volumen. Elevada.

- Dureza.

Coeficiente de desgaste de los ángeles entre 17\% y 25\%. Alta dureza.

- Coeficiente de pulimento acelerado

Entre 0,50 y 0,60

$-\mathrm{pH}$

Superior a 11. Puede provocar corrosión en contacto con aluminio y acero.

- Naturaleza expansiva

Debido en gran medida a la cal libre cuya rápida hidratación origina cambios de volumen en pocas semanas.

- Granulometría

Ajuste sencillo por machaqueo de árido grueso (tamaño máximo $25 \mathrm{~mm}$ ), pero difícil y costosa la obtención de árido fino. Es recomendable la sustitución del árido fino por filler calizo

\subsection{Valorización de las escorias negras de horno eléctrico (EAFS)}

En los últimos años se ha venido estudiando la valorización material de las escorias de horno eléctrico para su posterior utilización como materiales para su incorporación a las obras de construcción o a industrias relacionadas.

Durante muchos años la escoria negra no ha tenido una salida comercial, siendo transportada desde su salida del horno y enfriamiento a los vertederos de residuos inertes. Sin embargo la 
imposición de tasas al tratamiento ambiental de los residuos, ha requerido la valorización de dicho sub-producto. Sin embargo, es difícil un análisis económico ya que hasta la fecha no existen unos precios estipulados de la venta de las escorias negras para la obtención de áridos.

Hasta el momento, salvando variantes y similitudes, se han estudiado básicamente las siguientes alternativas de reutilización del árido de escoria negra de horno de arco (EAFS):

Inclusión en industria cementera.

Consiste en su inclusión en la fabricación del clínker, como aporte de hierro, silicio y cal.

El cemento obtenido sufre escasa variación química, habiendo estudios que sustituyen desde un 4\%, hasta el 15-30\% o incluso un 45\%. Estos cementos presentan una mejor trabajabilidad aunque un mayor tiempo de fraguado.

Utilización en la capa de rodadura de los firmes bituminosos.

Los áridos de escoria negra poseen un buen coeficiente de desgaste y un excelente coeficiente de pulimento acelerado. Así mismo la composición química y $\mathrm{pH}$ son óptimos para una buena adherencia junto al betún de la capa bituminosa. Por ello se consideran óptimas para su uso en las capas de rodadura.

\section{Utilización en bases, sub-bases y explanadas como sustitución de zahorras.}

Las escorias negras, adecuadamente tratadas, cumplen con las especificaciones mínimas necesarias para las capas granulares en la ejecución de carreteras.

Es importante evaluar su expansividad, a fin de evitar los problemas derivados.

\section{Utilización como sustitución de árido en morteros y hormigones.}

También se ha investigado la utilización de las escorias de acería en la fabricación de morteros y hormigones

Los morteros estudiados, presentan en general, buena resistencia a compresión, habiéndose estudiado diversas dosificaciones.

En los hormigones, se están investigan como sustitución de árido fino o grueso, llegándose a sustituir el 100\% del árido, no habiéndose notado especial diferencia en las principales propiedades. En árido fino, según estas investigaciones, la sustitución se limita al 30\%.

\section{Briófitos}

\subsection{Introducción}

El término de briófito se refiere a un tipo de pequeñas plantas desprovistas de tejidos vasculares, lo cual caracteriza a las plantas terrestres superiores, que mantienen unidas de forma permanente las 
dos fases del ciclo de vida: la generación sexual, con los órganos productores de gametos (gametofito), y la generación asexual, productora de esporas (esporofito) [35].

Estos se pueden clasificar en: Musgos, Hepáticas y Antocerotas. Representan las tres líneas evolutivas muy diferenciadas, que en conjunto suponen el segundo grupo, por número, de plantas sobre el planeta.
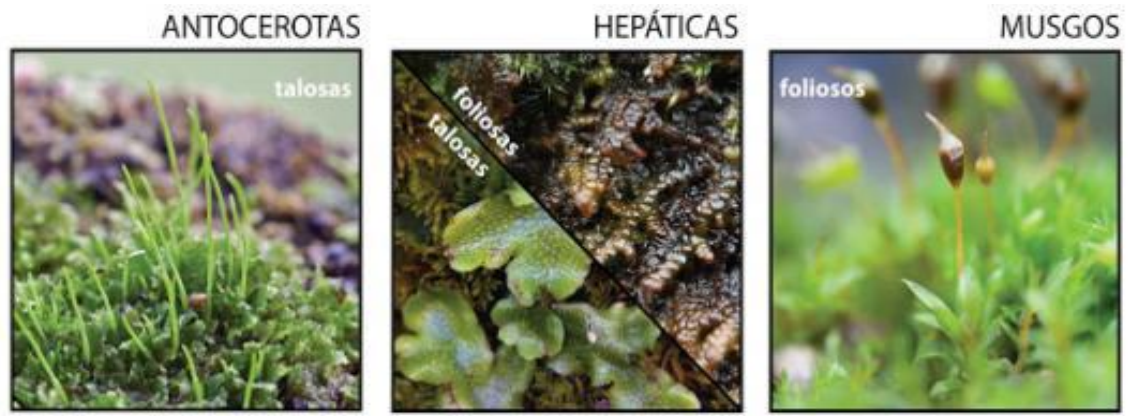

Imagen 54. Diferencias entre briófitos. Fuente: Blog Proyecto Musgo

Una de las principales diferencias entre briófitos viene dada por la forma de crecimiento. Mientras que las hepáticas y las antocerotas crecen formando una lámina de tejido sin hojas ni tallos, los musgos crecen formando hojas. Esto hace que fisionómicamente, los grupos más diferentes entre sí sean musgos y antocerotas.

Sin embargo sí guardan ciertas similitudes antocerotas y hepáticas talosas, es decir que tienen talo. Sus principales diferencias estriban que, por un lado las antocerotas son de un color verde oscuro y el talo es algo más amorfo y sin ningún tipo de reticulación, nervadura o poros. Así mismo al talo le salen estructuras con apariencia de hierba, en vez de cápsulas.

Por otro lado las hepáticas foliosas se diferencian de los musgos en que a menudo se disponen en dos filas en el tallo.

Las hepáticas poseen una cápsula que apenas dura unas semanas (en los musgos es duradera), y cuando se abre lo hace en cuatro valvas. Respecto a las hojas, las hepáticas tienen la punta redondeada o termina en dos espinas (o más)

Respecto a la modalidad de colonización, podemos dividir, en este caso los musgos, en dos subclases:

- Acrocárpicos: Son aquellos que portan los arquegonios, órgano reproductor, en el extremo del tallo. Su crecimiento tiende a ser perpendicular y en longitud.

- Pleurocárpico. Son aquellos que portan los arquegonios en las ramas laterales, en vez de en el extremo del tallo. Su crecimiento es tiende a ser extensivo, formando un tapiz sobre el terreno.

\subsection{Principales características}

Desde el punto de vista de la adaptación al medio terrestre, los briófitos son muy diferentes de las plantas vasculares. Esto es debido, principalmente, a la capacidad de los briofitos de perder y ganar agua, dependiendo de las características del medio sobre el que se asientan. Esta capacidad les permite equilibrar rápidamente la cantidad retenida 
en sus células, en función de la existencia o no de humedad en el ambiente.

Los briófitos no presentas raíces, propiamente dichas. Los gametofitos de los briófitos presentan rizoides cuya única función es la de sujetarse al substrato sobre el que están. Al no tener tejido vascular, no son capaces de captar el agua a través del sustrato ni de retenerlo. Ni los tallos (caulidios), sin estructura vascular, ni las hojas (filidios), con una fina e incompleta cutícula en la cara superior, son capaces de transportar líquidos de una parte a otra, aunque los rizoides estén en contacto con un medio húmedo. Es más, las hojas si están expuestas al aire seco durante unas horas, provocan la desecación de la planta. [36]

Es por ello que los briófitos poseen varios mecanismos para compensar su incapacidad de retener agua.

Por un lado eligen cuidadosamente el medio en el que se instalan. Muchos escogen hábitats en los que continuamente se encuentran en presencia de humedad. Estas son las condiciones óptimas para muchas especies y permiten el desarrollo máximo, ya que son capaces de absorber humedad a través de toda su superficie. Este es también el caso de otros musgos que buscan pequeños resquicios húmedos, como fisuras en rocas, que permiten la acumulación de agua, y evitan la desecación.

Por otro, existen otro tipo de briófitos que compensan la falta de capacidad de retención de agua, tolerando la desecación. En estos casos, el briófito permanece inactivo en los periodos de desecación hasta que se vuelven a hidratar (agua de lluvia, rocío, salpicaduras...). Como los tejidos permanecen totalmente funcionales, rápidamente recuperan la actividad fotosintética.

Una de las características menos conocidas de muchos briófitos es su capacidad fotosintética activa [37]. Pese a la inexistencia de un sistema vascular, los briófitos y, por ende, los musgos, contienen clorofilas tipo a y b que les permiten metabolizar almidón y celulosa como materiales de reserva energética. Según Larcher, las tasas fotosintéticas de los musgos, pese a ser muy inferiores a las plantas vasculares superiores, pueden ser equivalentes, en cuanto a absorción de $\mathrm{CO} 2$, a las del césped.

En general crecen en zonas templadas, presentando un rango óptimo de crecimiento entre 15 y $25^{\circ} \mathrm{C}$. Sin embargo destacan además por su capacidad de crecer tanto a altas temperaturas, llegando a los $70^{\circ} \mathrm{C} \sin$ sufrir daños [38], como a bajas, sobreviviendo en laboratorio a temperaturas entre -10 y $-27^{\circ} \mathrm{C}$ [39] El mecanismo capaz de esta regulación implica una inactivación metabólica, similar a la que actúa en la desecación, anteriormente expuesta.

\subsection{Reproducción}

Tal y como ya se ha explicado en el capítulo, los briófitos son plantas no vasculares. Como el resto de plantas vasculares, disponen de dos fases diferenciadas en su ciclo vital: gametofito y esporofito.

La fase gametofítica es la que se expande mediante procesos de reproducción sexual y asexual. [40] Se trata de una fase fotosintética.

La fase esporofitica en los briófitos es efímera. Al tratarse de una fase no fotosintética, el esporofito vive unido al gametofito femenino, 
dependiendo de él para su nutrición. Son morfológicamente sencillos y tienen crecimiento limitado.

Los briófitos son las únicas plantas terrestres en las cuales la fase dominante es el gametofito.

La reproducción sexual de los briófitos implica la presencia de una lámina de agua que permita que cuando se liberan los gametos masculinos móviles, estos puedan llegar hasta los gametangios femeninos para poder fecundar el gameto femenino. Por ello los gametofitos no alcanzan grandes tamaños y para que puedan reproducirse tienen que vivir en substratos húmedos.

Además muchas especies de musgos producen pequeños brotes que funcionan al modo de las semillas, cayendo de la planta adulta para germinar [41].

\subsection{Papel ecológico}

\section{Creación de suelos y hábitats}

Los musgos se encuentran en la base de las cadenas alimentarias en los ecosistemas donde se reproducen, siendo habitualmente las primeras plantas en crecer sobre los suelos tras un incendio [42], sirviendo de alimento para numerosas especies o material base para construir sus nidos o madrigueras. También suelen ser las especies pioneras en superficies a priori poco bio-receptivos, como pueden ser rocas.

También es a tener en cuenta su capacidad para detener la erosión de los suelos. Para ello influye una de sus características más típicas: la retención de agua. Esta característica permite, por un lado, la conservación de la humedad ambiental que a su vez fomenta la aparición de una mayor biomasa. Con ello, aparte de evitar la erosión del suelo, fomentan la creación de micro-hábitats en los cojinetes que forman los musgos y permiten la regulación térmica del suelo gracias a las extensas comunidades que forman en simbiosis con los árboles [43].

\section{Regulación de la humedad}

Como ya se ha indicado anteriormente, los briófitos disponen de una importante capacidad de retención de agua. Por ello pueden regular el grado de humedad del ambiente, variando la composición higrométrica y por tanto modificando el hábitat.

Sin embargo no es menos importante a la hora de la retención de agua, la composición de ella. Por ello también permiten la acumulación de nutrientes minerales disueltos en el agua de lluvia, los cuales se incorporan a la propia estructura del briófito, evitando una rápida evaporación y pérdida por drenaje de agua. [44]

\section{Sumideros de $\mathrm{CO}_{2}$}

Como se ha indicado en anteriormente, los musgos tienen actividad fotosintética, pese a la creencia popular de su incapacidad. Esto les permite a su vez funcionar como sumideros de CO2, si bien, su actividad depende en gran medida de unas condiciones ambientales óptimas. 


\section{Fijación de nitrógeno}

El nitrógeno suele ser un nutriente que limita el crecimiento de plantas. Se entiende como fijación de nitrógeno a la combinación del nitrógeno molecular con oxígeno (o incluso hidrógeno), con el fin de generar productos asimilables por el propio ecosistema.

Las costras de briofitos, que generalmente están dotadas de cianobacterias fijadoras del mismo, controlan la abundancia y actividad de sus epífitos en función de la disponibilidad de nitrógeno en el ecosistema [45]. Estas grandes cantidades de nitrógeno son transmitidas al suelo, particularmente en tierras secas de pastoreo [46].

\section{Estudios de polución}

Los briofitos juegan un importante rol en la monitorización de los cambios en la atmosfera terrestre, gracias a su especial sensibilidad y respuesta predecible frente a diversos niveles de contaminación del aire. Además son más apreciados que el resto de plantas vasculares gracias a su perennidad (le permite un mayor tiempo de bio-indicación a lo largo del año), y a su capacidad de absorción de sustancias tóxicas para el resto de especies.

Actualmente su uso como bio-indicadores está muy extendido, principalmente para el monitoreo de la contaminación industrial: metales pesados, dióxido de azufre y lluvia acida. Sin embargo su uso también se extiende en el estudio de la radiación ultravioleta.

Dada la sencillez fisionómica de los briófitos y la carencia de un sistema vascular, estos absorben tanto nutrientes como contaminantes directamente de la atmósfera. Es por ello que su capacidad de capturar contaminantes es limitada ya que rápidamente colmatan todo su sistema y se saturan, no pudiendo absorber más [47].

\subsection{Adaptación medio urbano}

Si bien los briófitos suelen asentarse, principalmente, en zonas de bosque y húmedas, ello no excluye su capacidad de adaptación al medio urbano. Los musgos son especialmente sensibles a las atmósferas contaminadas de las ciudades, siendo por ello buenos bioindicadores.

Sin embargo no se comportan igual todas las clases de musgos, ya que existen cuatro tipos de toxisensibilidad de las especies a la contaminación ambiental [48]:

- Especies toxífilas: Óptimas para su uso áreas urbanas e industriales.

- Especies toxitolerantes: Toleran niveles altos de SO2.

- Especies medianamente toxitolerantes: Disponen de cierta capacidad de adaptación al medio urbano.

- Especies sensibles: Disponen de poca capacidad de adaptación al medio urbano. Toleran poca polución

\subsection{Requerimientos de la especie de briófito}

Atendiendo a las necesidades requeridas para un revestimiento de fachada con una cubierta a base de briófitos, se precisan las siguientes características: 
- Especie resistente:

Deberá de ser capaz de crecer en ambientes adversos con contaminación ambiental, en ciertos casos, acentuada.

También deberá ser resistente a la desecación, sobreviviendo en los periodos de alto calor y baja humedad y periodos de soleamiento directo prolongado.

- Especie con poco requerimiento hídrico

Se considera más un deseo que una necesidad.

- Especie fácilmente acoplable al panel

Deberá implementarse fácilmente sobre el panel, permitiendo su cultivo en laboratorio sin necesidad de ser recolectado en el ecosistema.

La especie no deberá ser anual, con el fin de ser una cubierta vegetal permanente y viva.

Deberá poder sostenerse por si sola al soporte en posición vertical.

- Especie estéticamente correcta.

Especie pleurocárpica, es decir que su crecimiento sea generando tapices horizontales en vez de matas verticales.

La especie deberá generar tapices tupidos que permitan observar la cobertura verde.

Atendiendo a estas necesidades, se elabora una tabla con una serie de especies autóctonas disponibles en el medio natural.

Estas especies muestreadas se tratan de aquellas que, en principio, mejor se adaptarían al fin que se pretende dar. Para ello se muestran sus características según las fichas de la BBS Field Guide y el manual de Ecofisiología vegetal de Larcher.

\begin{tabular}{|c|c|c|c|c|c|c|}
\hline \multirow{2}{*}{\multicolumn{2}{|c|}{ Especie }} & \multicolumn{5}{|c|}{ Ficha BBS } \\
\hline & & \begin{tabular}{|c|} 
Tam. \\
$\mathrm{cm}$ \\
\end{tabular} & Estética & Soleamiento & Hábitat & Crece sobre \\
\hline 1 & Antitrichia curtipendula & $\begin{array}{l}\text { Hasta } \\
20\end{array}$ & Masas de brotes & & $\begin{array}{l}\text { Elevaciones, lagos, y } \\
\text { más raramente, } \\
\text { praderas, dunas }\end{array}$ & $\begin{array}{l}\text { Rocas elevadas, } \\
\text { acantilados, árboles y } \\
\text { arbustos }\end{array}$ \\
\hline 2 & Hypnum cupressiforme & 2 & $\begin{array}{l}\text { Ramas irregulares, hojas } \\
\text { muy curvadas }\end{array}$ & & $\begin{array}{l}\text { Muy común en rocas } \\
\text { silíceas o cortezas } \\
\text { ácidas o ligeramente } \\
\text { básicas }\end{array}$ & Rocas, cortezas, madera \\
\hline 3 & Homalothecium lutescens & $1-2$ & $\begin{array}{l}\text { Matas sueltas, o unido a } \\
\text { rocas }\end{array}$ & & $\begin{array}{l}\text { Praderas calizas, } \\
\text { espacios abiertos, dunas }\end{array}$ & Rocas, valles calizos \\
\hline 4 & Leucodon sciuroides & $4-5$ & En tallos como arcos & & No común & $\begin{array}{l}\text { Arboles con corteza, } \\
\text { monumentos, tumbas }\end{array}$ \\
\hline 5 & Hedwigia stellata & $3-10$ & Irregular, parches & Soporta el sol & $\begin{array}{l}\text { Páramos, brezales, } \\
\text { lagos }\end{array}$ & $\begin{array}{l}\text { Rocas ígneas, siliceas o } \\
\text { ácidas }\end{array}$ \\
\hline 6 & Brachythecium rutabulum & $1-2$ & Estética muy variada & & $\begin{array}{l}\text { Muy amplio, } \\
\text { especialmente rocas y } \\
\text { bosques }\end{array}$ & $\begin{array}{l}\text { Árboles, praderas, rocas... } \\
\text { En la sombra o en espacios } \\
\text { abierto }\end{array}$ \\
\hline 7 & Pseudoscleropodium purum & 10 & $\begin{array}{l}\text { Muy reconocible. Robusto, } \\
\text { apariencia "gorda" }\end{array}$ & $\begin{array}{l}\text { Necesita algo de } \\
\text { soleamiento, no } \\
\text { soporta total } \\
\text { sombreamiento }\end{array}$ & \begin{tabular}{|l|} 
Muy variado, \\
especialmente en \\
praderas ácidas, aunque \\
también soporta suelos \\
calizos
\end{tabular} & $\begin{array}{l}\text { Praderas, orillas, entre } \\
\text { rocas... }\end{array}$ \\
\hline 8 & Rhytidiadelphus triquetrus & $5-20$ & $\begin{array}{l}\text { Muy grande, con } \\
\text { apariencia de arbusto, } \\
\text { tallos rojos, hojas en } \\
\text { muchas direcciones }\end{array}$ & & $\begin{array}{l}\text { Suelos calcáreos, } \\
\text { bosques, tierras ácidas, } \\
\text { pinos }\end{array}$ & $\begin{array}{l}\text { Bosques, praderas abiertas, } \\
\text { dunas }\end{array}$ \\
\hline 9 & Hylocomium splendens & $10-20$ & $\begin{array}{l}\text { Brillante, tallos rojos, } \\
\text { robusto, ramas dispuestas } \\
\text { regularmente en dos } \\
\text { planos }\end{array}$ & & $\begin{array}{l}\text { Brezales, páramos, } \\
\text { bosques ácidos }\end{array}$ & Hierba, brezos, \\
\hline 10 & Thuidium tamariscinum & $5-25$ & Alfombras de brotes & & Bosques, setos, césped & Tierra, barro \\
\hline
\end{tabular}

Tabla 3. Comparativa de especies 


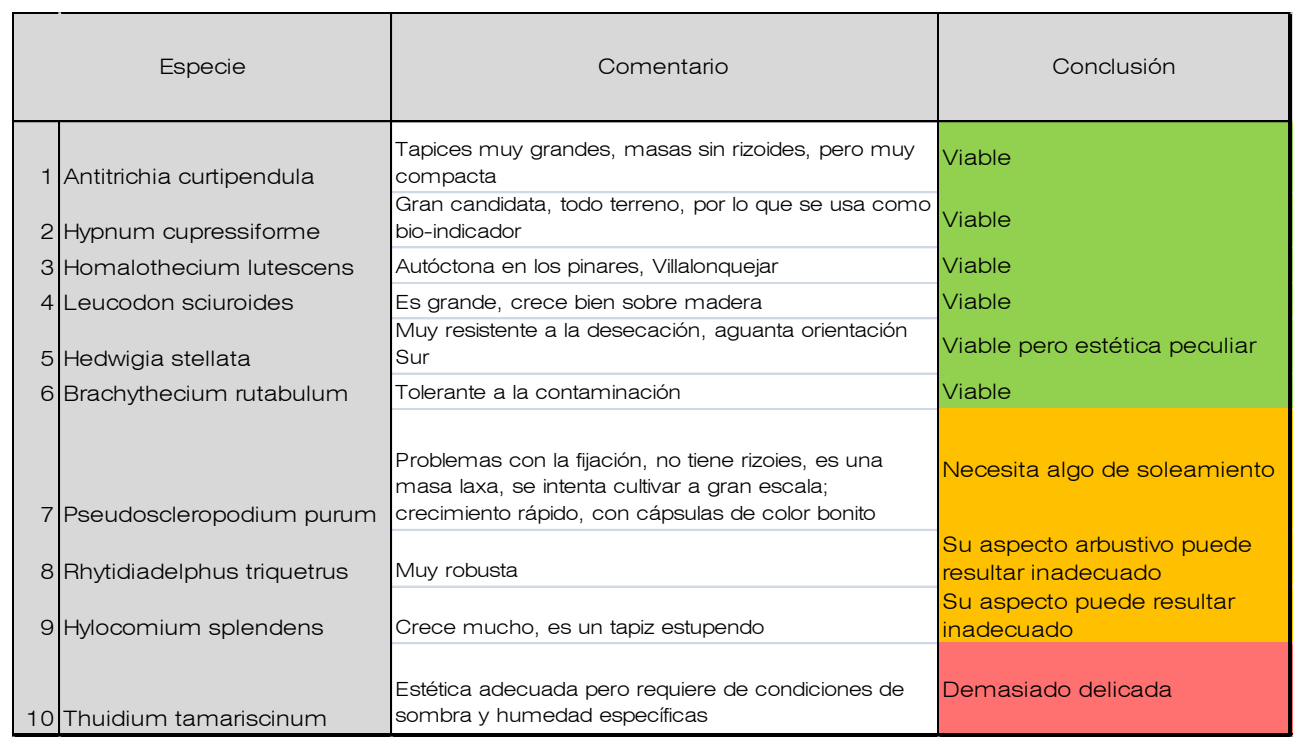

Tabla 4.1. Comparativa de especies

\subsection{Métodos de implantación/cultivo}

Para que un sistema como el estudiado en la tesis pudiera tener una aplicación industrial y fuera realmente sostenible, es necesario considerar un sistema de cultivo del briófito fuera de su entorno natural.

Para la implantación de las muestras de musgo sobre el soporte planteado se ha consultado la bibliografía existente en materia de cultivo de musgo.

Se ha estudiado este tipo de jardinería, puesto que la implantación directa sobre un soporte no se ha encontrado en la bibliografía consultada, con contadas excepciones.

Los sistemas estudiados son los siguientes:

\section{Batido de musgo}

Éste se trata de uno de los sistemas de cultivo de musgo con mayor difusión, existiendo incluso producción comercial [49] [50], y sin embargo de los que existe una opinión más diversa. El "batido de musgo" (moss milkshakes) es un método sencillo cuyo fundamento es batir brotes de una especie de musgo, adulta preferentemente, en un medio láctico.

Pese a su sencillez y a la citada comercialización existen varios expertos en la jardinería de musgos que se muestran escépticos acerca de este método, si bien, suelen incidir más bien en la tasa de éxito que en el método en sí. [51]

El método, descrito por diferentes expertos es sencillo:

- Se recolectan una serie de ejemplares maduros de musgo, a ser posible el medio en el que se han recolectado deberá ser parecido al medio en el que va a utilizar.

- Los brotes de musgo se introducen en una licuadora junto con un litro de leche.

- Con el producto obtenido, se pinta el soporte que se desea que sea colonizado por el briófito. En el plazo de unos meses se desarrolla un tapiz de musgo. 
Annie Martin hace varias aportaciones a este método. Por un lado amplía la gama de líquidos en el que se pueden triturar los musgos: cerveza, yogur, agua azucarada, etc... siempre y cuando sean un medio ácido.

Por otro lado, que hay que tener en cuenta, expone que no todas las especies de musgos ofrecen una garantía de éxito.

Finalmente, pese a ser uno de los autores escépticos, valora la capacidad bio-receptiva cuando se utilizan los batidos de musgo en sustratos muy porosos.

\section{Cultivo de ejemplares maduros}

Se trata de la forma más sencilla para el cultivo de musgos. Según explica Michael Fletcher [52], únicamente es necesario disponer el tapiz de musgo sobre un sustrato, que no tiene porque ser el original. Únicamente, indica, es necesario que dicho sustrato utilizado sea un medio ácido sin presencia de cal.

Sin embargo el sustrato puede ser sustituido por elementos artificiales. Estos deben ser lo más compatible con el musgo, siendo el geotextil sintético el que mejores resultados ha dado, tal y como indican tanto los investigadores de Briosistema como la propia Annie Martin.

Lo que sigue resultando ineludible es el riego, ya que se debe mantener un nivel de humedad adecuado, también durante el periodo de cultivo. Se recomienda para ello riegos cortos y frecuentes, incluso varias veces a lo largo del día, con pulverizadores o rociadores, especialmente en periodos secos (Martin, A.).

\section{Cultivo de fragmentos de ejemplares maduros}

Este método parte de una premisa y es la capacidad del musgo para ser una especie pionera, dicho de otra manera, suele ser la primera especie en colonizar un terreno y sirve como base para que otras especies se asienten.

Se trata de una técnica muy recomendable para el cultivo de nuevas praderas (Martin, A.). El método es sencillo:

Se extraen fragmentos, no muy pequeños, de la especie pionera de musgo. Posteriormente se implantan sobre el sustrato deseado, diseminándolos. Finalmente se recomienda regar abundantemente y pisar los tallos, con el fin de que se fijen al terreno.

Si no se consiguiese que los tallos queden bien asentados en el terreno, se puede disponer una red tejida, anclada al terreno, que los mantenga firmemente sobre el terreno, pero a su vez deje a los tallos con permeabilidad suficiente para su desarrollo.

\section{Cultivo de protonemas / brotes embrionarios}

Esta técnica explora la reproducción espontánea más habitual de los musgos, que consiste en su desarrollo a partir de un pequeño brote que al menos contenga un protonema. A partir de ese protonema, el musgo es capaz de reproducirse.

El cultivo se basa en disponer un cultivo de estos protonemas o brotes embrionarios, en un medio estéril (Fletcher, M.), tierra fresca, previamente esterilizada. Según Fletcher, dicha esterilización se puede hacer con lejía, dejando pasar un periodo de 24-48 horas, para que la lejía se haya evaporado antes de cultivar el brote. 
Una vez pasado el lapso de tiempo, se diseminan los brotes en la tierra y se colocan en un recipiente tapado con un film plástico transparente, que se ubicará en un espacio sombreado. No se destapa el recipiente, se perdería el medio estéril conseguido, hasta que comience a crecer el musgo. En ese momento, se destapa y se comienza a regar, mediante pulverización con bastante frecuencia y abundancia.

Según la experiencia (Fletcher, M.) aparecen en la totalidad de los casos algas que colonizan, en mayor o menor medida, el sustrato, y por lo tanto normalmente coartan el desarrollo de los brotes de musgo. Según el autor, la técnica tiene escaso éxito.

\section{Cultivos in-vitro}

Se trata de un método de cultivo, principalmente recomendado para laboratorio, en el cual en un medio estéril (tubo de ensayo) se consigue la reproducción de musgo mediante una solución nutritiva.

Este método se emplea en cierto tipo de especies. Fletcher no obtuvo buenos resultados en musgos que se desarrollan en sustratos ácidos, en principio debido a un $\mathrm{pH}$ básico del agua de enjuague.

También puede utilizarse fuera de laboratorio siempre y cuando se use una solución nutritiva correcta, recomendándose soluciones comerciales (Fletcher, M.).

El procedimiento es el siguiente:

- Lo primero es esterilizar los tubos de ensayo. Fletcher recomienda la utilización de lejía diluida en agua (concentración de un 10\%). Una vez esterilizados, se deben limpiar con agua del grifo o agua recién hervida, eliminando cualquier traza de lejía.

- Pasado un tiempo, unos días para asegurar la inexistencia de trazas de lejía, se dispone una solución nutritiva en el fondo del tubo de ensayo y se cierra el tubo, con un film plástico o un tapón esterilizado. Con ello se consigue un medio estéril.

- Se toma fragmentos de musgo (brote, tallo, hoja...) previamente limpiados con agua. Se disponen en el fondo de un recipiente vacio y se impregnan con lejía disuelta en agua. Fletchet utiliza una concentración del 10\%, pero recomienda distintas concentraciones en función del fabricante de lejía. Con unas pinzas se remueve el fragmento en la lejía.

- Ponemos el musgo bajo el microscopio. En segundos los bordes se comenzarán a desteñirse.

- Rápidamente se debe enjuagar el musgo con agua limpia y, una vez limpio, secarlo con papel. El fin es eliminar totalmente restos de lejía que maten al musgo. Repetimos este último proceso dos o tres veces.

- Una vez esterilizado el musgo, se dispone sobre la solución. El ritmo de crecimiento debería permitir ver nuevos protonemas en una semana.

Cabe tener las siguientes precauciones:

- Si el fragmento continúa decolorándose, se ha sobreexpuesto al concentrado de lejía. Se deberá repetir el procedimiento, bajando la concentración o exposición a la lejía o bien mejorar el proceso de enjuague-secado. 
- Si pasada una semana no se ha constatado la aparición de un nuevo protonema, el proceso también habrá fracasado.

- Si aparece una costra verde, es posible que no se haya esterilizado completamente el musgo, habiendo colonizado los mohos y algas el medio. Es probable que el proceso haya fracasado.

Fletcher atribuye buenos resultados en el trasplante de musgos cultivado in-vitro a cultivos convencionales.

\subsection{Tasa de crecimiento}

La tasa de crecimiento de los musgos se trata de un tema relativamente complejo, en el que además existen muy diversos, y no siempre precisos, procedimientos para medir el crecimiento del musgo. Así mismo hay que tener en cuenta que, dentro de las referencias consultadas, existen diferentes unidades de medida, con lo cual se complica la comparación entre las diversas mediciones.

Es importante comprender la tasa de crecimiento de los musgos. En la presente tesis se procede a la extracción de una pequeña superficie de musgo con el que realizar la investigación. Sin embargo si se pretende una derivación comercial del sistema propuesto, debe obtenerse de una forma alternativa y sostenible que no esquilme el medio natural.

Es el presente apartado se ha consultado la tasa de crecimiento relativo (Relative Growth Rate, RGR), que es la cantidad de crecimiento por unidad de biomasa y tiempo.

No se han encontrado datos de tasas de crecimiento de la especie Antitrichia Curtipendula. Esto puede suceder al no tratarse de una especie muy frecuente y en clara regresión, debido a la antropización de las zonas donde solía encontrarse.

Sin embargo, según consulta al catedrático Javier Martínez-Abaigar investigador del Grupo de Ecofisiología Vegetal, Cambio Climático y Medio Ambiente de la Universidad de la Rioja y también ex presidente de la Sociedad Española de Briología, podemos asumir que la Antitrichia Curtipendula tiene una tasa de crecimiento similar a otras especies como puede ser la del Hypnum Cupressiforme. Este tiene unos valores de crecimiento diario de de 0,01 gr/día [53]. Se tratarían de unas especies con una tasa más bien baja, sobre todo si se compara con Funaria hygrometrica $(0,063 \mathrm{gr} / \mathrm{día})$, la de mayor tasa de crecimiento según el estudio.

Sin embargo, se estima más relevante la "capacidad tapizante" del musgo sobre el sustrato que se asiente. Si traducimos ese crecimiento en masa a longitud, haciendo una simple transposición por su densidad, podemos pensar en un crecimiento aproximado de unos 5

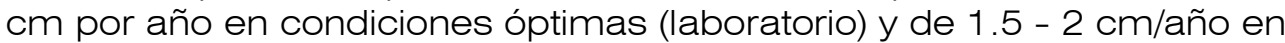
condiciones naturales.

Según otros investigadores [54], la producción anual por superficie, de Hypnum Cupressiforme y, por asimilación de Antitrichia Curtipendula, alcanza los $188 \pm 62 \mathrm{gm}^{2} \mathrm{yr}^{-1}$. de especies cultivadas en Austria. Esta apreciación viene motivada porque según la misma publicación ciertas especies de musgos producen entre un 10\% y un 39\% más en Europa Central que en el Norte de Europa o Canadá. 
No obstante, expertos en jardinería de musgo afirman que las especies pleurocárpicas, como es Antitrichia Curtipendula, duplican su tamaño en seis meses [55], siempre en condiciones ideales.

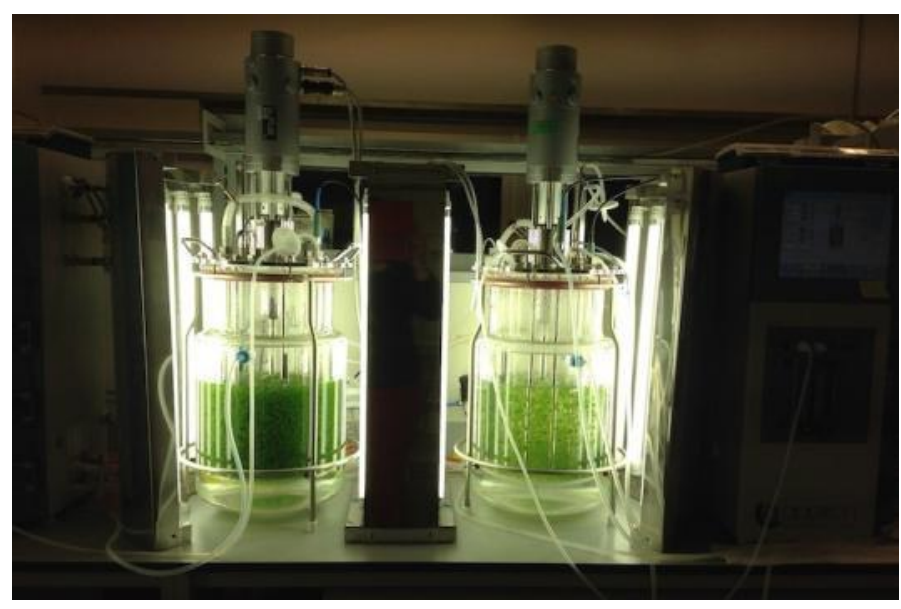

Imagen 55. Cultivo de Sphagnum en bio-reactor. Fuente: Universidad de Santiago de Compostela

Según esto, con la RGR anterior (0.01/día), bastarían aproximadamente 100 días para producir una masa equivalente a la inicial, y 200 para duplicarla. Es decir, podría ser viable una producción controlada, en la cual se va realizando una reposición del musgo utilizado.

Lógicamente, se podrían conseguir mayores tasas de crecimiento en bio-reactores (Imagen 55). Estos consiguen crear ambientes y situaciones excepcionalmente favorables y se consiguen crecimientos acelerados. Sin embargo existen varios inconvenientes. Por un lado en bio-reactores se obtienen fragmentos de musgo pequeños, cuando para la presente tesis convienen mejor la producción de tapices de mayor tamaño. Por otro el cultivo en bio-reactor disparará el coste de la producción de musgo, haciendo poco viable [56]. 
[1] Grupo de Investigación en Ingeniería de Edificación (GIIE). Publicaciones, Universidad de Burgos http://wwww.ubu.es/ingenieriade-edificacion-giie/publicaciones

[2] Malinowski, R.; Garfinkel, Y. Prehistory of Concrete. Concrete International. 1991: 62-68

[3] Martinet, G.; Deloye, F. X.; Golvin, J. C. Caractérisation des mortiers pharaoniques du temple d'Amon à Karnak. Bull.liaison Labo. P.et Ch. sept-oct 1992; 181: 39-45.

[4] Furlan, V.; Bisseger, P. Les mortiers anciens. Histoire et essais d'analyse scientifique. Revue suisse d'Art et d'Archéologie 1975; 32: 114

[5] Álvarez, J.I.; Martín, A.; García, P.J. Historia de los Morteros. Materiales y técnicas. (1995) PH Boletín Informativo n¹3, I.A.P.H. 52-59

[6] Norma Española UNE-EN 998-1 (2010) Especificaciones de los morteros para albañilería. Parte 1: Morteros para revoco y enlucido

[7] Norma Española UNE-EN 998-2 (2010) Especificaciones de los morteros para albañilería. Parte 2: Morteros para albañilería

[8] Ibíd.

[9] Ibíd.

[10] lbíd.

[11] Junco Petrement, C. Morteros aligerados con residuos de espumas rígidas de poliuretano. (2012) Universidad de Burgos, Tésis doctoral

[12] Norma Española UNE-EN 933-2 (1996) Ensayo para determinar las propiedades geométricas de los áridos. Parte 2: Determinación de la granulometría de las partículas. Tamices de ensayo, tamaño nominal de las aberturas.

[13] Norma Española UNE-EN 998-2 (2010) Especificaciones de los morteros para albañilería. Parte 2: Morteros para albañilería

[14] Norma Española UNE-EN 13139/AC (2004) Áridos para morteros.

[15] Junco, C. Morteros aligerados con residuos de espumas rígidas de poliuretano. (2012) Universidad de Burgos, Tésis doctoral.

[16] ASTM C 125 "Standard Terminology Relating to Concrete and Concrete Aggregates". American Society for Testing and Materials (ASTM), Philadelphia, PA. Annual Book of ASTM Standard. 2007

[17] Junco, C. Morteros aligerados con residuos de espumas rígidas de poliuretano. (2012) Universidad de Burgos, Tésis doctoral.

[18] lbíd.

[19] Ibíd.

[20] Ibíd.

[21] Mueller A., Hartley A. Materiales de hormigón reciclado en One Bryant Park (2009) Detail Green, pp 782

[22] Guillitte, O. Bioreceptivity: a new concept for building ecology studies (1995) Science of the Total Environment, 167 (1-3), pp. 215-220 
[23] Tran, T.H., Govin, A., Guyonnet, R., Grosseau, P., Lors, C., GarciaDiaz, E., Damidot, D., Devès, O., Ruot, B. Influence of the intrinsic characteristics of mortars on biofouling by Klebsormidium flaccidum (2012) International Biodeterioration and Biodegradation, 70, pp. 31-39

[24] Shirakawa, M.A., Beech, I.B., Tapper, R., Cincotto, M.A., Gambale, $\mathrm{W}$. The development of a method to evaluate bioreceptivity of indoor mortar plastering to fungal growth (2003) International Biodeterioration and Biodegradation, 51 (2), pp. 83-92

[25] Íbid

[26] Wiktor, V., Grosseau, P., Guyonnet, R., Garcia-Diaz, E., Lors, C. Accelerated weathering of cementitious matrix for the development of an accelerated laboratory test of biodeterioration (2011) Materials and Structures/Materiaux et Constructions, 44 (3), pp. 623-640

[27] Manso S, Segura I, Aguado A. Conjunto multicapa en base cemento, aplicable como soporte biológico para fachadas de edificios u otras construcciones, Patent PCT/ES2013/070438, 28 July 2013

[28] Manso, S., De Muynck, W., Segura, I., Aguado, A., Steppe, K., Boon, N., De Belie, N. Bioreceptivity evaluation of cementitious materials designed to stimulate biological growth (2014) Science of the Total Environment, 481 (1), pp. 232-241

[29] Tran, T.H., Govin, A., Guyonnet, R., Grosseau, P., Lors, C., GarciaDiaz, E., Damidot, D., Devès, O., Ruot, B. Influence of the intrinsic characteristics of mortars on biofouling by Klebsormidium flaccidum (2012) International Biodeterioration and Biodegradation, 70, pp. 31-39

[30] Manso, S., De Muynck, W., Segura, I., Aguado, A., Steppe, K., Boon, N., De Belie, N. Bioreceptivity evaluation of cementitious materials designed to stimulate biological growth (2014) Science of the Total Environment, 481 (1), pp. 232-241

[31] Rodríguez-Mora, O. Morteros para fábricas. (2004) Asociación nacional de fabricantes de mortero, ISBN 978-84-612-5455-2

[32] Litchtner, B., Hundt, J. Medidas de porosidad en morteros de cemento y en hormigón (1974) Materiales de construcción, 24, n¹53

[33] Manso, S., De Muynck, W., Segura, I., Aguado, A., Steppe, K., Boon, N., De Belie, N. Bioreceptivity evaluation of cementitious materials designed to stimulate biological growth (2014) Science of the Total Environment, 481 (1), pp. 232-241

[34] Cruz, M., Beckett, R. Bioreceptive design: A novel approach to biodigital materiality (2016) Architectural Research Quarterly, 20 (1), pp. $51-64$

[35] Elisabeth Barreda y Felipe Osorio. Briófitas: musgos, hepáticas y antocerotes. Biodiversidad de Chile, Patrimonio y desafíos. (340-344)

[36] Botánica y Temas de Ecología Vegetal. Briófitos (musgos, hepáticas y antoceros). http://www.aulados.net/

[37] Larcher, W. Ecofisiología vegetal (1999) ISBN: 9788428202893

[38] Martínez, J., Núñez, E. Los briófitos: plantas diminutas al borde del masoquismo (2004) Páginas de información ambiental, 17, pp. 24-28. 
[39] Belén Estébanez Pérez, Isabel Draper y Díaz de Atauri, Rafael Medina Bujalance. Briófitos: una aproximación a las plantas terrestres más sencillas (2011) Memorias R. Soc. Esp. Hist. Nat., 2ª ép., 9, 2011

[40] Botánica y Temas de Ecología Vegetal. Briófitos (musgos, hepáticas y antoceros). http://www.aulados.net/

[41] Fletcher, M. Moss grower's handbook (1991) ISBN 095171760 X

[42] Rams Sánchez, S. ¿Para qué siven los musgos después de navidad? Primera parte. El papel ecológico de los briófitos. (2008) Eubactera 15-18

[43] González S. Los musgos, una reliquia colonizadora, activa y protegida (2007) http://www.madrimasd.org/blogs/universo/

[44] Martínez, J., Núñez, E. Los briófitos: plantas diminutas al borde del masoquismo (2004) Páginas de información ambiental, 17, pp. 24-28.

[45] DeLuca, T.H, Zackrisson, O., Gentili, F, Sellstedt, A., Nilsson, M.-C. Ecosystem controls on nitrogen fixation in boreal feather moss communities. (2007) Oecologia, 152: 121-130.

[46] Glime, J. M. Economic and Ethnic Uses of Bryophytes. (2007) Flora of North America Editorial Committee, eds

[47] Íbid

[48] Soria, A. Ron, E. Datos para el conocimiento de la flora briológica urbana de la ciudad de Logroño. (1987) Comunicación del VII Simposio Nacional de Botánica Criptogámica. Madrid

[49] Moss Acres. http://www.mossacres.com

[50] Moss Milkshake. http://www.mossmilkshake.com/

[51] Martin, A. Moss gardening. (2015) ISBN 978-1-60469-560-1

[52] Fletcher, M. Moss grower's handbook. (1991) ISBN 095171760 X

[53] Furness, S.B., Grime, J.P. Growth rate and temperature responses in bryophytes. II. A comparative study of species of contrasted ecology. (1982) Journal of Ecology, 70 (2), pp. 525-536

[54] Zechmeister, H.G. Annual growth of four pleurocarpous moss species and their applicability for biomonitoring heavy metals (1998) Environmental Monitoring and Assessment, 52 (3), pp. 441-451

[55] Moss and Stone gardens Understanding the growth rate of pleurocarps versus acrocarps http://www.mossandstonegardens.com/

[56] Beike, A.K., Spagnuolo, V., Lüth, V., Steinhart, F., Ramos-Gómez, J., Krebs, M., Adamo, P., Rey-Asensio, A.I., Angel Fernández, J., Giordano, S., Decker, E.L., Reski, R.

Clonal in vitro propagation of peat mosses (Sphagnum L.) as novel green resources for basic and applied research (2015) Plant Cell, Tissue and Organ Culture, 120 (3), pp. 1037-1049 


\section{Capítulo 5. Metodología experimental}

En el presente capítulo se detallan los ensayos y procesos utilizados para llevar a cabo la caracterización tanto del mortero MPC elaborado en la presente tesis, así como los ensayos llevados a cabo para la colonización vegetal de la superficie y su cuantificación.

A partir de la bibliografía recogida en el estado del arte, se planifica una metodología experimental para analizar tanto las características de un mortero de magnesio fosfato con agregados de escorias negras de horno eléctrico de arco (EAFS), como un procedimiento para cuantificar la bio-receptividad del producto en sí.

El objetivo final es la consecución de un material bio-receptivo en cuya elobaración se incluyan varios componentes procedentes de subproductos de procesos industriales.

El proceso experimental llevado a cabo se ha desarrollado en dos fases diferenciadas:

a) Caracterización del mortero MPC

b) Determinación de la bio-receptividad del mortero

\section{Caracterización del mortero MPC}

En esta sección se detalla la tecnología y los procedimientos que se han empleado para conseguir una caracterización del mortero MPC utilizado como soporte.

\subsection{Ensayos físicos}

\subsubsection{Densidad aparente}

Tanto los morteros MPC como los cementos CBPC no disponen una normativa específica que determine el procedimiento a seguir para determinar sus propiedades, máxime cuando estos a su vez contienen subproductos industriales o residuos.

Para la determinación de la densidad aparente del mortero MPC endurecido se utiliza la norma europea UNE-EN 1015-10, parte 10 [1], de determinación de la densidad aparente en seco del mortero endurecido. Se estima que esta normativa define el ensayo que más puede encajar con la casuística del mortero MPC, aunque a continuación se explica exactamente el procedimiento llevado a cabo. 


\section{Equipo empleado}

Para el ensayo se requiere el siguiente instrumental:

\section{- Balanza electrónica}

Cobos Precisión, serie CS, modelo D-4000.

Capacidad máxima $4.100 \mathrm{~g}$

Precisión $\pm 0,1 \mathrm{~g}$

- Estufa de secado

Estufa J.P. Selecta, modelo Digitronic TFT 145 I

Temperatura $+5^{\circ} \mathrm{C}$ (temperatura ambiente) hasta $250{ }^{\circ} \mathrm{C}$.

Precisión $\pm 2 \%$
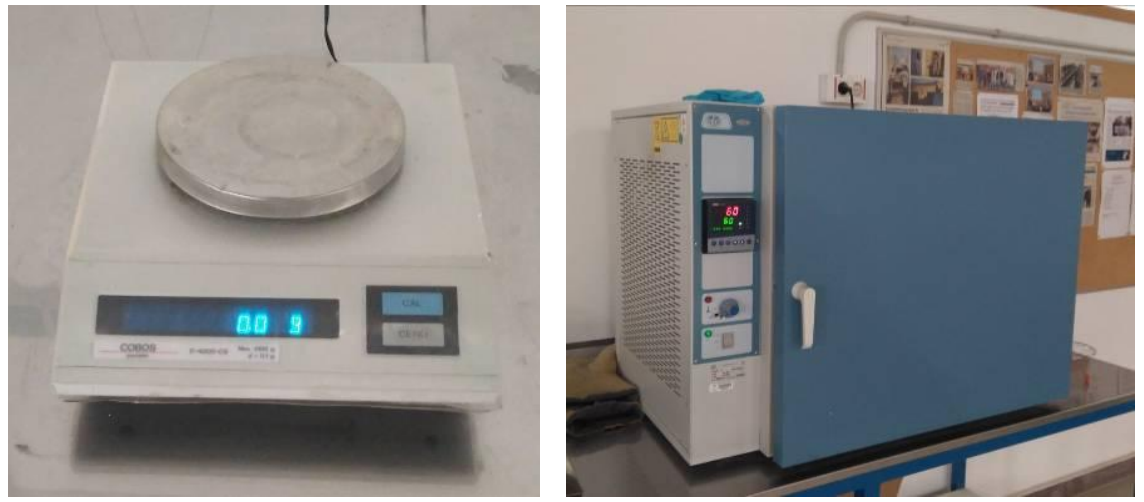

Imagen 56. Equipo empleado

\section{Fundamento}

La densidad aparente en seco de un mortero endurecido se obtiene al dividir su masa en estado seco (en estufa) por el volumen que ocupa cuando se sumerge en agua, en estado saturado.

$$
V s=\frac{m s, s a t-m s, i}{\rho w}
$$

\section{Procedimiento operatorio}

- Se emplean probetas de forma rectangular.

- Estas probetas se han secado en estufa a temperara de $80^{\circ} \mathrm{C}$ durante 12 horas hasta obtener un valor de masa constante.

- Las probetas se han sumergido en agua a temperatura ambiente $\left(20^{\circ} \mathrm{C} \pm 2^{\circ} \mathrm{C}\right)$ hasta que no se observa variación en la masa, después de sucesivas pesadas.

- El peso saturado sumergido se haya mediante pesada hidrostática. Una vez saturada y sumergida se espera a una estabilización y se anota el valor.

- La densidad aparente es la media aritmética de los valores ensayados.

\section{Desviaciones respecto del procedimiento}

- La norma UNE-EN 1015-10, parte 10 indica un procedimiento concreto para el amasado y la elaboración de las probetas. Sin embargo la problemática a la hora de elaborar el mortero MPC, 
expresado en el capítulo de caracterización, hace que no haya sido posible llevar a cabo este procedimiento.

- Las probetas empleadas no han podido ser de la forma que se recoge en la norma EN 1015-11, y se han utilizado semiprobetas procedentes de otros ensayos 0 probetas de dimensiones $50 \times 50 \times 50 \mathrm{~mm}$.

- El secado de las muestras se ha realizado en una estufa a temperatura de $80^{\circ} \mathrm{C} \pm 2^{\circ} \mathrm{C}$.
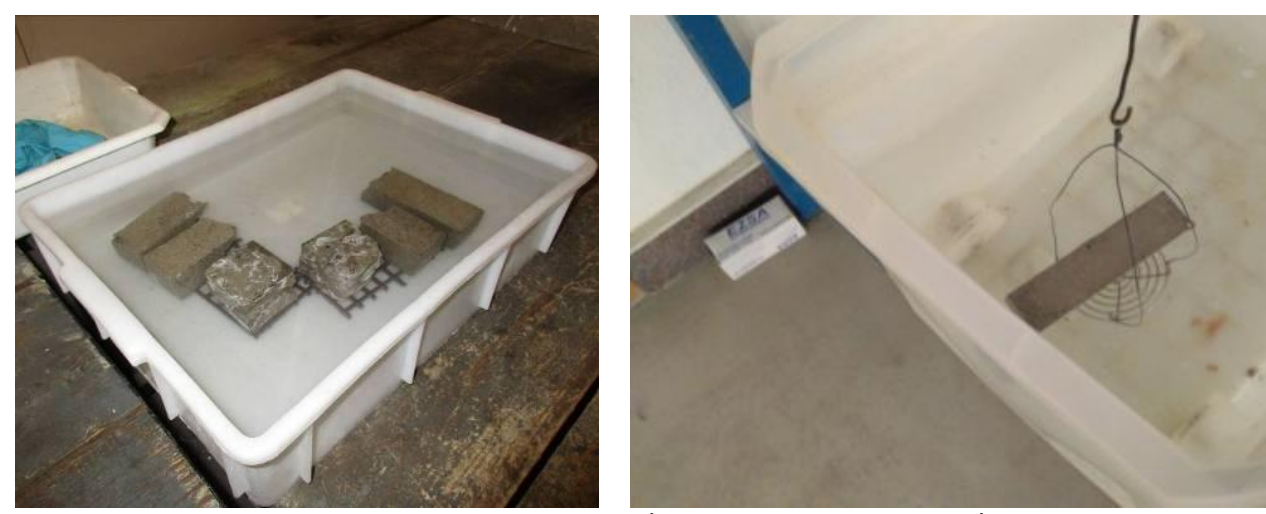

Imagen 57. Probetas en agua hasta saturación y en balanza hidrostática

\subsubsection{Absorción de agua}

Al igual que en el resto de propiedades físicas, los morteros MPC no disponen una normativa específica que determine el procedimiento a seguir para determinar sus propiedades.

Para la determinación del coeficiente de absorción del mortero MPC se utiliza la norma europea UNE-EN 1015-18, parte 18 [2], de determinación del coeficiente de absorción de agua por capilaridad del mortero endurecido.

Esta normativa determina el ensayo que más puede encajar con la casuística del mortero MPC.

\section{Equipo empleado}

Para el ensayo se requiere el siguiente instrumental:

- Balanza electrónica

Cobos Precisión, serie CS, modelo D-4000.

Capacidad máxima $4.100 \mathrm{~g}$

Precisión $\pm 0,1 \mathrm{~g}$

- Estufa de secado

Estufa P. Selecta, modelo Digitronic TFT 145 I

Temperatura $+5^{\circ} \mathrm{C}$ (temperatura ambiente) hasta $250{ }^{\circ} \mathrm{C}$.

Precisión $\pm 2 \%$

- Cronómetro

bq aquaris $U$ Plus.

Precisión $\pm 0,01 "$ 


\section{Fundamento}

El coeficiente de absorción de agua por capilaridad es la pendiente de la recta que une los puntos representativos de las medidas tomadas después de 10 minutos y después de 90 minutos.

$$
C=0,1(M 2-M 1) \mathrm{kg} / \mathrm{m}^{2} \cdot \mathrm{min}^{0,5}
$$

\section{Procedimiento operatorio}

- Se emplean probetas de forma regular.

- Estas probetas se han secado en estufa a temperara de $80^{\circ} \mathrm{C}$ durante 12 horas hasta obtener un valor de masa constante.

- Seguidamente se rompen las probetas por flexión.

- Las probetas se introducen en un recipiente con soportes que permitan mantener la probeta con la cara de rotura sumergida en $7 \mathrm{~mm}$ de agua durante la duración del ensayo. El recipiente se tapa para evitar la evaporación de agua.

- Se mantiene el nivel de agua constante durante todo el ensayo.

- Se retiran las probetas del recipiente después de 10 minutos. Se elimina el agua superficial con un paño humedecido y se pesa la probeta.

- Se repite el proceso a los 90 minutos.
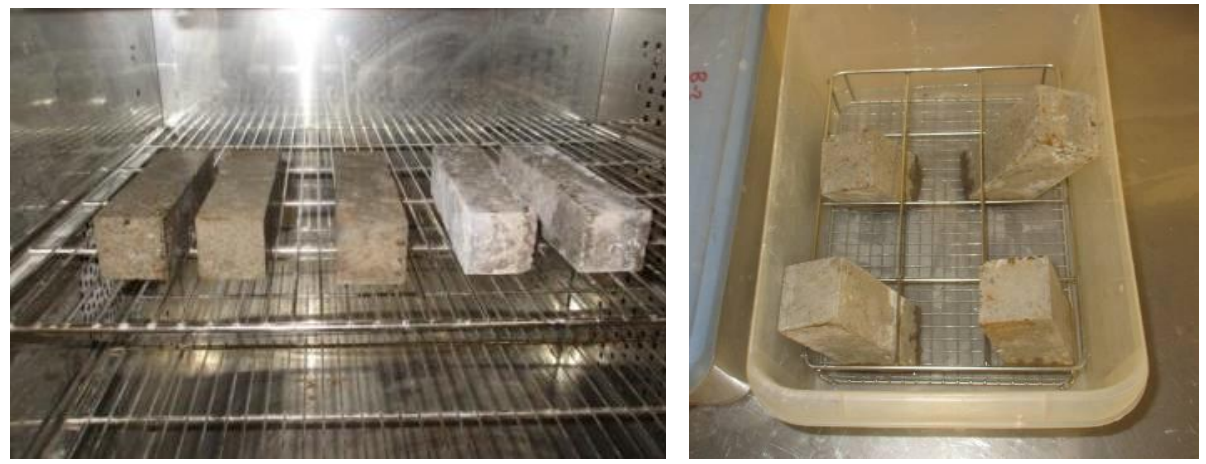

Imagen 58. Probetas en estufa y en recipiente con agua

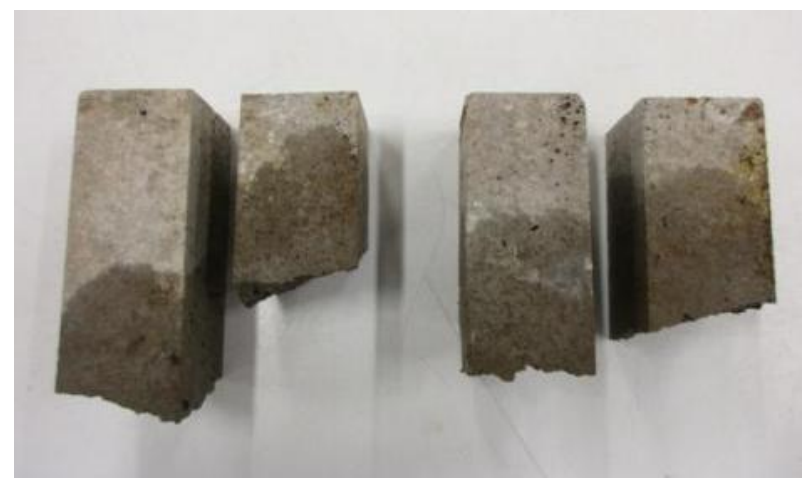

Imagen 59. Probetas al final del ensayo

\section{Desviaciones respecto del procedimiento}

- El secado de las muestras se ha realizado en una estufa a temperatura de $80^{\circ} \mathrm{C} \pm 2^{\circ} \mathrm{C}$. 


\subsection{Características químicas}

\subsection{1. $\mathrm{pH}$}

Para la medición del $\mathrm{pH}$ se sigue el procedimiento habitual llevado a cabo y que se describe en el procedimiento operatorio.

\section{Equipo empleado}

Para el ensayo se requiere el siguiente instrumental:

- Medidor $\mathrm{pH}$

Crison modelo Basic 20

Precisión $\pm 0,01$

Calibración se emplean tampones de $\mathrm{pH}$ 4,00 y 7,02.

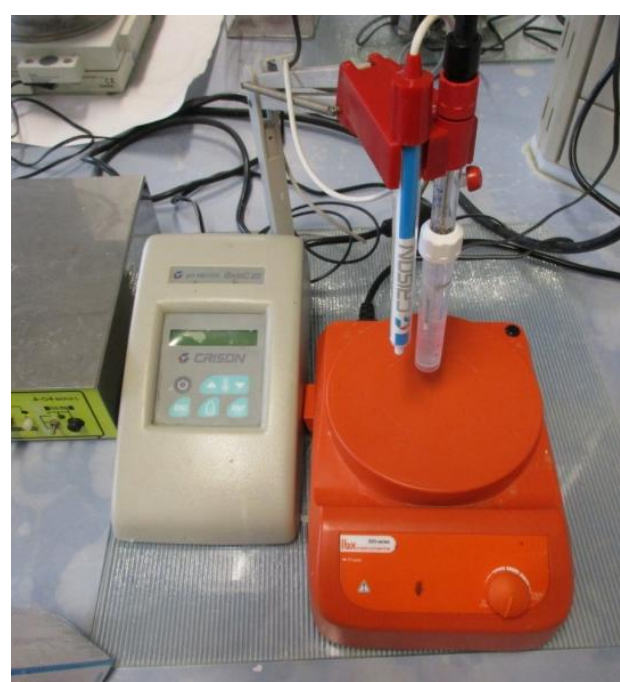

Imagen 60. Medidor pH

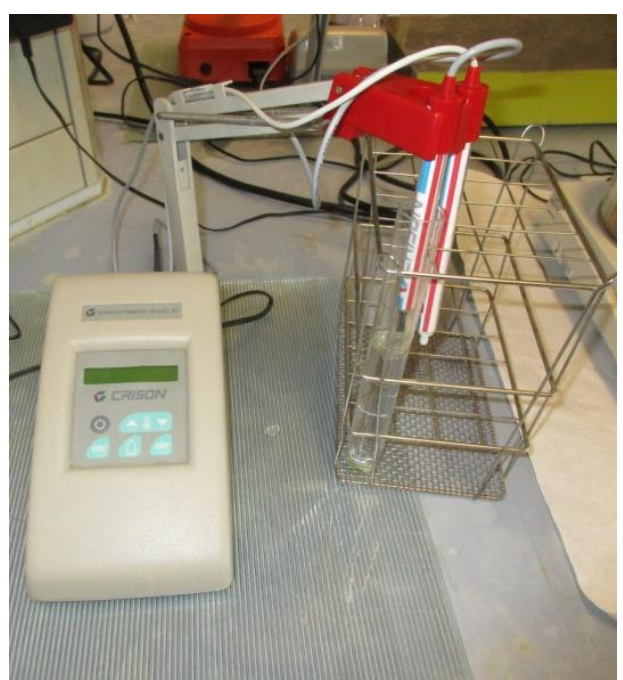

Imagen 61. Conductímetro

\section{Procedimiento operatorio}

- Se introducen las placas en recipiente plástico de $13 \times 15 \times 20 \mathrm{~cm}$ con $200 \mathrm{ml}$ de agua destilada.

- Se mide el pH a los 0, 1, 2 y 8 días.

- El valor 0 corresponde con el pH del agua destilada: 7,04

\subsubsection{Conductividad eléctrica}

Para la medición de la conductividad eléctrica se sigue el procedimiento llevado a cabo en el ensayo de $\mathrm{pH}$.

\section{Equipo empleado}

Para el ensayo se requiere el siguiente instrumental:

\section{- Conductimetro}

Crison modelo Basic 30

Precisión $\pm 0,01 \mu S$

Calibración se emplean estándares de 1,413 y 12,88dS/m. 


\section{Procedimiento operatorio}

- Se introducen las placas en un recipiente plástico de $13 \times 15 \times 20 \mathrm{~cm}$ con $200 \mathrm{ml}$ de agua destilada.

- Se mide la conductividad eléctrica a los 0, 1, 2 y 8 días.

- El valor 0 corresponde con la conductividad eléctrica del agua destilada: 0,0224 dS/m

\subsection{Características mecánicas}

Al igual que en las propiedades físicas, los morteros MPC no disponen una normativa específica que determine el procedimiento a seguir para determinar sus propiedades mecánicas.

Para la determinación de las resistencias mecánicas, tanto a flexión como a compresión, se utiliza la norma UNE-EN 1015-11, parte 11 [3], de determinación de la resistencia a flexión y compresión del mortero endurecido.

\subsubsection{Resistencia a flexión}

\section{Equipo empleado}

Para el ensayo se requiere el siguiente instrumental:

- Dispositivo de carga

Suzpecar - Sistemas de ensayos modelo MEM 101/SDC

Equipo de conexión digital.

Precisión $\pm 0,5 \%$

\section{- Estufa de secado}

Estufa J.P. Selecta, modelo Digitronic TFT 145 I

Temperatura $+5^{\circ} \mathrm{C}$ (temperatura ambiente) hasta $250{ }^{\circ} \mathrm{C}$.

Precisión $\pm 2 \%$

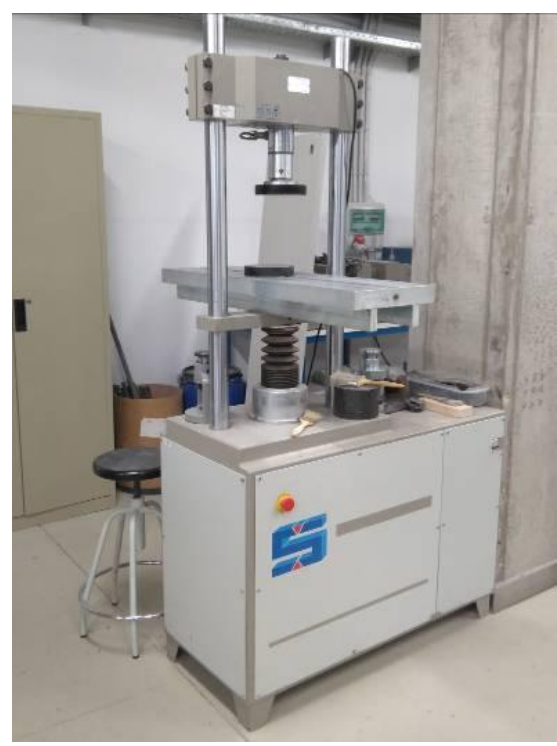

Imagen 62. Dispositivo de carga 


\section{Fundamento}

La resistencia a flexión se determina aplicando una carga en tres puntos de los prismas enmoldados de mortero endurecido hasta su rotura.

La resistencia a flexión de la probeta, $f$, se calcula por medio de la expresión:

$$
f=1,5 \frac{F l}{b d^{2}}
$$

donde $b$ y $d$ son las dimensiones interiores del molde

\section{Procedimiento operatorio}

- Se emplean probetas de forma rectangular de dimensiones $4 \times 4 \times 16 \mathrm{~cm}$.

- Estas probetas se han secado en estufa a temperara de $50^{\circ} \mathrm{C} \pm$ $2^{\circ} \mathrm{C}$ durante 12 horas hasta obtener un valor de masa constante.

- La probeta se coloca entre dos rodillos de apoyo de acero, separados entre ejes una longitud de 100,00 mm 0,5 mm. La probeta se dispone dejando la cara sin moldar perpendicular a la carga. El tercer rodillo, que transmite la carga, se instala entre los rodillos de apoyo.

- La carga se aplica sin aceleraciones y se aumenta progresivamente a un ritmo comprendido entre $50 \mathrm{~N} / \mathrm{s}$ y $500 \mathrm{~N} / \mathrm{s}$ de tal modo que la rotura se produzca entre $30 \mathrm{~s}$ y $90 \mathrm{~s}$.
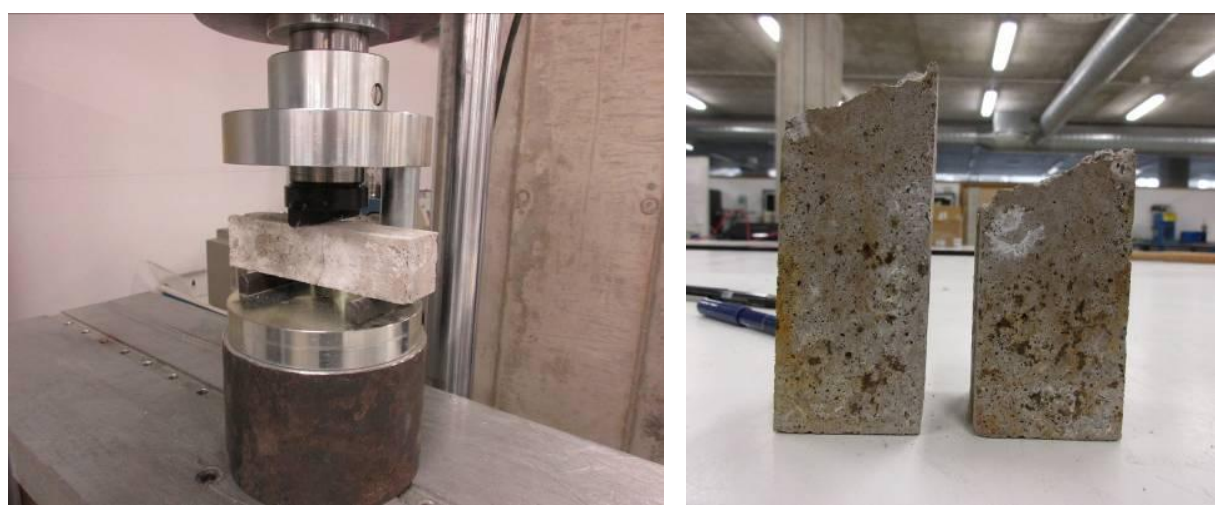

Imagen 63. Equipo empleado y probeta ensayada

\section{Desviaciones respecto del procedimiento}

- La norma UNE-EN 1015-11, parte 11 indica un procedimiento concreto para la elaboración de las probetas y los moldes necesarios. Sin embargo la problemática a la hora de elaborar el mortero MPC, expresado en el capítulo de caracterización, hace que haya sido necesario descartar la utilización de moldes metálicos y utilizar unos con acabado plástico para evitar la adherencia al mismo.

- La norma indica que las probetas se ensayarán pasados 28 días, sin embargo, dado el tipo de mortero, estos se ensayan a los 7 días de su fabricación, habiendo llegado en ese punto a su máxima resistencia. 


\subsubsection{Resistencia a compresión}

\section{Equipo empleado}

Para el ensayo se requiere el siguiente instrumental:

\section{- Dispositivo de carga}

Suzpecar - Sistemas de ensayos modelo MEM 101/SDC

Equipo de conexión digital.

Precisión $\pm 0,5 \%$

\section{- Estufa de secado}

Estufa P. Selecta, modelo Digitronic TFT 145 I

Temperatura $+5{ }^{\circ} \mathrm{C}$ (temperatura ambiente) hasta $250{ }^{\circ} \mathrm{C}$.

Precisión $\pm 2 \%$

\section{Fundamento}

La resistencia a compresión se determina aplicando una carga sobre dos superficies opuestas del prisma hasta su rotura.

Las resistencia a compresión se calcula dividendo la carga máxima soportada entre su sección transversal.

$$
c=\frac{F}{b \cdot d}
$$

\section{Procedimiento operatorio}

- Se emplean cada una de las dos mitades (semiprismas) resultantes del ensayo de la resistencia a flexión.

- Estas probetas se han secado en estufa a temperara de $50^{\circ} \mathrm{C} \pm$ $2^{\circ} \mathrm{C}$ durante 12 horas hasta obtener un valor de masa constante.

- Se colocan los semiprismas de tal modo que la extremidad enmoldada se sitúa a $16 \mathrm{~mm} \pm 0,1 \mathrm{~mm}$ del borde más próximo de los platos o de la placa de carga. La probeta se alinea, cuidadosamente de tal modo que la carga se aplique en todo el ancho de las caras en contacto con los platos

- La carga se aplica sin aceleraciones y se aumenta progresivamente a un ritmo comprendido entre $50 \mathrm{~N} / \mathrm{s}$ y $500 \mathrm{~N} / \mathrm{s}$ de tal modo que la rotura se produzca entre $30 \mathrm{~s}$ y $90 \mathrm{~s}$.

\section{Desviaciones respecto del procedimiento}

- La norma UNE-EN 1015-11, parte 11 indica un procedimiento concreto para la elaboración de las probetas y los moldes necesarios. Sin embargo la problemática a la hora de elaborar el mortero MPC, expresado en el capítulo de caracterización, hace que haya sido necesario descartar la utilización de moldes metálicos y utilizar unos con acabado plástico para evitar la adherencia al mismo.

- La norma indica que las probetas se ensayarán pasados 28 días, sin embargo, dado el tipo de mortero, estos se ensayan a los 7 días de su fabricación, habiendo llegado en ese punto a su máxima resistencia. 

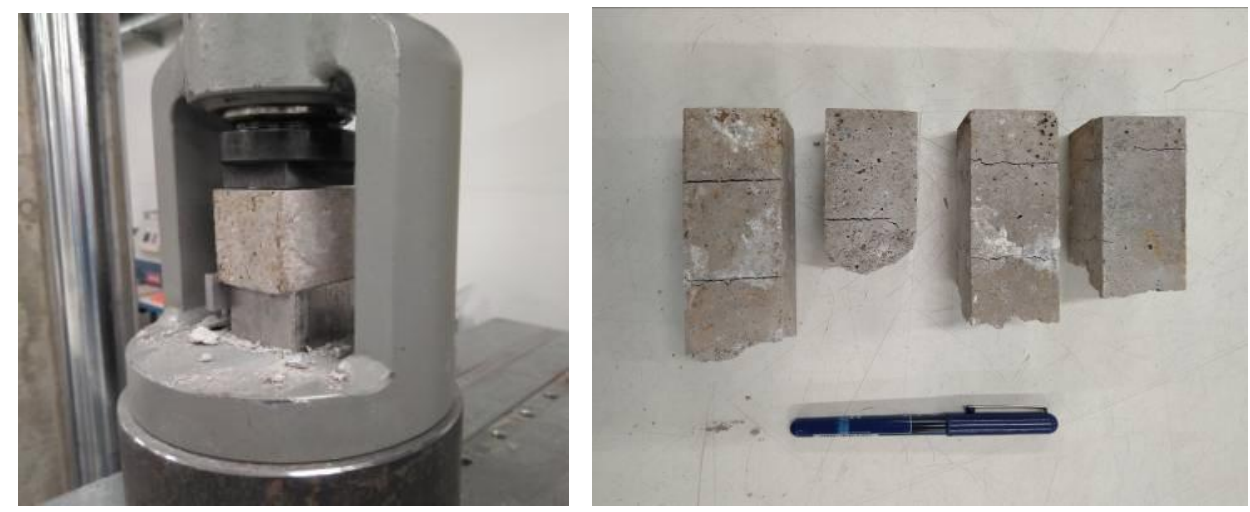

Imagen 64. Equipo empleado y probeta ensayada

\subsection{Durabilidad}

\subsubsection{Heladicidad}

Al igual que en las anteriores propiedades, los morteros MPC no disponen una normativa específica que determine el procedimiento a seguir para determinar sus propiedades.

Para determinar la heladicidad del mortero MPC se utiliza las normas UNE-67028-EX [4], de ensayo de heladicidad en ladrillos cerámicos de arcilla cocida y la norma UNE-EN 12371:2011 de determinación de la resistencia a heladicidad de la piedra natural.

Si bien ambas normativas difieren en el material en sí que se ensaya, una determina un ensayo que se considera aplicable para el tipo de mortero de la presente investigación y la otra una expresión más entendible de los resultados.
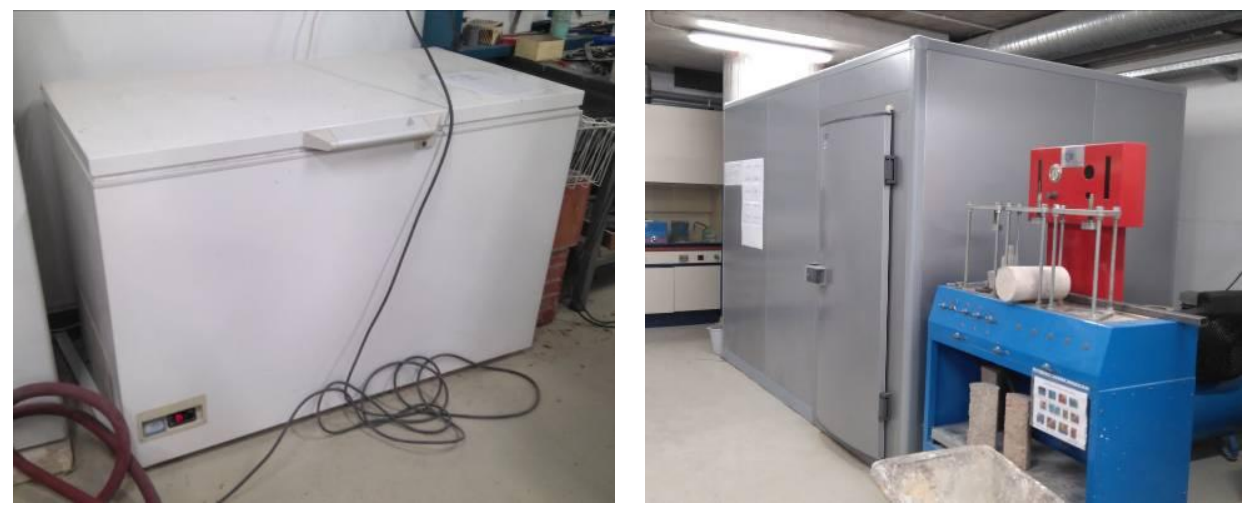

Imagen 65. Equipo utilizado en el ensayo

\section{Equipo empleado}

Para el ensayo se requiere el siguiente instrumental:

- Arcón congelador

P. Selecta, modelo Combatemp

Rango $-14{ }^{\circ} \mathrm{C}$ a $-28^{\circ} \mathrm{C}$

Precisión $\pm 0,5^{\circ} \mathrm{C}$

\section{- Cámara de curado}

Modelo Matrix 


\section{Fundamento}

El comportamiento de cualquier material frente a la acción del proceso hielo-deshielo provoca una pérdida de volumen que lleva aparejado una disminución en las resistencias mecánicas.

\section{Procedimiento operatorio}

- Se emplean probetas de forma regular de dimensiones $4 \times 4 \times 16 \mathrm{~cm}$.

- Estas probetas se disponen en el tanque de deshielo durante 48 horas a una temperatura de $15^{\circ} \mathrm{C} \pm 5^{\circ} \mathrm{C}$.

- Transcurridas 48 horas se sacan del agua, se dejan escurrir un minuto, introduciéndose en la cámara frigorífica a $-15^{\circ} \mathrm{C} \pm 5^{\circ} \mathrm{C}$ durante 18 horas.

- Seguidamente se sacan de la cámara frigorífica y se introducen en el tanque de deshielo durante 6 horas.

- Este ciclo hielo-deshielo se repite 15 veces.

- Durante las interrupciones las probetas se mantendrán en cámara frigorífica $a-15^{\circ} \mathrm{C} \pm 5^{\circ} \mathrm{C}$.

- Los resultados se observan por comparación de los siguientes parámetros:

- Densidad aparente por comparación antes del ensayo, a los 6 ciclos y al finalizar

- Resistencias a flexión y compresión por comparación entre la resistencia establecida del mortero y las obtenidas al finalizarlo.
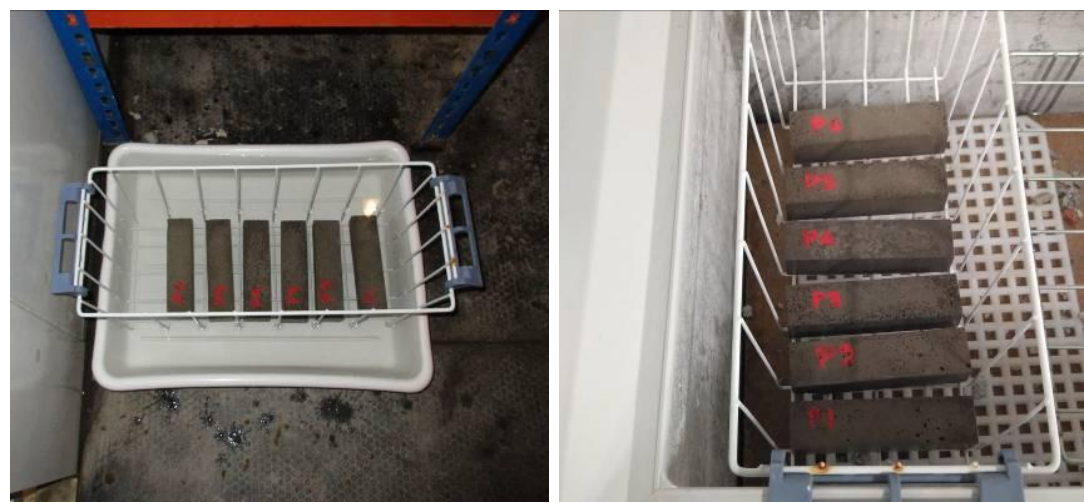

Imagen 66. Probetas en tanque de deshielo y cámara frigorífica

\section{Desviaciones respecto del procedimiento}

- El número de ciclo hielo-deshielo difiere del establecido en la UNE-EN 12371:2011, reduciéndose a 15 ciclos.

- Para el ensayo se han utilizado dos probetas de cada tipo, en vez de las seis que propone. 


\section{Caracterización conjunto soporte + briófito}

\subsection{Implantación briófito}

\subsubsection{Batido de musgo}

Para el enraizamiento del briófito en la superficie de la placa de mortero MPC mediante el denominado "batido de musgo" se opta por la solución nutritiva empleada en el "Bio-ceramic system" [5] proyecto llevado a cabo por Luna, l. et al.

Los productos empleados son los siguientes:

- Brotes adultos verdes de antitrichia curtipendula

- Cerveza

- Yogurt

- Azúcar

Todos los productos empleados son de marca blanca, disponibles en cualquier supermercado.

La dosificación de la solución nutritiva es la siguiente:

$\begin{array}{cc}\text { Producto } & \text { Cantidad } \\ \text { Musgo } & 25 \mathrm{gr} . \\ \text { Cerveza } & 100 \mathrm{ml} . \\ \text { Yogurt } & 25 \mathrm{ml} \\ \text { Azúcar } & 70 \mathrm{gr}\end{array}$

Tabla 5. Composición nutritiva del batido de musgo

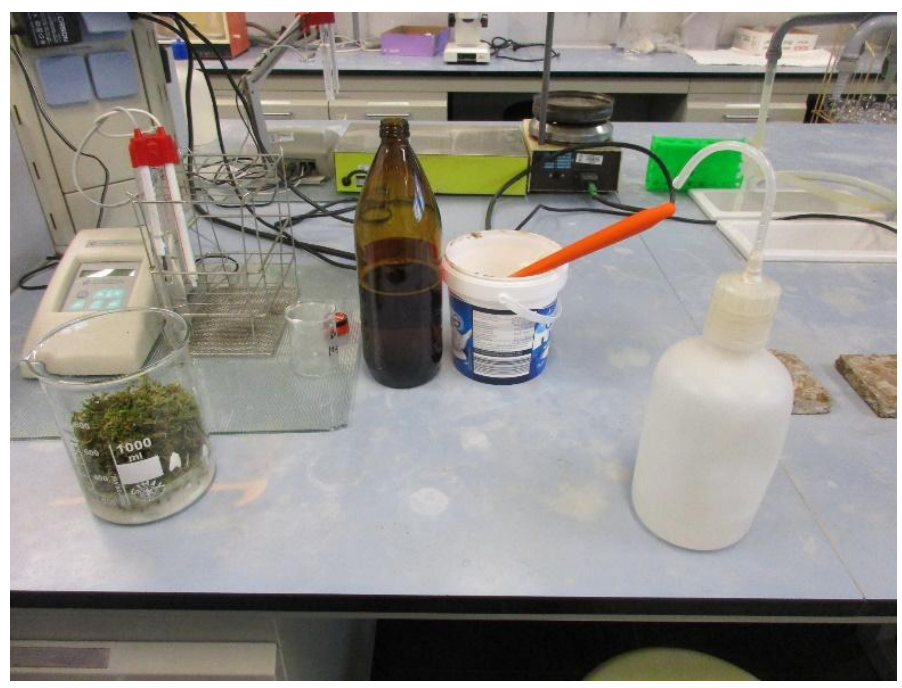

Imagen 67. Productos solución nutritiva

\section{Equipo empleado}

Para el ensayo se requiere el siguiente instrumental:

\section{- Balanza electrónica}

Sartorius, BP 610. 
Capacidad máxima $610 \mathrm{~g}$

Precisión $\pm 0,01 \mathrm{~g}$

- Batidora doméstica
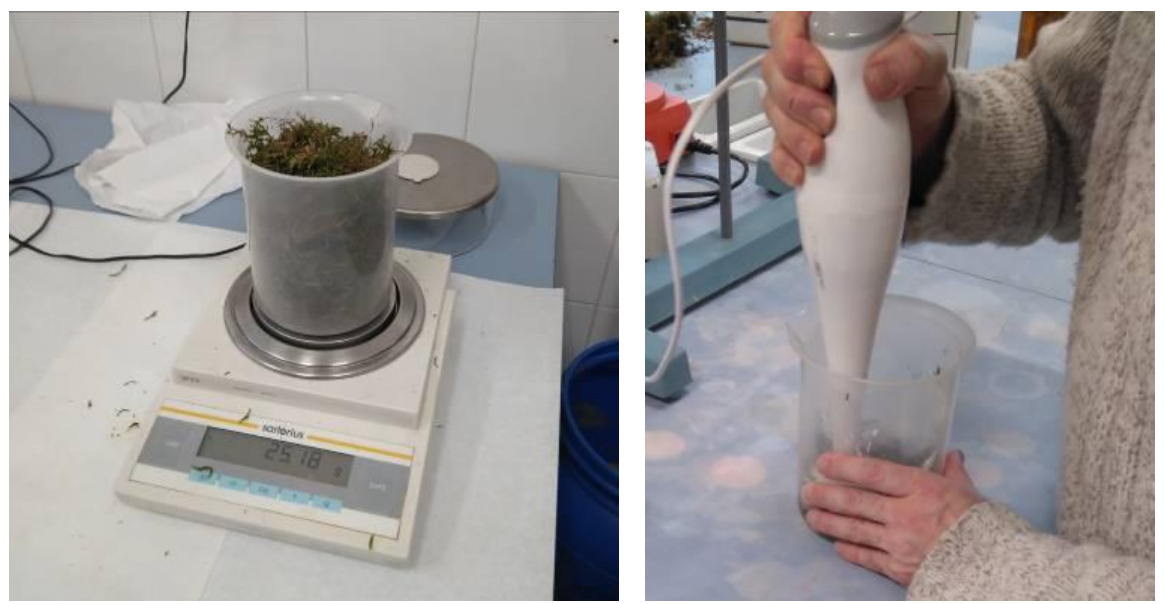

Imagen 68. Equipo utilizado
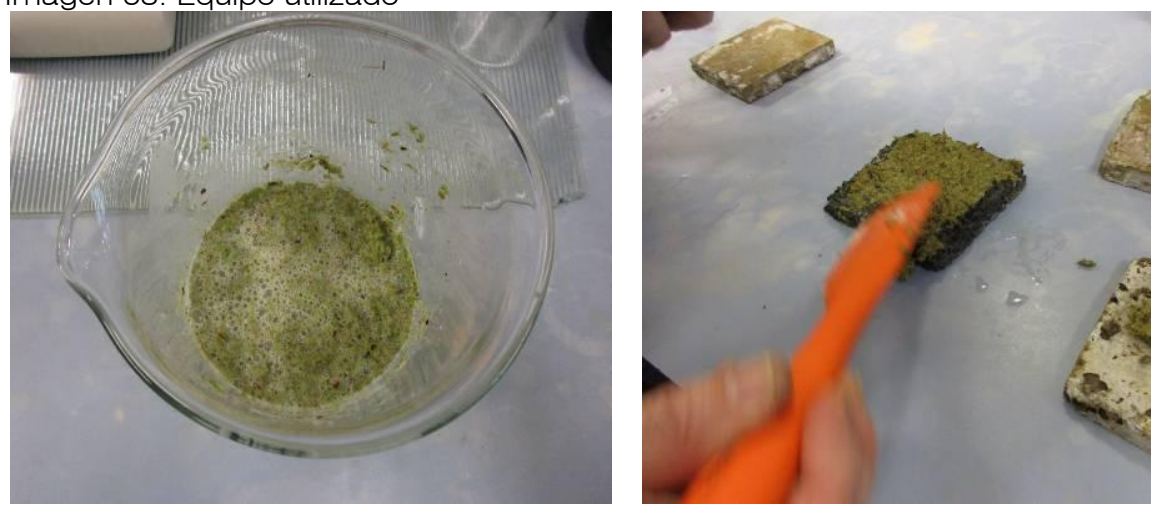

Imagen 69. Batido y su diseminación sobre placa

\section{Procedimiento operatorio}

- Antes de la elaboración del batido se procede a una esterilización de las placas mediante baño de agua caliente y lejía en una concentración de un $5 \%$, durante 5 minutos. Pasados los cinco minutos se deslavan las placas y se dejan otros cinco minutos en remojo en agua caliente.

- Se seleccionan brotes verdes adultos húmedos y se disponen en un envase.

- Se vierte sobre el briófito el resto de los componentes: cerveza, yogurt y azúcar.

- Se bate todo el conjunto hasta conseguir una mezcla medianamente homogénea y de consistencia fluida pero no líquida.

- Con ayuda de una paleta se dispone la mezcla conseguida sobre la superficie de la placa, intentado un reparto uniforme.

\subsubsection{Ejemplares adultos}

Para el enraizamiento del briófito en la superficie de la placa de mortero MPC mediante la utilización de ejemplares adultos no existe un 
procedimiento estandarizado. Sin embargo, en base a consultas realizadas a distintos briólogos se ha establecido una pequeña operativa.
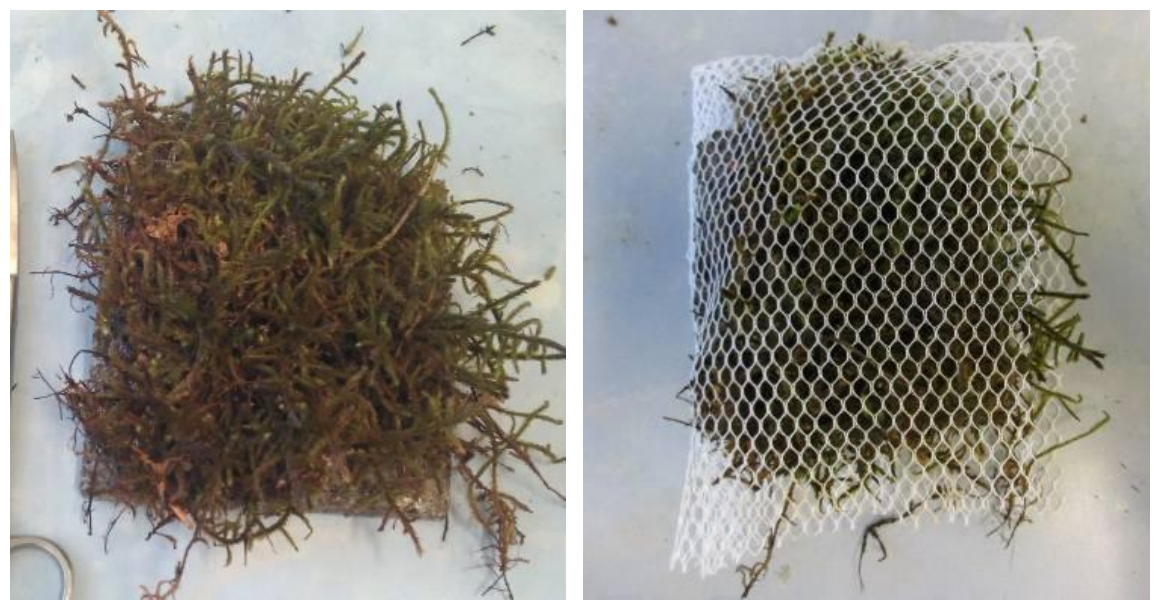

Imagen 70. Procedimiento operatorio

\section{Procedimiento operatorio}

- Se seleccionan brotes verdes adultos húmedos y se disponen sobre la superficie. Estos se presionan fuertemente, para una mayor fricción entre el briófito y el soporte.

- Una vez se ha cubierto toda la superficie de la placa con brotes de briófitos, se introduce el conjunto en una malla de tela de rejilla amplia. Esta malla se afianza a la superficie para que quede bien fijado el musgo, mediante una o varias bridas.

\subsection{Evaluación bio-receptividad con mico-algas}

Para la evaluación de la bio-receptividad del mortero MPC con microalgas se dispone las muestras de mortero MPC en un canal en el que recircula agua con varias especies de microalgas inoculadas.

Dado el escaso tiempo del que se dispone para el ensayo, es imposible el montaje de una infraestructura que permita un seguimiento fotográfico mediante LabVIEW [6] como correspondería. El seguimiento fotográfico se realizará mediante apreciación visual de la secuencia de fotos dispuestas en idénticas condiciones.

También se realizarán dos pesadas de la biomasa generada, una vez se ha extraído y se ha eliminado el agua presente en ella. De esta manera se puede determinar el peso total de la biomasa generado por superficie y día.

\section{Equipo empleado}

Para el ensayo se requiere el siguiente instrumental:

\section{- Canal de agua}

El canal de agua utilizado ha sido diseñado por Miñón, J. dentro del proyecto "IntegralCarbon. Desarrollo e implementación integrada de fotobioreactores de captura de gases de efecto invernadero en agroindustria" [7]

Este canal se utiliza para la optimización en el cultivo de algas. Éste se compone de tres planos (Imagen 71): 
a) Plano de transición. Plano paralelo a la superficie del suelo donde desagua la bomba y que tiene la función de reducir la turbulencia de la lámina de agua posterior a su vertido sobre el plano de monitorización.

b) Plano de monitorización. Plano inclinado $45^{\circ}$ respecto a la superficie del suelo donde se ancla la malla de crecimiento.

c) Plano de recepción. Este plano queda paralelo al plano de transición y permite regular la lámina de agua que está discurriendo por el plano de monitorización. [8]
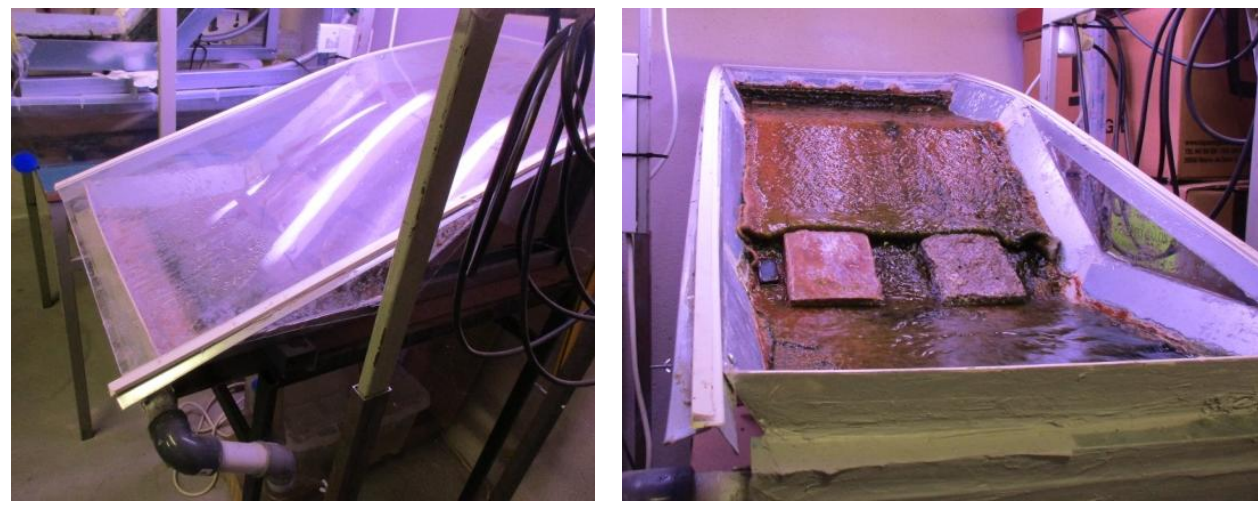

Imagen 71. Canal de agua para cultivo de microalgas
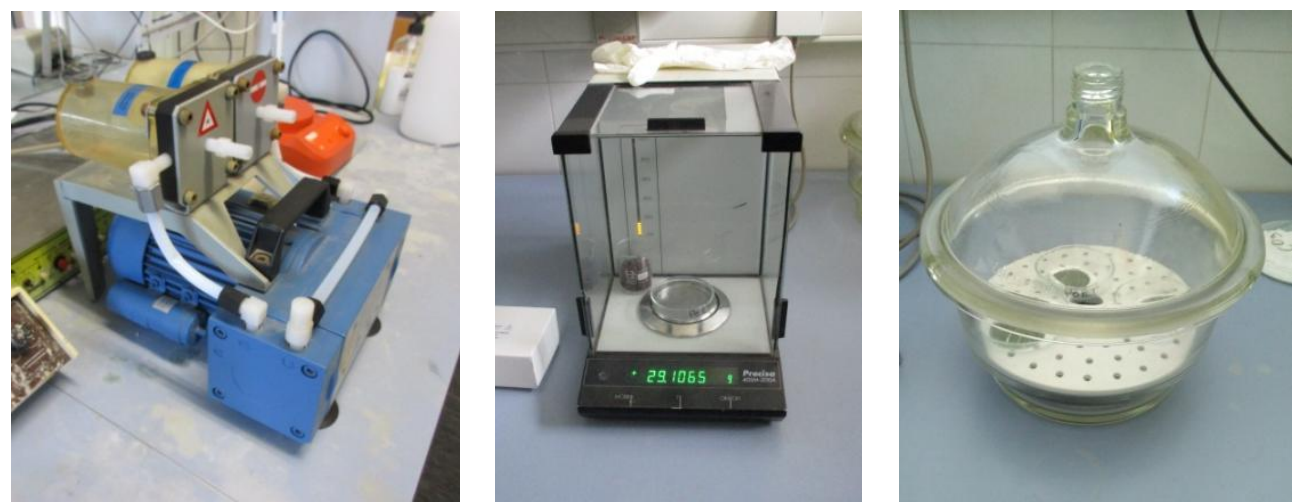

Imagen 72. Equipo utilizado

- Balanza electrónica de precisión

Marca Precisa, modelo 40SM-200A

Capacidad máxima $200 \mathrm{~g}$

Precisión $\pm 0,0001 \mathrm{~g}$

- Bomba de vacío de membrana

Marca Vacuubrand, modelo MZ-2C

Caudal máximo 1,7 m³/h

Presión final 9 mbar

- Campana de cristalización

\section{Fundamento}

El crecimiento de microalgas en el canal de agua, sobre una superficie de un mortero MPC supone determinar la bio-compatibilidad del material de soporte con la vida vegetal y por tanto su bio-receptividad. 


\section{Procedimiento operativo}

- Disposición de las placas al final del plano de transición permitiendo que la totalidad del agua bañe la superficie de la placa.

- Cada diez días se realiza un seguimiento fotográfico para determinar si existe o no crecimiento en la superficie. También se altera la posición de la placa, dentro del mismo plano para que las placas queden expuesta de igual manera a la corriente de agua.
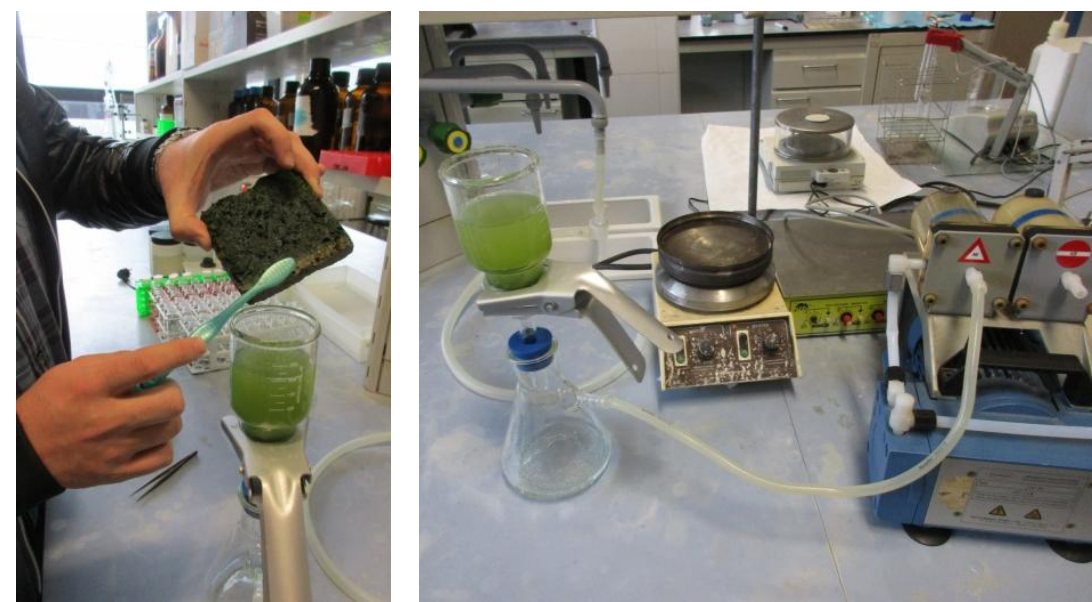

Imagen 73. Cepillado superficie (izda) y filtrado (dcha.)
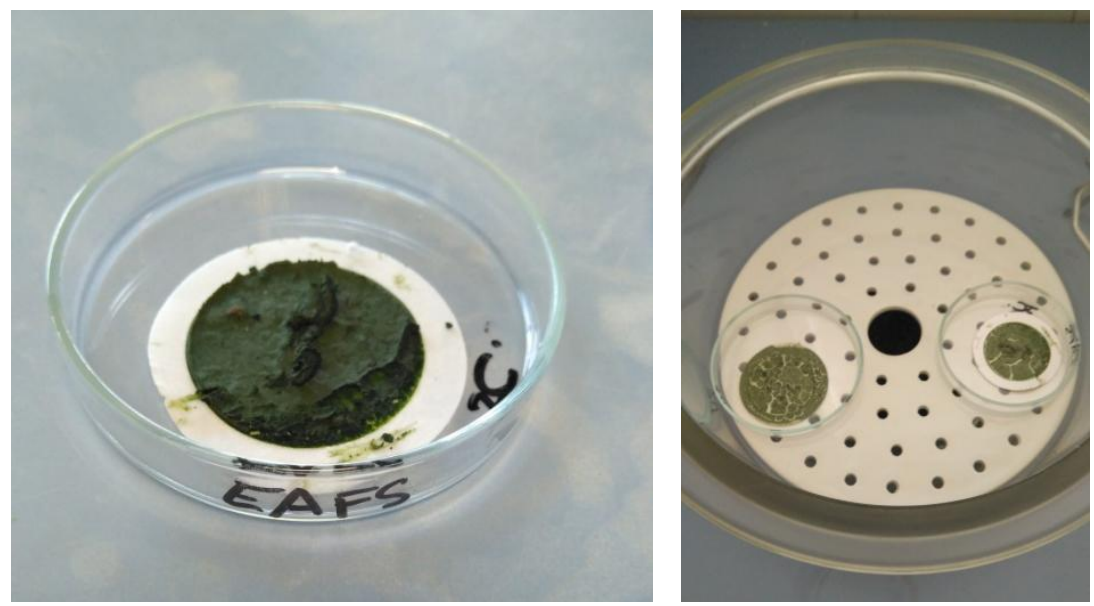

Imagen 74. Filtro con biomasa (izda). Muestras en campana de cristalización (dcha)

Al finalizar el ensayo, se procede a determinar el total de la biomasa generada en la superficie de la placa. Para ello se sigue el siguiente procedimiento:

- Se cepilla la superficie de la placa para extraer la biomasa generada y se limpia la superficie con agua. (Imagen 73)

- El conjunto se filtra con ayuda de una bomba de vacío de membrana y un filtro microfibra de vidrio de borosilicato. (Imagen 73)

- Una vez filtrada la biomasa (Imagen 74), se deposita el filtro en una placa de petri que se introduce en una estufa donde se deja 24 horas. 
- Se saca de la estufa y se introduce en una campana de cristalización (Imagen 74), dejando que se enfríe durante 15 minutos.

- Finalmente se pesa el filtro, obteniendo así la biomasa generada neta. 
[1] Norma UNE-EN 1015-10 (2000) Determinación de densidad aparente en seco del mortero endurecido

[2] Norma UNE-EN 1015-18 (2000) Determinación del coeficiente de absorción de agua por capilaridad del mortero endurecido

[3] Norma Española UNE-EN 1015-11 (2000) Determinación de la resistencia a flexión y compresión del mortero endurecido

[4] Norma UNE-67028-EX (1997) Ladrillos cerámicos de arcilla cocida. Ensayo de heladicidad.

[5] Institute for Advanced Architecture of Catalonia (laaC). Open Thesis Fabrication Program in 2013. https://iaac.net/research-projects/selfsufficiency/bio-ceramic-system/

[6] LabVIEW http://www.ni.com/labview/why/esa

[7] LIFE+ IntegralCarbon (2013) Programa LIFE http://www.integralcarbon.eu/

[8] Miñón, J., Ruiz, G., Navas, L.M., Rad, C., Martínez, V. Sistema de monitorización del crecimiento de algas filamentosas basado en análisis de imagen (2014) I Symposium Nacional de Ingeniería Hortícola "La Agromótica en la Horticultura" 



\section{Capítulo 6. Caracterización del mortero}

\section{Introducción}

Tal y como se ha explicado anteriormente, el mortero que se investiga en la presente tesis se trata de un derivado de los morteros de Magnesio Fosfato (MPC) en el cual se hacen dos variaciones principalmente.

Por un lado, la fuente de magnesio utilizada no se trata de una de muy alta pureza, como se viene utilizando en los morteros MPC sino un subproducto obtenido en los filtros de mangas en forma de polvo de ciclón (PC) mientras se elabora el producto principal.

Por otro, se realiza una adición de árido a la mezcla, en forma de residuo de proceso industrial inerte, como son las escorias negras de horno de arco eléctrico (EAFS). Este aporte se realizará en un rango entre el 40 y el $60 \%$ del peso, ya que esta aportación en estas dosificaciones supone una mejora en las características mecánicas del mortero [1].

\subsection{Criterios de referencia}

Para estudiar la viabilidad técnica del presente mortero bio-receptivo MPC con adición de escoria negra de horno eléctrico de arco (EAFS), se han escogido una serie de materiales que se utilizan en obra en fachadas y envolventes. El fin es poder establecer unos criterios mínimos con los que poder comparar las muestras de mortero elaboradas en función de estos condicionantes:

1. Mortero de cemento convencional.

Mortero de cemento CEM IV/B 42,5 N

2. Morteros aligerados con residuos de espumas de poliuretano.

Mortero de cemento CEM IV/B 42,5 N con sustitución del 100\% del árido por residuo de espuma de poliuretano

3. Morteros con sustitución de árido por escoria LFS

Mortero de cemento CEM I 42,5 R con sustitución del 30\% del cemento y del 25 del árido por escoria (LFS)

4. Mortero mineral.

Mortero aislante térmico T1 Onexit $\AA$ Thermic $₫$

5. Paneles de madera-cemento

Cement wood board Viroc ${ }^{\circledR}$ by Investwood ${ }^{\circledR}$ 
6. Paneles de cemento con fibras para revestimiento de fachada Panel de cemento reforzado con fibras PVA. Euronit ${ }^{\circledR}$ Panel Natura ${ }^{\circledR}$

Estos materiales se han elegido por dos características principalmente: bien por su similitud con el mortero objeto de la presente tesis o bien porque se considera que puede ser un material similar y su función viene a ser parecida al mortero/panel de la investigación.

\begin{tabular}{|c|c|c|c|c|c|c|}
\hline & \multicolumn{2}{|c|}{ Resistencia mecánica } & \multirow{2}{*}{$\begin{array}{c}\text { Peso } \\
\text { específico }\end{array}$} & \multirow{2}{*}{ Porosidad } & \multirow{2}{*}{$\mathrm{pH}$} & \multirow{2}{*}{$\begin{array}{c}\text { Conductividad } \\
\text { térmica }\end{array}$} \\
\hline & Flexión & Compresión & & & & \\
\hline 1 & $5,5 \mathrm{~N} / \mathrm{mm}^{2}$ & $26 \mathrm{~N} / \mathrm{mm}^{2}$ & $1994 \mathrm{~kg} / \mathrm{m}^{3}$ & $3,50 \%$ & $11-13$ & $0,93 \mathrm{~W} / \mathrm{m}^{\circ} \mathrm{K}$ \\
\hline 2 & $2,5 \mathrm{~N} / \mathrm{mm}^{2}$ & $10 \mathrm{~N} / \mathrm{mm}^{2}$ & $1084 \mathrm{~kg} / \mathrm{m}^{3}$ & $11,90 \%$ & $11-13$ & $<0,93 \mathrm{~W} / \mathrm{m}^{\circ} \mathrm{K}$ \\
\hline 3 & $3,55 \mathrm{~N} / \mathrm{mm}^{2}$ & $8,83 \mathrm{~N} / \mathrm{mm}^{2}$ & $1700 \mathrm{~kg} / \mathrm{m}^{3}$ & - & - & $\mathrm{W} / \mathrm{m}^{\circ} \mathrm{K}$ \\
\hline 4 & $0,9 \mathrm{~N} / \mathrm{mm}^{2}$ & $1,5 \mathrm{~N} / \mathrm{mm}^{2}$ & $450 \mathrm{~kg} / \mathrm{m}^{3}$ & - & - & $0,06 \mathrm{~W} / \mathrm{m}^{\circ} \mathrm{K}$ \\
\hline 5 & $10,5 \mathrm{~N} / \mathrm{mm}^{2}$ & $40 \mathrm{~N} / \mathrm{mm}^{2}$ & $1350 \mathrm{~kg} / \mathrm{m}^{3}$ & - & 12 & $0,25 \mathrm{~W} / \mathrm{m}^{\circ} \mathrm{K}$ \\
\hline 6 & $20 \mathrm{~N} / \mathrm{mm}^{2}$ & $-\mathrm{N} / \mathrm{mm}^{2}$ & $1650 \mathrm{~kg} / \mathrm{m}^{3}$ & $18 \%$ & - & $-W / m^{\circ} K$ \\
\hline & $>2 \mathrm{~N} / \mathrm{mm}^{2}$ & $>5 \mathrm{~N} / \mathrm{mm}^{2}$ & $<2000 \mathrm{~kg} / \mathrm{m}^{3}$ & $>20 \%$ & $<7$ & $<0,93 \mathrm{~W} / \mathrm{m}^{\circ} \mathrm{K}$ \\
\hline
\end{tabular}

Tabla 6. Valores de referencia y propiedades deseadas.

Viendo las comparativas entre paneles y morteros, las características mecánicas deseadas vendrán condicionadas por su disposición. Si el mortero que se busca, se dispone sobre una subestructura (tipo panel) tendrán que ser mayoradas las resistencias mecánicas. Sin embargo, si el mortero se dispone directamente sobre el soporte, las resistencias no requerirán ser mayoradas, puesto que está sometido a menores solicitaciones, principalmente frente al impacto.

Dado que el mortero que se va a utilizar adiciona escorias de horno eléctrico, el peso específico del mortero se disparará frente al resto de productos comparables. Sin embargo este debería no ser muy superior a $2000 \mathrm{~kg} / \mathrm{m}^{3}$.

La porosidad deberá ser alta y con un conjunto de poros interconectados entre sí, para conseguir una red capilar por la que discurra el agua y los nutrientes.

El pH deberá ser ligeramente ácido para conseguir una mejor bioreceptividad del sustrato.

La conductividad térmica deberá ser lo más baja posible para poder contribuir a un mejor aislamiento térmico de las envolventes.

Respecto a la durabilidad, no se han encontrado variables de comparación, sin embargo si se pueden establecer unos requisitos mínimos:

Resistencia a heladicidad, ya que su disposición es en exteriores.

Resistencia a atmósferas agresivas.

Resistencia a la acción del briófito sobre el sustrato.

Tampoco se han encontrado parámetros con los que medir la sostenibilidad del mortero, por lo que se establecen unos requisitos mínimos:

Incorporación de residuos o sub-productos procedentes de procesos industriales.

Los productos utilizados deberían tener una mayor sostenibilidad que un mortero de cemento convencional... 


\subsection{Estudios previos}

La primera toma de contacto para la elaboración de un soporte de mortero se ha realizado utilizando cemento portland sustituyendo parte del árido por escoria negra de acería de horno eléctrico (EAFS).

Estas muestras se han basado en la línea de investigación sobre sustitución de los áridos del mortero por materiales de reciclaje, investigación realizada por Ángel Rodríguez en el Departamento de Construcciones Arquitectónicas e Ingenierías de la Construcción y del Terreno de la Universidad de Burgos [2] [3].

El cemento empleado ha sido cemento Portland CEM IV/B (V) 32,5 N, cuya densidad es de $3.030 \mathrm{~kg} / \mathrm{m}^{3}$. Las características y composición del cemento se muestran en la ficha técnica (Tabla 7).

\section{Fábrica Olazagutía. Navarra}

\section{EN 197-1 CEM IV/B (V) 32,5 N}

\section{CARACTERÍSTICAS}

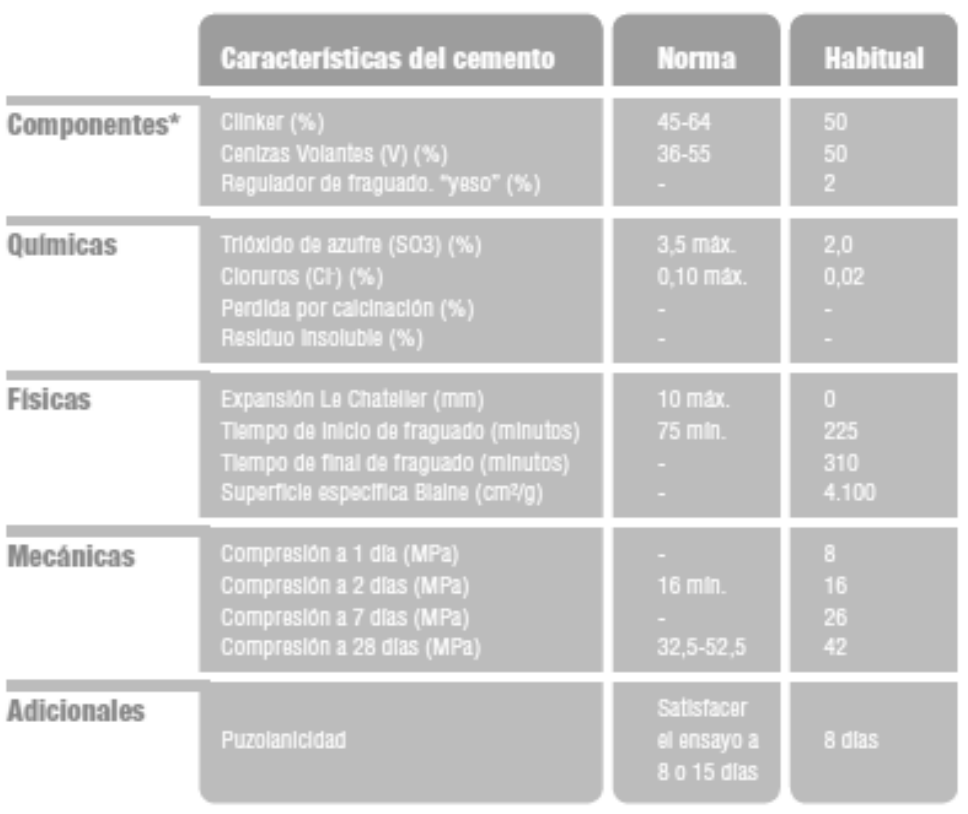

Tabla 7. Características CEM IV/B (V) 32,5 N. Fuente: Cementos Portland Valderrivas

El árido empleado es arena lavada de río, de tamaño 0-4 mm y densidad de $2.700 \mathrm{~kg} / \mathrm{m}^{3}$. La distribución del tamaño de las partículas es acorde con la norma española EN 13139 [4]. 


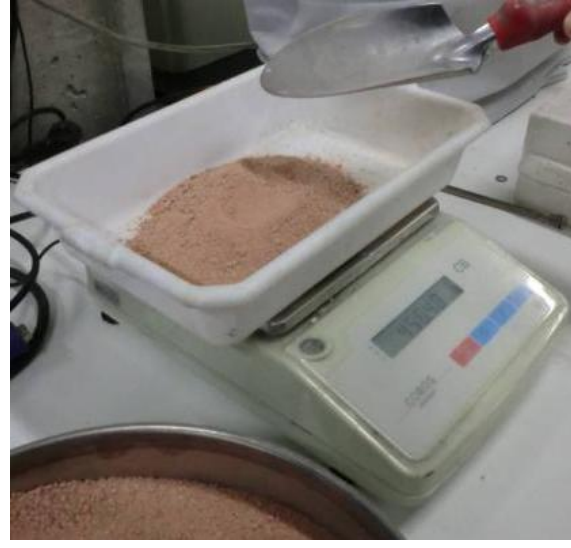

Imagen 75. Arena empleada

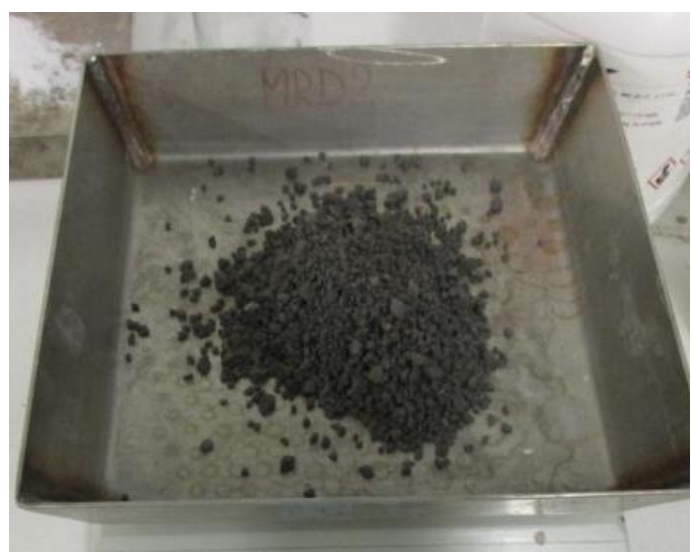

Imagen 76. Escoria empleada.

La escoria empleada (Imagen 76) se ha tamizado, eliminando los finos, manteniendo un tamaño de 0-4 mm.

Su densidad es de $3,72 \mathrm{~g} / \mathrm{cm}^{3}$, y su composición química, se ha obtenido mediante el análisis de los principales componentes, elaborado por Ortega $\vee$. [5]

\begin{tabular}{l|c}
\hline Óxido & Valor medio \\
$\mathrm{FeO}$ & $25 \%$ \\
$\mathrm{Fe}_{2} \mathrm{O}_{3}$ & $25 \%$ \\
$\mathrm{CaO}$ & $25 \%$ \\
$\mathrm{SiO}_{2}$ & $11 \%$ \\
$\mathrm{Al}_{2} \mathrm{O}_{3}$ & $5 \%$ \\
$\mathrm{MgO}$ & $5 \%$ \\
$\mathrm{MnO}$ & $4 \%$
\end{tabular}

Tabla 8. Valores promedio composición EAFS.

El procedimiento y las dosificaciones para elaborar estas muestras de mortero con sustitución de árido por escoria negra, se han realizado según la investigación sobre sustitución de los áridos del mortero por materiales de reciclaje del laboratorio de Materiales de la Universidad de Burgos.

Las dosificaciones EAFS-mortero empleadas han sido las siguientes (Tabla 9):

$\begin{array}{llll}\text { Relación cem./EAFS } & \text { Cemento } & \text { EAFS } & \text { a/c } \\ \text { Dosificación 1 } & 1 & 6 & \mathrm{~s} / \mathrm{c} \\ \text { Dosificación 2 } & 1 & 6 & \mathrm{~s} / \mathrm{c}\end{array}$

Tabla 9: Dosificación Mortero con EAFS

Ambas dosificaciones han sustituido el $100 \%$ del peso de la arena por escoria negra, con el fin de conseguir una porosidad abierta que permita el aspecto que se pretende para las presentes muestras.

Las muestras se han elaborado con una amasadora del laboratorio con la finalidad de conseguir una perfecta mezcla de los componentes del mortero y asegurar así un alto grado de homogeneidad. 
Posteriormente, el mortero resultante se ha vertido en un molde y se ha trasladado a una cámara de fraguado para su correcto curado.

Tras procederse a su desmoldado, las muestras de mortero presentan el siguiente aspecto:

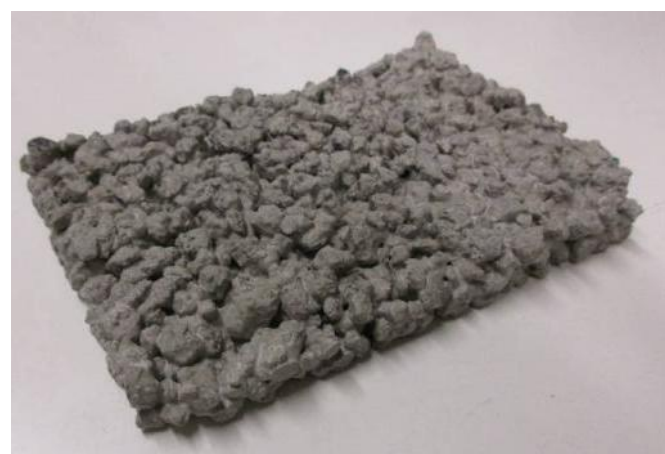

Imagen 77. Muestra dosificación 1.

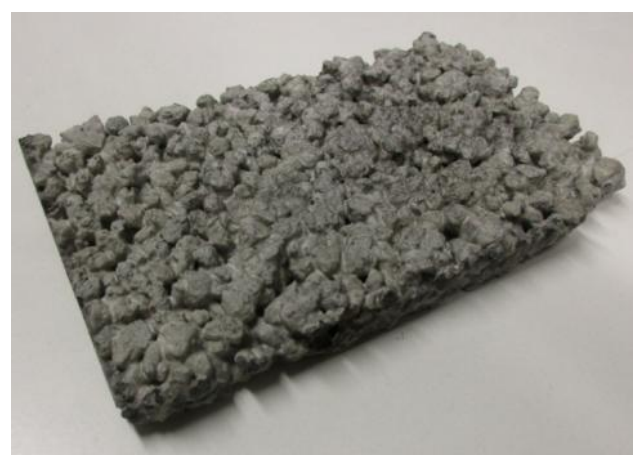

Imagen 78. Muestra dosificación 2.

No se procede a caracterizar el material, puesto que no se considera necesario, al tratarse de pruebas preliminares. Las principales características que se aprecian son:

- Textura y porosidad adecuada para el acoplamiento de los musgos.

- Resistencia: Aparentemente la resistencia de las muestras es suficiente para su uso previsto.

- Peso elevado. La utilización de escorias como sustitutivo del árido conlleva un aumento en el peso.

\subsection{Elaboración del mortero propuesto}

Para la elaboración del sustrato se ha optado por un cemento químico de fosfato magnesio, denominado con el acrónimo MPC (MagnesiaPhosphate Cement). Pertenece también a la familia de los cementos químicos de fosfato, denominados con el acrónimo CBPC (Chemically Bonded Phosphate Ceramics).

Este tipo de cementos se forman a partir de una reacción ácido-base, la cual forma un hidrogel salino cementoso al interaccionar, de estructura cristalina. Se caracterizan por un rápido fraguado a temperatura ambiente [6], y resistencias mecánicas iniciales buenas. [7]. De hecho el cemento MPC es utilizado en situaciones que requieren un rápido fraguado y muy buenas resistencia mecánicas iniciales, como son la reparación de estructuras [8] o la estabilización de residuos altamente peligrosos [9]

Sin embargo ninguno de los anteriores aspectos ha sido el principal factor para la elección de este tipo de cemento. Para la presente investigación se intentaba conseguir un material que reuniese unas características de bio-receptividad suficientes para albergar vida vegetal en su superficie ya que los morteros convencionales tienen un $\mathrm{pH}$ elevado (en torno a 12) mientras este tipo de morteros se sitúan en un ratio entre 5.5 y 7 [10], pH adecuado para el desarrollo de briófitos.

Volviendo a los CBPC, estos se forman al reaccionar el elemento ácido (fosfato) con una base metálica (óxido de magnesio en el caso de los 
MPC), generando una reacción exotérmica cuyo producto resultante es un gel que al cristalizar forma el mortero, según la siguiente reacción:

$\mathrm{MO}_{x / 2}+n \mathrm{H}_{3} \mathrm{PO}_{4}+m \mathrm{H}_{2} \mathrm{O} \rightarrow \mathrm{MH}_{3 n-x}\left(\mathrm{PO}_{4}\right)_{n}+(m+x / 2) \mathrm{H}_{2} \mathrm{O}$

El elemento ácido más empleados son los hidrogenofosfatos de amonio, calcio, sodio, potasio y aluminio a causa de criterios de optimización. Interesa que la fuente de fosfato contenga el máximo contenido de $\mathrm{P}_{2} \mathrm{O}_{5}$ para emplear menos cantidad en la formación de CBPC [11].

La base metálica más empleada para la formación de este tipo de cementos es la que contiene óxidos de magnesio (MgO) y zinc $(\mathrm{ZnO})$.

Debido a las características de este tipo de morteros, hay que tener bastante cuidado con la velocidad de reacción y endurecido. Esta puede alterar de forma drástica el resultado final de la muestra y sus propiedades, como $\mathrm{pH}$ y resistencias mecánicas. [12]

Por ello hay que tener en cuenta dos aspectos fundamentalmente:

- La reactividad de los materiales y pureza. La pureza del óxido metálico es inversamente proporcional a la velocidad de reacción.

- Baja solubilidad, ya que la velocidad de la reacción depende de la velocidad de disolución del óxido metálico. [13].

\subsection{Adición de áridos a partir de residuos}

La adición de materiales de residuo en sustitución de áridos es una línea de investigación bastante común en la búsqueda de nuevos materiales. La utilización de áridos procedentes de procesos industriales o de demoliciones son temas en los que se centran varios estudios. De hecho, el grupo de investigación en Ingeniería de Edificación de la Universidad de Burgos desarrolla en la actualidad varias investigaciones en los que se sustituye parcial o totalmente los áridos de la mezcla de morteros y hormigones por residuos inertes procedentes tanto de la industria como de derribos de la propia construcción. El fin último es poder reducir la presencia de árido natural y con ello intentar reintroducir el residuo en el proceso, generando así una economía circular que valoriza los residuos.

Los cementos MPC contienen una fuente de óxido de magnesio MgO con fillers inertes que actúan como áridos. El producto que se emplea en la presente tesis se trata de un subproducto denominado Polvo de Ciclón, que según sus especificaciones contiene entre un 15 y un $35 \%$ de otros componentes que actúan como fillers inertes.

Dado que no podemos sustituir estos fillers y la mezcla no contiene otros áridos en su dosificación, la intención es poder introducir residuos, en este caso escoria negras de horno eléctrico de arco (EAFS), en la composición con el fin de reducir la presencia de otros componentes, menos sostenibles.

Estos residuos deben de ser inertes para evitar que alteren la composición química del cemento y a su vez no menoscaben las propiedades físicas y mecánicas del producto endurecido. No obstante, la adición de escorias puede mejorar el comportamiento mecánico del conjunto [14], llegando a un comportamiento óptimo con una adición entre el $40-60 \%$ del peso total, lo que supone un ratio aproximado de $1: 1$. Esto, que de por sí, supone la sustitución de un $50 \%$ del peso total 
de la muestra de productos por residuos, supone un plus sostenible a considerar, ya que las propiedades mecánicas no se ven afectadas.

Sin embargo también existen otro tipo de áridos añadidos a este tipo de cementos, que mejoran el comportamiento mecánico, como las fibras; u otros elementos que hacen más sostenible el conjunto, como cenizas de estiércol [15], cenizas volantes [16], fibras de papel triturado [17], fibras de cáñamo [18], escorias de horno alto [19]..

Este tipo de productos vienen a aportar a los cementos CBPC ese incremento de sostenibilidad que, en principio, no poseen al estar elaborados por productos de alta pureza. Con este tipo de implementación de economía circular cumplimos con una doble función: valorizar este tipo de residuos, sacándolos de los vertederos y reintroduciéndolos en el proceso industrial, a la vez que conseguimos reducir la presencia de materiales de alta pureza y alto coste industrial.

Los estudios realizados por el grupo de investigación en Ingeniería de Edificación de la UBU han consistido en elaborar muestras de mortero tradicional en las que progresivamente se ha ido reemplazando diferentes porcentajes de la arena por residuos de espumas rígidas de poliuretano [20] [21], pizarras [22], arcillas expandidas [23] o escorias [24] [25] [26], utilizando como conglomerante tanto cementos y hormigones como yesos.

La inclusión de escorias de acería en sustitución de árido en morteros de cemento convencionales no supone un menoscabo excesivo de las resistencias mecánicas del producto terminado. [27] De hecho la sustitución paulatina de árido por escoria supone un incremento en todos casos de las resistencias. En el caso de sustitución del 100\% del árido por escorias, la resistencia a flexión a 90 días aumenta un $21 \%$ y la de compresión, también a 90 días, un 34\%. [28]. Por lo tanto la adición de escorias supone un enorme beneficio en las propiedas mecánicas del producto.

La densidad del estado fresco del mortero oscila desde $2.100 \mathrm{~kg} / \mathrm{m}^{3}$ para las muestras de mortero en las que no se ha producido sustitución de la arena hasta $2.400 \mathrm{~kg} / \mathrm{m}^{3}$ para las muestras en las que se ha realizado la sustitución del 100\% de la arena por escorias. Sin embargo la cantidad de aire ocluido no varía en exceso rondando el $8 \%$.

Del mismo modo, los valores de retención de agua son muy parecidos entre los que incorporan escorias y los que no. De hecho el rango oscila entre el $66,5 \%$ en aquellos en los que no se sustituye nada de árido por un $67 \%$ en aquellos en los que se sustituye la totalidad del árido por escorias. Si se agregan aireantes, este valor sí que podría aumentar considerablemente llegando hasta el 88,4\% [29]. Esta propiedad es inversamente proporcional a la permeabilidad al vapor de agua. Según los estudios de /. Santamaría-Vicario et al, la permeabilidad al vapor de agua, varía entre 19,5 del mortero sin sustitución al 18,8 en el que se sustituye la totalidad del árido. Si se agregan aireantes, al igual que antes, este valor sí que podría reducirse drásticamente, bajando hasta 7,4.

Los morteros fabricados con finos de escoria de acero presentaron alta exudación de agua, lo que significa que no es esencial dosificar las mezclas.

En cuanto a la durabilidad, la adición de escorias no supuso un cambio ni en apariencia ni en pérdida de material después de los test de durabilidad. El comportamiento es similar a los morteros convencionales. 
Un tema a considerar es la presencia de depósitos de sales tanto en la matriz del mortero como en su superficie. Según los estudios de Santamaría-Vicario et al la aparición de estos no impidió que las muestras se comportaran satisfactoriamente a varios ensayos de durabilidad. Sin embargo, este extremo preocupa en la presente tesis, especialmente desde un punto de bio-receptividad.

Esta presencia se evidencia después del ensayo Kesternich [30] dado que los especímenes estaban en una atmósfera saturada de SO2. Los óxidos de hierro contenidos en las EAFS reaccionan en un ambiente ácido de un SO2 saturado provocando un proceso corrosivo que conduce a una cristalización.

Por tanto se tendrá que estudiar la aparición de estas sales, con el fin de evitar que inhiban la vida vegetal, tanto en su superficie como en su interior.

La escasa literatura acerca del aporte de escorias negras (EAFS) a cementos de magnesio fosfato (MPC) hace que nos basemos en los estudios elaborados a partir de cementos convencionales.

De hecho, dos de los estudios en los que se ha basado esta tesis [31] [32] no aportan ningún árido en sus dosificaciones. Si bien, los CBPC no son cementos al uso, y se acercan más a los materiales cerámicos, no requerirían, per se, ningún árido. En su investigación Manso S. et al, no consideran la necesidad de aportar ningún árido a la capa biológica de su conjunto multicapa. Formosa J. considera que en los cementos CBPC que utilizan óxido de magnesio de baja riqueza, los fillers inertes que aporta este último hacen la función de árido y por lo tanto no considera la necesidad de aportar más.

Sin embargo otros autores sí que apuestan por la presencia de otro tipo de componentes a la hora de elaborar cementos CBPC [33]. En estos estudios se evalúa la aportación de distintos áridos o agregados a los cementos CBPC, consiguiéndose una serie de ventajas frente al producto sin ellos.

Aparte de las mejoras mencionadas anteriormente sobre la economía circular, la principal ventaja que aporta la adicición de escorias, es la mejora en el comportamiento mecánico del producto terminado, llegando a ser óptimo cuando se agrega entre un 40 y un $60 \%$ del peso del cemento con cierto tipo de escorias [34]. Esto vendría a confirmar lo estudiado antes con morteros convencionales, en los cuales la sustitución de áridos por escorias (EAFS) supone en gran aumento en las resistencias a flexión y compresión.

También inciden en el control de la reacción y propiedades del producto endurecido. El control de la velocidad de reacción se consigue al controlar la masa térmica y permite un producto final más homogéneo y más trabajable en estado fresco.

\section{Caracterización de las materias primas}

Las materias primas empleadas en la confección de los morteros empleados en la presente tesis son los siguientes:

- Óxido de Magnesio.

- Dihidrógeno fosfato de amonio $\mathrm{NH}_{4}\left(\mathrm{H}_{2} \mathrm{PO}_{4}\right)$

- Bórax (Na2B4O7·10H2O)

- Escorias negras de horno eléctrico de arco (EAFS) 
- Agua de amasado

Se ha utilizado un único tipo de cada componente, a excepción de la fuente de magnesio, de la cual se han utilizado tres tipos diferentes.

\section{1. Óxido de magnesio, $\mathrm{MgO}$}

Para la elaboración del mortero de magnesio fosfato (MPC) de la presente tesis, se ha empleado una fuente de Óxido de Magnesio proporcionado directamente desde la empresa Magnesitas Navarras S.A. productoras de magnesita cruda.

El Óxido de Magnesio se obtiene a través de la calcinación de la magnesita mineral $\left(\mathrm{MgCO}_{3}\right)$. En la presente tesis se ha optado por la utilización de dos productos:

- Magnesita sintetizada

- Magnesita calcinada caústica (Polvo de Ciclón)

La diferencia entre ambos productos viene a ser la calidad y el coste en su obtención.

La magnesita calcinada a muerte y sinterizada se obtiene en horno a temperatura muy elevada $\left(\approx 1800^{\circ} \mathrm{C}\right)$. El producto final son cristales de óxido de magnesio de tamaño grande, denso y por lo tanto más estables químicamente.

La magnesita calcinada caústica se obtiene en horno a temperatura menor que la anterior $\left(\approx 900^{\circ} \mathrm{C}\right)$. Se trata de un producto cuyo tamaño de partícula es inferior y mucho más reactivo que el anterior.

Inicialmente se ha tratado de replicar otras investigaciones similares [35] En estas se utiliza magnesita calcinada a muerte (sinterizada), de gran pureza (98\% en contenido de MgO). Sin embargo este producto no es sencillo de encontrar en la riqueza exacta, aparte de tratarse de un material especialmente caro (entre 90 y $180 € / \mathrm{kg}$ ). Por ello se opta por un óxido de magnesio de menor riqueza, 83\%, y el resto fillers inertes e impurezas. Este producto se provee en dos tamaños.

No obstante, en pro de aplicar la teoría de economía circular, la cual es una de las motivaciones de la presente investigación, se intenta que este producto sea más sostenible aún. La empresa Magnesitas Navarras SA dispone de un subproducto obtenido en los filtros de las mangas durante la sintetización del óxido de magnesio. De estos se obtiene óxido de magnesio de baja ley, de un 65\% y en forma de Polvo de Ciclón.

Este subproducto (PC), a diferencia del MgO de riqueza 83\%, contiene una mayor cantidad de partículas finas. Estas se recogen en las corrientes de aire que circulan en dirección opuesta a la del mineral durante el proceso de sintetización del $\mathrm{MgO}$.

El mayor inconveniente viene derivado de su reactividad. Al ser un producto con menor riqueza en $\mathrm{MgO}$ y mucho más reactivo, se requerirá más cantidad de retardarte para evitar un fraguado demasiado rápido que evite un correcto mezclado de los componentes.

\section{Magnesita sinterizada (riqueza MgO 83\%)}

Actualmente no existe ninguna normativa que regule las características que deben cumplir los morteros de magnesio fosfato (MPC). Dada la 
peculiaridad de su composición, tampoco ninguna incide acerca de las características de las materias primas de esta clase de mortero.

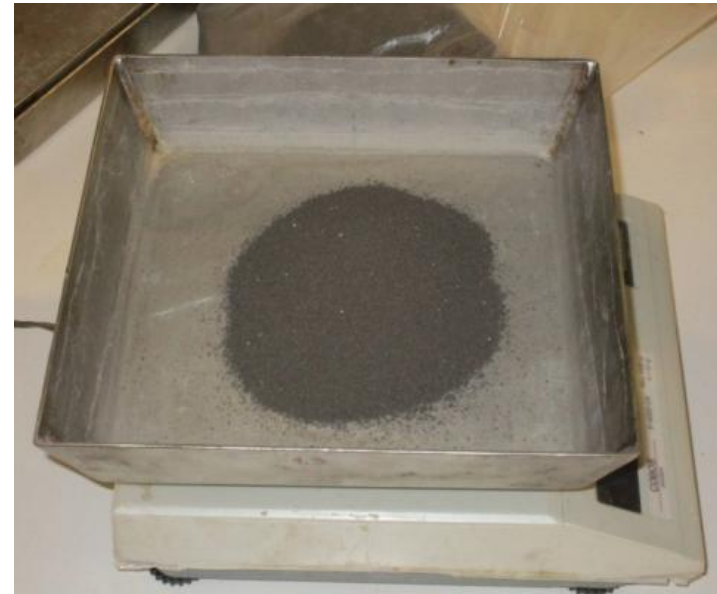

Imagen 79. Muestra de Mag7
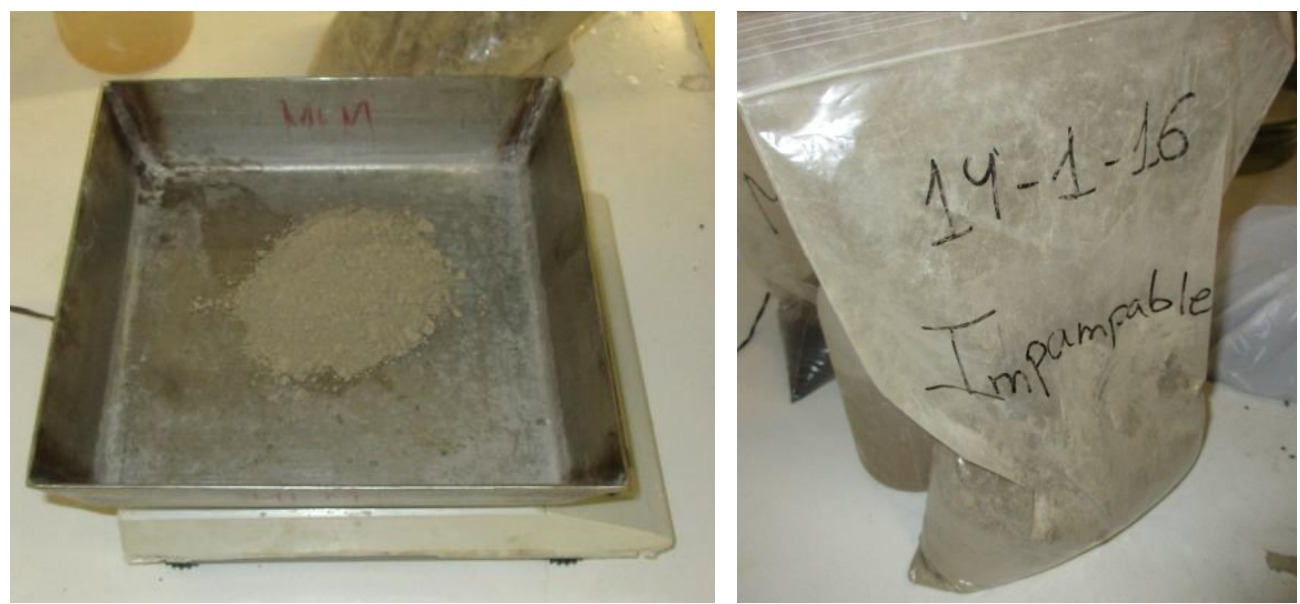

Imagen 80. Muestra de ImpalMag

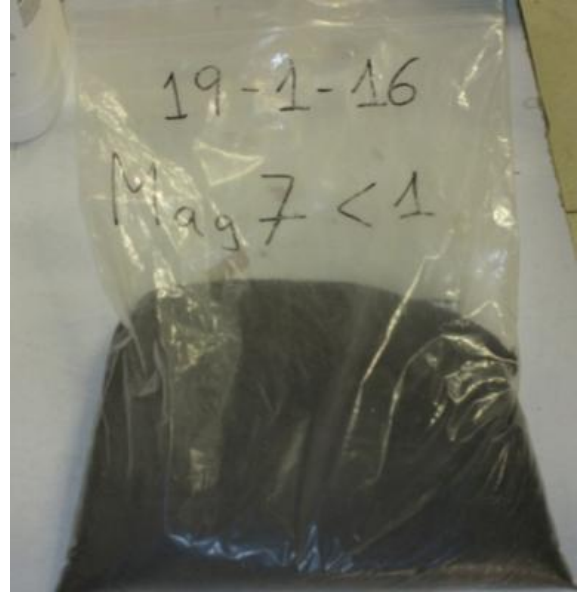

Se han elegido estos dos tipos de magnesitas sintetizadas, con una alta pureza, $83 \%$, pero inferior a la utilizada en otras investigaciones, con la de Manso, $S$ et al. que utiliza del 98\%. De este modo se consigue un coste, tanto energético como económico, muy inferior.

Las magnesitas empleadas se tratan de dos productos manufacturados a partir del mineral extraído la mina de Eugui (Navarra) por la empresa Magnesitas Navarras S.A. (Magna)

Estos dos artículos, utilizados en la base de los productos fabricados por la empresa, tienen la siguiente denominación comercial:

- Mag 7: $\quad$ Tamaño $<1 \mathrm{~mm}$, y un 5\% $<100$ micras

- ImpalMag Tamaño 100\% < 150 micras

El análisis químico realizado por la empresa el 19 de Enero de 2016, se muestra en las Tabla 10 y Tabla 11. 
Análisis químico Mag 7

$\begin{array}{ll}\text { Elementos } & (\%) \\ \mathrm{MgO} & 82,58 \\ \mathrm{CaO} & 10,00 \\ \mathrm{SiO} 2 & 3,90 \\ \mathrm{Fe} 2 \mathrm{O} 3 & 3,00 \\ \mathrm{Al} 2 \mathrm{O} 3 & 0,41 \\ \mathrm{P} 2 \mathrm{O} 5 & 0,09 \\ \mathrm{~S} & 0,020\end{array}$

Tabla 10. Análisis químico Mag7 <1mm

\begin{tabular}{ll}
\multicolumn{3}{c}{ Análisis químico ImpalMag } \\
Elementos & $(\%)$ \\
$\mathrm{MgO}$ & 81,65 \\
$\mathrm{CaO}$ & 10,91 \\
$\mathrm{SiO} 2$ & 3,68 \\
$\mathrm{Fe} 2 \mathrm{O} 3$ & 3,01 \\
$\mathrm{Al} 2 \mathrm{O} 3$ & 0,40 \\
$\mathrm{P} 2 \mathrm{O} 5$ & 0,09 \\
P.F. & 0,35
\end{tabular}

Tabla 11. Análisis químico ImpalMag

Además de la composición química, también se aporta la granulometría de ambos productos. Como se observa en las Tabla 12 y Tabla 13 la distribución no es uniforme. En el Mag 7, el tamaño de la partícula principal es un tamaño medio, conteniendo también finos y partículas algo más grandes. Sin embargo en ImpalMag el tamaño de referencia es el más pequeño, siendo más del 50\% del total partículas menores de 25 micras.

Dado que el producto está caracterizado por la empresa, no se considera necesario realizar más análisis a la magnesita.

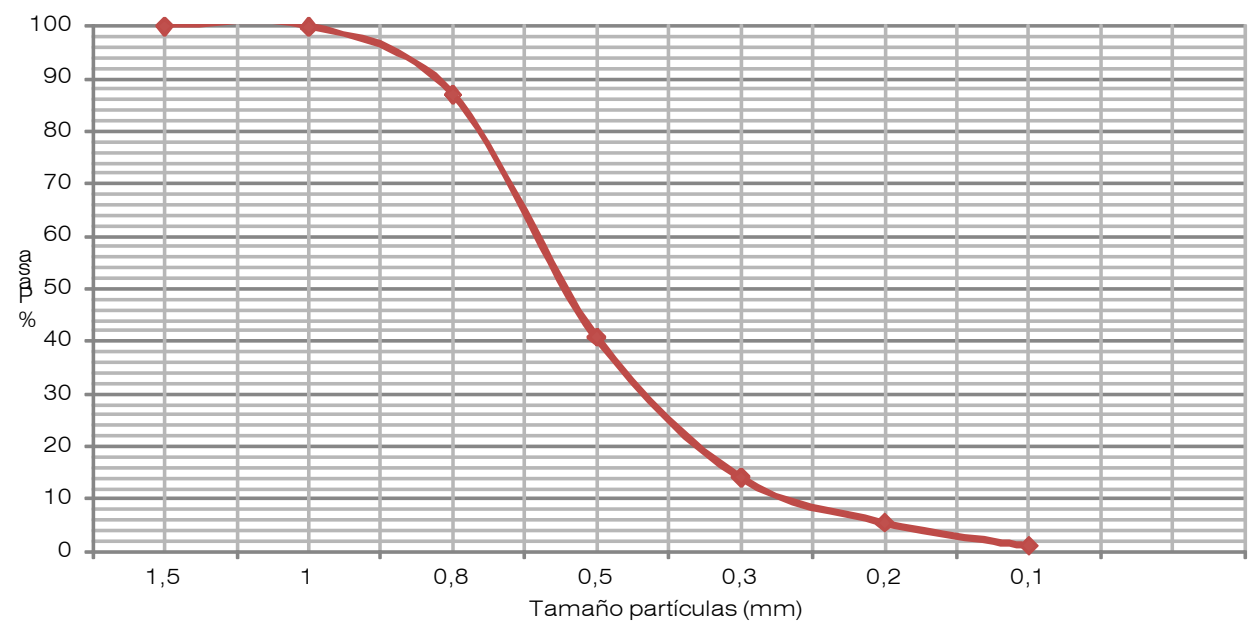

Imagen 81. Gráfico distribución granulométrica Mag7 
Granulometría Mag 7

$\begin{array}{ll}\text { Tamaño partículas }(\mathrm{mm}) & \text { (\%) Pasa } \\ 1,5 & 100,0 \\ 1 & 99,8 \\ 0,8 & 87,0 \\ 0,5 & 40,8 \\ 0,3 & 14,2 \\ 0,2 & 5,5 \\ 0,1 & 1,1\end{array}$

Tabla 12. Granulometría Mag7

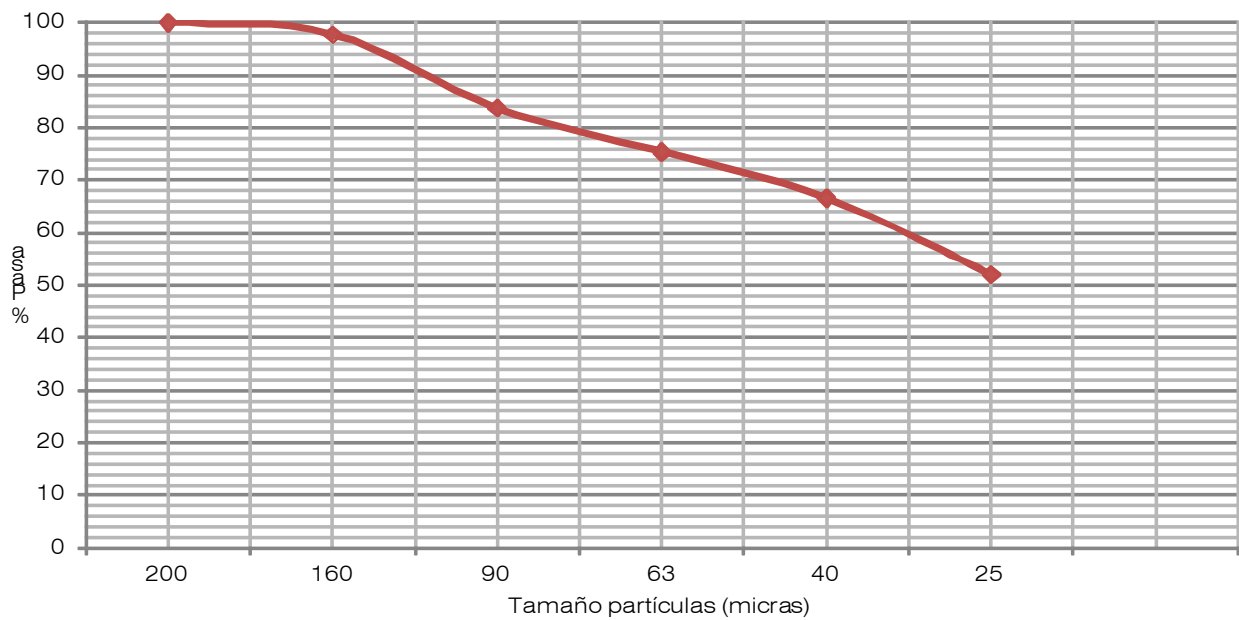

Imagen 82. Gráfico distribución granulométrica ImpalMag

\section{Granulometría ImpalMag}

Tamaño partículas
(micras)
200
160
90
63
40
25

(\%) Pasa

100

97,7

83,7

75,3

66,6

52,1

Tabla 13. Granulometría ImpalMag

\section{Magnesita calcinada PC (riqueza MgO 65\%)}

Actualmente no existe ninguna normativa que regule las características que deben cumplir los morteros de magnesio fosfato (MPC). Dada la peculiaridad de su composición, tampoco ninguna incide acerca de las características de las materias primas de esta clase de mortero.

Se ha elegido un sub-producto, en forma de polvo de ciclón, obtenido durante la sintetización de la magnesita. Tiene una pureza del $65 \%$ en $\mathrm{MgO}$ y una mayor concentración en fillers inertes que la magnesita sintetizada. 
Este producto está desarrollado también por la empresa Magnesitas Navarras S.A. (Magna) y tiene la denominación comercial de PC8.

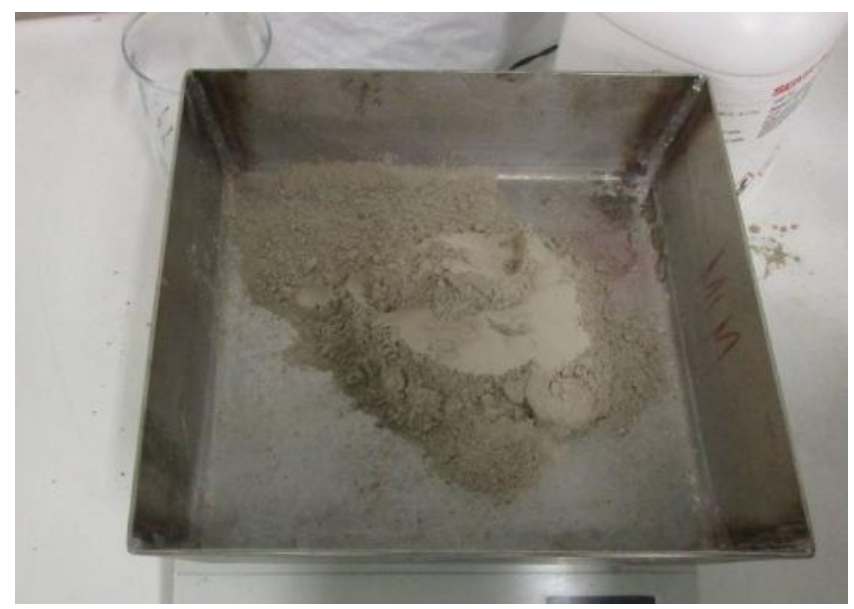

Imagen 83. Muestras de PC8

El análisis químico realizado por la empresa el 19 de enero de 2016 se muestra en la Tabla 14

\begin{tabular}{lc}
\multicolumn{2}{c}{ Análisis químico PC8 } \\
Elementos & $(\%)$ \\
$\mathrm{MgO}$ & 60,80 \\
$\mathrm{SO} 3$ & 8,43 \\
$\mathrm{CaO}$ & 8,38 \\
$\mathrm{SiO} 2$ & 2,77 \\
$\mathrm{Fe} 2 \mathrm{O} 3$ & 2,35 \\
$\mathrm{Al} 2 \mathrm{O} 3$ & 0,49 \\
$\mathrm{P} . \mathrm{F}$. & 16,78 \\
Tabla 14. Análisis químico & $\mathrm{PC} 8$
\end{tabular}

Además de la composición química, también se aporta la granulometría. Como se observa en la Tabla 15, el tamaño de referencia es el más pequeño, siendo casi el $90 \%$ menor de 0,1 $\mathrm{mm}$, lo que le confiere el aspecto polvoriento que dispone.

\begin{tabular}{ll}
\multicolumn{3}{c}{ Granulometría PC8 } \\
Tamaño partícula $(\mathrm{mm})$ & (\%) Pasa \\
0,5 & 100,0 \\
0,3 & 98,5 \\
0,2 & 95,8 \\
0,1 & 89,2 \\
Tabla 15. Granulometría PC8
\end{tabular}




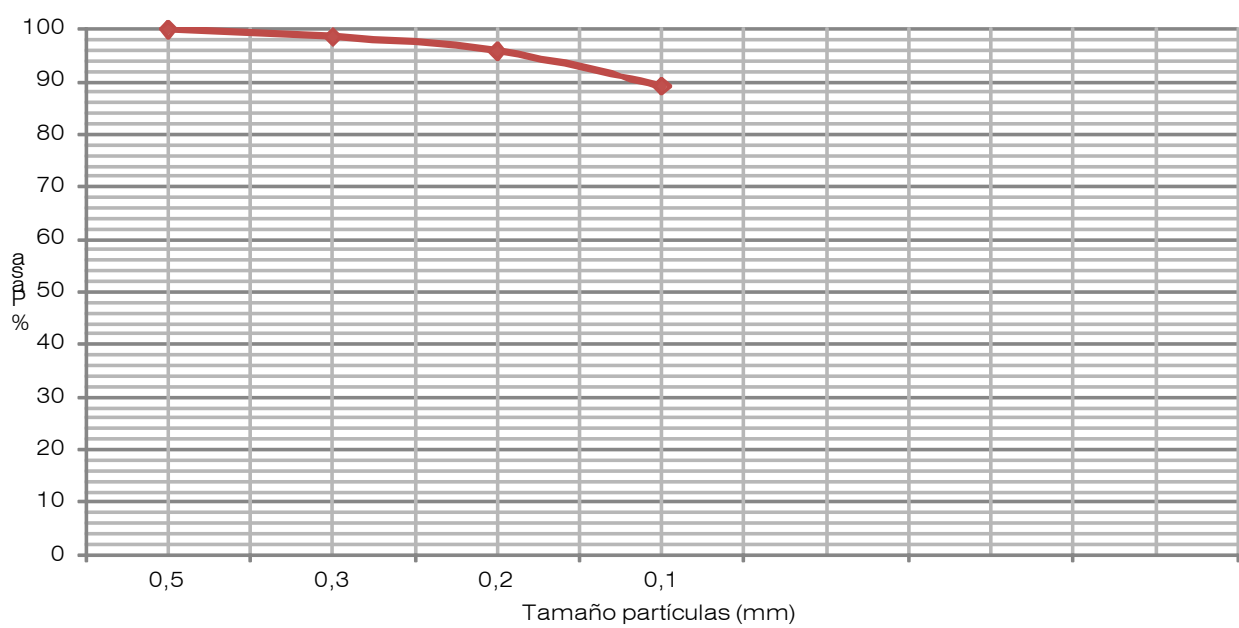

Imagen 84. Gráfico distribución granulométrica PC8

\subsection{Dihidrógeno fosfato de amonio}

Para la elaboración del mortero de magnesio fosfato (MPC) de la presente tesis, se ha empleado dihidrógeno fosfato de amonio o o fosfato monoamónico, monoammonium phosphate $(M A P)$, de la empresa Sigma-Aldrich. Se trata de una sociedad germanoamericana, y por lo tanto los productos deben ser importados.

El MAP, cuya formulación química es NH4H2PO4, se presenta en forma de sales solubles. Estas se obtienen a partir de la reacción de neutralización entre el ácido fosfórico y el amoniaco:

$$
\mathrm{NH}_{3}+\mathrm{H}_{3} \mathrm{PO}_{4} \rightarrow\left(\mathrm{NH}_{4}\right) \mathrm{H}_{2} \mathrm{PO}_{4}
$$
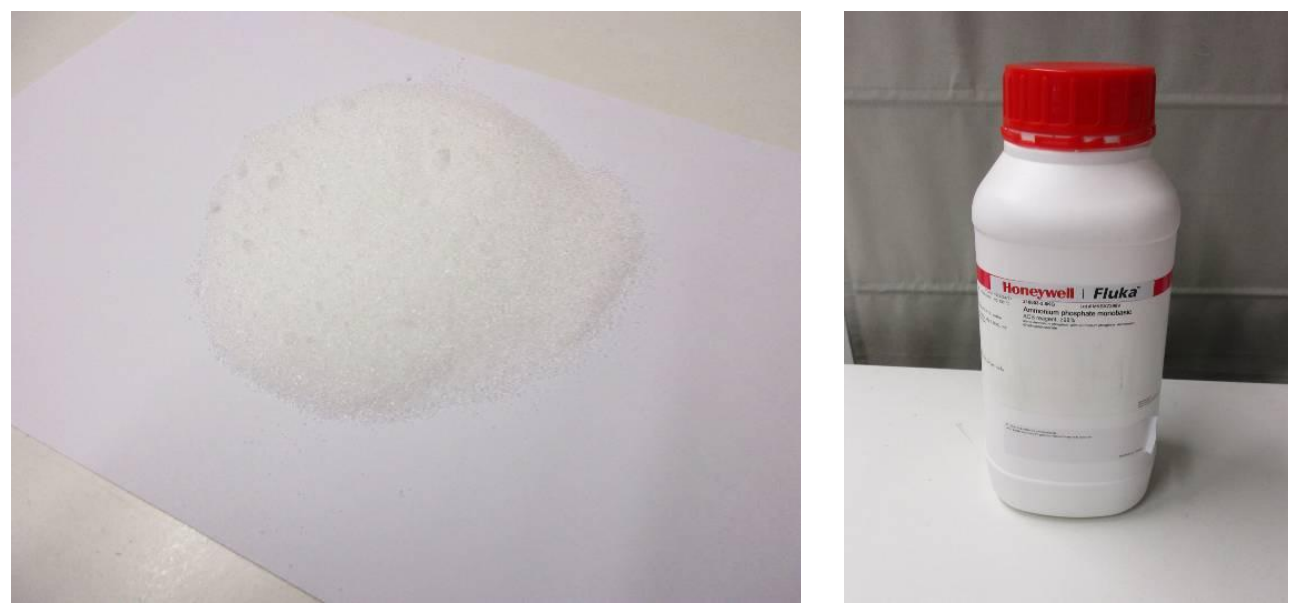

Imagen 85. Muestra del MAP empleado

Las características del MAP empleado se relacionan en la Tabla 16.

\begin{tabular}{ll} 
& \multicolumn{1}{c}{ Características MAP } \\
Ensayo & $\geq 98.0 \%$ ACS reactivo \\
$\mathrm{pH}$ & $3.8-4.4\left(25^{\circ} \mathrm{C}, 50 \mathrm{mg} / \mathrm{mL}\right.$ en $\left.\mathrm{H}_{2} \mathrm{O}\right)$ \\
Punto de fusión & $190^{\circ} \mathrm{C}$ (dec.)(lit.)
\end{tabular}




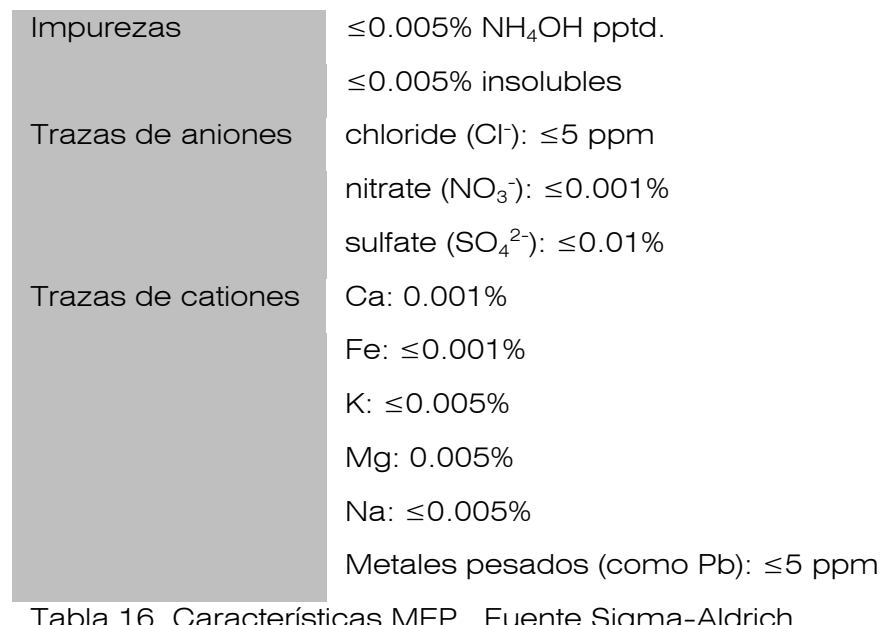

\subsection{Tetraborato de sodio}

Se ha optado por la utilización de tetraborato de sodio o Bórax, como retardador del fraguado. Este procede, al igual que el MAP, de la empresa germano-americana Sigma-Aldrich.

El Borax, cuya formulación química es $\mathrm{Na}_{2} \mathrm{~B}_{4} \mathrm{O}_{7} \cdot 1 \mathrm{OH}_{2} \mathrm{O}$, se presenta en forma de sal soluble. Su utilización para la presente investigación se basa en su capacidad de reducir la velocidad de fraguado en los MPC, ya que los retardadores habituales de los morteros convencionales no funcionan [36]. Este consigue generar un film superficial de compuestos de borato de magnesio alrededor de los granos de magnesia, el cual retrasa la reacción. [37]

La reacción ácido-base del MPC es especialmente rápida, a la vez que exotérmica. Varias investigaciones apuestan por el uso del boro para reducir la velocidad de la reacción. Con ello conseguimos una mayor trabajabilidad.
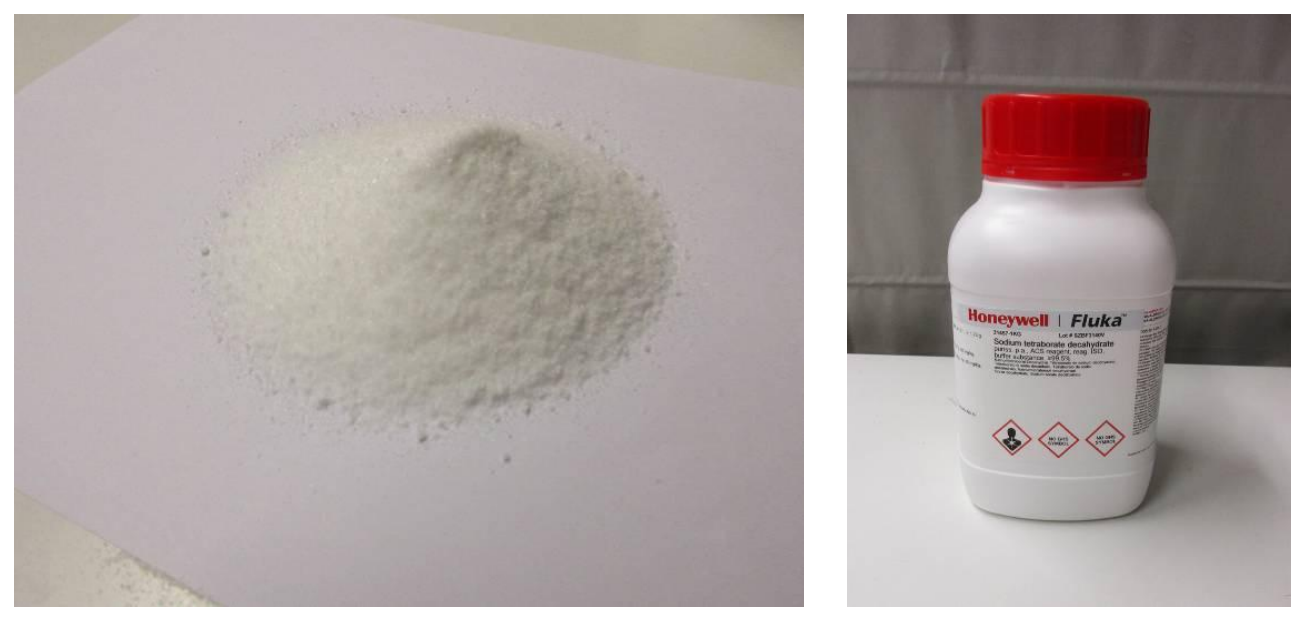

Imagen 86. Muestra del Bórax empleado

El presente MPC basa su composición en dos productos: Un dihidrógeno fosfato de amonio de muy alta pureza y un óxido de magnesio de menor riqueza. La adición de un $1 \%$ del peso con ácido bórico respecto al $\mathrm{MgO}$ (en estado puro) puede incrementar el tiempo de fraguado de 1,5 a 4,5 horas [38]. Al no ser puro el MgO empleado, 
es menos estable y más reactivo, por lo tanto los periodos de trabajo se reducen y la adición de Borax debe ser mayor.

\begin{tabular}{|c|c|}
\hline \multicolumn{2}{|r|}{ Características Borax } \\
\hline Ensayo & $\geq 99.5 \%$ ACS reactivo \\
\hline $\mathrm{pH}$ & $9.0-9.6(20 \mathrm{C}, 5 \%)$ \\
\hline Densidad & $1.73 \mathrm{~g} / \mathrm{mL}$ at $25^{\circ} \mathrm{C}$ (lit.) \\
\hline Trazas de aniones & chloride (Cl-): $\leq 10 \mathrm{mg} / \mathrm{kg}$ \\
\hline & phosphate (PO43-): $\leq 10 \mathrm{mg} / \mathrm{kg}$ \\
\hline Trazas de cationes & sulfate (SO42-): $\leq 50 \mathrm{mg} / \mathrm{kg}$ \\
\hline & As: $\leq 1 \mathrm{mg} / \mathrm{kg}$ \\
\hline & $\mathrm{Ca}: \leq 50 \mathrm{mg} / \mathrm{kg}$ \\
\hline & $\mathrm{Cu}: \leq 5 \mathrm{mg} / \mathrm{kg}$ \\
\hline & $\mathrm{Fe}: \leq 5 \mathrm{mg} / \mathrm{kg}$ \\
\hline & $\mathrm{Pb}: \leq 5 \mathrm{mg} / \mathrm{kg}$ \\
\hline & Ca: $\leq 50 \mathrm{mg} / \mathrm{kg}$ \\
\hline
\end{tabular}

\subsection{Escoria negra de alto horno (EAFS)}

Uno de los objetivos de esta Tesis Doctoral es el estudio de la inclusión de escoria negra de horno eléctrico en la fabricación del mortero que sirva como soporte de la capa vegetal. Esta escoria vendría a mejorar las características físicas del propio mortero, así como "aligerar" la carga de producto MPC propiamente dicho.

Para ello primero se requiere la caracterización física y química de la escoria negra que posteriormente se utilizará en el mortero objeto de la investigación.

\section{Obtención de la EAFS}

Como ya se ha explicado en el capítulo 4, la escoria negra de acería es un subproducto formado en la etapa de fusión, durante la fase de oxidación, en los hornos eléctricos de arco. En esta fase, se produce el colado del caldo de acero del horno, el cual pasa al horno-cuchara donde se procederá al afino de la muestra para ajustarla a la calidad del acero.

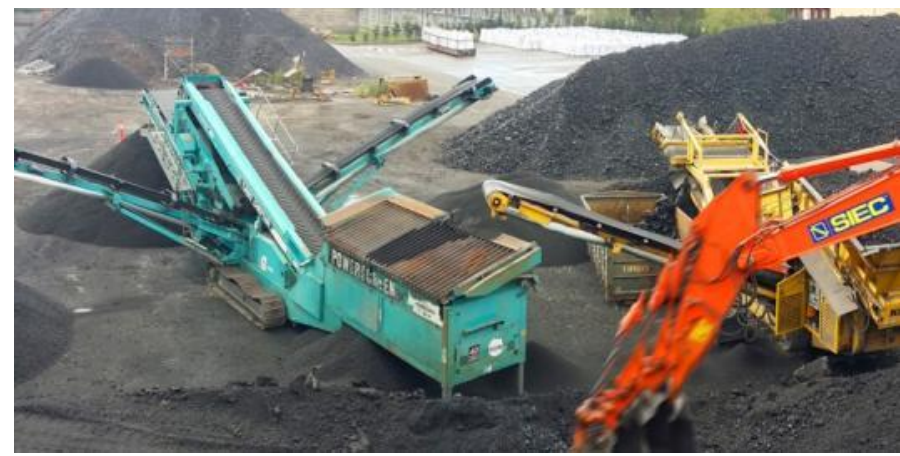

Imagen 87. Planta de tratamiento de escorias 
La escoria del horno eléctrico de arco (EAFS), que aparece en ese colado, es vertida en estado semilíquido (a unos $1200^{\circ} \mathrm{C}$ ) a un foso de almacenamiento. Una vez en dicho foso, se procede a un regado de agua que provoca un enfriamiento espontáneo. Este producto es trasladado a la planta de tratamiento donde se procede a su trituración, molienda, tamizado y separación por tamaños; después de los cuales queda preparada para su posterior distribución.

Para el procedimiento de estabilización, las escorias son sometidas a un proceso de riego por aspersión suave desde las 9 de la noche hasta las 8 de la mañana. Entre las 12 y las 12,30 de la mañana se voltean. Con este proceso de estabilización, la escoria negra queda prácticamente estable si se extienden estos ciclos en una duración de 90 días. [39]

\subsubsection{Caracterización química y mineralógica}

Para la caracterización de las escorias utilizadas en la presente investigación, se van a utilizar los datos extraídos de las tesis doctorales de Ortega V. [40] y Rodríguez A. [41]. Estos ensayos se han realizado sobre las mismas muestras de escorias que se utilizaron en las respectivas tesis.

La escorias utilizadas proceden de tres acerías diferentes: Orbegozo de Zumarraga (Guipúzcoa), Aristrain de Bergara (Guipúzcoa) y Compacta de Bizkaia de Sestao (Vizcaya).

Para la caracterización Ortega $V$. [42] toma como referencia nueve muestras diferentes: tres de Zumárraga, una de Bergara y cinco de Sestao.

\section{Análisis químico}

Los análisis químicos llevados a cabo por las acerías productoras de las escorias determinan la composición química de las mismas. De este análisis completo, podemos subdividirlo en tres categorías:

- Óxidos principales

- Magnesia y cal libre

- Sulfatos, sulfuros y cloruros

Estos análisis se han llevado a cabo mediante espectrofotometría de absorción atómica y fluorescencia de rayos-X. Del análisis completo se pueden extraer los rangos e intervalos en los que están presentes los diferentes óxidos y un valor medio.

\begin{tabular}{lll} 
& \multicolumn{2}{c}{ Óxidos principales } \\
Óxido & Intervalo & Valor medio \\
$\mathrm{FeO}$ & $7-35 \%$ & $25 \%$ \\
$\mathrm{Fe}_{2} \mathrm{O}_{3}$ & $11-40 \%$ & $25 \%$ \\
$\mathrm{CaO}$ & $23-32 \%$ & $25 \%$ \\
$\mathrm{SiO}_{2}$ & $8-15 \%$ & $11 \%$ \\
$\mathrm{Al}_{2} \mathrm{O}_{3}$ & $3,5-7 \%$ & $5 \%$ \\
$\mathrm{MgO}_{\mathrm{MnO}}$ & $4,8-6,6 \%$ & $5 \%$ \\
$\mathrm{MnO}$ & $4 \%$
\end{tabular}


De la composición química evaluada destaca que la mitad son óxidos de hierro, lo cual tiene lógica puesto que los componentes principales utilizados para la fabricación de acero es chatarra. También es importante la presencia de Cal (óxido de calcio), que viene a ser una cuarta parte del total. Prácticamente todo el material de la escoria negra son óxidos simples o combinados.

\section{Magnesia y cal libre}

El contenido de magnesia y cal libre es importante ya que determina la estabilidad dimensional y volumétrica de la escoria. Ortega $\vee$. [43] ha realizado uno de los ensayos determinados en la norma UNE-EN 17441 para determinar la cal libre en las escorias de fundición de acero.

Según los resultados de su análisis (Tabla 19) el contenido medio de Cal libre oscila entre 0,20 y 1,20\%. Se deberá procurar conseguir las escorias con menor contenido en cal libre, para así controlar la estabilidad volumétrica.

Según estos mismos datos, el contenido en magnesia oscila entre 4,90 y $6,65 \%$. Sin embargo el valor de la magnesia libre es muy bajo, puesto que la mayor parte de esta se encuentra combinada.

\begin{tabular}{lll}
\multicolumn{2}{c}{ Magnesia y cal libre } \\
Óxido & Intervalo & Valor medio \\
Cal libre & $0,20-1,20 \%$ & $0,77 \%$ \\
Magnesia & $4,90-6,65 \%$ & $5,58 \%$ \\
\hline Tabla 19. Cal libre y magnesia total presentes en EAFS &
\end{tabular}

Tabla 19. Cal libre y magnesia total presentes en EAFS

\section{Sulfatos, cloruros y sulfuros}

Finalmente también Ortega $V$. [44] analiza la presencia de cloruros y sulfuros en las muestras según la UNE-EN 1744-Parte 1. Según los resultados (Tabla 20) la presencia de sulfatos es bastante baja y la casi ausencia de cloruros y sulfuros, ya que las escorias negras tipo EAFS carecen de este tipo de compuestos y suelen estar en las blancas.

\begin{tabular}{lll} 
& \multicolumn{2}{c}{ Sulfatos, cloruros y sulfuros } \\
Óxido & Intervalo & Valor medio \\
Azufre total en SO3- & $0,20-0.5 \%$ & $0,37 \%$ \\
Sulfatos solubles en SO3- & $0,18-0,5 \%$ & $0,33 \%$ \\
Cloruros Cl- & & \\
\multicolumn{2}{l}{ Tabla 20. Sulfatos, cloruros y sulfuros presentes en EAFS } &
\end{tabular}

No existe una normativa de referencia con la que poder establecer valores límites de estos compuestos. La instrucción de hormigón armado estructural (EHE-08) establece unos valores de máximos de un $1 \%$ para el Azufre, $0,80 \%$ para los Sulfatos y 0,05\% para los Cloruros. Los tres valores son adecuados para el uso como agregados estructurales por lo que se consideran adecuados para morteros. 


\subsubsection{Caracterización física}

\section{Granulometría}

Los ensayos granulométricos realizados por Ortega $V$. [45] se han realizado según la norma UNE-EN 933-1.

La serie granulométrica obtenida es la siguiente:

$\begin{array}{lrrrrrrrrrrrrr}\begin{array}{l}\text { Tamiz } \\ (\mathrm{mm})\end{array} & 20 & 40 & 25 & 20 & 16 & 10 & 8 & 4 & 2 & 5 & 0,25 & 0,125 & 0,063 \\ \% \text { Pasa } & 100 & 100 & 94,3 & 88,4 & 80 & 62 & 54,3 & 28,7 & 11,6 & 1,1 & 0,5 & 0,2 & 0,1\end{array}$

Tabla 21. Granulometría EAFS

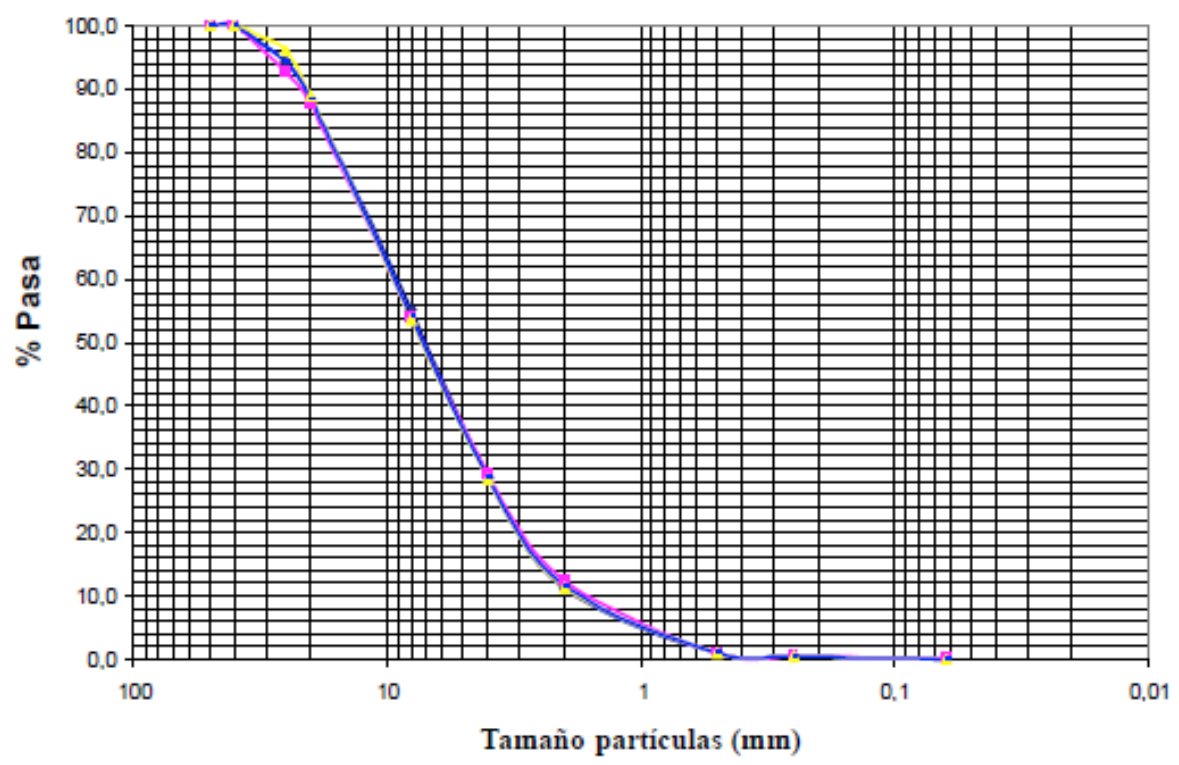

De acuerdo con los datos granulométricos se puede observar que existe una presencia alta de árido grueso y una menor distribución del árido intermedio y de los finos.

Para árido fino la norma UNE-EN 13139 de áridos para morteros recomienda 0/1, 0/2, 0/4, 0/8 y 2/8. Dado que este tipo de mortero es distinto a los convencionales, la escala granulométrica puede diferir para ajustarla a los propósitos de la investigación. Por ello, se emplea una granulometría con pocos finos para obtener una superficie más rugosa. La escala a utilizar estará en la horquilla entre 4 y $1 \mathrm{~mm}$.

Se elabora una nueva granulometría, esta vez extrayendo las escorias de una saca pre-cribada, con tamaño menor de $4 \mathrm{~mm}$. 


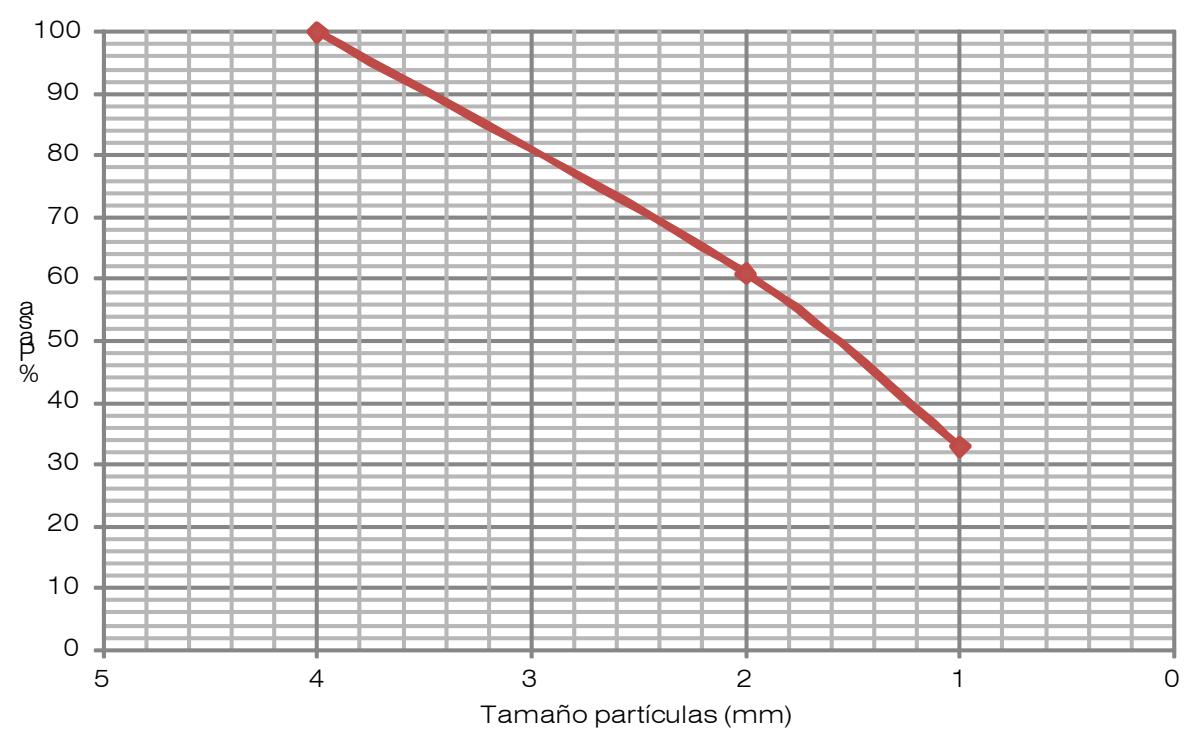

$\begin{array}{lrrr}\text { Tamiz }(\mathrm{mm}) & 4 & 2 & 1 \\ \text { \% Pasa } & 100 & 60,9 & 32,9\end{array}$

Tabla 22. Granulometría muestras a utilizar

El hecho de descartar los finos no supone que el mortero carezca de ellos. Los fillers inorgánicos del polvo de ciclón PC8 (Tabla 15), actúan a modo de árido, tal y como se ha constatado anteriormente.

\section{Densidad}

Para el estudio de la densidad de las EAFS se han considerado diferentes clases de este valor, para conseguir una caracterización más completa.

Por ello se han obtenido la densidad real y la aparente siguiendo las determinaciones de la UNE-EN 1097-6, discriminando la fracción granulométrica que más conviene de cara al objeto de la presente Tesis Doctoral.

$\begin{array}{ll} & \text { Tamaño 0/6 mm } \\ \text { Densidad real }\left(\mathrm{kg} / \mathrm{dm}^{3}\right) & 3,68 \\ \text { Densidad aparente }\left(\mathrm{kg} / \mathrm{dm}^{3}\right) & 3,74 \\ \text { Densidad conjunto }\left(\mathrm{kg} / \mathrm{dm}^{3}\right) & 2,3 \\ \text { Tabla 23. Densidad EAFS. Fuente [46] } & \end{array}$

De los datos obtenidos en la Tabla 23 y su estudio se pueden establecer las siguientes conclusiones:

- La densidad real de la escoria negra como material es mayor que la densidad media real de los cementos MPC $(\approx 3000$ $\left.\mathrm{kg} / \mathrm{m}^{3}\right)$, por lo que cabe considerarlo como un árido pesado, atendiendo al Código Modelo CEB-FIP 1990.

- Puesto que el mortero MPC no requiere de sustitución de árido, la comparación cabe únicamente entre la adición o no de EAFS frente a MPC. En este caso los $2,3 \mathrm{~kg} / \mathrm{dm}^{3}$ de densidad media 
del conjunto contrastan con los $1,25 \mathrm{~kg} / \mathrm{dm}^{3}$ de los morteros, suponiendo más de un $50 \%$ de aumento en peso.

\section{Porosidad y absorción de agua}

La porosidad y la capacidad de absorción de agua se consideran dos ensayos importantes, sobre todo desde un punto de vista bio-receptivo. Una mayor porosidad con una red porosa que permita al agua circular por ella es un modo con el que la presente Tesis Doctoral pretende incentivar la bio-receptividad del material resultante, más aún cuando la presencia de escorias, en peso, suponen entre un 40 - 50\% del producto final.

Estos ensayos se encuentran regulados por la norma UNE 1097-3 y la norma UNE 1097-6.

Sin embargo, para áridos finos, que son los que se utilizan en la investigación, no se tiene en consideración la porosidad. No obstante la porosidad puede estimarse basándose en los resultados de las EAFS de mayor tamaño (entre 10,68 \% y 6,95\%), aplicando una progresión lineal.

Dentro de las EAFS las que tienen una mayor capacidad de absorción de agua son las finas, pero sin sobrepasar el 5\%.

\begin{tabular}{ll} 
& Tamaño 0/6 mm \\
Absorción de agua (\%) & 3,65 \\
Porosidad (\%) & $\approx 12$ \\
\hline Tabla 24. Porosidad y absorción de agua. Fuente [47]
\end{tabular}

\section{Fabricación y caracterización del mortero}

\subsection{Muestras preliminares}

Para determinar el criterio de dosificación en las pruebas preliminares se han consultado los trabajos previos utilizados por otros autores, donde contemplan la utilización de magnesitas sintetizadas de alta pureza y sub-productos procedentes de la sintetización del óxido de magnesio, para la elaboración de morteros MPC.

Se distinguen las dosificaciones en función de la fuente de magnesio utilizada y de la adición o no de áridos en forma de escorias.

\subsubsection{Justificación de las dosificaciones empleadas}

\section{Magnesita sinterizada (83\% MgO)}

Según Manso, $S$ et al [48] el ratio adecuado para la elaboración del mortero bio-receptivo que se propone es de $\mathrm{NH} 4(\mathrm{H} 2 \mathrm{PO} 4)$ : $\mathrm{MgO}=1: 1,75$. Sin embargo éste se basa en la utilización de una magnesita de mayor pureza (98\%) a la que se propone en la presente tesis (83\%).

Debido a esta situación, se propone emplear una relación que contenga mayor concentración de $\mathrm{MgO}$ para que consiga reaccionar la totalidad del fosfato con la magnesita. Estimando esa diferencia de concentración de $\mathrm{MgO}$ en ambas magnesitas se debería multiplicar el ratio por 1,20 para compensar la pureza quedando una relación $\mathrm{NH} 4(\mathrm{H} 2 \mathrm{PO} 4): \mathrm{MgO}=1: 2,25$. 
Respecto a la utilización de tetraborato (Bórax), Na2B4O7·10H2O, existen dos posiciones bastante distantes. Por un lado la misma investigadora propone una concentración del $6 \%$ del peso del MPC. Sin embargo, por otro, la tesis doctoral de Formosa $J$ [49], recomienda una adición entre el 0,5 y $0,75 \%$.

Dado que la primera contempla un mortero con una magnesita de alta pureza (98\%) y la segunda propone la utilización de un sub-producto de $\mathrm{MgO}$ (55\%), en el presente caso se estima, inicialmente, una concentración en torno al 3\%.

Finalmente, respecto a la relación agua-cemento para el amasado, se toma como referencia la que propone Manso, $S$ et al de 0,28.

$\begin{array}{ll}\mathrm{NH}_{4}\left(\mathrm{H}_{2} \mathrm{PO}_{4}\right): \mathrm{MgO} & 1: 1,75-1: 2,25 \\ \mathrm{Na}_{2} \mathrm{~B}_{4} \mathrm{O}_{7} \cdot 10 \mathrm{H}_{2} \mathrm{O} & 3 \% \\ \text { agua /cemento } & 0,28\end{array}$

\section{Magnesita calcinada (65\% MgO)}

Según Manso, $S$. el ratio adecuado para la elaboración del mortero bioreceptivo que se propone es de $\mathrm{NH}_{4}\left(\mathrm{H}_{2} \mathrm{PO}_{4}\right)$ : $\mathrm{MgO}=1: 1,5$.

Al igual que con la magnesita sintetizada, no estamos utilizando productos de alta pureza en $\mathrm{MgO}$, de hecho en este caso se utiliza un sub-producto industrial con una pureza el 65\%.

Por ello se va a tomar como referencia la dosificación de Formosa J, ya que emplea en su tesis un sub-producto industrial (Low-grade MgO) de riqueza similar (55\%).

Sin embargo existe una diferencia, Formosa J. emplea como fuente ácida fosfato monopotásico de grado alimentario $\left(\mathrm{KH}_{2} \mathrm{PO}_{4}\right)$. Este se trata de un producto químico no-reactivo, a diferencia del dihidrógeno fosfato de amonio, por lo que será interesante la optimización del ratio con una mayor concentración de magnesita calcinada, del orden de $1: 1,175 \circ 1: 2,00$.

Para controlar la velocidad de reacción Formosa J. emplea ácido bórico en una concentración entre 0,5 y 0,75\%. Existen ciertas diferencias entre ambas tesis. Por un lado se utiliza tetraborato de sodio de alta pureza en vez del ácido bórico. Por otro lado en la investigación objeto de la tesis se utilizan ambos productos de mayor pureza y reactividad, por lo que cabe la posibilidad de que requieran una mayor necesidad de retardador de fraguado. Se propone una concentración en torno al $1 \%$.

Finalmente, respecto a la relación agua-cemento para el amasado Formosa J. recomienda un ratio de 0,24.

$\begin{array}{ll}\mathrm{NH}_{4}\left(\mathrm{H}_{2} \mathrm{PO}_{4}\right): \mathrm{MgO} & 1: 1,50-1: 20 \\ \mathrm{Na}_{2} \mathrm{~B}_{4} \mathrm{O}_{7} \cdot 1 \mathrm{OH}_{2} \mathrm{O} & 1 \% \\ \text { agua /cemento } & 0,24\end{array}$




\section{Escoria negra de horno eléctrico de arco (EAFS).}

En cuanto a la adición de escorias negra de horno eléctrico (EAFS), no existe una bibliografía específica en base a morteros de fosfato magnesio (MPC).

Si que existe alguna aportación referente al humo de sílice [50], también sub-producto procedente del horno eléctrico de arco. En este estudio se indica que la adición de un 40-60\% del peso total en este sub-producto confiere una resistencia óptima al cemento químico cerámico de fosfato enlazados químicamente (CBPC).

Por otro lado sí que se tiene constancia de la utilización de EAFS en morteros convencionales, algunos de ellos en estudios realizados por el grupo de investigación en Ingeniería de Edificación de la UBU [51] [52] [53], utilizando como conglomerante tanto cementos, hormigones como yesos.

La escasa literatura acerca del aporte de escorias negras (EAFS) a cementos de magnesio fosfato (MPC) hace que la presente investigación se base en los estudios elaborados a partir de cementos convencionales, intentando conseguir a su vez una textura adecuada para la bio-receptividad.

En base a esto se estima como adecuado la adición de un 50\% del peso total de los conglomerantes.

\subsubsection{Fabricación de las muestras preliminares}

Se ha procedido a elaborar unas muestras previas a las probetas definitivas. Esto se debe a la inexistencia de investigaciones que utilicen las mismas materias primas que la presente tesis. De este modo se pretende conseguir una dosificación basada en las investigaciones previas, determinadas en el anterior punto, pero con una mayor precisión en base a una metodología empírica.

Los morteros de referencia se han fabricado con los tres tipos de óxido de magnesio determinados antes (Magnesita sintetizada $<1 \mathrm{~mm}$ (Mag7); Magnesita sintetizada Impalpable (ImpalMag) y Magnesita calcinada (PC8). Por el contrario solo se ha utilizado un único tipo de Dihidrógeno fosfato de amonio y de Borax.

Este protocolo se ha dividido en dos fases. Una primera en la que se elabora sin la adición de escorias EAFS y otra en la que se adicionan. Para estos últimos se ha añadido una cantidad igual al peso del conjunto de magnesita y dihidrógeno fosfato de amonio.

Las muestras se han elaborado en forma de placa de $100 \mathrm{~mm} \times 100$ $\mathrm{mm} \times 1,5 \mathrm{~mm}$ confeccionado una sola probeta en cada amasada

En las Tablas Tabla 25, Tabla 26 y Tabla 27 se explicitan las dosificaciones empleadas, siendo el peso aproximado del conjunto empleado, unos 375 gramos por placa. 


\begin{tabular}{|c|c|c|c|c|c|c|}
\hline & Dosif. 1 & Dosif. 2 & Dosif. 3 & Dosif. 4 & Dosif. 5 & Dosif. 6 \\
\hline MgO 83\%, Mag7 & $x$ & $x$ & & & & \\
\hline MgO 83\%, ImpalMag & & & $x$ & & & \\
\hline PC8 (MgO 65\%) & & & & $x$ & $x$ & $x$ \\
\hline $\mathrm{NH} 4(\mathrm{H} 2 \mathrm{PO} 4) 99 \%$ & $1: 1,75$ & $1: 2,25$ & $1: 2,25$ & $1: 2,50$ & $1: 2,50$ & $1: 2,50$ \\
\hline $\mathrm{Na} 2 \mathrm{~B} 4 \mathrm{O} 7 \cdot 1 \mathrm{OH} 2 \mathrm{O}$ & $3 \%$ & $3 \%$ & $1 \%$ & $3 \%$ & $3 \%$ & $3 \%$ \\
\hline Ratio Escoria/MPC & $1: 1,5$ & $1: 1$ & & $1: 1$ & $1: 1$ & \\
\hline Ratio agua/MPC & 0,5 & 0,28 & 0,20 & 0,56 & 0,76 & 0,70 \\
\hline \multicolumn{7}{|c|}{ Tabla 25. Muestras preliminares } \\
\hline & Dosif. 7 & Dosif. 8 & Dosif. 9 & $\begin{array}{l}\text { Dosif. } \\
10\end{array}$ & $\begin{array}{l}\text { Dosif. } \\
11\end{array}$ & $\begin{array}{l}\text { Dosif. } \\
12\end{array}$ \\
\hline MgO 83\%, Mag7 & & & & $x$ & $x$ & \\
\hline MgO 83\%, ImpalMag & & & & & & $x$ \\
\hline PC8 (MgO 65\%) & $x$ & $x$ & $x$ & & & \\
\hline $\mathrm{NH} 4(\mathrm{H} 2 \mathrm{PO} 4) 99 \%$ & $1: 2,50$ & $1: 1,75$ & $1: 1,75$ & $1: 1,75$ & $1: 2,25$ & $1: 1,75$ \\
\hline $\mathrm{Na} 2 \mathrm{~B} 4 \mathrm{O} 7 \cdot 1 \mathrm{OH} 2 \mathrm{O}$ & $3 \%$ & $3 \%$ & $3 \%$ & $3 \%$ & $3 \%$ & $5 \%$ \\
\hline \multicolumn{7}{|l|}{ Ratio Escoria/MPC } \\
\hline Ratio agua/MPC & 0,76 & 0,28 & 0,58 & 0,20 & 0,20 & 0,28 \\
\hline \multicolumn{7}{|c|}{ Tabla 26. Muestras preliminares } \\
\hline & $\begin{array}{l}\text { Dosif. } \\
13\end{array}$ & $\begin{array}{l}\text { Dosif. } \\
14\end{array}$ & $\begin{array}{l}\text { Dosif. } \\
15\end{array}$ & $\begin{array}{l}\text { Dosif. } \\
16\end{array}$ & $\begin{array}{l}\text { Dosif. } \\
17\end{array}$ & $\begin{array}{l}\text { Dosif. } \\
18\end{array}$ \\
\hline MgO 83\%, Mag7 & & & & $x$ & & \\
\hline MgO 83\%, ImpalMag & $x$ & & & & $x$ & \\
\hline PC8 (MgO 65\%) & & $x$ & $x$ & & & $x$ \\
\hline $\mathrm{NH} 4(\mathrm{H} 2 \mathrm{PO} 4) 99 \%$ & $1: 1,25$ & $1: 1,75$ & $1: 1,25$ & $1: 2,25$ & $1: 2,25$ & $1: 1,75$ \\
\hline $\mathrm{Na} 2 \mathrm{~B} 4 \mathrm{O} 7 \cdot 1 \mathrm{OH} 2 \mathrm{O}$ & $5 \%$ & $10 \%$ & $10 \%$ & $3 \%$ & $5 \%$ & $10 \%$ \\
\hline Ratio Escoria/MPC & & & & $1: 1$ & $1: 1$ & $1: 1$ \\
\hline Ratio agua/MPC & 0,28 & 0,36 & $>0,36$ & 0,20 & 0,28 & 0,36 \\
\hline
\end{tabular}

\section{Proceso de elaboración}

Para la elaboración de estas mezclas se utilizan, preferentemente, materiales plásticos, puesto que la adherencia del mortero MPC al metal es elevada.

El proceso de elaboración que se ha seguido para confeccionar el mortero MPC, es el siguiente:

1. Pesado de los componentes en balanza de precisión.

2. Mezclado de los componentes en seco: Magnesita, Dihidrógeno fosfato de amonio y bórax. Si la dosificación contiene escoria, también se agrega la escoria.

3. Adición de agua.

4. Amasado manual de los componentes durante 2-5 minutos hasta conseguir una masa homogénea. El tiempo de amasado depende directamente de la magnesita utilizada.

5. Vertido de la masa sobre el molde plástico utilizado. 
6. Curado de las mezclas en cámara de curado.
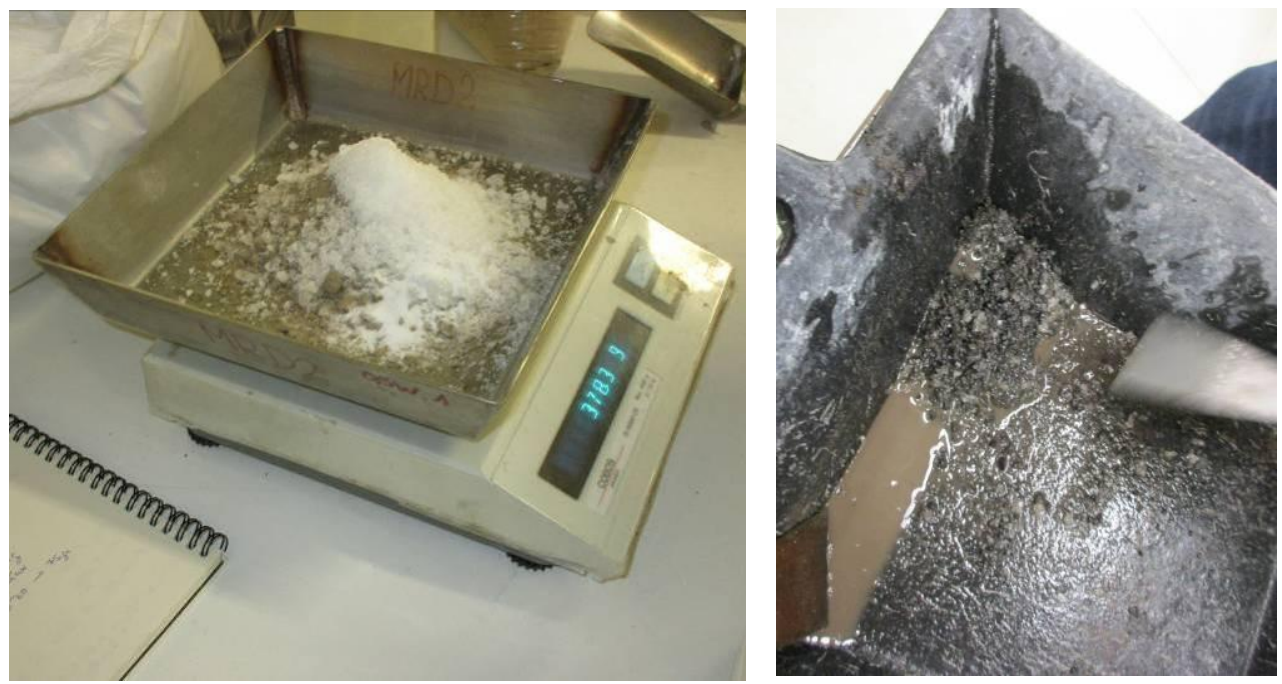

Imagen 88. Proceso de elaboración muestras

\section{Conclusiones}

\section{Dosificación 1}

Se toma la dosificación elaborada en base a la bibliografía consultada.

El ratio agua-cemento recomendado en la bibliografía es de 0,28. Dado que en la bibliografía no se añadía árido, aumentamos el ratio hasta 0,50 para hidratar las EAFS.

El NH4H2PO4 se presenta en forma de cristal.

El producto final es desechado. El agua de amasado ha sido excesiva y la presencia de numerosos cristales de $\mathrm{NH} 4 \mathrm{H} 2 \mathrm{PO} 4$ indica que no ha reaccionado con la magnesita.

Dosificación 2 (Imagen 89)

Esta dosificación difiere respecto a la anterior en lo siguiente:

- Se utiliza el ratio agua-cemento de la bibliografía.

- Se utiliza el rango alto del abanico de las dosificaciones de la bibliografía (1:2.25) en la relación de la magnesita con el dihidrógeno fosfato de amonio.

Durante el amasado se sigue observando un exceso de agua de amasado y varios cristales de dihidrógeno fosfato de amonio que no se han disuelto.

El tiempo de endurecido no es inmediato, es mayor a dos horas. El resultado es interesante, ya que presenta una resistencia aparentemente buena y un aspecto y rugosidad adecuados.

Dosificación 3 (Imagen 90)

Esta dosificación difiere respecto a la anterior en lo siguiente:

- Se utiliza el ImpalMag en vez de Mag7

- Visto el exceso de agua de la anterior dosificación, se reduce el ratio agua cemento. 
- Se utiliza, de nuevo, el rango alto del abanico de las dosificaciones de la bibliografía (1:2.25) en la relación de la magnesita con el dihidrógeno fosfato de amonio.

- Se machacan ligeramente los cristales de dihidrógeno fosfato de amonio, para ver si se consigue que reaccione en su totalidad con la magnesita.

- Se reduce la adición de Borax, para buscar una reacción más rápida.

El producto final es desechado, ya que la rápida reacción no ha hecho viable la posibilidad de verter la masa al molde. De hecho la reacción es fuertemente exotérmica y genera un fuerte olor a amoniaco.

En este caso la reducción del tamaño de partícula de la magnesita (de $<1 \mathrm{~mm}$ a impalpable) ha hecho que la reacción sea más rápida.

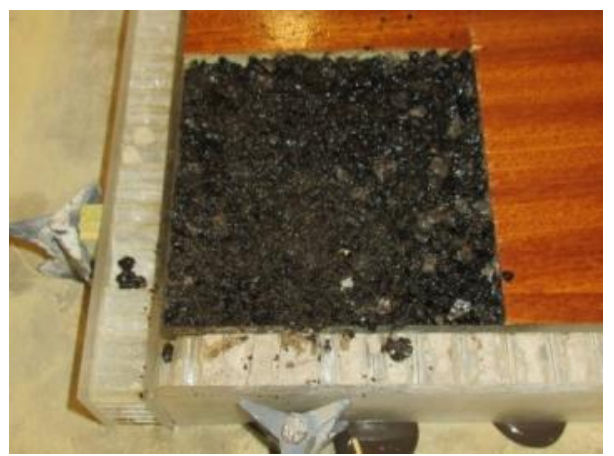

Imagen 89. Probeta dosificación 2

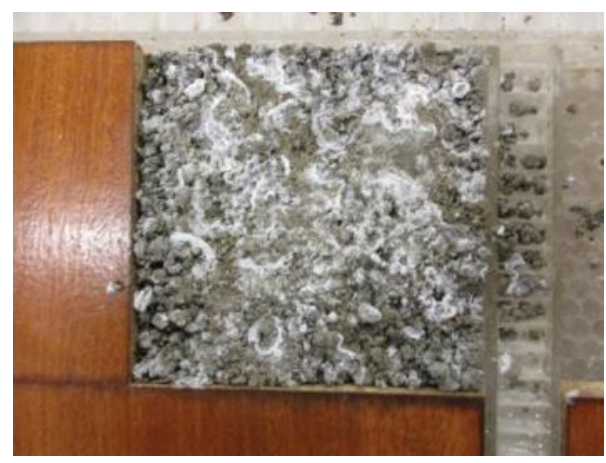

Imagen 91. Probeta dosificación 4

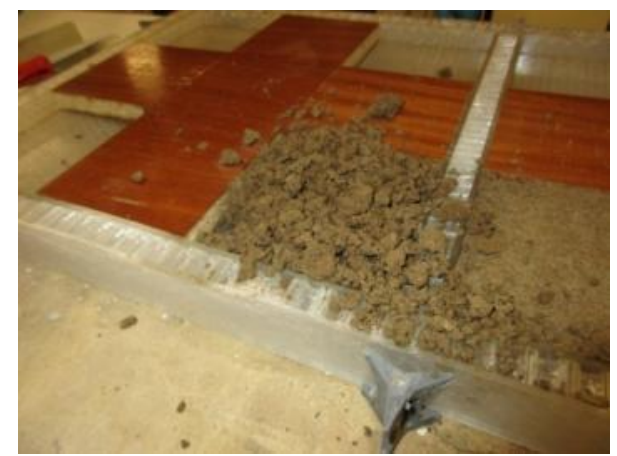

Imagen 90. Probeta dosificación 3

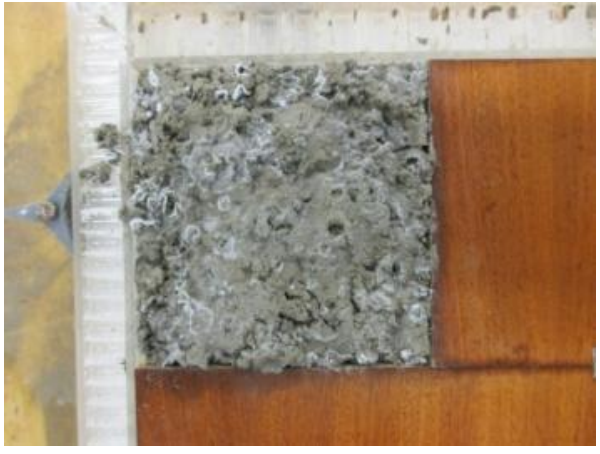

Imagen 92. Probeta dosificación 5

\section{Dosificación 4 (Imagen 91)}

Esta dosificación difiere respecto a la anterior en lo siguiente:

- Se utiliza el subproducto PC8

- Se utiliza un rango más elevado en la relación de la magnesita con el dihidrógeno fosfato de amonio $(1: 2,50)$.

- Visto que el ratio agua/cemento de la anterior dosificación, utilizando también una mezcla en polvo, era escaso y retrasaba y complicaba el amasado, se aumenta.

- Visto el endurecimiento tan rápido, se triplica la dosificación de Bórax, volviendo a la recomendada en la bibliografía. 
El producto final tiene una consistencia demasiado seca $y$, aparentemente poco cohesionada. Una vez seca, se comprueba que la muestra disgrega al aplicar una pequeña fuerza con la mano.

Superficialmente aparecen multitud de eflorescencias.

Dosificación 5 (Imagen 92)

Esta dosificación únicamente difiere de la anterior en la relación aguacemento. La dosificación anterior tenía una consistencia demasiado seca, por lo que se aumenta más el ratio.

El resultado tiene una consistencia aparentemente seca y no muy cohesionada. Una vez fraguada, se comprueba que la muestra disgrega al aplicar fuerza con las manos.

Superficialmente aparecen multitud de eflorescencias.

Dosificación 6 (Imagen 93)

Esta dosificación únicamente difiere de la anterior en dos cosas:

- No se añade árido (EAFS). Se va a intentar controlar primero la dosificación con polvo de ciclón (PC8) y sin árido.

- Se varía levemente la relación agua-cemento, para ajustarla a la ausencia de escorias.

El resultado tiene una consistencia un poco seca y poco cohesionada. Una vez fraguada y desmoldadas, se comprueba que la muestra disgrega al aplicar fuerza con las manos.

Superficialmente aparecen eflorescencias.

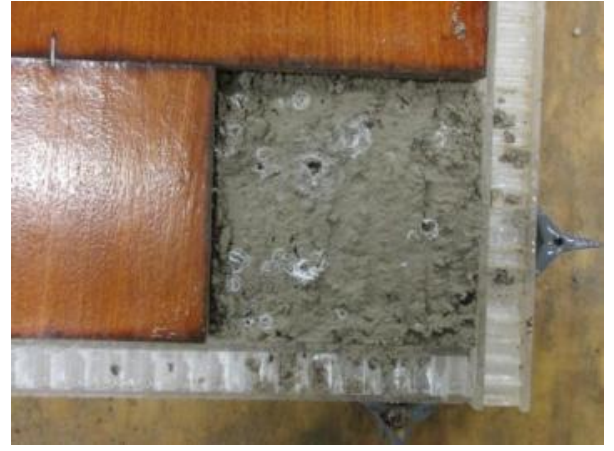

Imagen 93. Probeta dosificación 6

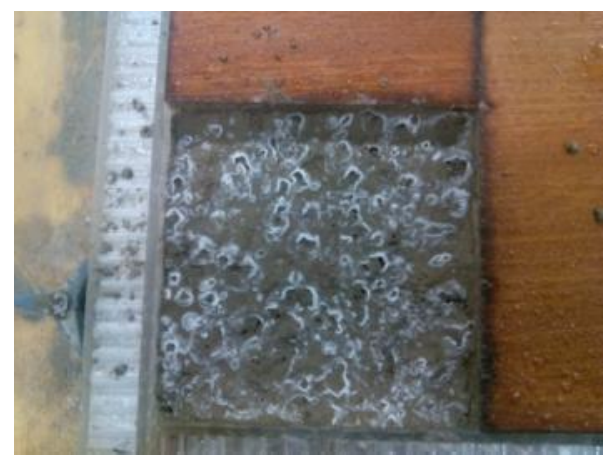

Imagen 95. Probeta dosificación 8

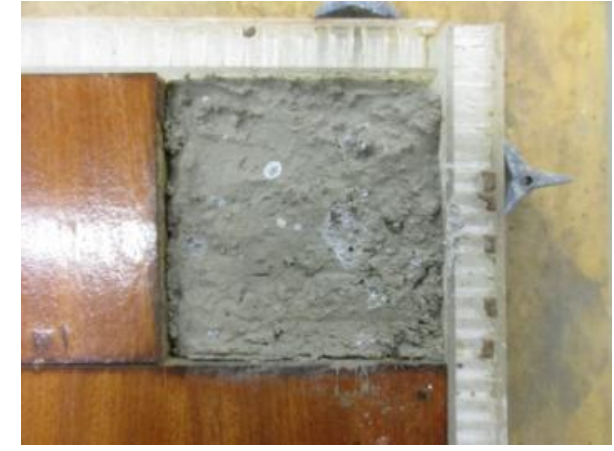

Imagen 94. Probeta dosificación 7

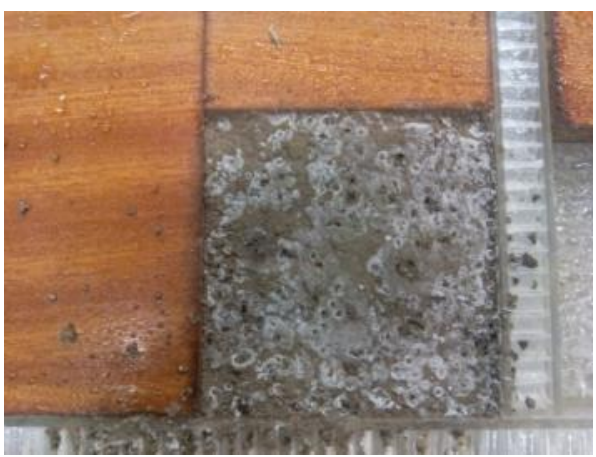

Imagen 96. Probeta dosificación 9 


\section{Dosificación 7 (Imagen 94)}

Esta dosificación únicamente difiere de la anterior en la relación aguacemento. La dosificación anterior tenía una consistencia demasiado seca, por lo que se aumenta más el ratio.

El resultado tiene una consistencia más fluida que la anterior y con una cohesión mayor. Sin embargo, una vez fraguada, se comprueba que la muestra, pese a tener mejor aspecto y mejor resistencia mecánica, vuelve a romperse al aplicar fuerza con las manos.

Superficialmente aparecen multitud de eflorescencias.

\section{Dosificación 8 (Imagen 95)}

Se replica la dosificación 2, pero sin agregar árido (EAFS) y sustituyendo la magnesita Mag7 por el polvo de ciclón PC8.

El resultado tiene una consistencia extremadamente seca y sin apenas cohesión. Una vez fraguada, la muestra se rompe en el proceso de desmolde, presentando resistencias mecánicas nulas.

Superficialmente aparecen eflorescencias masivas.

\section{Dosificación 9 (Imagen 96)}

Se replica la dosificación anterior, pero con una mayor concentración de agua.

Al igual que la anterior, el resultado tiene una consistencia muy seca y sin apenas cohesión. Una vez fraguada, la muestra se rompe en el proceso de desmolde, presentando resistencias mecánicas nulas.

Superficialmente aparecen eflorescencias masivas.

Una vez hechas estas dosificaciones preliminares parece haberse comprendido el comportamiento de las materias primas y cómo reaccionan, por lo que se proponen hacer dos dosificaciones con cada tipo de magnesita, dosificaciones 10 a 15.

Con la dosificación de las probetas que han presentado un mejor comportamiento se han replicado añadiendo escorias (EAFS) en concentración 1:1, dosificaciones 16 a 18.

\section{Dosificaciones 10 y 11}

El producto final presenta una resistencia aparentemente buena y un aspecto y rugosidad adecuados.

\section{Dosificaciones 12 y 13}

El producto final presenta una resistencia aparentemente muy buena.

La superficie es muy lisa, lo que podría influir negativamente en su bioreceptividad.

Superficialmente aparecen eflorescencias generalizadas.

\section{Dosificación 14 y 15}

El producto final difiere bastante entre una dosificación y otra. La dosificación 13 presenta una resistencia aparentemente buena rugosidad superficial, mientras que la dosificación 14 carece de la misma resistencia y cohesión.

Superficialmente aparecen eflorescencias, siendo mucho mayores en la dosificación 14. 


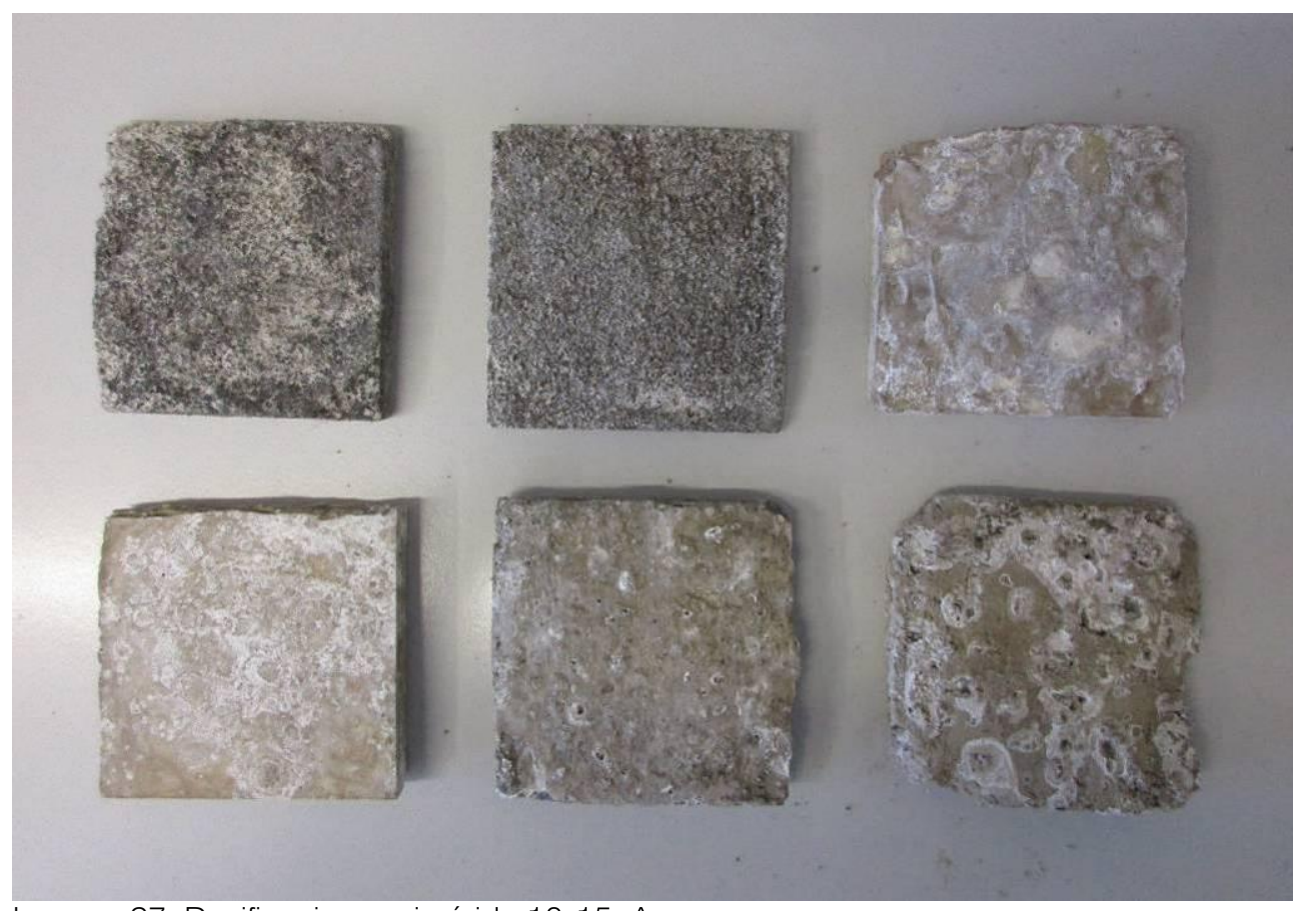

Imagen 97. Dosificaciones sin árido 10-15. Anverso

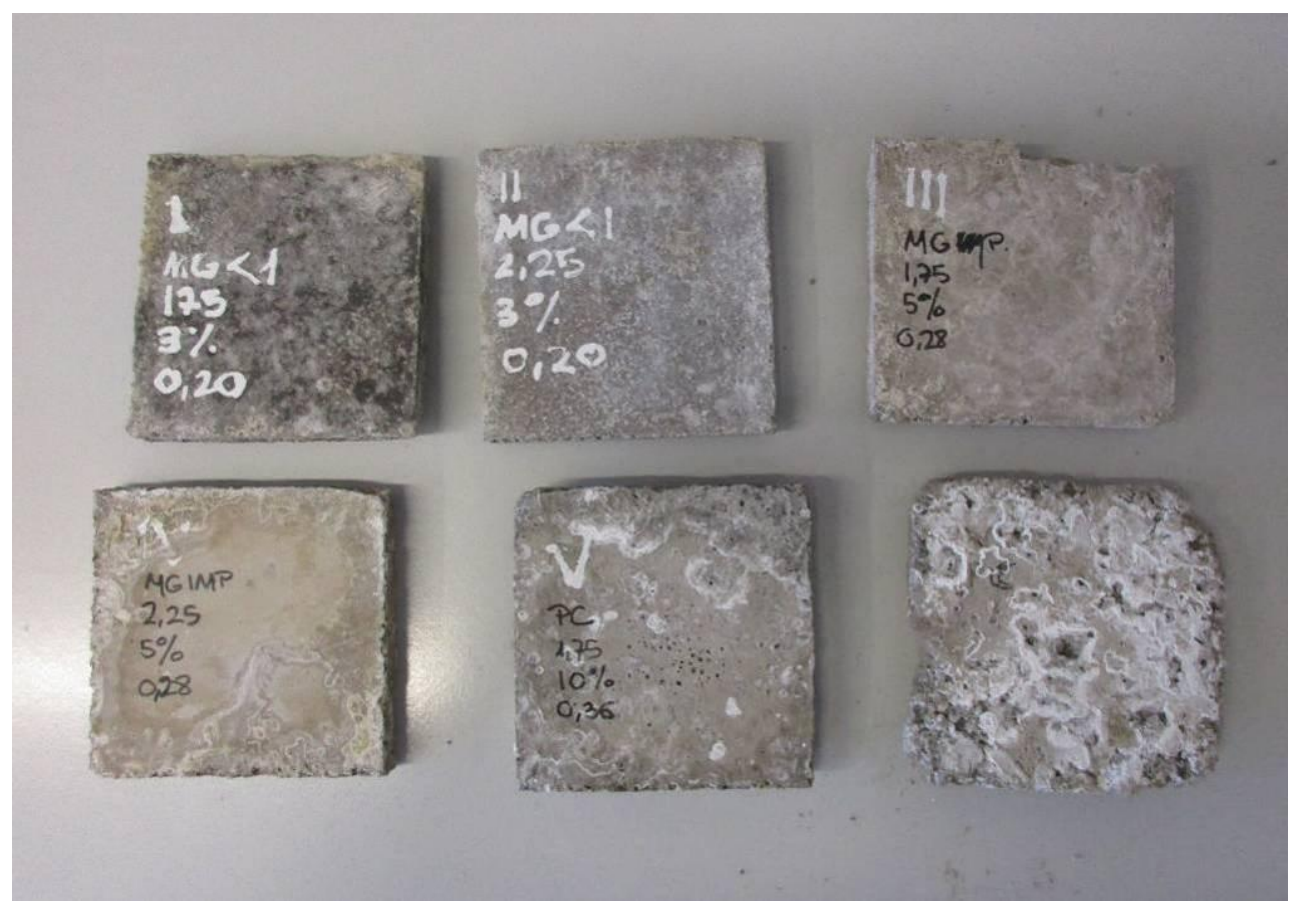

Imagen 98. Dosificaciones sin árido 10-15. Reverso

\section{Dosificación 16}

El producto final presenta una resistencia aparentemente muy buena y una rugosidad muy adecuada para adecuada.

Superficialmente aparecen eflorescencias.

\section{Dosificación 17}

El producto final presenta una resistencia aparentemente muy buena. La placa se rompe debido a su gran adherencia al molde. 
Superficialmente aparecen eflorescencias.

\section{Dosificación 18}

El producto final presenta una resistencia aparentemente buena.

Superficialmente aparecen numerosas eflorescencias.

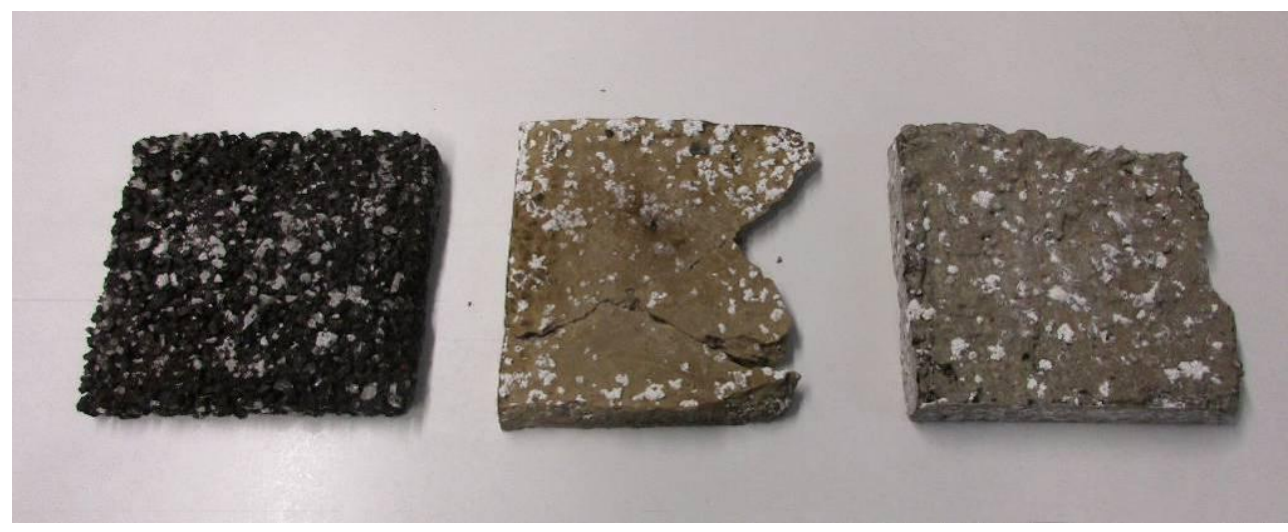

Imagen 99. Dosificaciones con EAFS 16-18. Anverso

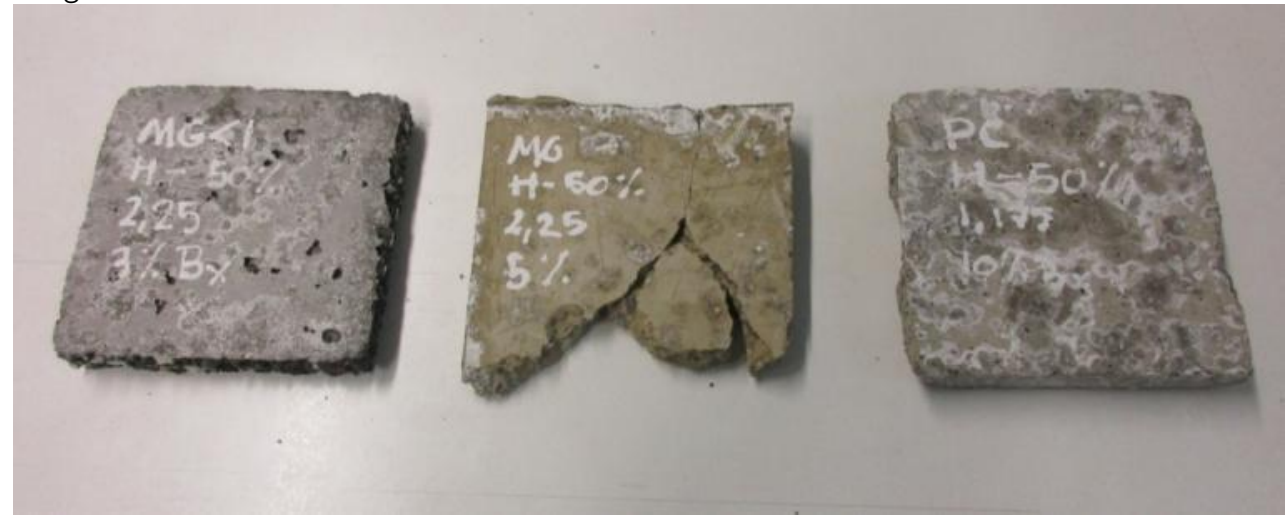

Imagen 100. Dosificaciones con EAFS 16-18. Reverso

De la experimentación anterior se pueden extraer varias conclusiones:

- Los morteros que utilizan un óxido de magnesio de mayor tamaño de partícula (Mag7), disponen de un mayor tiempo de trabajabilidad hasta que el mortero endurece.

- El ratio de agua-cemento aumenta en función de la pureza del óxido de magnesio y también del tamaño de partícula. Los morteros que contiene Mag7 son los que menos ratio de agua requieren frente a los que contienen PC8 que son los mayores.

- La reactividad del óxido de magnesio influye en una mayor concentración de bórax. De hecho los morteros que incluyen PC8 requieren tres veces el doble de bórax que los que adicional ImpalMag o el triple frente a los que llevan Mag7.

- Las placas con menor riqueza (PC8), para un mejor comportamiento endurecido, requieren menor ratio ácido-base que las que se realizan con productos de mayor pureza.

- Todas las muestras presentan eflorescencias, incluyendo las que adicionan EAFS, que aparecen en cristales de mayor tamaño. 


\subsection{Dosificación y fabricación del mortero de referencia.}

Los morteros MPC bio-receptivos que investiga la presente tesis se elaboran en base a una mezcla básicamente de dos productos que al reaccionar "cristalizan" formando el conjunto.

Este mortero se ha diseñado, en principio, en forma de placa o prisma, sin embargo también podría llegarse a utilizar revistiendo directamente un paramento.

La fabricación de este mortero se realiza mediante la mezcla homogénea de los componentes. Esta mezcla tiene que mantener una consistencia adecuada para conseguir un moldeado correcto del producto mientras se encuentra en estado fresco. Este concepto, denominado trabajabilidad, obliga a que el mortero mantenga una plasticidad que permita su adaptación al molde o al soporte sobre el cual piensa disponerse.

Por otro lado, una vez situadoen el molde, debe endurecerse de forma que logre las prestaciones de resistencia y durabilidad requeridas.

La caracterización de un mortero implica la caracterización del producto en los dos estados físicos en los que se encuentra: fresco (plástico) y endurecido (rígido). Sin embargo, en los morteros MPC el estado fresco no tiene la misma importancia que en los morteros convencionales fuera de la trabajabilidad, ya que la reacción ácidobase, al menos con los productos experimentados, es especialmente rápida y no se produce retracción significativa.

El presente apartado trata de determinar las propiedades y prestaciones de los morteros de fosfato magnesio (MPC), en los que la fuente de óxido de magnesio es un sub-producto industrial en forma de polvo de ciclón, denominado PC8.

Estas características, a falta de existencia de normativa específica, se evaluarán basándose en las Normas UNE-EN 998-1 y 998-2 de morteros para albañilería, haciendo referencia a los morteros diseñados.

La presente tesis investiga un mortero MPC que se elabora con un subproducto de óxido de magnesio y agrega un árido a base de escorias negras de horno eléctrico (EAFS). La inexistencia de experimentación con este tipo de mortero al que se le ha agregado a su vez árido, obliga a confeccionar morteros que puedan servir de referencia para ser comparados. Por ello se establecen en este apartado las características del mortero sin adición de escorias.

Previamente se han fijado las dosificaciones de las mezclas, en función de la experimentación llevada a cabo en los anteriores apartados. El objetivo es poder llevar a cabo una comparativa entre el producto con y sin agregado.

\subsubsection{Dosificación}

El mortero de referencia se ha fabricado con un único componente y una única dosificación. A esta dosificación se ha llegado después de varias pruebas que se han documentado a lo largo de la tesis.

Estos morteros se atienen a una dosificación de 1/1,75 entre el óxido de magnesio (PC8) y el dihidrógeno fosfato de amonio. 
Cumpliendo con los requisitos de consistencia de la norma se han confeccionado unas series de probetas de dimensiones $160 \times 40 \times 40$ $\mathrm{mm}$. Adicionalmente también se han elaborado otras probetas de dimensiones $50 \times 50 \times 50 \mathrm{~mm}$, con el fin de obtener el mayor número de probetas con el menor material posible.

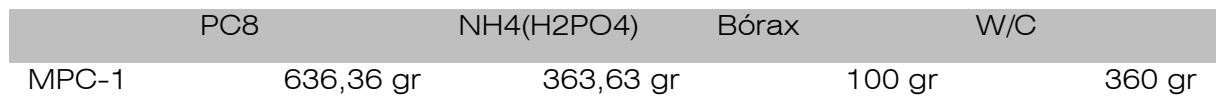

Tabla 28. Dosificación MPC con PC8 y sin EAFS para $1 \mathrm{~kg}$ de producto final

\subsubsection{Resultados obtenidos}

Las características ensayadas en los morteros de referencia son aquellas que permitan obtener los datos mínimos para caracterizar el material. También se evalúan las aptitudes que aumentan la bioreceptividad del producto resultante, como pueden ser la porosidad o la absorción de agua.

\section{Mortero fresco}

Los ensayos del mortero fresco que se ha realizado a estas mezclas ha consistido únicamente en el periodo de trabajabilidad. No se han realizado más puesto que no se considera necesario en este tipo de productos de endurecido rápido.

\section{Periodo de trabajabilidad}

La trabajabilidad, en los morteros tipo MPC, se entiende como el tiempo durante el cual el mortero no opone resistencia añadida a su moldeo. Este periodo es especialmente importante, a tenor de lo observado en la presente investigación, ya que la reacción ácido-base entre ambos componentes es súbita y rápida.

Si bien es verdad que influyen otros factores, ninguno se considera relevante, debido a que entre el comienzo de pérdida de plasticidad del mortero hasta el endurecido completo, no pasan más que pocos minutos.

El periodo de trabajabilidad de los morteros MPC difiere de los morteros tradicionales. Mientras que a estos, una vez comienza a perder plasticidad la masa fresca puede añadirse agua, en los MPC, al ser una reacción cristalizadora, no se han encontrado medios que aminoren la velocidad una vez comenzada.

Para el aumento de la trabajabilidad se ha agregado tetraborato de sodio (Bórax). Por el contrario, incrementar la relación agua/cemento no disminuye la velocidad de fraguado.

La norma UNE-EN 1015-9, define la trabajabilidad como el tiempo que tarda un mortero en alcanzar un cierto grado de rigidez, o lo que es lo mismo, una cierta resistencia al moldeo ocasionada por el inicio de fraguado del cemento, que se suma a la resistencia inicial del mortero recién amasado.

También se estima necesario el control del tiempo total en el que el mortero endurece por completo, no permitiendo moldeo. 


\begin{tabular}{ccc} 
& \multicolumn{2}{c}{ Tiempo (minutos) } \\
Trabajabilidad & $\begin{array}{c}\text { Endurecido } \\
\text { completo }\end{array}$ \\
Ensayo 1 & $0: 48$ & $1: 40$ \\
Ensayo 2 & $0: 52$ & $1: 58$ \\
Ensayo 3 & $0: 45$ & $1: 45$ \\
Ensayo 4 & $0: 42$ & $1: 39$
\end{tabular}

Tabla 29. Tiempo de trabajabilidad

De los resultados obtenidos se deduce que el tiempo de trabajabilidad no es baladí, ya que es tan bajo debido a la fuente de magnesio utilizada. En las muestras preliminares, en las cuales se utilizaron magnesitas calcinadas a muerte (Mag7 e Impalmag), el tiempo de trabajabilidad era más amplio permitiendo un periodo suficiente en estado fresco.

Esta velocidad de reacción tan acentuada es debido a la presencia de los óxidos $\mathrm{MgO}$ y $\mathrm{CaO}$ activos en el PC8, con tendencia a interaccionar con el agua hidratándose con una reacción exotérmica, mientras que en las otras magnesitas utilizadas estos óxidos están calcinados a muerte y su interacción es muy lenta o casi nula.

En consulta con la empresa suministradora Magnesitas Navarras S.A., se ha sugerido la hidratación previa del PC8, inferior a 24 horas puesto que una vez pasado se consigue la hidratación total del PC8.

\section{Características físicas}

\section{Densidad aparente}

Para determinar la densidad aparente del mortero endurecido se ha empleado la norma UNE-EN 1015-10. La densidad depende, en último término, de la densidad de los componentes por separado y la compactación que se haya llevado a cabo.

\begin{tabular}{lllllll}
\multicolumn{7}{c}{ Pesos y densidad del MPC endurecido } \\
& Peso seco & Peso saturado & Peso sumergido & Volumen & Densidad \\
& gr & gr & gr & $\mathrm{cm}^{3}$ & $\mathrm{~kg} / \mathrm{m}^{3}$ \\
Ensayo 1 & 129,3 & 166,6 & 49,9 & 116,7 & 1110 \\
Ensayo 2 & 133,7 & 165,0 & 54,0 & 111,0 & 1200 \\
Ensayo 3 & 323,0 & 363,6 & 107,4 & 256,2 & 1260 \\
Ensayo 4 & 322,8 & 368,7 & 108,7 & 260,0 & 1240 \\
& & & & Valor medio & 1200
\end{tabular}

Tabla 30. Densidad del MPC endurecido

\section{Absorción de agua}

La presencia de agua en las superficies externas de las fachadas pueden provenir de diferentes fuentes: precipitaciones del agua de lluvia, por capilaridad desde el terreno, por las condiciones de humedad ambientales o por un aporte adicional externo.

Esta humedad presente en la cara exterior del cerramiento puede resbalar por la superficie y precipitarse o bien por permeabilidad penetrar hacia el interior. Tradicionalmente se ha intentado inhibir 0 , al menos, intentar reducir la capacidad de absorción de agua, ya que 
provoca el deterioro del acabado incluso fomenta la aparición de hongos.

Sin embargo el mortero MPC bio-receptivo que investiga la presente Tesis Doctoral busca una capacidad de absorción y retención de agua elevada, a fin de crear un medio adecuado para la proliferación de la vida vegetal y conseguir que prospere la especie briófita que se va a utilizar como especie pionera.

No existe una normativa específica para evaluar la capacidad de absorción en los morteros MPC. Esta se evalúa según la norma UNEEN 1015-18 para los morteros convencionales. Esta absorción depende de la porosidad y la morfología de los poros. Dado que se busca una red capilar con micro-poros o poros pequeños, con parte de ellos abiertos, el coeficiente de absorción será un indicativo de su presencia.

\begin{tabular}{llll} 
& \multicolumn{3}{l}{ Coeficiente de absorción de agua } \\
& $\mathrm{M} 1$ & $\mathrm{M} 2$ & $\mathrm{C}$ \\
& $\mathrm{gr}$ & $\mathrm{gr}$ & \\
Ensayo 1 & 197,9 & 212,6 & 1,47 \\
Ensayo 2 & 212,1 & 228,3 & 1,62
\end{tabular}

Tabla 31. Coeficiente de absorción de agua MPC

Los coeficientes de absorción son extremadamente mayores que los de morteros tradicionales con cemento Portland. Mientras que estos últimos pueden situarse entre 0,10 y 0,30 el mortero MPC quintuplica estos resultados.

Esto puede deberse, a que la cristalización del mortero MPC al ser una reacción rápida y exotérmica, genera una red capilar desarrollada, que facilita una mayor absorción de agua.

\section{Características mecánicas}

Para la realización de los ensayos de resistencias mecánicas se han utilizado probetas de $40 \times 40 \times 160 \mathrm{~mm}$ que se rompen inicialmente en dos trozos a flexotracción y que posteriormente se ensayan a compresión.

No existe una normativa que contemple los ensayos de resistencias mecánicas de los morteros MPC. Se toma como referencia la norma UNE-EN 1015-11, para la determinación de la resistencia a flexión y compresión del mortero endurecido. Esta norma hace referencia a los morteros de albañilería, pero es la más adecuada para la obtención de la información requerida.

No obstante las normas de los morteros para albañilería exigen como requisito una resistencia mínima a compresión a los 28 días. Para el presente ensayo, dado que el mortero MPC funciona de manera diferente, no es necesario esperar ese periodo de tiempo y se tomarán datos pasados un mínimo de 7 días.

\section{Resistencia a flexión}

La resistencia a flexión es un parámetro que no se suele determinar en los morteros de albañilería tradicionales. El mortero MPC que se investiga puede tener una serie de usos que van desde su disposición 
como revestimiento hasta la formación de placas autoportantes, cobrando, de este modo, mayor importancia la resistencia a flexión.

También cabe tener en consideración que un mortero dispuesto como revestimiento de un muro puede estar a merced de diversos esfuerzos a flexión, derivados de agentes climatológicos externos.

\section{Resistencia a compresión}

Los resultados obtenidos de resistencia a compresión son una prueba fehaciente de la capacidad resistente del mortero. Para evaluar esta resistencia se ha vuelto a tomar en consideración la normativa de morteros de albañilería, Norma UNE-EN 1015-11.

El valor de referencia a compresión de los morteros de albañilería tradicionales se sitúa entre $1 \mathrm{~N} / \mathrm{mm}^{2}$ y $7,5 \mathrm{~N} / \mathrm{mm}^{2}$. No obstante estos valores no son especialmente representativos, ya que su utilización habitual viene a ser en juntas de trabazón en las fábricas.

Por ello, en los criterios de referencia se establecieron unos mínimos pensados para las resistencias a flexión y compresión. Según las resistencias deseadas serían mayores de $2 \mathrm{~N} / \mathrm{mm}^{2}$ a flexión y mayores de $5 \mathrm{~N} / \mathrm{mm}^{2}$ a compresión. De esta manera se consigue un producto con mejores prestaciones que las mínimas determinadas por la propia normativa.

En la Tabla 32 se relacionan las resistencias a flexión y compresión de las probetas evaluadas.

\begin{tabular}{lll} 
& \multicolumn{2}{c}{ Resistencia a flexión-compresión MPC } \\
& Resistencia a flexión & Resistencia a compresión \\
& $\mathrm{N} / \mathrm{mm}^{2}$ & $\mathrm{~N} / \mathrm{mm}^{2}$ \\
Ensayo 1 & 0,95 & 4,60 \\
& & 7,45 \\
Ensayo 2 & 0,50 & 2,90 \\
& & 4,60 \\
Ensayo 3 & 2,20 & 4,45 \\
& & 4,70 \\
Ensayo 4 & 2,00 & 4,30 \\
& & 3,90 \\
Valor medio & 2,1 & 4,4
\end{tabular}

Tal y como se observa, los resultados resultan dispares.

A la hora de obtener la resistencia media descartamos los valores muy dispares. Por ello en la Resistencia a flexión descartamos los valores de los ensayos 1 y 2 y en la Resistencia a compresión rechazamos el valor más bajo (ensayo 2.1) y el más alto (ensayo 1.2)

Tal y como se puede observar, las muestras evaluadas alcanzan la resistencia mínima establecida a flexión en los valores no descartados. Sin embargo se tratan de valores muy ajustados, que pueden llegar a comprometer el uso del mortero en placas.

El comportamiento a compresión tampoco es especialmente bueno, no llegando al mínimo de $5 \mathrm{~N} / \mathrm{mm}^{2}$ que se buscaba. 


\section{Durabilidad}

La durabilidad se puede definir como la capacidad de un elemento de resistir, durante su vida útil, las condiciones físico-químicas a las que está expuesto.

Uno de los objetivos de la presente tesis es analizar si el mortero tiene ciertas propiedades durables a lo largo de su periodo útil. De este modo se evalúa uno de los principales agentes a los que estaría sometido el mortero MPC como es la heladicidad.

Esto se debe a que el mortero va a tener siempre un cierto grado de humedad por su utilización como elemento biocolonizable. Tanto una vez endurecido, como con el agua aportado exteriormente, el mortero contendrá agua en los poros. Esta agua, al congelarse, puede aumentar hasta un 9\% su volumen. Por esto la acción del hielo-deshielo tiene relevancia especialmente en latitudes continentales.

\section{Resistencia a la heladicidad}

Los ciclos de hielo-deshielo cuando los poros tienen un nivel de saturación, por el agua contenida, que cuando se congela no dispone de espacio suficiente para expandirse.

Esta resistencia viene condicionada por el tamaño de los poros. Cuanto menor es el tamaño de los poros, mayor es la presión a la que están sometidos, por lo que el fenómeno estudiado se producirá a una menor temperatura de congelación [54].

El comportamiento frente a los ciclos de hielo-deshielo se evalúa utilizando de marco experimental las normas UNE-67028-EX [55] y UNE-EN 12371:2011 dado que no existe una normativa específica que determine el procedimiento a seguir.

El procedimiento descrito en la metodología experimental, determina un periodo de congelación de 16 horas y un periodo de descongelación mediante inmersión en agua de 6 horas.

Durante todo el proceso, 15 ciclos, se han inspeccionado visualmente las probetas para ver si se producían fisuras o alteraciones significativas en su aspecto.

Los resultados del presente ensayo se evalúan en dos parámetros: pérdida de volumen y pérdida de resistencias mecánicas.

\begin{tabular}{lllll}
\multicolumn{5}{c}{ Variación de volumen MPC endurecido $\left(\mathrm{cm}^{3}\right)$} \\
& Ciclo 0 & Ciclo 7 & Ciclo 15 & \\
Ensayo 1 & 256,2 & 255,8 & 255,3 & $-0,35 \%$ \\
Ensayo 2 & 260,0 & 259,8 & 258,3 & $-0,65 \%$
\end{tabular}

Tabla 33. Variación de volumen MPC ensayo heladicidad

\begin{tabular}{llll}
\multicolumn{4}{c}{ Variación de resistencia flexión $\left(\mathrm{N} / \mathrm{mm}^{2}\right)$} \\
& Probeta Referencia & Probeta ensayada & \\
Ensayo 1 & 2,1 & 0,23 & $-89,05 \%$ \\
Ensayo 2 & & 0,16 & $-92,38 \%$
\end{tabular}

Tabla 34. Variación de resistencia a flexión MPC ensayo heladicidad 


\begin{tabular}{llll}
\multicolumn{4}{c}{ Variación de resistencia compresión $\left(\mathrm{N} / \mathrm{mm}^{2}\right)$} \\
Ensayo 1 & Probeta Referencia & Probeta ensayada & \\
& & 2,25 & $-48,86 \%$ \\
Ensayo 2 & 4,4 & 2,24 & $-49,09 \%$ \\
& & 0,92 & $-79,09 \%$ \\
& & 1,80 & $-59,09 \%$
\end{tabular}

Tabla 35. Variación de resistencia a compresión MPC ensayo heladicidad

Durante los ciclos que ha durado el ensayo, no se han visualizado roturas, fisuras o exfoliaciones de dimensión mayor a $15 \mathrm{~mm}$, tal y como determina la norma UNE 67028 EX.

Esta apreciación visual permite concluir que las probetas no presentan alteraciones superficiales significativas después de soportar los 15 ciclos de hielo-deshielo.

Respecto a las variaciones volumétricas, una vez comprobados los volúmenes a los 7 y 15 ciclos, estas son inferiores a 0,65\%, por lo tanto, no se ha producido una destrucción destacable de la estructura porosa del mortero.

Es significativo que durante el proceso de saturación se ha manifestado la presencia de cristales salinos en puntos determinados de alguna probeta.

Los resultados de los ensayos de rotura a compresión y flexión en comparación con las probetas de referencia muestran que estas variaciones son significativas en ambos ensayos. La resistencia a flexión desciende en más del $89 \%$ y, descartando el valor del ensayo 2.1, una media cercana al 50\% a flexión. Por lo tanto, se puede considerar, que el material es un material claramente heladizo, en parte debido a sus macroporos internos.

\section{Características químicas}

$\mathrm{pH}$

Para la caracterización química se han tomado como referencia las placas elaboradas en el punto 3.1 del presente capítulo. En este apartado se hicieron varias placas de $10 \times 10 \times 1,5 \mathrm{~cm}$ a modo de referencia con distintos productos. Las placas que se han utilizado son las que se relacionan en la Tabla 36.

\section{Dosif. 11 \\ Dosif. 14$$
\text { PL2 }
$$ \\ Tabla 36. Relación dosificación y placa elaborada}

Mientras que la PL2 utiliza Mag7, es decir una magnesita calcinada a muerte, la PL5 utiliza el sub-producto PC8 que se ha caracterizado en el presente capítulo. Si bien, la caracterización de la placa PL2 podría parecer que carece de valor, puesto que el producto que se trata de caracterizar es el de la placa PL5, se han tomado estos dos para tener una referencia, de cara al cultivo del briófito en su superficie y como puede variar en función de la pureza o no del óxido de magnesio.

Los valores de $\mathrm{pH}$ obtenidos según la metodología experimental, se pueden observar en la Tabla 37. 


\begin{tabular}{cccc} 
& \multicolumn{2}{c}{ pH muestras MPC } \\
& Día 1 & Día 2 & Día 8 \\
PL2 & 7,75 & 5,71 & 6,51 \\
PL5 & 8,01 & 8,48 & 9,88
\end{tabular}

Tabla 37. pH muestras MPC

Según se puede observar, la placa PL2 se sitúa en un rango entre 6 y 7, lo que supone un estado neutro, muy similar al que posee el agua de lluvia. Este se supone que es un medio perfecto para la proliferación vegetal. Sin embargo la placa PL5, elaborada con la magnesita PC8, se sitúa en un $\mathrm{pH}$ cercano a 10, moderadamente básico. En este medio comienza a ser más difícil la proliferación de vida vegetal y complica la reproducción efectiva del briófito en su superficie.

\section{Conductividad eléctrica}

La conductividad eléctrica (CE) es un método para medir la salinidad del sustrato en los suelos, dado que los cultivos están condicionados, entre otros factores, por el contenido de sales, que reducen el potencial y reducen también el agua disponible para las plantas a pesar de que el suelo presente una humedad alta. [56]

La CE mide la capacidad de un suelo para conducir la corriente eléctrica al aprovechar la conducción eléctrica de las sales. De este modo se mide la concentración sales solubles presentes en el suelo.

$\begin{array}{ccc} & \begin{array}{c}\text { Clasificación del suelo } \\ \text { CE }\end{array} & \mathrm{pH} \\ \text { Salino } & >4 & <8,5 \\ \text { Sódico } & <4 & >8,5 \\ \text { Salino-sódico } & >4 & <8,5\end{array}$

Tabla 38. Clasificación de suelos afectados por sales de acuerdo a sus propiedades químicas. Fuente: Havlin, 2013

De este modo, pese a no tratarse de un terreno como tal, el sustrato puede verse condicionado por la presencia de sales solubles que, al regarse o sumergirse la superficie del MPC, condicionen cualquier cultivo en su superficie.

En este punto se vuelven a utilizar las placas de $10 \times 10 \times 1,5 \mathrm{~cm}$ sobre las que se ha ensayado el pH en el punto anterior ensayadas a modo de referencia con distintos productos. Estas placas vuelven a ser las de la Tabla 36. La placa PL2 utiliza magnesita calcinada a muerta (Mag7) y la PL5 utiliza el sub-producto PC8.

\begin{tabular}{cccc}
\multicolumn{4}{c}{ CE muestras MPC $(\mathrm{dS} / \mathrm{m})$} \\
& Día 1 & Día 2 & Día 8 \\
PL2 & 27,1 & 30,6 & 38,5 \\
PL5 & 12,56 & 16,67 & 25,8
\end{tabular}

Tabla 39. Conductividad eléctrica muestras MPC 
Viendo los resultados obtenidos, el valor de la conductividad eléctrica es extremadamente elevado y por lo tanto se considera un medio salino (Tabla 38)

Cuando la Conductividad Eléctrica es mayor de $16 \mathrm{dS} / \mathrm{m}$ se considera que el suelo es extremadamente salino [57] condicionando el crecimiento de la mayoría de cultivos tradicionales.

\subsection{Dosificación y fabricación del mortero con adición de EAFS}

\subsubsection{Resultados obtenidos}

\section{Características físicas}

\section{Densidad aparente}

La Tabla 40 muestra la densidad aparente de las muestras de mortero endurecido, medidas siguiendo la misma normativa que el mortero de referencia sin adición de EAFS.

Como se observa, la variación de la densidad aparente del mortero MPC con escorias frente al de referencia es importante, suponiendo en torno a un $40 \%$ más de peso.

\begin{tabular}{llllll}
\multicolumn{7}{c}{ Pesos y densidad del MPC endurecido } \\
& Peso seco & Peso saturado & Peso sumergido & Volumen & Densidad \\
& gr & gr & gr & $\mathrm{cm}^{3}$ & $\mathrm{~kg} / \mathrm{m}^{3}$ \\
Ensayo 1 & 179,8 & 199,4 & 109,6 & 89,8 & 2000 \\
Ensayo 2 & 202,0 & 225,0 & 116,9 & 108,1 & 1870 \\
Ensayo 3 & 542,4 & 556,4 & 294,9 & 261,5 & 2070 \\
Ensayo 4 & 529,5 & 551,7 & 285,1 & 266,6 & 1990 \\
& & & & Valor medio & 1990
\end{tabular}

Tabla 40. Densidad aparente MPC con EAFS

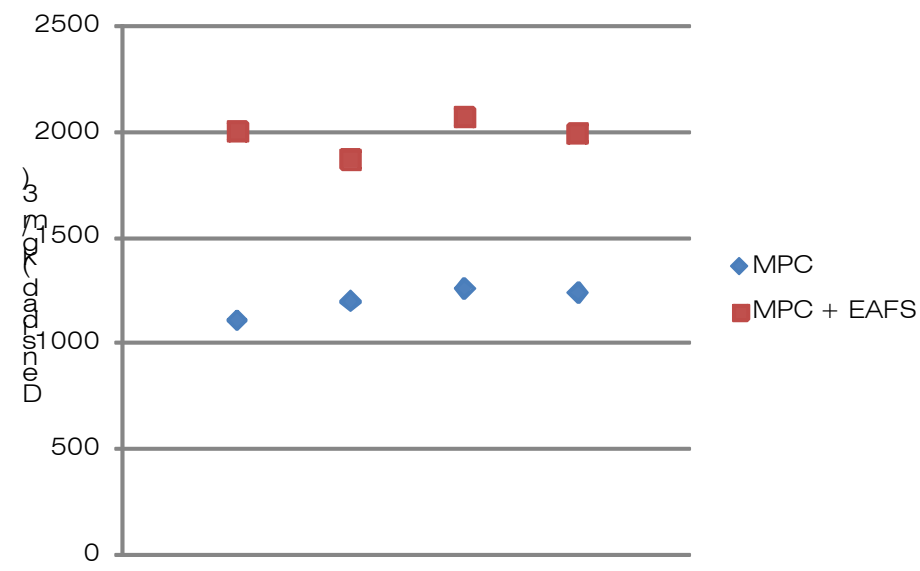

Imagen 101. Gráfico comparativo densidad con y sin EAFS

Esto supone un incremento importante del peso del mortero, sin embargo también se tiene que tener en cuenta que la adición de EAFS en el mortero MPC supone la sustitución del 50\% del mortero por un 
subproducto que, a priori, mejora las resistencias mecánicas del conjunto.

\section{Absorción de agua}

La capacidad de absorción de agua se ha evaluado siguiendo la misma normativa que el mortero de referencia sin adición de EAFS.

\begin{tabular}{llll} 
& \multicolumn{3}{l}{ Coeficiente de absorción de agua } \\
& M1 & M2 & C \\
& gr & gr & \\
Ensayo 1 & 210,7 & 221,7 & 1,10 \\
Ensayo 2 & 282,1 & 292,6 & 1,05 \\
Ensayo 3 & 222,7 & 234,0 & 1,13 \\
Ensayo 4 & 259,2 & 269,4 & 1,02
\end{tabular}

Tabla 41. Coeficiente de absorción de agua MPC con EAFS

Los coeficientes de absorción son mucho mayores que los de morteros tradicionales con cemento Portland, que normalmente se sitúan entre 0,10 y 0,30 , sin embargo rebajan los coeficientes obtenidos en el MPC de referencia sin adición EAFS.

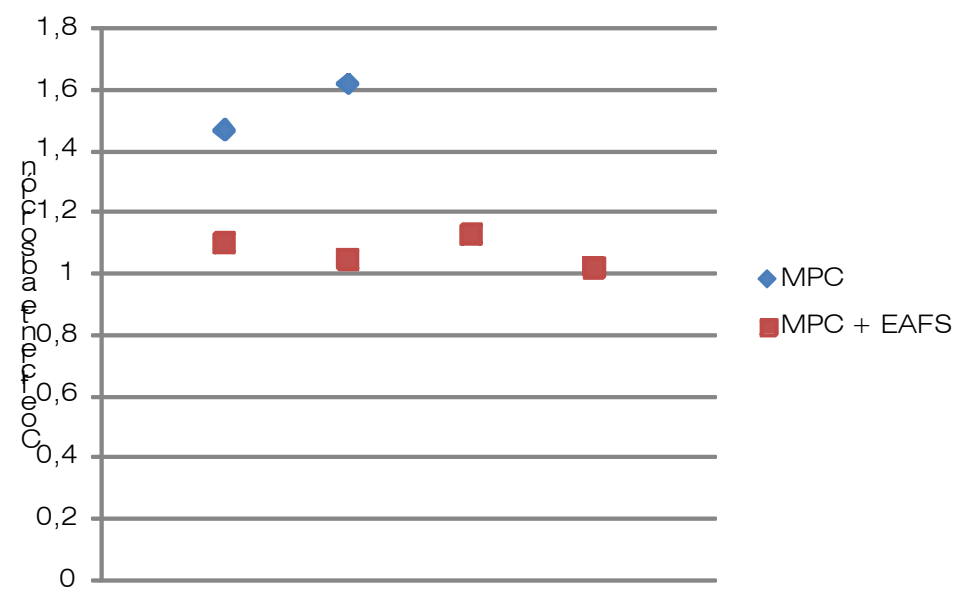

Imagen 102. Gráfico comparativo coeficiente absorción con y sin EAFS

En las muestras ensayadas con adición de escorias el coeficiente de absorción se ha situado en una horquilla entre 1,02 y 1,10 lo que supone una reducción de coeficiente de absorción de en torno un $31 \%$ respecto al mortero sin adiciones. La reacción ácido-base de cristalización del mortero MPC se controla mejor cuando se le añaden áridos como las EAFS, mitigando el impacto de una reacción excesivamente rápida. De este modo la red porosa creada, parece disponer de una menor macro-porosidad abierta, pero manteniendo los micro-poros interconectados que permiten una correcta absorción y retención de agua. 


\section{Características mecánicas}

El estudio de las características mecánicas se han realizado llevando a cabo la misma metodología que para las muestras de referencia sin adición de escoria.

Las probetas usadas han sido de 40,0 × 40,0 $\times 160,0 \mathrm{~mm}$ que se rompen inicialmente en dos trozos a flexotracción y que posteriormente se ensayan a compresión.

\section{Resistencia a flexión}

El comportamiento a flexión de las muestras evaluadas debería ser mejor que el de las muestras de referencia. Según se ha especificado en el capítulo, la adición de escorias, especialmente si estas son de tamaño pequeño, supone una mejora considerable en las características mecánicas tanto de los morteros tradicionales como de los cementos CPBC. Los resultados se pueden ver en la Tabla 42 y se han comparado con los del mortero MPC de referencia sin adición de árido en la Imagen 103.

Tal y como se observa, los resultados resultan dispares.

A la hora de elaborar la resistencia media descartamos los valores muy desiguales. Por ello en la Resistencia a flexión descartamos los valores del ensayo 1 y en la Resistencia a compresión descartamos los dos valores más bajos (ensayo 1.1 y 1.2).

Las probetas a las que se ha agregado EAFS, tienen un comportamiento muy superior a los que no tienen adiciones. Estas aumentan más del doble los valores de resistencia a flexión dotando al mortero de un buen comportamiento a flexión que lo habilita para su utilización como placas. Excluyendo la probeta que da un valor inusualmente bajo, el comportamiento ha sido muy superior al que se buscaba (superior a $2 \mathrm{~N} / \mathrm{mm}^{2}$ ) en los criterios de referencia.

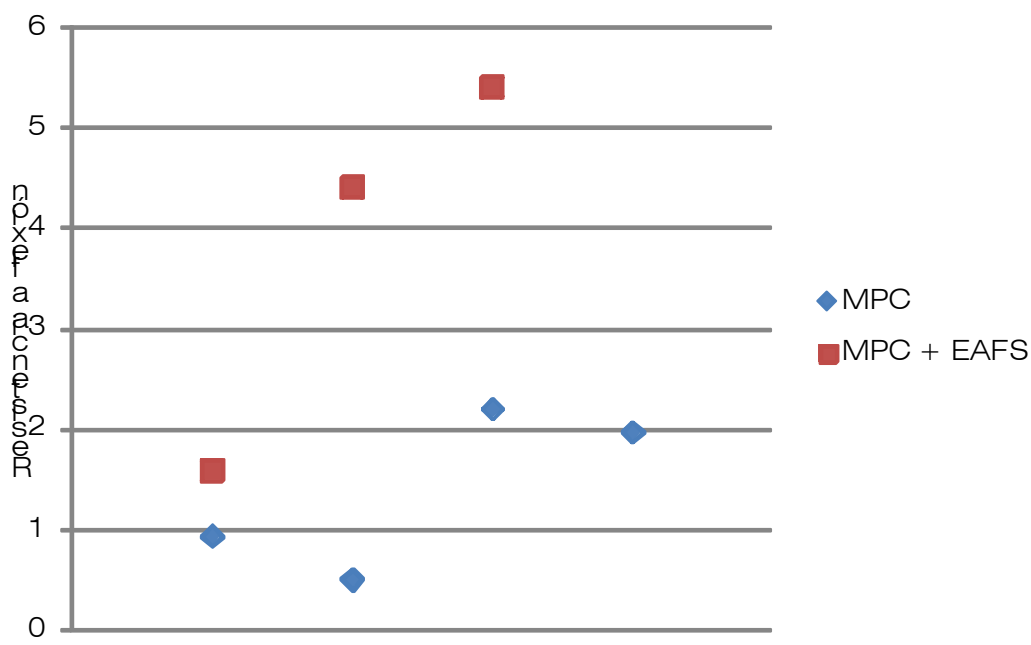

Imagen 103. Gráfico comparativo resistencias a flexión con y sin EAFS 


\begin{tabular}{|c|c|c|}
\hline & \multicolumn{2}{|c|}{ Resistencia a flexión y compresión MPC con EAFS } \\
\hline & Resistencia a flexión & Resistencia a compresión \\
\hline \multirow{3}{*}{ Ensayo 1} & $\mathrm{~N} / \mathrm{mm}^{2}$ & $\mathrm{~N} / \mathrm{mm}^{2}$ \\
\hline & \multirow{2}{*}{1,60} & 10,75 \\
\hline & & 9,60 \\
\hline \multirow{2}{*}{ Ensayo 2} & \multirow{2}{*}{4,40} & 15,20 \\
\hline & & 15,30 \\
\hline \multirow{2}{*}{ Ensayo 3} & \multirow{2}{*}{5,40} & 15,75 \\
\hline & & 18,00 \\
\hline Valor medio & 4,9 & 16,1 \\
\hline
\end{tabular}

Tabla 42. Resistencia a flexión y compresión MPC con EAFS

Pese a tener valores favorables, parte la resistencia a flexión podría mejorarse actuando sobre la granulometría de las escorias negras, ya que para obtener una superficie con una rugosidad adecuada, aumentando así la bio-receptividad del material, se ha tenido que ir a una granulometría que descarta los finos $(<1 \mathrm{~mm})$.

Otro factor ha sido la reactividad del óxido de magnesio (PC8), por la cual el mortero se hacía prácticamente intrabajable, llegando a un endurecimiento total en menos de dos minutos. De esta manera, se ha generado algunos macroporos internos que inciden negativamente en esta resistencia.

\section{Resistencia a compresión}

La resistencia a compresión, al igual que anteriormente a flexión, de las muestras evaluadas debería ser mejor que la de las muestras de referencia gracias a la incorporación de escorias, que mejoran el comportamiento mecánico del mortero.

Los resultados se pueden ver en la Tabla 42 y se han comparado con los del mortero MPC de referencia sin adición de árido en la Imagen 104.

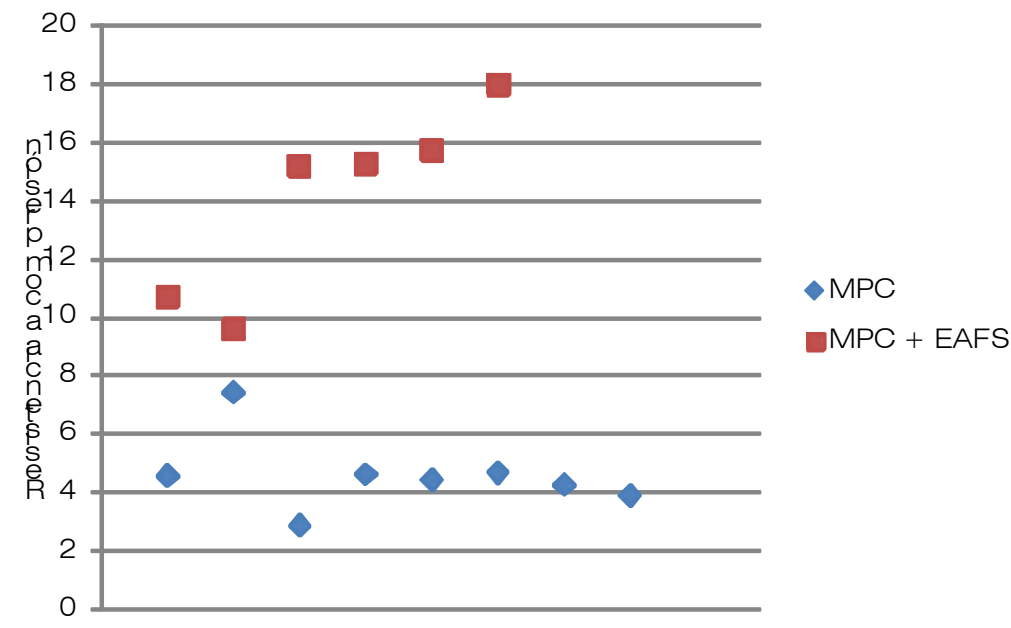

Imagen 104. Gráfico comparativo resistencias a compresión con y sin EAFS

Las probetas a las que se ha agregado EAFS, tienen un comportamiento muy superior a los que no contienen. De hecho, 
mientras que las de referencia se situaron de media en los $4,4 \mathrm{~N} / \mathrm{mm}^{2}$ las que adicionamos escorias promedian los $16,1 \mathrm{~N} / \mathrm{mm}^{2}$, un $365,9 \%$ más.

Estos valores suponen un comportamiento óptimo, muy superior a las prestaciones mínimas deseadas $\left(7 \mathrm{~N} / \mathrm{mm}^{2}\right)$. De igual modo, una buena resistencia a compresión es un buen indicativo de su durabilidad. Todos los morteros cumplen con la resistencia mínima exigida por la normativa de morteros de albañilería para su uso como revoco.

\section{Durabilidad}

\section{Heladicidad}

El comportamiento frente a los ciclos de hielo-deshielo se ha evaluado utilizando la misma metodología que en el ensayo con el MPC sin EAFS. Debido a la inexistencia de una normativa específica se ha utilizado como marco experimental las normas UNE-67028-EX [58] y UNE-EN 12371:2011 [59].

Las probetas utilizadas son de dimensiones 40,0 x 40,0 x 160,0 mm y los ciclos llevados a cabo, que se describen en la metodología experimental, son de 18 horas de congelación y 6 horas de descongelación mediante inmersión en agua de 6 horas.

Los resultados obtenidos se evalúan por comparación. Por un lado la variación de volumen y por otro la pérdida de resistencias mecánicas respecto a la resistencia media de referencia.

Durante los ciclos que ha durado el ensayo, no se han visualizado roturas, fisuras o exfoliaciones de dimensión mayor a $15 \mathrm{~mm}$, tal y como determina la norma UNE 67028 EX.

La diferencia de volumen, comprobada a los 7 y 15 ciclos, es inferior a $0,69 \%$. Por comparación con el mortero MPC de referencia, sin adición de escorias, esta es muy similar, no siendo, en ninguno de los dos casos, significativa.

\begin{tabular}{lllll}
\multicolumn{5}{c}{ Variación de volumen MPC + EAFS $\left(\mathrm{cm}^{3}\right)$} \\
& Ciclo 0 & Ciclo 7 & Ciclo 15 & \\
Ensayo 1 & 261,5 & 260,5 & 259,7 & $-0,69 \%$ \\
Ensayo 2 & 266,6 & 266,6 & 266,2 & $-0,15 \%$
\end{tabular}

Tabla 43. Variación de volumen MPC + EAFS ensayo heladicidad

\begin{tabular}{llll}
\multicolumn{4}{c}{ Variación de resistencia flexión $\left(\mathrm{N} / \mathrm{mm}^{2}\right)$} \\
& Probeta Referencia & Probeta ensayada & \\
Ensayo 1 & 4,9 & 2,4 & $-51,02 \%$ \\
Ensayo 2 & & 2,1 & $-57,14 \%$
\end{tabular}

Tabla 44. Variación de resistencia a flexión MPC + EAFS ensayo heladicidad

\begin{tabular}{clll}
\multicolumn{4}{c}{ Variación de resistencia compresión $\left(\mathrm{N} / \mathrm{mm}^{2}\right)$} \\
Ensayo 1 & Probeta Referencia & Probeta ensayada & \\
& & 8,2 & $-49,07 \%$ \\
Ensayo 2 & 16,1 & 11,4 & $-29,19 \%$ \\
& & 9,0 & $-44,10 \%$ \\
& & 8,4 & $-47,83 \%$
\end{tabular}

Tabla 45. Variación de resistencia a compresión MPC + EAFS ensayo heladicidad 
La disminución de resistencias mecánicas, tanto a compresión como a flexión, es muy elevada, situándose en una intervalo en torno al 50\% de disminución en ambas resistencias. El material, sometido a los 15 ciclos, claramente ha padecido las consecuencias del ensayo, sin embargo sus resistencias siguen estando dentro de los parámetros de referencia buscados inicialmente.

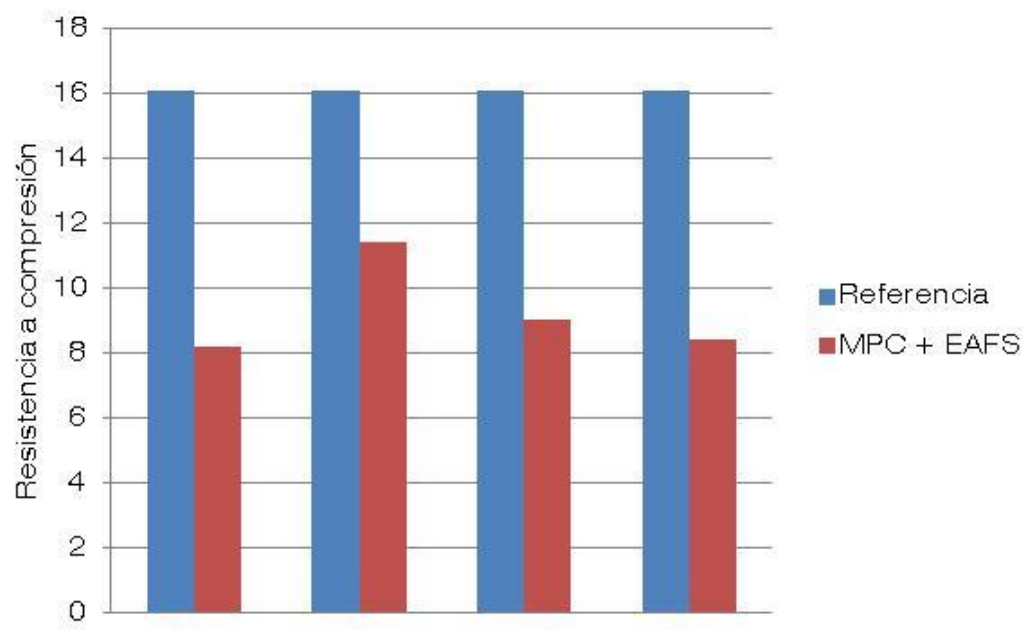

Imagen 105. Gráfico comparativo variación resistencias a compresión después del ensayo.

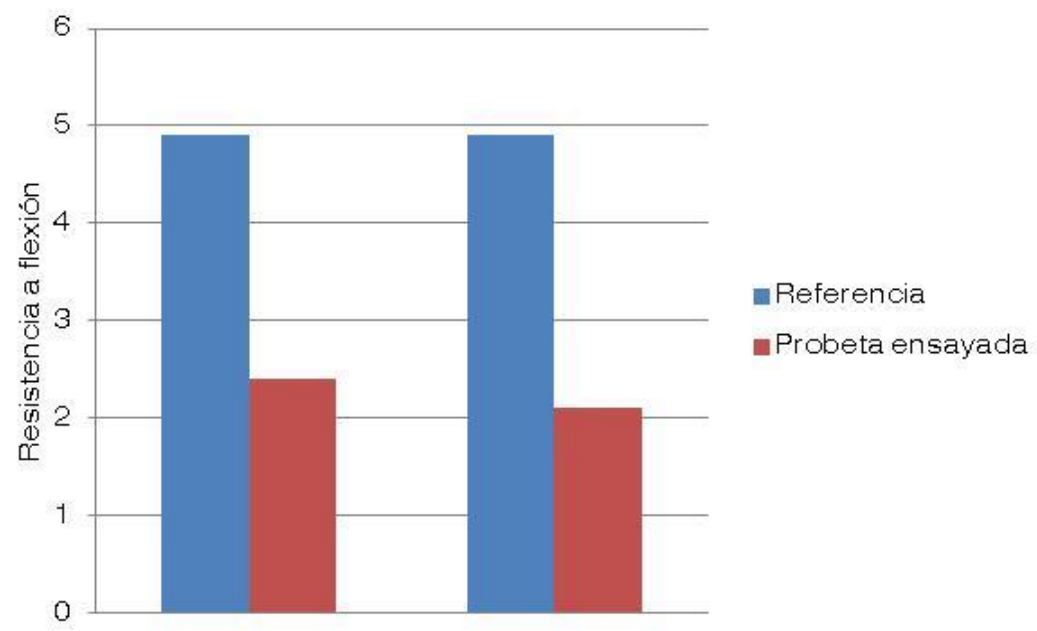

Imagen 106. Gráfico comparativo variación resistencias a flexión después del ensayo

En comparativa con el MPC sin escorias, esta disminución de resistencias mecánicas es inferior, especialmente en la resistencia a flexión, por lo cual la adición de EAFS negras mejora su comportamiento, aunque el material siga siendo heladizo.

\section{Características químicas}

\section{$\mathrm{pH}$}

Se determina el $\mathrm{pH}$ de tres placas que contienen escorias negras mediante la misma metodología empleda con el MPC de referencia.

Se han vuelto a utilizar varias placas de dimensiones $10 \times 10 \times 1,5 \mathrm{~cm}$ con las dosificaciones que figuran en el punto 3.1, pero esta vez se adicionan escorias negras de horno eléctrico de arco. Las placas que se han utilizado son las que se relacionan en la Tabla 46. 


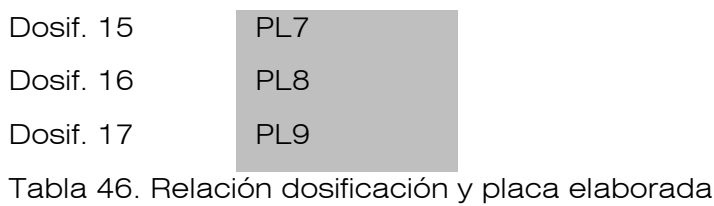

Al igual que ocurrieran en las del MPC de referencia se han tomado dos placas elaboradas con magnesita calcinada (Mag7 e Impalmag) y otra con el subproducto PC8. Estas placas se han elaborado para comprobar después la capacidad del musgo para reproducirse en la superficie del mortero MPC con diferentes componentes y cómo influye la utilización de una fuente u otra de óxido de magnesio.

Los valores de $\mathrm{pH}$ obtenidos se relacionan en la Tabla 47.

\begin{tabular}{cccc}
\multicolumn{4}{c}{ PH muestras MPC con EAFS } \\
& Día 1 & Día 2 & Día 8 \\
PL7 & 5,9 & 8,18 & 6,83 \\
PL8 & 5,99 & 5,72 & 6,31 \\
PL9 & 6,45 & 6,57 & 6,93
\end{tabular}

Tabla 47. pH muestras MPC con EAFS

Según se puede observar las tres placas sitúan su pH entre 6 y 7 , un valor neutro y muy bueno para la reproducción vegetal. Si comparamos estos valores con los de las muestras de MPC de referencia, descartando la placa PL5 que da un valor anómalamente alto, todos los valores son muy parecidos, entre 6,31 y 6,93. Esto homogeneidad en los datos permite afirmar que con la utilización del mortero MPC en vez de uno tradicional con cemento Portland se ha conseguido la disminución drástica del $\mathrm{pH}$, creando una superficie bio-compatible con la vida vegetal.

La influencia real del pH se podrá observar a tenor de los resultados del capítulo siguiente.

\section{Conductividad eléctrica}

La conductividad eléctrica (CE) mide la concentración de sales solubles presentes en un suelo. La presencia de iones procedentes de las sales contribuyen a facilitar el paso de la corriente eléctrica, con lo que a mayor presencia de estos iones, mayor conductividad eléctrica.

En este punto se vuelven a utilizar las placas de $10 \times 10 \times 1,5 \mathrm{~cm}$ sobre las que se ha ensayado el $\mathrm{pH}$ en el punto anterior (Tabla 46). Las placas PL7 y PL8 utilizan magnesita calcinada a muerte (Mag7 e Impalmag) y la PL9 utiliza el sub-producto PC8.

\begin{tabular}{cccc}
\multicolumn{4}{c}{ CE muestras MPC con EAFS $(\mathrm{dS} / \mathrm{m})$} \\
& Día 1 & Día 2 & Día 8 \\
PL7 & 40,3 & 43,3 & 46,6 \\
PL8 & 25,8 & 27,7 & 30,3 \\
PL9 & 20,2 & 26,6 & 37,7
\end{tabular}

Tabla 48. Conductividad eléctrica muestras MPC con EAFS 
Los resultados muestran que la conductividad eléctrica vuelve a ser extremadamente alta (Tabla 48), no siendo muy diferentes a los resultados de la muestras sin escorias.

Dado que la Conductividad Eléctrica en todos los casos supera los 16 $\mathrm{dS} / \mathrm{m}$ se considera que el suelo es extremadamente salino [60].

\subsection{Conclusiones}

La investigación desarrollada dentro de la presente Tesis Doctoral evalúa y compara las propiedades físico-químicas, mecánicas y de durabilidad de un tipo de mortero con propiedades bio-receptivas. Para ello se desarrolla un mortero de magnesio fosfato (MPC) al cual agrega la mitad de su peso con escorias negras de horno eléctrico de arco (EAFS).

Este tipo de mortero, aparte de tener una componente de biocompatibilidad vegetal también utiliza áridos reciclados y sub-productos industriales que contribuyen a la idea de una economía circular.

En este punto, se ha caracterizado un mortero MPC que incluye el subproducto industrial PC8 que sustituye a la magnesita. Este mortero, denominado en este capítulo como mortero de referencia, se ha comparado con otro idéntico al que se ha agregado un $50 \%$ del peso del mortero en escorias. En la Tabla 49 se comparan los resultados obtenidos en los ensayos entre ambos morteros y en la Tabla 50 con los valores de referencia deseados en el punto 1.1. de este capítulo.

\begin{tabular}{|c|c|c|c|}
\hline & MPC & MPC+EAFS & Variación \\
\hline Densidad aparente & $1200 \mathrm{~kg} / \mathrm{m}^{3}$ & $1990 \mathrm{~kg} / \mathrm{m}^{3}$ & $+65,83 \%$ \\
\hline Coeficiente absorción & 1,52 & 1,43 & $-5,92 \%$ \\
\hline Resistencia a flexión & $2,1 \mathrm{~N} / \mathrm{mm}^{2}$ & $4,9 \mathrm{~N} / \mathrm{mm}^{2}$ & $+133,3 \%$ \\
\hline Resistencia a compresión & $4,4 \mathrm{~N} / \mathrm{mm}^{2}$ & $16,1 \mathrm{~N} / \mathrm{mm}^{2}$ & $+265,90 \%$ \\
\hline Heladicidad $\Delta \mathrm{Vol}$ & $-0,50 \%$ & $-0,42 \%$ & $-0,08 \%$ \\
\hline$\Delta$ Rflex & $-90,72 \%$ & $-54,08 \%$ & $-36,64 \%$ \\
\hline$\Delta$ Rcom & $-52,35 \%$ & $-42,55 \%$ & $-9,80 \%$ \\
\hline $\mathrm{pH}$ & 9,88 & 6,93 & $-29,86 \%$ \\
\hline CE & $25,8 \mathrm{dS} / \mathrm{m}$ & $37,7 \mathrm{dS} / \mathrm{m}$ & $+46,12 \%$ \\
\hline
\end{tabular}

Tabla 49. Comparativa resultados obtenidos

\begin{tabular}{llll}
\hline & Valores deseados & MPC+EAFS & Variación \\
\hline Densidad aparente & $<2000 \mathrm{~kg} / \mathrm{m}^{3}$ & $1990 \mathrm{~kg} / \mathrm{m}^{3}$ & $-0,5 \%$ \\
Coeficiente absorción & No determinado & 1,43 & Positivo \\
Resistencia a flexión & $>2 \mathrm{~N} / \mathrm{mm}^{2}$ & $4,9 \mathrm{~N} / \mathrm{mm}^{2}$ & $+145 \%$ \\
Resistencia a compresión & $>5 \mathrm{~N} / \mathrm{mm}^{2}$ & $16,1 \mathrm{~N} / \mathrm{mm}^{2}$ & $+222 \%$ \\
$\mathrm{pH}$ & $<7$ & 6,93 & $1 \%$ \\
$\mathrm{CE}$ & No determinado & $37,7 \mathrm{dS} / \mathrm{m}^{2}$ & Muy negativo \\
Conductividad térmica & $<0,93 \mathrm{~W} / \mathrm{m}^{\circ} \mathrm{K}$ & No ensayado & Se desconoce
\end{tabular}

Tabla 50. Comparativa entre valores deseados y los obtenidos MPC+EAFS 
Con relación a la adición de escorias negras, los valores obtenidos, en general son mejores a los del MPC de referencia. Son especialmente buenos los resultados obtenidos en las resistencias mecánicas.

Si bien la adición de escorias negras EAFS supone un inconveniente al agregar un peso adicional, aumentando la densidad aparente un $66 \%$, todas las publicaciones consultadas indicaban que mejorarían las resistencias mecánicas. Pese a este aumento, al ajustar la dosificación, se ha conseguido reducir la densidad máxima determinada en los criterios de referencia, no llegando al límite.

De este modo la resistencia a flexión es un 133 \% mejor con la adición de escorias que sin la adición de ellas. De hecho supera en un 145\% el valor de referencia mínimo que se estableció en los criterios de referencia. De este modo, el mortero MPC con escoria podría utilizarse directamente como soporte único en la elaboración de placas o paneles de fachada. Por otro lado la resistencia a compresión es mejor aún, mejorando un $265 \%$ los valores que agregan EAFS y un $222 \%$ los criterios de referencia.

Otro valor a considerar ha sido el coeficiente de absorción. Si bien no se había considerado en los criterios de referencia, se ha obtenido un valor adecuado para el uso bio-receptivo.

Un aspecto relativamente negativo ha sido la alta reducción de prestaciones mecánicas, cuando incide la heladicidad. Si bien, una vez pasados los 15 ciclos previstos en el ensayo, el material sigue teniendo prestaciones por encima de las buscadas inicialmente, hace falta solucionarlo. Esto, básicamente puede deberse a la reactividad del polvo de ciclón (PC8), que al reaccionar de forma tan súbita provoca la aparición de macroporos, más sensibles a los ciclos hielo-deshielo.

Respecto a las características químicas, que se relacionan con la bioreceptividad del mortero, los valores han dado dos resultados dispares. Por un lado se buscada un mortero cuyo pH fuera neutro (7), consiguiendo un valor que se desvía solamente un $1 \%$, siendo este un valor óptimo.

El punto negativo ha sido la conductividad eléctrica. Si bien no se había determinado en los criterios de referencia, el valor obtenido genera un medio extremadamente salino. Esto indica una gran presencia de sales solubles, las cuales, cuando se han saturado las probetas han aparecido en la superficie, cristalizadas. Esto genera un medio, altamente hostil para la proliferación de especies vegetales. Sin embargo, existen métodos para poder reducir este valor, tanto tratando el PC8, como sobre el mortero endurecido haciendo pasar una corriente continua de agua. 
[1] Hong, L.T., Lubell, A.S. Phosphate cement-based concretes containing silica fume (2015) ACl Materials Journal, 112 (4), pp. 587596

[2] Rodríguez A. Fabricación de morteros de albañilería con escoria blanca de horno cuchara y su utilización en construcción (2008) Universidad de Burgos, Tesis Doctoral

[3] Rodriguez, A., Manso, J.M., Aragón, A., González, J.J., Strength and workability of masonry mortars manufactured with ladle furnace slag (2009) Resources, Conservation and Recycling, 53(11), pp. 645-651

[4] EN 13139. (2002) Aggregates for mortar

[5] Ortega $V$. Aprovechamiento de escorias blancas (LFS) y negras (EAFS) de aceria electrica en la estabilizacion de suelos y en capas de firmes de caminos rurales (2011) Universidad de Burgos. Tésis doctoral.

[6] Wagh A S. Chemically bonded phosphste ceramics, Twenty First century materials with diverse applications (2004) Elsevier B.V., Amsterdam

[7] Formosa J. Formulaciones de nuevos morteros y cementos especiales basadas en subproductos de magnesio (2012) Universitat de Barcelona, PhD thesis

[8] Íbid

[9] Wagh, A.S., Strain, R., Jeong, S.Y., Reed, D., Krause, T., Singh, D. Stabilization of Rocky Flats Pu-contaminated ash within chemically bonded phosphate ceramics (1999) Journal of Nuclear Materials, 265 (3), pp. 295-307

[10] Manso, S., Mestres, G., Ginebra, M.P., De Belie, N., Segura, I., Aguado, A. Development of a low pH cementitious material to enlarge bioreceptivity (2014) Construction and Building Materials, 54, pp. 485495. Cited 4 times.

[11] Formosa J. Formulaciones de nuevos morteros y cementos especiales basadas en subproductos de magnesio (2012) Universitat de Barcelona, PhD thesis

[12] Íbid

[13] Wagh, A., Jeong, S. Chemically Bonded Phosphate Ceramics: I, A Dissolution Model of Formation (2003) Journal of the American Ceramic Society, 1838-1844

[14] Hong, L.T., Lubell, A.S. Phosphate cement-based concretes containing silica fume (2015) ACl Materials Journal, 112 (4), pp. 587 596

[15] Feng, P., Zhou, S., Zhao, J. Effect of cattle manure ash on workability and mechanical properties of magnesium phosphate cement (2016) Construction and Building Materials, 129, pp. 79-88

[16] Huang, R., Kong, X. The application analysis of fly ash in magnesium phosphate cement (2015) Advances in Civil Engineering and Building Materials IV - Selected and Peer Reviewed Papers from the 2014 4th International Conference on Civil Engineering and Building Materials, CEBM 2014, pp. 113-116 
[17] Donahue, P.K., Aro, M.D. Durable phosphate-bonded natural fiber composite products (2010) Construction and Building Materials, 24 (2), pp. 215-219

[18] Del Valle-Zermeño, R., Aubert, J.E., Laborel-Préneron, A., Formosa, J., Chimenos, J.M. Preliminary study of the mechanical and hygrothermal properties of hemp-magnesium phosphate cements (2016) Construction and Building Materials, 105, pp. 62-68

[19] Gardner, L.J., Bernal, S.A., Walling, S.A., Corkhill, C.L., Provis, J.L., Hyatt, N.C. Characterisation of magnesium potassium phosphate cements blended with fly ash and ground granulated blast furnace slag (2015) Cement and Concrete Research, 74, pp. 78-87

[20] Junco C. Morteros aligerados con residuos de espumas rígidas de poliuretano: obtención, caracterización y puesta en obra (2012) Universidad de Burgos, Tesis Doctoral

[21] Gutiérrez S. Yesos aligerados fabricados a partir de residuos de espumas de poliuretano y polvo de poliamida (2012) Universidad de Burgos, PhD thesis

[22] Campo P.L. Reactividad y reciclado de pizarras para su empleo como áridos en construcción (2016) Universidad de Burgos, Tesis Doctoral

[23] Muñoz C. Propiedades físicas y durabilidad de morteros aligerados con arcilla expandida y agregados con áridos reciclados (2015) Universidad de Burgos, Tesis Doctoral

[24] Rodríguez A. Fabricación de morteros de albañilería con escoria blanca de horno cuchara y su utilización en construcción (2008) Universidad de Burgos, Tesis Doctoral

[25] Santamaria I., Fabricación de morteros de albañilería con escoria negra de horno eléctrico de arco EAF y escoria blanca de horno cuchara LF (2015) Universidad de Burgos, Tesis Doctoral

[26] De la Fuente J.A., Comportamiento del hormigón con áridos siderúrgicos (EAF) reforzado con fibras (2016) Universidad de Burgos, Tesis Doctoral

[27] Santamaría-Vicario, I., Rodríguez, A., Gutiérrez-González, S. \& Calderón, $\mathrm{V}$. Design of masonry mortars fabricated concurrently with different steel slag aggregates (2015) Construction and Building Materials, 95, pp. 197-206

[28] Santamaría-Vicario, I., Rodríguez, A., Junco, C., GutiérrezGonzález, S. \& Calderón, V. Durability behavior of steelmaking slag masonry mortars (2016) Materials and Design, 97, pp. 307-315.

[29] Santamaría-Vicario, I., Rodríguez, A., Gutiérrez-González, S. \& Calderón, V. Design of masonry mortars fabricated concurrently with different steel slag aggregates (2015) Construction and Building Materials, 95, pp. 197-206

[30] EN 6988, Metallic and Other Non Organic Coatings - Sulfur Dioxide Test with General Condensation of Moisture, 1996.

[31] Formosa J. Formulaciones de nuevos morteros y cementos especiales basadas en subproductos de magnesio (2012) Universitat de Barcelona, PhD thesis 
[32] Manso S, Segura I, Aguado A, Conjunto multicapa en base cemento, aplicable como soporte biológico para fachadas de edificios u otras construcciones, Patente PCT/ES2013/070438, 28 Julio 2013.

[33] Hong, L.T., Lubell, A.S. Phosphate cement-based concretes containing silica fume (2015) ACl Materials Journal, 112 (4), pp. 587596

[34] Wagh, A. S., Chemically Bonded Phosphate Ceramics: TwentyFirst Century Material with Diverse Applications, Elsevier Science, Oxford, UK, 2004, 304

[35] Manso, S., Mestres, G., Ginebra, M.P., De Belie, N., Segura, I., Aguado, A. Development of a low pH cementitious material to enlarge bioreceptivity (2014) Construction and Building Materials, 54, pp. 485495.

[36]. Hipedinger, E., Aglietti, E., Scian, A. Utilización de ácido bórico como retardador en materiales refractarios cordieríticos de liga química magnesia-ácido fosfórico (2006) $6^{\circ}$ Congreso Binacional de Metalurgia y Materiales . CONAMET/SAM 2006

[37] Yang, Q., Wu, X. Factors influencing properties of phosphate cement-based binder for rapid repair of concrete (1999) Cement and Concrete Research, 29 (3), pp. 389-396

[38] Wagh, A.S. Chemically Bonded Phosphate Ceramics: Twenty-First Century Materials with Diverse Applications (2004) Chemically Bonded Phosphate Ceramics: Twenty-First Century Materials with Diverse Applications, pp. 1-283

[39] Ortega $V$. Aprovechamiento de escorias blancas (LFS) y negras (EAFS) de aceria electrica en la estabilizacion de suelos y en capas de firmes de caminos rurales (2011) Universidad de Burgos. Tesis doctoral.

[40] íbid

[41] Rodríguez A. Fabricación de morteros de albañilería con escoria blanca de horno cuchara y su utilización en construcción (2008) Universidad de Burgos, Tesis Doctoral

[42] Ortega $V$. Aprovechamiento de escorias blancas (LFS) y negras (EAFS) de aceria electrica en la estabilizacion de suelos y en capas de firmes de caminos rurales (2011) Universidad de Burgos. Tesis doctoral.

[43] íbid

[44] íbid

[45] Íbid

[46] Íbid

[47] íbid

[48] Manso, S., De Muynck, W., Segura, I., Aguado, A., Steppe, K., Boon, N., De Belie, N. Bioreceptivity evaluation of cementitious materials designed to stimulate biological growth, 2014. Science of the Total Environment, 481 (1), pp. 232-241

[49] Formosa J. Formulaciones de nuevos morteros y cementos especiales basadas en subproductos de magnesio. (2012) Universitat de Barcelona, Tésis doctoral. 
[50] Hong, L.T., Lubell, A.S. Phosphate cement-based concretes containing silica fume (2015) ACl Materials Journal, 112 (4), pp. 587596

[51] Rodríguez A. Fabricación de morteros de albañilería con escoria blanca de horno cuchara y su utilización en construcción (2008) Universidad de Burgos, PhD thesis

[52] Santamaria I., Fabricación de morteros de albañilería con escoria negra de horno eléctrico de arco EAF y escoria blanca de horno cuchara LF (2015) Universidad de Burgos, PhD thesis

[53] De la Fuente J.A., Comportamiento del hormigón con áridos siderúrgicos (EAF) reforzado con fibras (2016) Universidad de Burgos, $\mathrm{PhD}$ thesis

[54] Muñoz C. Propiedades físicas y durabilidad de morteros aligerados con arcilla expandida y agregados con áridos reciclados (2015) Universidad de Burgos, Tesis Doctoral

[55] Norma UNE-67028-EX (1997) Ladrillos cerámicos de arcilla cocida. Ensayo de heladicidad.

[56] La conductividad eléctrica del suelo en desarrollo de cultivos. Intagri. https://www.intagri.com/articulos/suelos/la-conductividadelectrica-del-suelo-en-el-desarrollo-de-los-cultivos

[57] Castellanos, R. J. Z. México 2000. Manual de Interpretación de Análisis de Suelos y Aguas.

[58] Norma UNE-67028-EX (1997) Ladrillos cerámicos de arcilla cocida. Ensayo de heladicidad.

[59] Norma UNE-12371:2011 (2011) Métodos de ensayo para piedra natural. Determinación de la resistencia a la heladicidad.

[60] Castellanos, R. J. Z. México 2000. Manual de Interpretación de Análisis de Suelos y Aguas. 



\section{Capítulo 7. Caracterización conjunto mortero + briófito}

\section{Especie vegetal escogida}

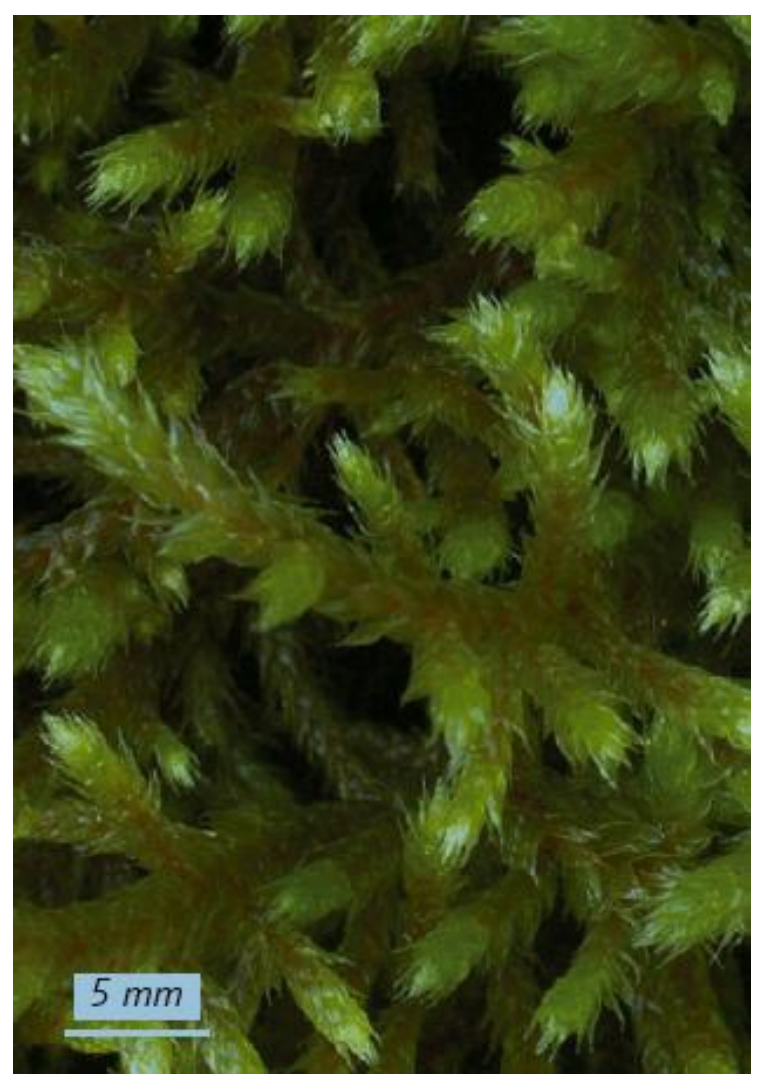

Imagen 107 Antitrichia curtipendula. Fuente: David Long (BBS)

La especie de briófito escogida entre las estudiadas (Imagen 107) es Antitrichia Curtipendula. Se ha elegido esta especie para su utilización en la presente tesis doctoral, ya que se considera que cumple con los estándares necesarios:

- Es una especie autóctona, que se puede encontrar en la naturaleza en numerosas localizaciones.

- Es una especie pleurocárpica que crea unos tapices grandes y tupidos. 
- Es una especie resistente al medio urbano y tolerante al soleamiento.

Únicamente se considera que existe un inconveniente en la elección de la especie, que se tiene que comprobar en la fase experimental: El agarre al soporte no es óptimo, como puede ser el de otras especies de briófitos. Sin embargo se considera un problema menor, ya que su solución pasaría por disponer una malla de nylon que evite el desprendimiento del tapiz.

\subsection{Características}

Antitrichia Curtipendula es una especie de briófitos pleurocárpica caracterizada por unos tallos rojizos que pueden crecer hasta los 15 $\mathrm{cm}$ de largo. Las hojas son alargadas y puntiagudas con un tamaño de 2 a $2.5 \mathrm{~mm}$ de largo, de color verde, teñidos a veces con un tono amarillo dorado. No es muy frecuente la presencia de cápsulas.

Crece en zona húmedas con una exposición moderada a la luz, soliéndose encontrar en zonas de sombra adherida a rocas, pedregales o acantilados. También suele aparecer sobre los árboles o arbustos en bosques abiertos o matorrales.[1]

Se trata de una especie vegetal muy extendida en la Europa Central del siglo XIX, si bien su paulatina desaparición se debió en parte a la contaminación y a la tala de los árboles de madera dura en los que se desarrollaba.

\section{Recolección de muestras}

Para comprobar el comportamiento de las muestras vegetales, se procede a realizar una recolección de musgos de un emplazamiento natural. El fin último es comprobar la viabilidad global de la especie vegetal cuando se proceda a su "cultivo" sobre el panel.

Para esta labor nos acompañan los profesores Javier Martínez-Abaigar y Encarnación Núñez, investigadores del Grupo de Ecofisiología Vegetal, Cambio Climático y Medio Ambiente de la Universidad de la Rioja. Ambos tienen autorización para la recolección de briófitos en la comunidad autónoma de La Rioja.

El diez de octubre de 2014 se visita el parque natural de la Sierra Cebollera, donde se procede a la recolección de las matas de musgo de la especie elegida. Este parque se localiza al sur de La Rioja, en el límite con la provincia de Soria, entre los términos municipales de Villoslada de Cameros y Lumbreras.

Se trata de un enclave geológico dentro del Sistema Ibérico, caracterizado por sus formaciones glaciares, en altitudes superiores a los 2.000 metros. Predominan los extensos bosques naturales de pino silvestre, haya y roble rebollo.

Desde un punto de vista climático, se trata una zona de clima continental, influido por la alta montaña, con precipitaciones relativamente escasas y bajas temperaturas aunque con una gran amplitud entre estaciones. Por lo tanto los briófitos presenten en la zona están acostumbrados a variaciones climáticas, térmicas, viento, soleamiento...

La zona muestreada se ubica cerca el Embalse de Pajares. Se trata de una zona de praderas higroturbosas con una cubierta importante de biomasa procedente de los grandes pinos silvestres y queijos, que 
predominan en el área, y con gran influencia del viento y nieve como se puede observar en los troncos inclinados por su acción.

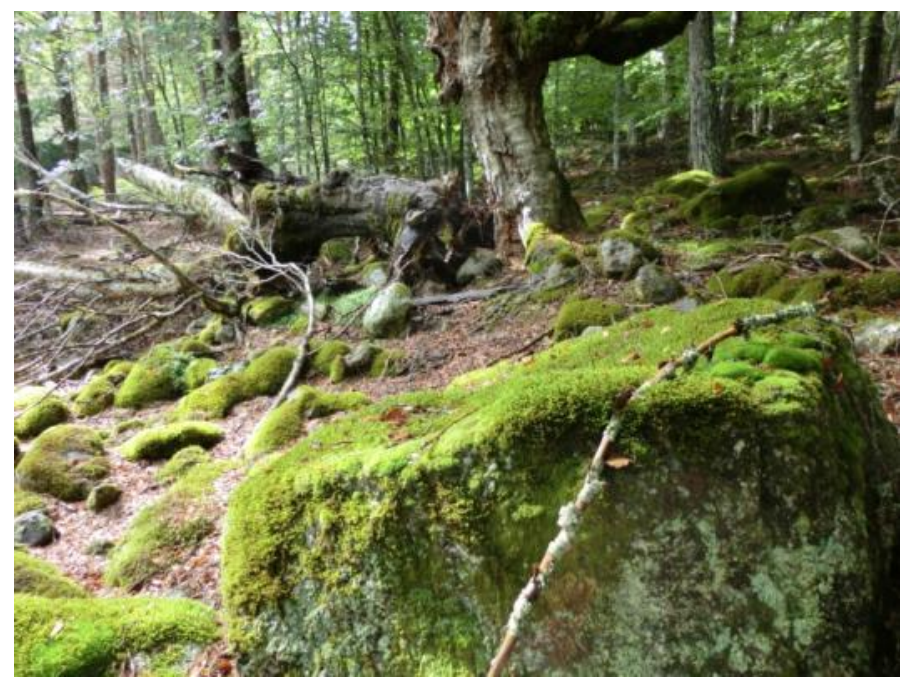

Imagen 108. Zona de recolección

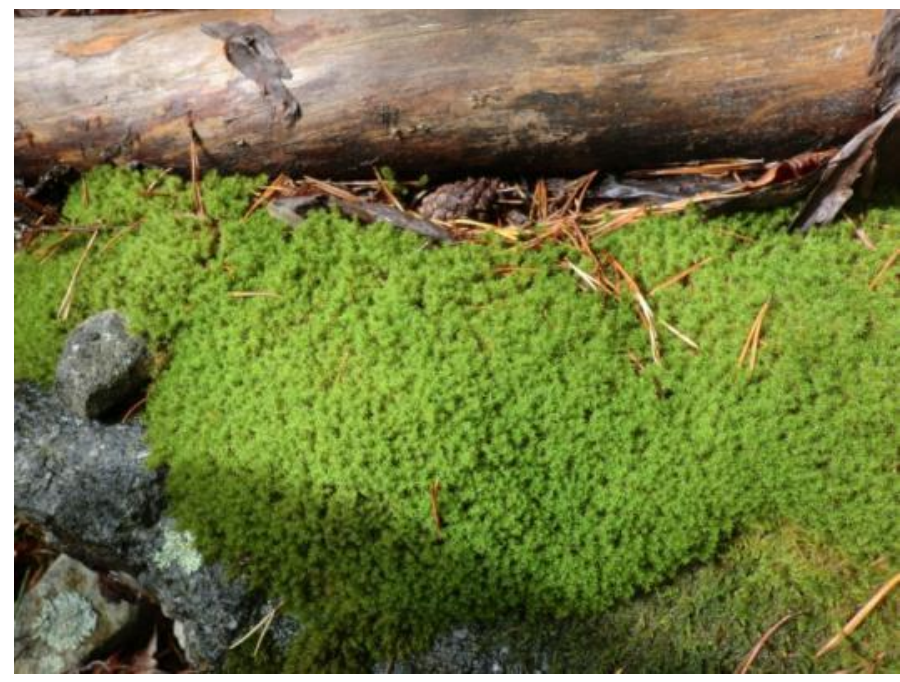

Imagen 109. Muestra de Antitrichia Curtipendula

La zona tiene una alta presencia de humedad ambiental. A las elevadas precipitaciones de los días anteriores se une la existencia de un pequeño curso fluvial. La mayoría de musgos se encuentran en zonas de relativa sombra, descartando orientaciones. Sin embargo en otras rocas los musgos se encuentran directamente incididos por la radicación solar durante buena parte del día.

Según se indica por los profesores que nos asesoran, el crecimiento de los musgos se produce principalmente al amanecer conjugándose dos factores: escasa intensidad solar, aunque con incidencia directa y alta tasa de humedad, coincidiendo con el rocío matutino. El periodo de menor crecimiento coincide con el periodo de mayor intensidad e incidencia de luz solar directa.

Existen numerosas especies de musgos y líquenes en la zona, adheridas a los troncos de los árboles, a rocas o directamente sobre el propio terreno. Se reconocen numerosas especies, tanto de Antitrichia Curtipendula como de hypnum cupressiforme y otras especies descartadas para la investigación. 
Muchas de los tapices presentes se encuentran colonizados 0 solapados por otras especies de musgo distintas. Esta simbiosis permite a los musgos crear muestras mucho más densas. Sin embargo, para la investigación, se opta por recolectar muestras de una única especie.

La recolección es sencilla, se comienza despegando suavemente los bordes del tapiz y se va arrancando suavemente para conseguir muestras del mayor tamaño posible. Con el fin de que los musgos no pierdan la humedad que contienen, se depositan en bolsas de plásticos y se van apilando los tapices uno sobre otro.

Los tapices recolectados de Antitrichia Curtipendula se caracterizan por ser de un tamaño grande, aproximadamente de unos $30 \mathrm{~cm}$., y adheridos someramente a rocas. Una vez recolectados se trasladan en las bolsas descritas al laboratorio donde se dispondrán en bandejas.

La recolección ha supuesto una obtención de unos 0,60 m2 de musgo, produciendo un impacto sobre el entorno despreciable. No obstante en caso de producción industrial de los productos derivados de la presente tesis, se debe idear un proceso de cultivado que no esquilme el medio ambiente.
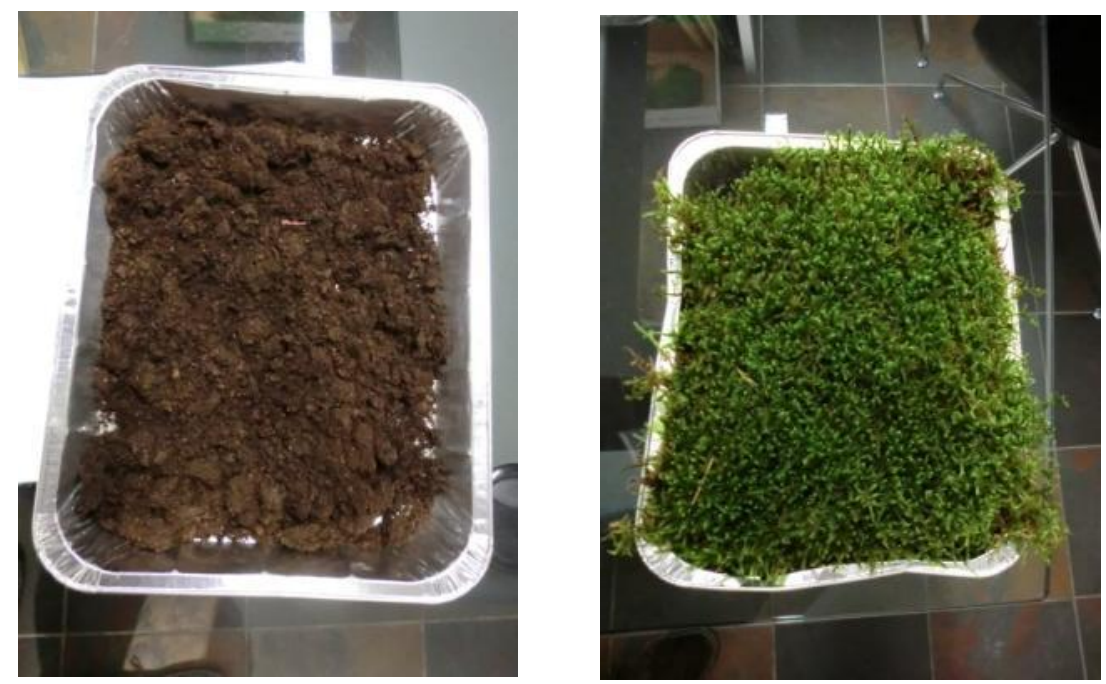

Imagen 110. Muestra sobre bandeja

\section{Conservación muestras}

Posteriormente a la recolección se procede depositar las muestras en un medio que permita su conservación. Para ello se utilizan bandejas de aluminio que se rellenan con un sustrato de tierra vegetal natural mezclada con sustrato de jardinería (Imagen 110). Dicho suelo se humidificará para conseguir un aporte hídrico a través los rizoides.

Estas bandejas se disponen inicialmente en un patio interior de un bloque de viviendas. Debido a la existencia de seis plantas por encima del nivel, la irradiación solar nunca es directa, sino que se trata de una iluminación somera de muy escasa intensidad.

Pese a que, como se ha comentado en el apartado anterior, el pico de crecimiento de los musgos es cuando la irradiación es directa, aunque de escasa intensidad, para esta primera fase se estima más importante la supervivencia de los musgos, con su agarre o "enraizado". Una vez que los musgos se encuentren estabilizados, su tolerancia a los ciclos de desecado, aumenta. Según la experiencia del 
profesor Martínez-Abaigar, una vez estabilizados, los musgos pueden soportar hasta tres ciclos de desecado.
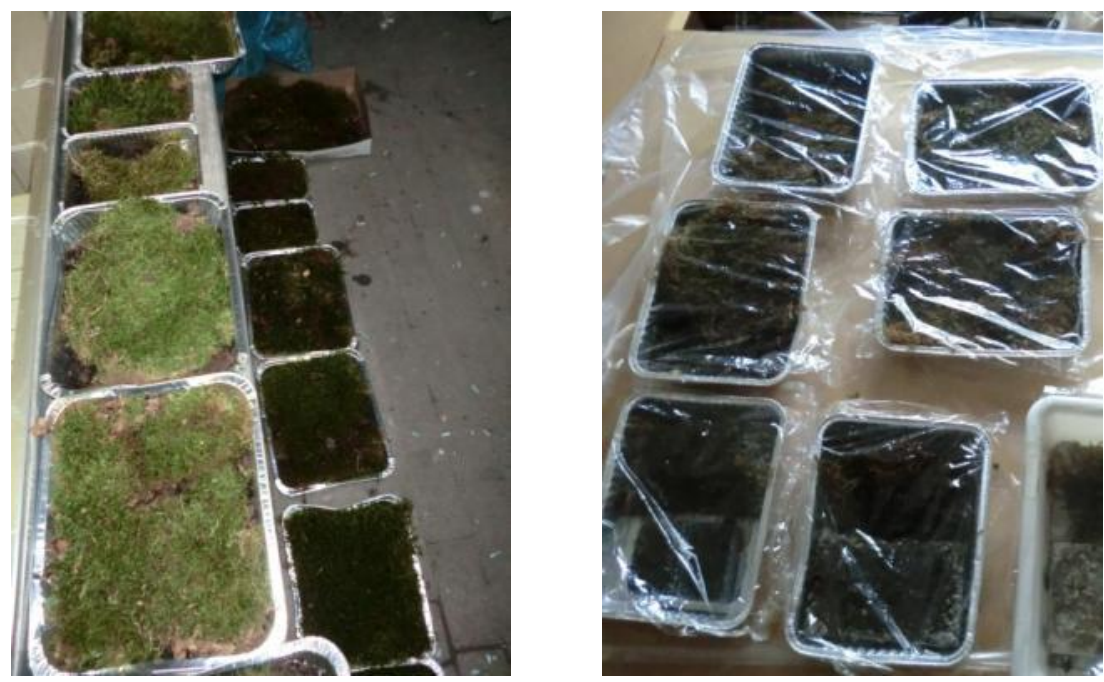

Imagen 111. Muestras en patio y después en local interior.

Se ha procedido a realizar un riego por pulverización cada dos días de las muestras. Para evitar la evaporación de la humedad se ha dispuesto un film transparente sobre las bandejas que contienen las muestras que evita la pérdida de humedad, pero a su vez con orificios que permiten la respiración y fotosíntesis del musgo.

Posteriormente parte de las muestras se han trasladado a un local interior con una temperatura controlada. En ningún caso la temperatura ha sido inferior a $15^{\circ} \mathrm{C}$ ni superior a $25^{\circ} \mathrm{C}$. Se ha continuado con el riego por pulverización con la misma frecuencia. Estas condiciones se suponen ideales para la proliferación del musgo.

Se ha controlado la incisión de luz natural. Esta se ha realizado a través de una ventana con orientación noroeste, permitiendo una iluminación directa durante aproximadamente una-dos horas diarias, dependiendo de la estación del año.

\section{Estudios previos}

La primera toma de contacto para la elaboración de un conjunto soporte de mortero y briófito se ha realizado utilizando las muestras elaboradas en base a un cemento portland con sustitución de árido por EAFS. La composición de estas muestras se ha indicado en los estudios previos del capítulo 5.

La especie de musgo dispuesta es Antitrichia curtipendula, recolectada escasas semanas antes directamente del bosque de la Sierra Cebollera, en La Rioja.

Estas pruebas suponen una primera toma de contacto con el sistema de implantación de los musgos en soportes cementosos. 


\subsection{Metodología}

Para esta experimentación se han analizado cinco tipos de siembra, atendiendo a la bibliografía consultada anteriormente:

- Implantación de la mata de musgo

- En seco / sin sustrato

- Con sustrato

- Con sustrato y acidificando la superficie

- Batido de musgo

- En seco / sin sustrato

- Con sustrato

Implantación en seco / sin sustrato

El procedimiento para este tipo de siembra es el más sencillo de todos. Se dispone una mata del musgo directamente sobre la superficie del soporte. (Imagen 112)

Dicho soporte ha sido previamente limpiado mediante una solución en base lejía, que permite la eliminación total de los microorganismos presentes en él.
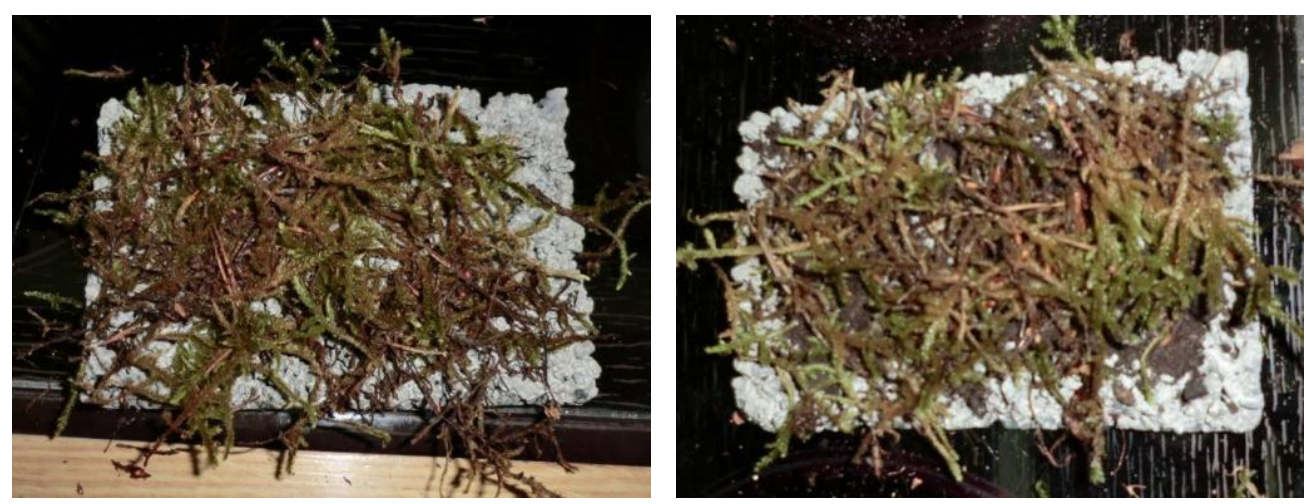

Imagen 112. Implantación en seco / sin Imagen 113. Implantación con sustrato sustrato

\section{Implantación con sustrato}

El procedimiento para este tipo de siembra es muy parecido al anterior. La diferencia radica en que la mata de musgo no se implanta directamente sobre el soporte, sino que sobre este se ha dispuesto tierra vegetal. El fin es que los rizoides estén en contacto con terreno y puedan conseguir nutrientes de él.

Dicho soporte ha sido previamente limpiado mediante una solución en base lejía, que permite la eliminación total de los microorganismos presentes en él.

\section{Implantación con sustrato y acidificación de la superficie}

El musgo crece preferiblemente en medios ácidos. Sin embargo el sustrato sobre el que se dispone en este caso, al tratarse de cemento portland, es netamente básico; el medio más sencillo para acidificar la superficie es impregnarlo con una solución de yogurt natural. Con esto, además, conseguimos dotar de nutrientes al musgo para desarrollarse. 
El procedimiento para este tipo de siembra es muy parecido al anterior. Se dispone la tierra vegetal directamente sobre el soporte, previamente esterilizado con lejía, intentando que ésta entre en la porosidad abierta del mortero. Una vez está dispuesto, con una brocha se procede a distribuir la solución de yogurt.

Cuando se ha completado, se dispone la mata de musgo sobre la superficie.

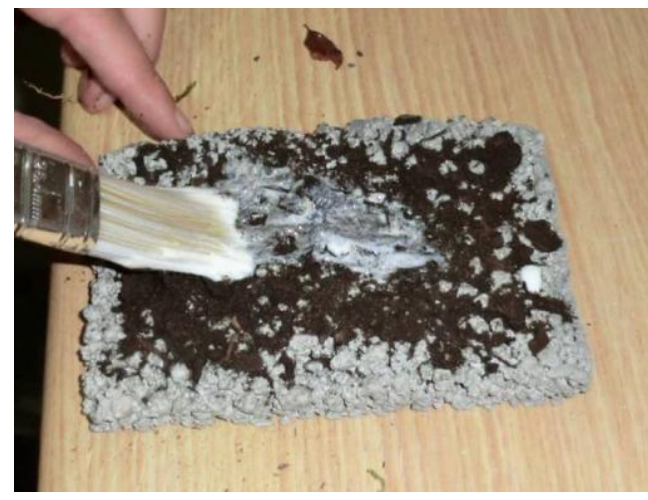

Imagen 114. Impregnación con yogurt

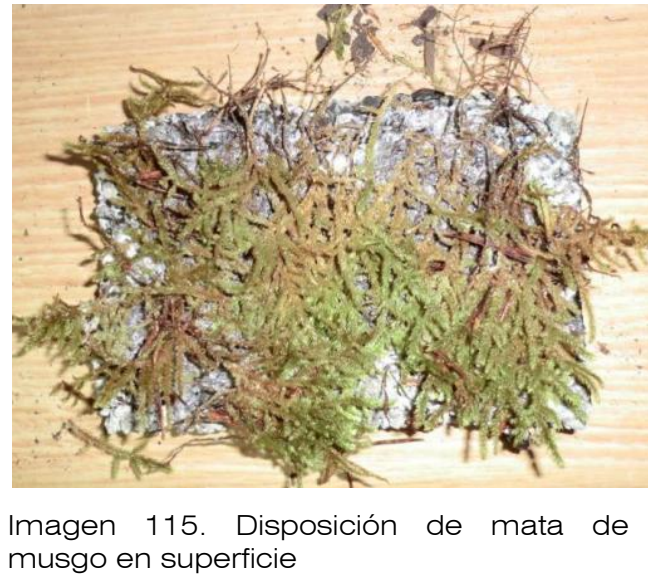

\section{Batido de musgo en seco.}

Los batidos de musgo (moss milkshakes) es uno de los sistemas de reproducción de musgos con mayor difusión en libros de jardinería existiendo incluso productos comerciales.

El método, tal y como se ha indicado en el capítulo 4, consiste en licuar brotes maduros naturales de la especie de musgo escogida junto con yogurt natural hasta obtener un batido verde.

A continuación se pinta con este batido el soporte, previamente limpiado para evitar la proliferación de microorganismos.
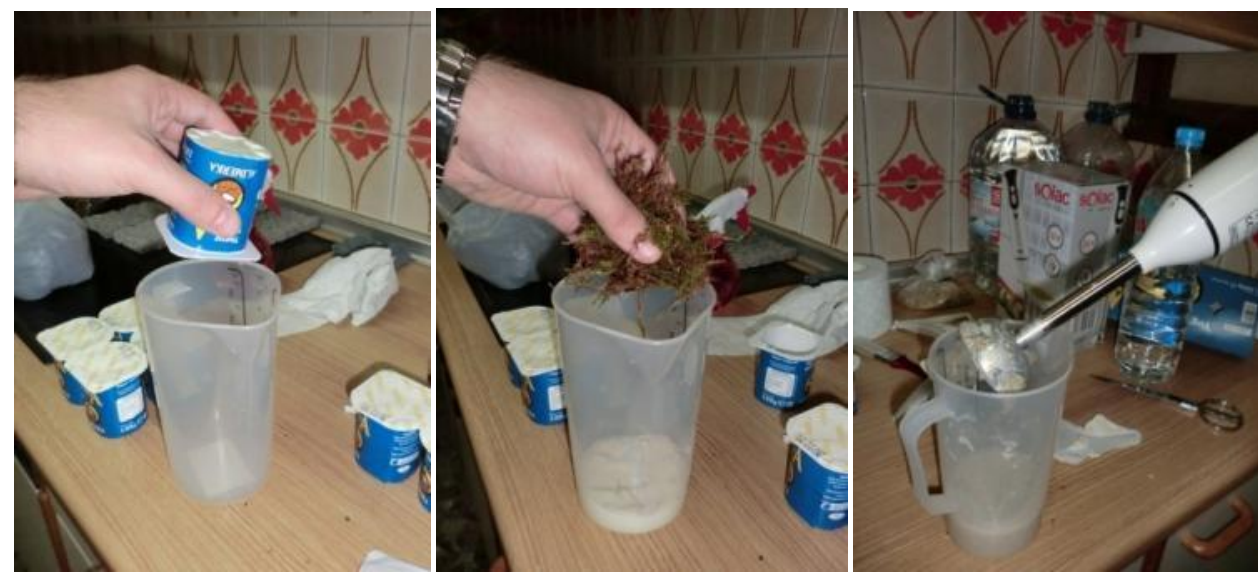

Imagen 116. Elaboración batido de musgo

\section{Batido de musgo con sustrato.}

El procedimiento es exactamente el mismo que el anterior, con la salvedad que volvemos a disponer una tierra vegetal como base. 


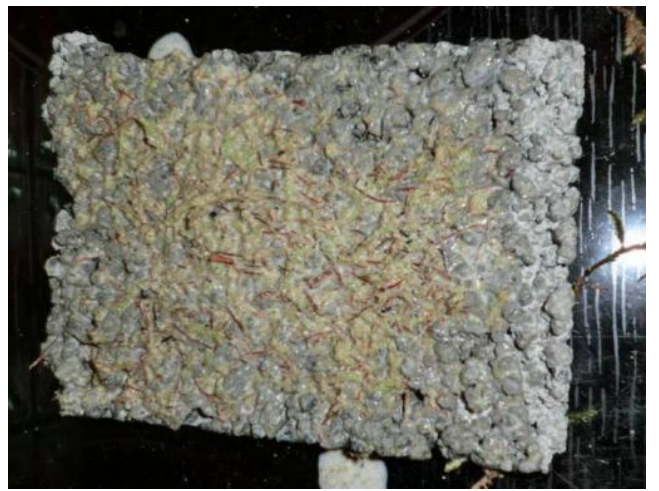

Imagen 117. Batido de musgo en seco

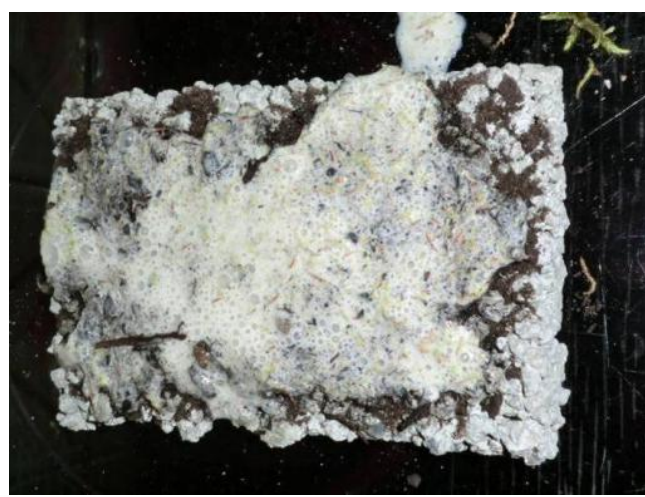

Imagen 118. Batido de musgo con sustrato

\subsection{Resultados preliminares}

Su plantación se ha realizado, controlando los siguientes factores:

- Humedad. Se ha procedido a realizar un riego de las muestras por pulverización cada dos días. Para evitar la evaporación de la humedad se ha dispuesto un film transparente sobre las bandejas que contienen las muestras, que evite la pérdida de humedad, pero a su vez con orificios que permiten la respiración y fotosíntesis del musgo.

- Temperatura controlada mediante termostato. En ningún caso la temperatura ha sido inferior a $15^{\circ} \mathrm{C}$ ni superior a $25^{\circ} \mathrm{C}$. Estas condiciones se suponen ideales para la proliferación del musgo.

- Se ha controlado la incisión de la luz natural. Esta se ha realizado a través de una ventana con orientación noroeste, permitiendo una iluminación directa durante aproximadamente una-dos horas diarias, dependiendo de la estación del año.

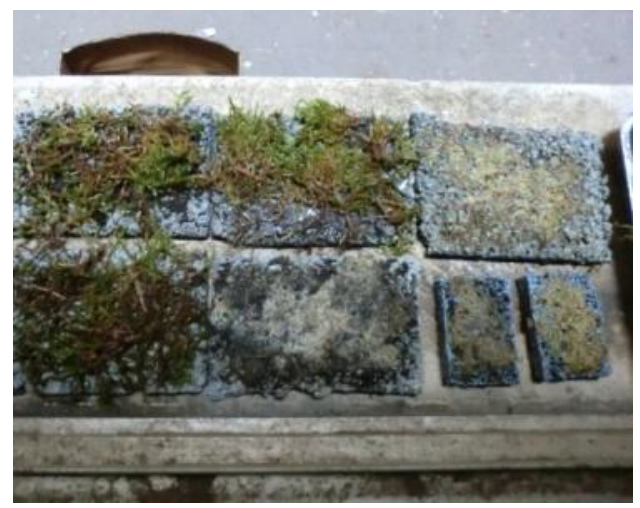

Imagen 119. Estado inicial de las muestras

El resultado obtenido de estos ensayos previos ha sido negativo. Ninguna de las muestras elaboradas ha conseguido sobrevivir en un periodo de un año.

Como conclusiones de esta investigación con los ensayos previos, pueden señalarse las siguientes:

- El soporte base, elaborado con cemento portland ha sido demasiado agresivo, al tratarse de un medio básico, y no ha permitido el crecimiento del briófito. 
- Para que se produzca la viabilidad del briófito se requeriría que el soporte fuera un medio ácido, y por lo tanto, medianamente bio-receptivo.

- No se puede realizar riego mediante capilaridad de la propia muestra, puesto que la proliferación de hongos y mohos copan la superficie del musgo.

- Paralelamente se han mantenido sobre tierra vegetal matas de musgo, recolectadas el mismo día, de dos especies: Antitrichia curtipendula y hypnum cupressiforme. Durante el periodo estival, en el cual la temperatura fue máxima, dichas matas se desecaron, pese al riego. Sin embargo, una vez la temperatura se volvió a estabilizar en torno a los $15-20^{\circ} \mathrm{C}$, el hypnum cupressiforme volvió a recuperar su verdor.

- Antitrichia curtipendula requiere un mayor nivel de humedad para la "reviviscencia" que Antitrichia curtipendula.

\section{Colonización vegetal del mortero}

El mortero MPC elaborado y caracterizado en el capítulo anterior se presupone bio-receptivo. Eso se debe a sus características mejoradas, con un pH neutro, mayor porosidad, un alto coeficiente de absorción de agua y una mayor rugosidad superficial.

La presente Tesis Doctoral investiga la capacidad de repropucción de una especie de briófito, Antitrichia curtipendula, en la superficie y que esta sirva como especie colonizadora primaria.

Para conseguir esta colonización se opta inicialmente, como se ha indicado anteriormente, por el sistema denominado "batido de musgo" (moss milkshake), es decir una mezcla batida de brotes de musgo en un medio láctico.

Sin embargo, dado que este método de cultivo tiene cierta contestación entre algunos expertos en jardinería de musgos [2], en los sucesivos experimentos se alternan con los cultivos de ejemplares adultos.

\subsection{Cuantificación de la bio-receptividad}

La bio-receptividad del material propuesto en la tesis es algo difícilmente cuantificable. La capacidad de un material de ser bioreceptivo existe o no, por lo tanto los métodos empleados determinarán si el MPC es bio-compatible con la vida vegetal o no, sin conseguir un valor medible.

Los métodos para evaluar esta cualidad del material pasan por cuantificar el crecimiento de la masa vegetal o el biofilm generado en la superficie.

Unos de los más empleados es el que evalúa el cambio de coloración de la clorofila. Este consiste, básicamente, en un análisis de imagen en el que se controla el crecimiento de la clorofila mediante varias imágenes tomadas en las mismas condiciones. La clorofila tiene un color característico por lo que no es complicado cuantificar por comparación el crecimiento. De hecho en la investigación llevada a cabo por Prieto, B. et al [3] en la que se evalúan diferentes métodos, este se considera como el óptimo. 
Otras investigaciones como las de Manso, S. et al [4] o Guillite, O et al [5] también contemplan el análisis de la clorofila generada en los biofilms.

Sin embargo también existen otros métodos empleados por estos mismos investigadores. Por ejemplo Manso, $S$. et al, evalúa la producción de biomasa algal mediante fluorimetría. Para ello se utiliza un fluorímetro PAM (pulsos de amplitud modulada), que excita simultáneamente la clorofila presente mediante diferentes longitudes de onda, evaluando el contenido de pigmentos.

También en la investigación, anteriormente mencionada, de Prieto, $B$. et al utilizan otros métodos para la cuantificación de la biomasa generada, aparte del cambio de coloración. Se ensaya con la hidrólisis de diacetato de fluoresceína y la cuantificación de la clorofila a presente. La hidrólisis de diacetato se descarta ya que en las propias conclusiones se determina que los resultados obtenidos mediante el método difieren ampliamente de la biomasa real obtenida. La evaluación de la clorofila-A es un ensayo destructivo, por lo que se descarta.

Vistos los métodos utilizados en otras investigaciones se procederá a realizar un seguimiento fotográfico de las superficies de las placas empleadas, con el fin de realizar un análisis de imagen que permita cuantificar la biomasa generada por el briófito en la superficie.

\subsection{Fase experimental 1. Batido de musgo.}

La implantación del briófito en la superficie del mortero MPC se realiza mediante un "batido de musgo". Las muestras empleadas son las placas en las que se ha ensayado su $\mathrm{pH}$ y conductividad eléctrica en el capítulo anterior.

Estas placas se han elaborado tomando como referencia las dosificaciones del punto 3.1 del capítulo anterior. Estas placas de $10 \times 10 \times 1,5 \mathrm{~cm}$ utilizan distintas fuentes de magnesio y dosificaciones. Las placas que se han utilizado son las que se relacionan en la Tabla 51.

Las placas PL2 y PL7 utilizan Mag7, es decir una magnesita calcinada a muerte. La placa PL8 utiliza ImpalMag y las placas PL5 y PL9 utilizan el sub-producto PC8 que se ha venido caracterizando.

\begin{tabular}{cccc} 
& \multicolumn{2}{c}{ Placas utilizadas } \\
& $\mathrm{pH}$ & Dosificación & EAFS \\
PL2 & 6,51 & 11 & \\
PL5 & 9,88 & 14 & \\
PL7 & 6,83 & 15 & Sí \\
PL8 & 6,31 & 16 & Sí \\
PL9 & 6,93 & 17 & Sí
\end{tabular}

Tabla 51. Placas utilizadas en el ensayo

\section{Ensayo 1}

Para la elaboración del "batido de musgo" se consultan distintas muestras nutritivas. Se opta por la solución nutritiva elaborada en la investigación de Luna, l. et al en el denominado Bio-ceramic system 
[6]. Este sistema utiliza un "batido de musgo" con buenos resultados utilizados sobre un soporte cerámico, que aunque difiere de la investigación de la presente Tesis, si dispone ciertos puntos en común.

$\begin{array}{cc}\text { Producto } & \text { Cantidad } \\ \text { Musgo } & 25 \mathrm{gr} . \\ \text { Cerveza } & 100 \mathrm{ml} . \\ \text { Yogurt } & 25 \mathrm{ml} \\ \text { Azúcar } & 70 \mathrm{gr} \\ \text { Agua } & 100 \mathrm{ml}\end{array}$

Tabla 52. Composición nutritiva del batido de musgo

La adición de agua en la solución nutritiva depende del grado de humedad que contiene el musgo. En este caso, el briófito utilizado es antitrichia curtipendula que está humectado, por lo que no se requiere adicionar agua.
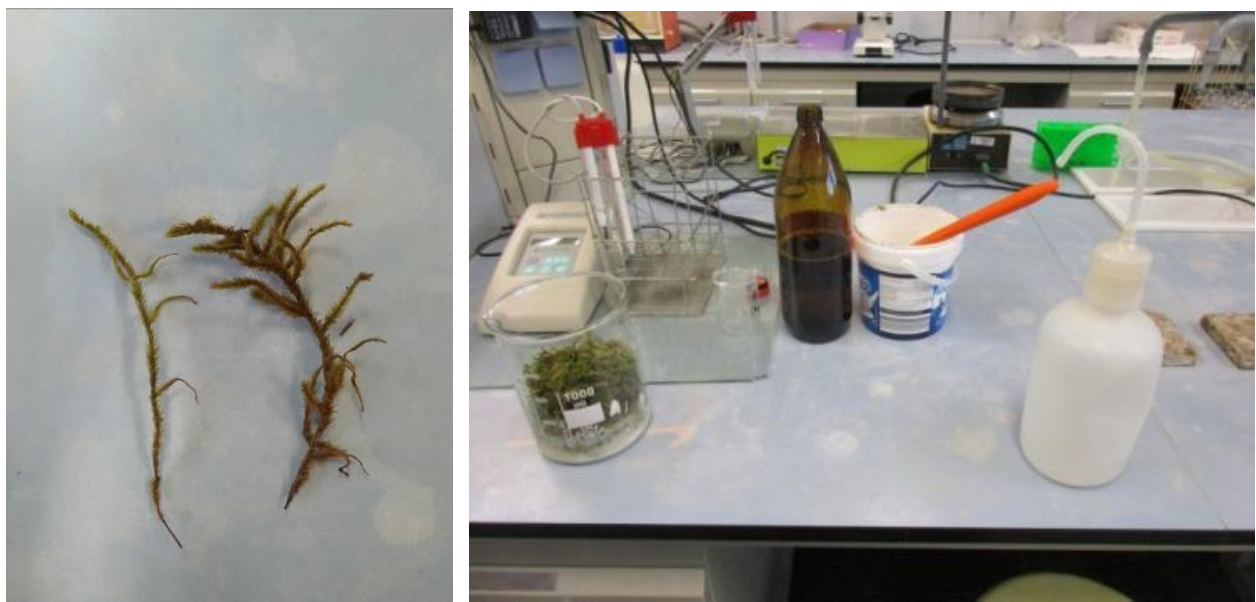

Imagen 120. Productos y brotes de musgo utilizados para la solución nutritiva

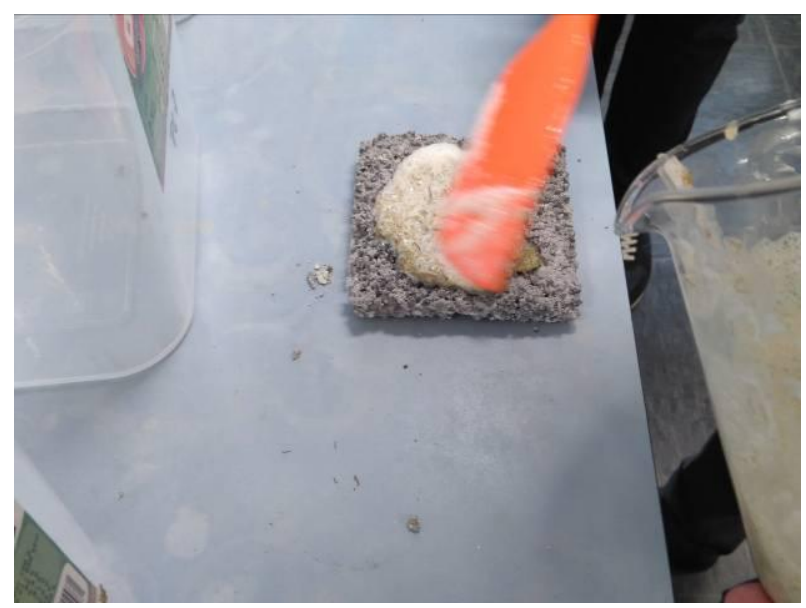

Imagen 121. Diseminación del batido sobre placa

Previamente a la elaboración del batido se han esterilizado las placas. Para ello se les baña en un recipiente con agua caliente y lejía en una concentración de un 5\%, durante 5 minutos. Una vez pasados se elimina el agua con lejía y se deslavan para eliminar los restos de lejía que pudieran permanece en los poros. 
Posteriormente se procede a diseminar el batido sobre la superficie de las placas de MPC. Se procura que la disposición sea uniforme y con contenido suficiente de brotes del briófito (Imagen 121).

Las placas, una vez se ha dispuesto el batido sobre su superficie, se introducen en unos recipientes de plástico transparente. Para que se mantengan las condiciones de humedad se dispone una lámina de agua que impregne el mortero y se tapa el recipiente realizando perforaciones en su superficie (Imagen 122). De este modo se intenta evitar que existan condensaciones en el interior de la caja.

Dichos recipientes se trasladan al interior del Laboratorio de Edafología y Química Agrícola de la Facultad de Ciencias de la Universidad de Burgos. Las muestras se ubican anexas a una ventana situada en la fachada norte, en la cual se consigue luminosidad pero se evita incidencia directa de la luz solar.

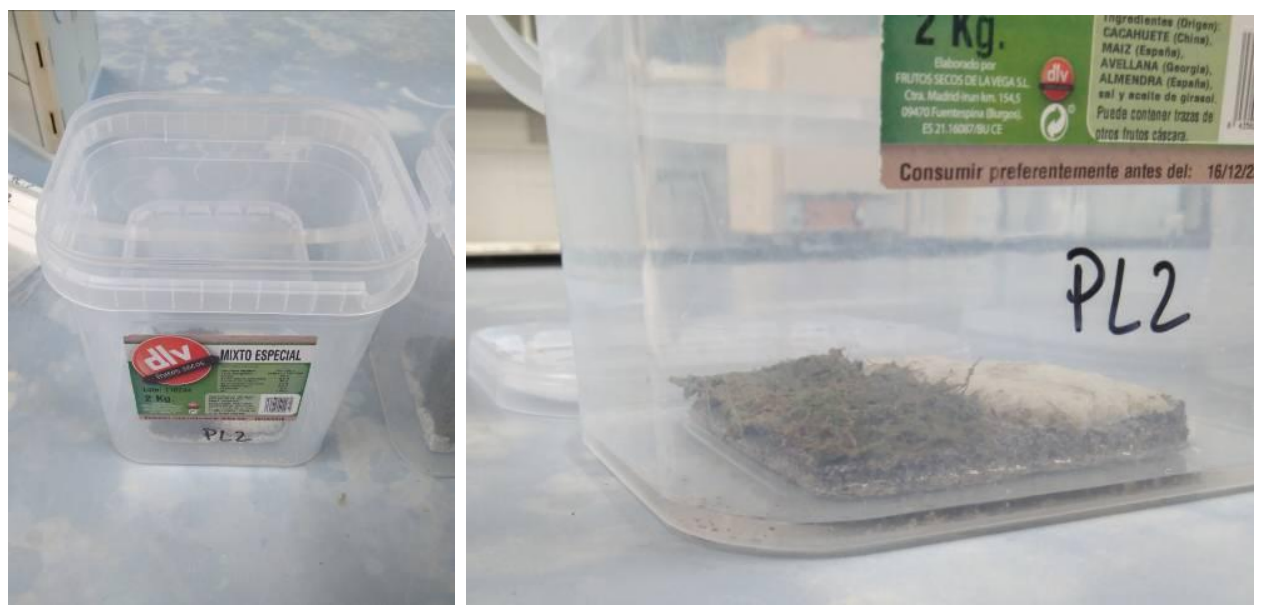

Imagen 122. Muestra en recipiente con lámina de agua

\section{Resultados}

Pasados tres días desde el batido de musgo se procede a un control del estado de las muestras. Todas las muestras han sido colonizadas por hongos, los cuales proliferan tanto en la superficie del mortero como en la lámina de agua.
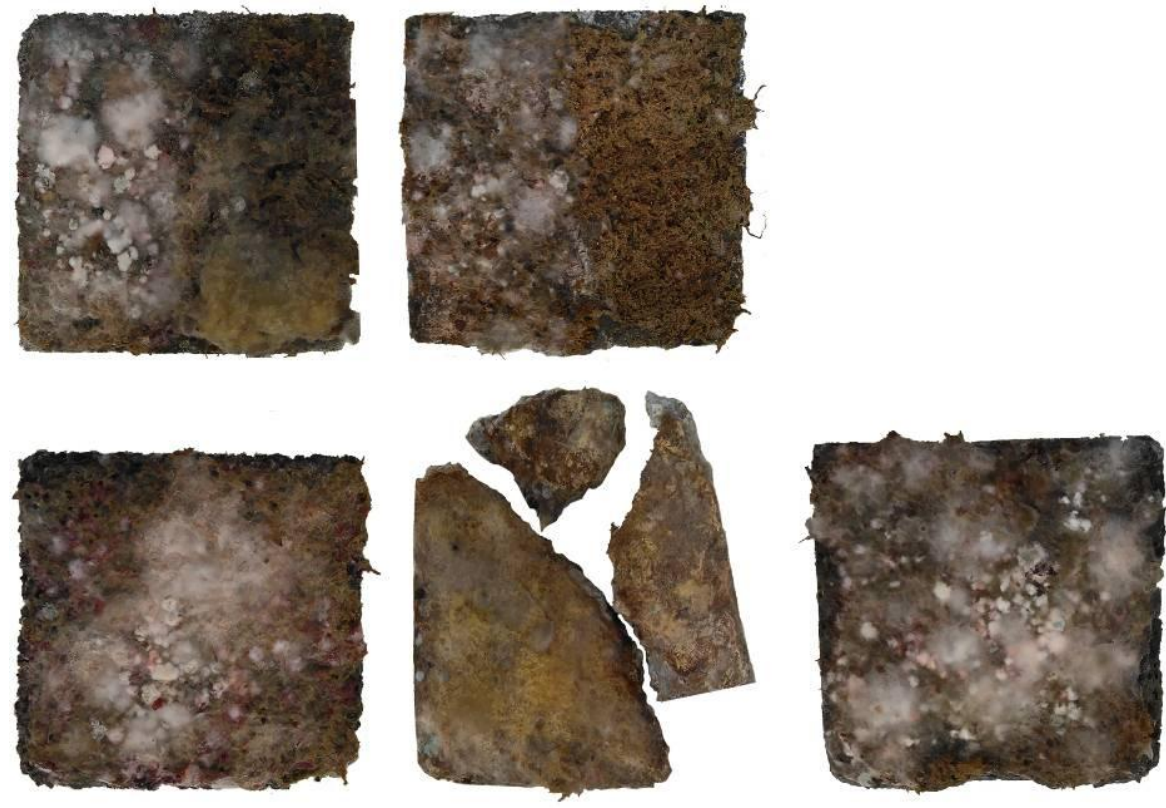
Debido a las buenas condiciones de humedad, temperatura constante y la existencia de una solución nutritiva, el recipiente había condensado. Sabido esto se destapan las cajas para ver si la colonización revierte dejando pasar otros cuatro días. Sin embargo, pasado este periodo, los recipientes perdieron humedad, la lámina de agua se evaporó pero las muestras no prosperaron y tuvo que darse el experimento por fracasado, y se procedió a un nuevo cultivo.

\section{Conclusiones}

Se considera que la combinación entre la alta humedad, aportada por la lámina de agua, y un recipiente cerrado, además de una temperatura elevada (la del interior del laboratorio) y la presencia de la solución nutritiva generaron unas condiciones óptimas para la proliferación de hongos.

También se ha comprobado que la lámina de agua, una vez destapados los recipientes, se evapora rápidamente, dejando al musgo sin aporte hídrico.

El "batido de musgo" genera una costra que se adhiere a la superficie de la placa, lo cual es interesante ya que permite entender que si el musgo hubiese prosperado, la costra vegetal hubiera servido de soporte sólido. Como era de esperar, las placas con mayor rugosidad superficial (PL2 y PL7) son las que presentan una mayor adherencia al soporte de esta capa vegetal.

\section{Ensayo 2}

Este ensayo pretende revertir algunos de los fallos determinados en las conclusiones del ensayo anterior.

Se repite el "batido de musgo" con la solución nutritiva elaborada en el ensayo anterior (Tabla 52), sin embargo esta vez los recipientes plásticos no se cierran para evitar la condensación.
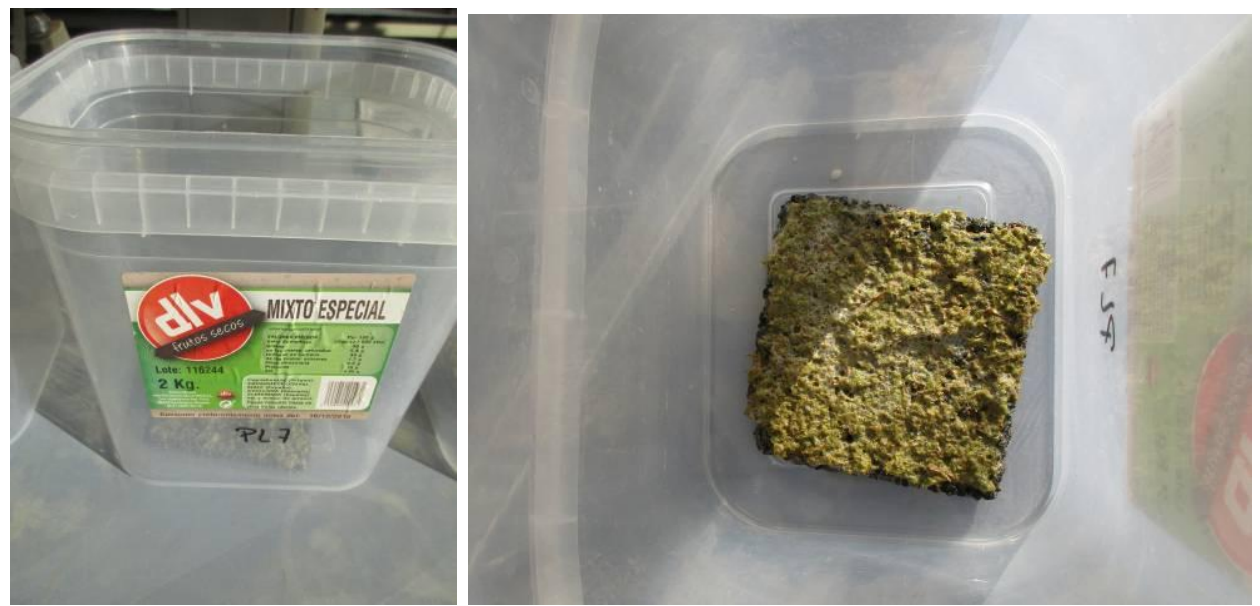

Imagen 124. Muestra en recipiente

En las muestras PL2 y PL5 se dispone, al igual que en el ensayo anterior, dos batidos de musgo con especies diferentes que ocupan cada uno la mitad de la placa. En el lado derecho de la placa se dispone una solución con la especie Antitrichia Curtipendula y al lado izquierdo otra con la especie Hypnum Cupressiforme. Dado que esta 
especie se está estudiando en una investigación paralela, con su utilización se intenta ampliar las probabilidades de éxito en el ensayo.

Sin embargo existen varias diferencias entre el anterior ensayo y el actual:

- Emplazamiento:

Para este ensayo se opta únicamente por emplazamientos en exterior. Se eligen dos localizaciones: una principal y otra secundaria. Para la localización principal (1) se opta de nuevo por el laboratorio de Edafología y química agrícola de la Facultad de Ciencias, pero esta vez en el exterior. Para ello se disponen las muestras junto a las ventanas, situadas en una fachada con orientación a $18^{\circ}$ del norte exacto.

En este caso se trata de un emplazamiento urbano, situado en una fachada en la que no existe soleamiento directo, con excepción de unos minutos diarios a primera hora

Para la localización secundaria (2) se opta por un espacio exterior situado en el centro de Burgos, junto a una de las principales vías de comunicación. En este caso las muestras se disponen en una terraza con orientación situadas en una fachada con orientación a $25^{\circ}$ del noreste.

Las placas utilizadas en el ensayo anterior se dispondrán en la ubicación principal (1) y las otras dos, que no se han ensayado con anterioridad, en la ubicación secundaria (2). (Tabla 53)

- Riego:

Para el riego se descarta la disposición de una lámina de agua y se opta por rociado por pulverización. Para abarcar el mayor número de opciones, las muestras dispuestas en el emplazamiento principal (1) se regaran cada 3 días y las muestras dispuestas en el emplazamiento secundario (2) se regaran intensamente a diario

$\begin{array}{ccccc} & & \text { Placas utilizadas } & & \\ \text { Dosificación } & \text { EAFS } & \text { Ubicación } \\ \text { PL2 } & 6,51 & 10 & \text { No } & 2 \\ \text { PL4 } & & 13 & \text { No } & 1 \\ \text { PL5 } & 9,88 & 14 & \text { No } & 2 \\ \text { PL7 } & 6,83 & 15 & \text { No } & 1 \\ \text { PL8 } & 6,31 & 16 & \text { Sí } & 1 \\ \text { PL9 } & 6,93 & 17 & \text { Sí } & 1\end{array}$

Tabla 53. Placas utilizadas en el ensayo

\section{Resultados}

El análisis fotográfico se va a realizar a dos escalas diferentes. Por un lado se realizará utilizando un microscopio estereoscópico modular Leica MZ6 con zoom 6.3:1. Dicho microscopio (Imagen 125) permite la incorporación de una cámara móvil para poder hacer las imágenes. 

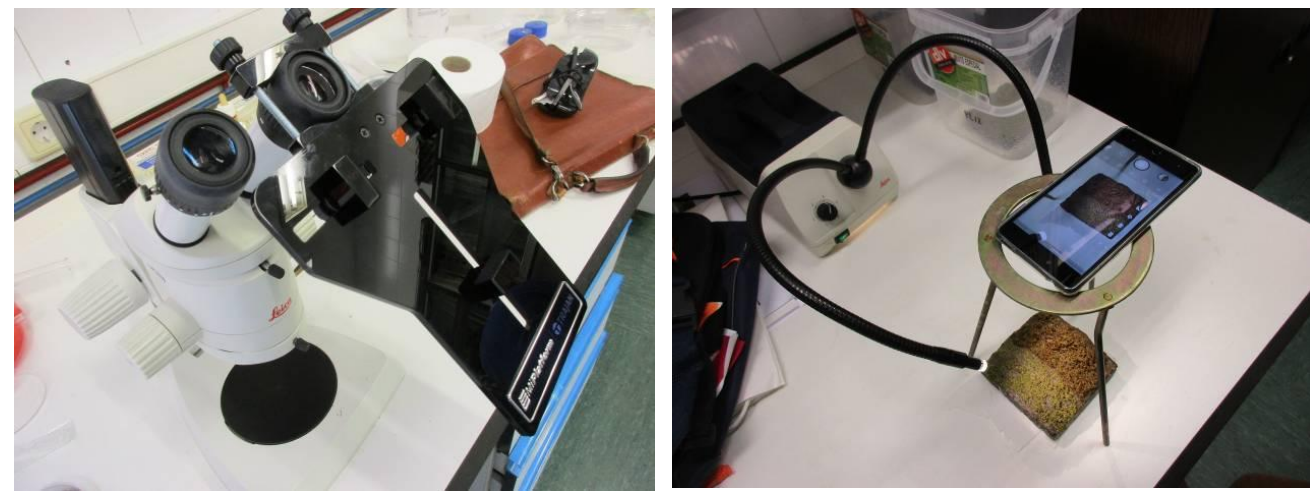

Imagen 125. Microscopio Leica MZ6 con Imagen 126. Toma de fotografías adaptador de cámara empleado

Este análisis se lleva a cabo los días 5 y 10 del seguimiento de las muestras. Se desiste de continuar con este análisis puesto que el musgo parece no prosperar. En las imágenes se puede ver el rojo intenso del tallo del musgo y las hojas verdes. Sin embargo no parece, ya a los diez días, que los tejidos vegetales estén reproduciéndose, de hecho parecen secos.

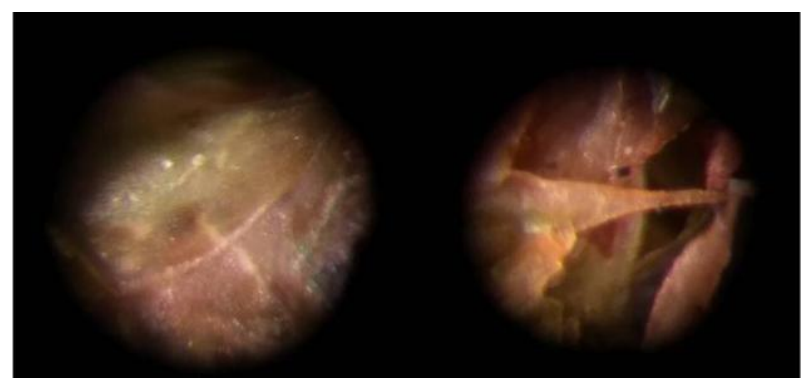

Imagen 127. Análisis microscopio día 5

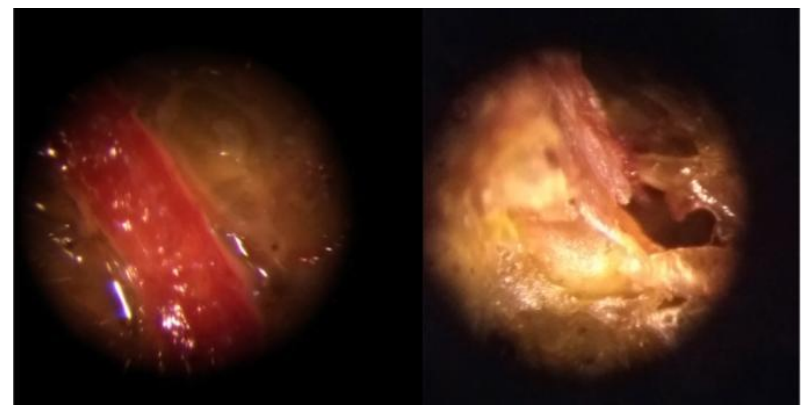

Imagen 128. Análisis microscopio día 10

Simultáneamente se realiza un análisis fotográfico sin ampliación al microscopio. Para esto se emplea siempre el mismo equipo y como iluminación se utiliza una fuente de luz LED marca Leica. Las fotografías se toman después de regar las muestras mediante pulverización.

Como se puede observar en la secuencia fotográfica de la Imagen 129, el briófito no ha prosperado en el emplazamiento principal (1). Es patente que desde el día 10 el musgo ha perdido casi toda la humedad que contenía y se ha ido secando paulatinamente pese al riego periódico que se hacía. El día 17, visto que las estructuras del briofito están totalmente secas y no hay punto de retorno se da por finalizado el ensayo. 
Día 5

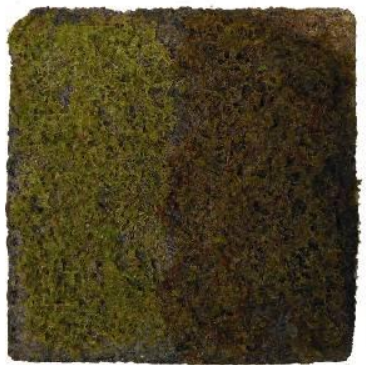

PL2

PL5

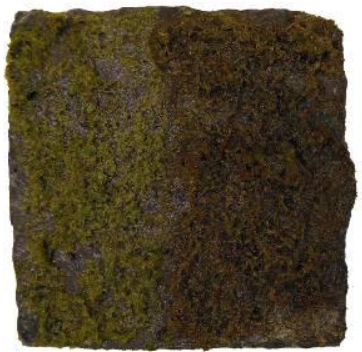

PL7
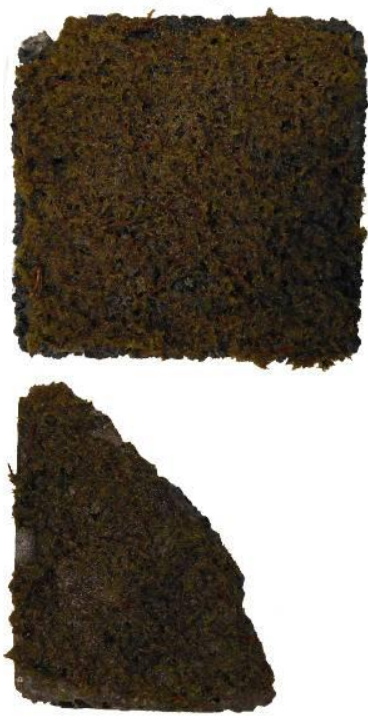

PL8

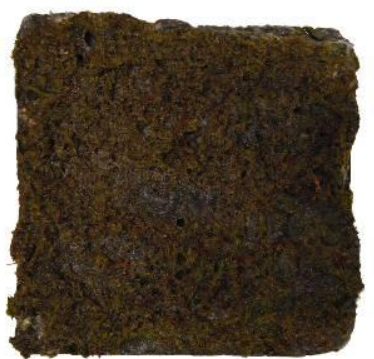

Día 10
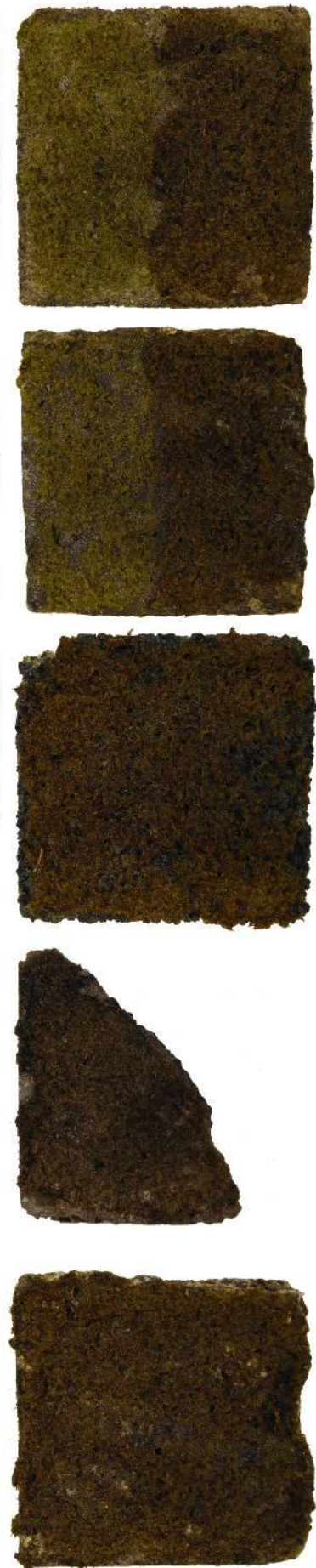

Día 17
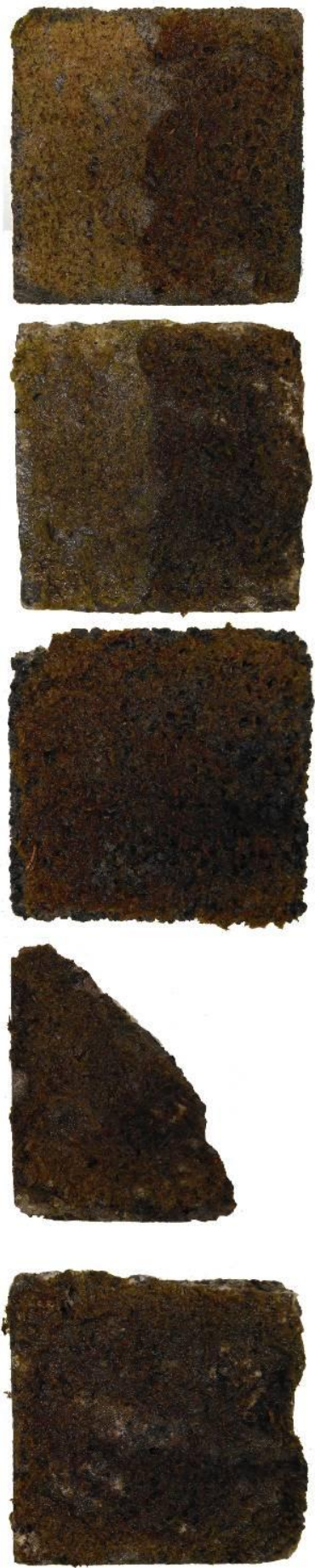

Imagen 129. Análisis fotográfico muestras en emplazamiento principal (1)

En el emplazamiento secundario (2), a diferencia del principal, el análisis se ha llevado a cabo hasta completar cuatro semanas de ensayo (Imagen 130). En este caso, pese a que el resultado final ha sido el mismo que el anterior, las estructuras del briófito han mantenido verdor y humedad mayor tiempo. Pese a ser un emplazamiento más soleado, no se han evidenciado signos claros de que el cultivo no estaba prosperando hasta el día 14. Finalmente, el día 28 pese a existir 
áreas verdes, estas están totalmente secas y no tiene visos de mejora. En este punto se da por finalizado el ensayo.

PL1

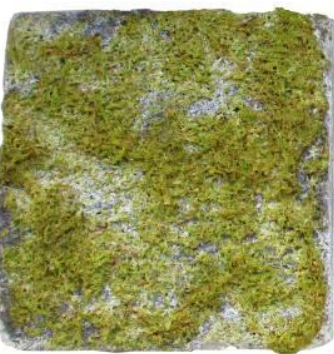

Día 1

Día 5

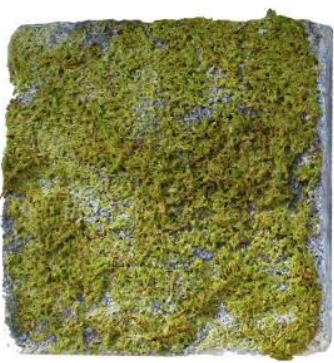

Día 14

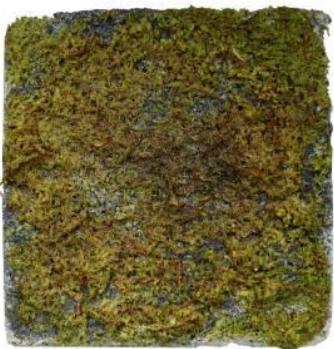

Día 21

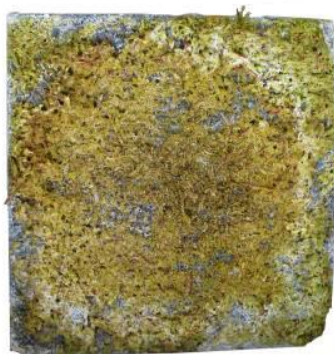

\section{Día 28}

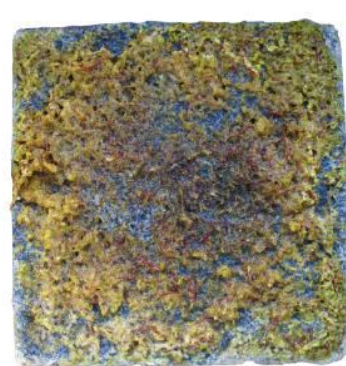

PL4
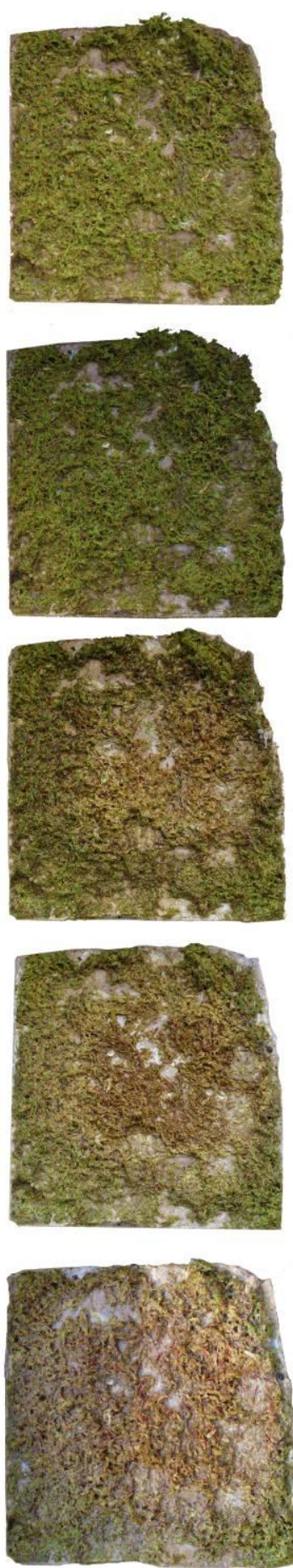

Imagen 130. Análisis fotográfico muestras en emplazamiento secundario (2)

\section{Conclusiones}

De este experimento se pueden sacar varias conclusiones gracias a la combinación de intensidades de riego y ubicaciones. Es patente que las muestras ubicadas en el emplazamiento principal (1), pese a estar en una ubicación prácticamente norte, han carecido de la humedad 
necesaria para que prosperen. Este hecho se ha evidenciado en comparación entre ambos emplazamientos. Si bien el emplazamiento secundario (2) debería haber sido mucho más agresivo para el briófito que el principal, debido a que se trata de una zona con mucha mayor incidencia solar, el hecho de haber doblado el riego (de 2-3 días a 1 día), ha permitido que el musgo no perdiera verdor tan rápido.

En las muestras dispuestas en el emplazamiento secundario (2) parecen haber resistido mejor aquellas zonas que presentan siempre zona en sombra (laterales y bordes). Parece interesante utilizar esta intensidad de riego o aumentarla pero controlar mejor la luminosidad de las muestras.

Al igual que en el anterior ensayo, el "batido de musgo" ha generado una costra que se adhiere a la superficie de la placa.

\section{Ensayo 3}

Este ensayo, a la vista de los resultados negativos de los anteriores, y vistas las conclusiones que se pueden sacar de ellos, trata de abarcar una mayor número de variables con las que poder conseguir que el briófito prospere en la superficie del mortero MPC.

Para ello se opta por distintos tipos de riego, grados de humedad, tipos de oscurecimiento y ubicaciones. El fin último es poder llegar a conclusiones que vayan descartando los condicionantes negativos que han llevado al malogro de las anteriores experimentaciones.

Para ello se alternará los siguientes factores, que se muestran en la Tabla 54.

\section{Ubicación}

- Se repite con el emplazamiento principal (1) del anterior ensayo, es decir el exterior del laboratorio de Edafología y Química Agrícola de la Facultad de Ciencia, situado en una fachada con orientación a $18^{\circ}$ del norte exacto.

- Como emplazamiento secundario (3) se opta por la misma situación, pero esta vez en una terraza sin incidencia solar directa pero con luminosidad indirecta. Dado que en esta terraza se han estado conservando los briófitos traídos desde el parque de Sierra Cebollera con éxito, se considera adecuado para evitar su desecación.

\section{Oscurecimiento}

- La mayoría de muestras se disponen directamente sobre los recipientes plásticos transparentes utilizados en los anteriores ensayos. Únicamente se dispondrá un film transparente, debidamente agujereado para evitar una evaporación del agua tan rápida.

- Varias muestras son tapadas lateralmente con un cartón. De esta forma el cartón evita que la superficie del musgo pueda recibir una incidencia lumínica excesiva.

- Una muestra se dispondrá directamente en una caja de cartón tapada totalmente evitando que haya contacto solar son la muestra.

\section{Riego}

- El riego va a ser alternativo para todas las muestras entre lámina de agua y riego por pulverización directamente sobre el musgo. 
Este riego se cambia para evitar, en todo momento, la desecación de las muestras.

\section{Muestra contraste}

- Para contrastar si el mortero es bio-compatible con el mortero MPC o los fallos provienen del tipo de implantación (batido de musgo), se opta por disponer otra placa, esta vez de piedra natural. Se ha elegido una placa de roca lutita de $20 \times 20 \times 2 \mathrm{~cm}$. utilizada en el montaje de fachadas ventiladas.

\begin{tabular}{cccccc} 
& \multicolumn{5}{c}{ Placas utilizadas } \\
PL4 & pH & Dosificación & EAFS & Ubicación & Oscurecimiento \\
PL7 & 6,83 & 13 & No & 3 & Sí. Total \\
PL8 & 6,31 & 15 & Sí & 1 & Sí \\
PL9 & 6,93 & 17 & Sí & 1 & No \\
PL Lutita & - & - & Sí & 1 & No
\end{tabular}

Tabla 54. Placas utilizadas en el ensayo

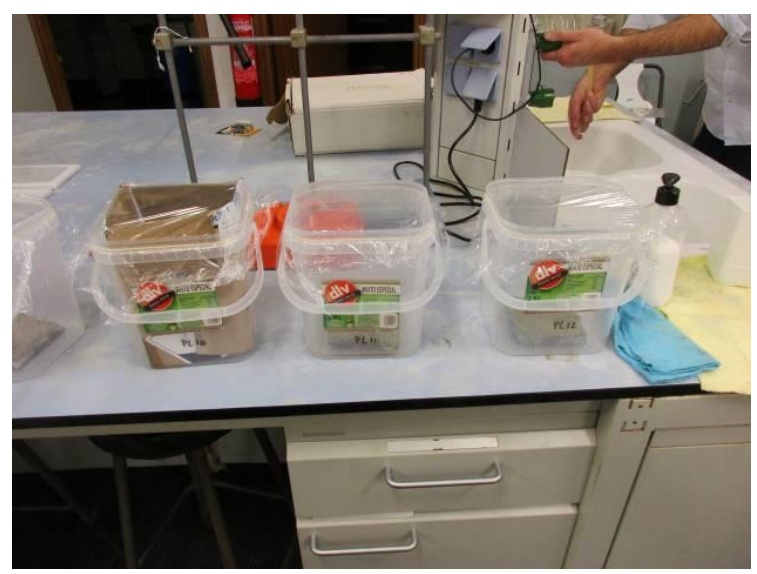

Imagen 131. Envases con distintos grados de oscurecimiento

\section{Resultados}

Pasados siete días desde el batido de musgo se procede a un control del estado de las muestras. La mayoría de las muestras han sido colonizadas por hongos. Varias de las muestras, en ambas ubicaciones, han sufrido una colonización tan masiva que se deben descartar para continuar con el ensayo. Estas son la PL4, PL8 y la PL9.

PL4

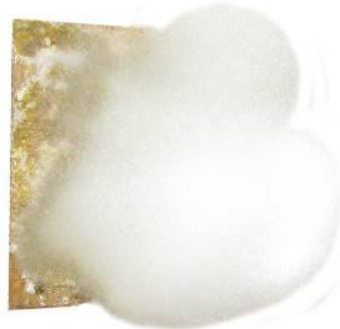

PL8

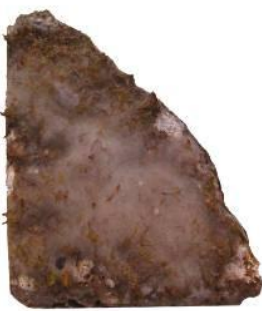

PL9

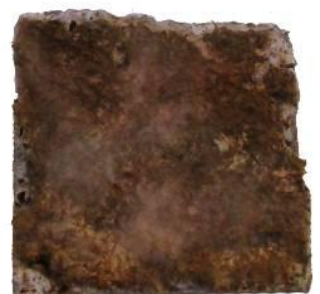


Las muestras restantes (PL7 y PL Lutita), se continúan monitorizando durante un mayor periodo de tiempo. La placa PL7 ha experimentado contaminación por presencia de hongos. Esto puede deberse a que la muestra ha sido regada mediante lámina de agua. De este modo, pese a tener bastante cuidado en el control de la traspiración del recipiente, parece no haber sido suficiente ya que aparece con condensaciones, en mayor o menor medida.

No obstante, para culminar con el ensayo, se continúa con el riego y los envases hasta el final de la experimentación.

Día 7

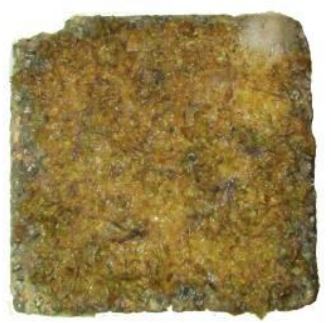

PL7

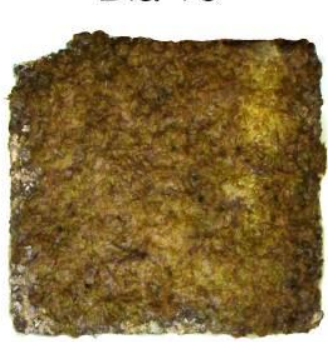

Día 21
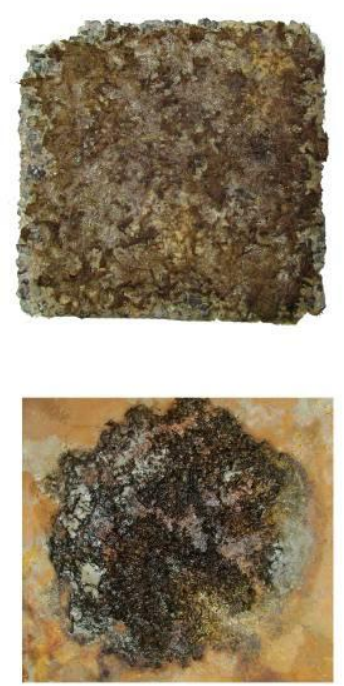

PL LT

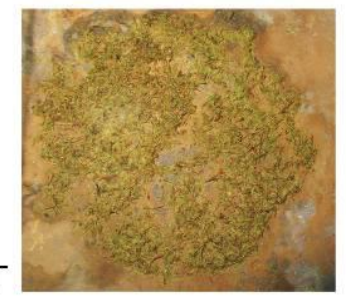

Imagen 133. Resultado placas PL 7 y PL Lutita

El día 21, ya es patente que las muestras elaboradas con batido de musgo se han secado y se da por finalizado en ensayo.

\section{Conclusiones}

Del ensayo se pueden sacar básicamente dos conclusiones. Por un lado la mínima presencia de condensaciones, y la creación de un microclima bajo el film plástico, junto con un clima benévolo, propicia la rápida colonización del batido por los hongos y mohos.

La PL Lutita, debido al material en sí y a su baja capacidad de absorción, ha propiciado una mayor necesidad de riego por rociado. Sin embargo, y pese a disponerse lámina de agua en las mismas condiciones que al restos de las muestras, el briófito no ha presentado colonización de hongos.

Dado que los resultados con batido de musgo se reproducen tanto en el mortero MPC empleado, como en una roca natural, totalmente biocompatible en el hábitat natural, se entiende que los fallos surgen de cualquiera de estos factores: solución nutritiva, especie vegetal o método de cultivo. 


\subsection{Fase experimental 2. Ejemplares adultos}

La presente fase experimental se desarrolla paralelamente al ensayo 4 de la fase 1. En este caso se ha optado por modificar el método de cultivo, tal y como recomiendan Fletcher, M. o Martin, A.

Por ello se dispone directamente sobre la superficie del mortero MPC, concretamente la placa PL2 (Tabla 55), brotes adultos verdes de Antitrichia Curtipendula. Estos brotes se sitúan dentro de una red la cual se ajusta al soporte para conseguir que se adhiera.

\begin{tabular}{ccccccc} 
& \multicolumn{8}{c}{ Placas utilizadas } \\
& pH & Dosificación & EAFS & Ubicación & Oscurecimiento & Batido \\
PL2 & 6,51 & 11 & No & 3 & No & No
\end{tabular}

Tabla 55. Placa utilizada en el ensayo
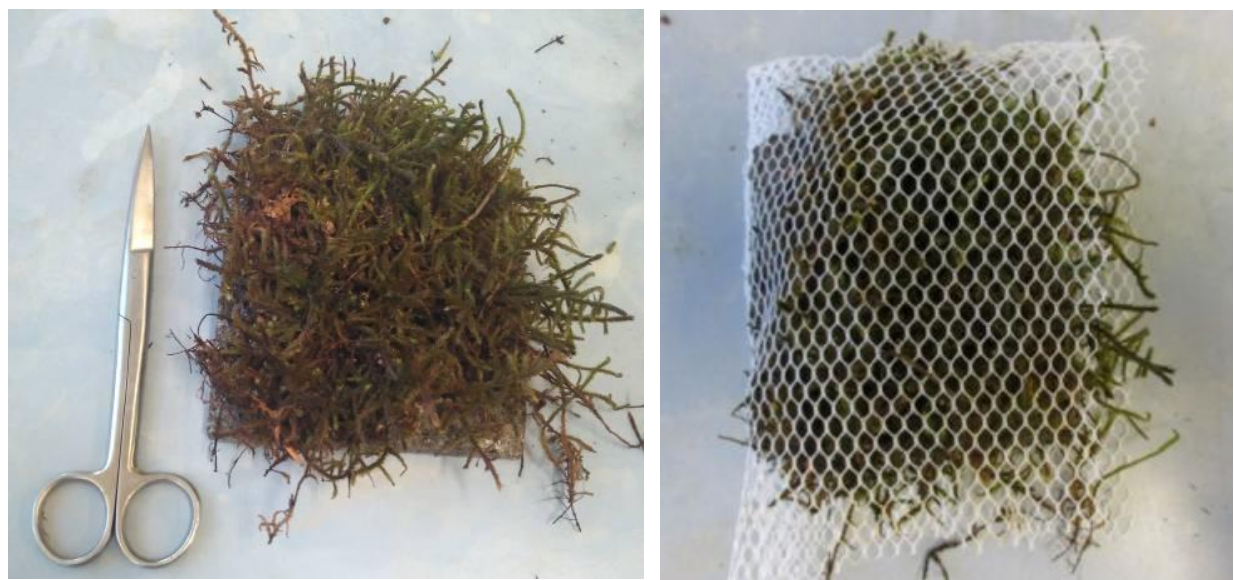

Imagen 134. PL2 con brotes adultos de musgo.

\section{Resultados}

Para esta muestra el ensayo se alarga hasta los 34 días. En este caso se busca que el briófito haya prosperado, anclándose a la placa, dispuesta en horizontal. Finalmente se retiraron las gomas y la malla que hacían de "arnés", comprobando que el briófito no había conseguido adherirse a la placa.

Día 7

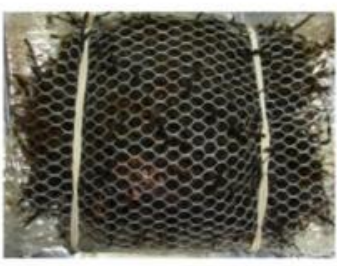

Día 15

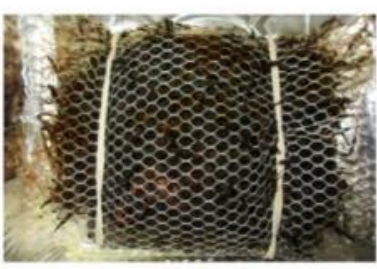

Día 34

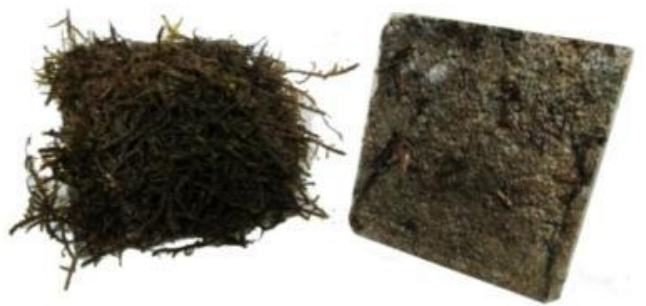

Imagen 135. Resultado muestra PL2 con ejemplar adulto.

\section{Conclusiones}

No se debe descartar este método de cultivo pese al resultado fallido en este ensayo. El día 34 del ensayo, una vez se quitó la malla, se comprobó que, aparentemente el briófito no había perdido humedad, si bien esto se ha podido corroborar durante todo el ensayo. Esto permite 
pensar que el briófito puede, en parte, haber seguido "vivo", pero que no ha conseguido anclarse a la placa.

A su vez, hay que constatar que la Antitrichia Curtipendula carece de rizoides, por lo que puede que la masa de briófito, que normalmente crece adherida al sustrato, requiera otras condiciones para prosperar.

\subsection{Fase experimental 3. Utilización otros briófitos}

Las siguientes fases experimentales no se habían previsto realizar. Sin embargo debido a la carencia de resultados positivos en los ensayos y experimentaciones realizadas hasta el momento, nos ha llevado a probar con otros métodos y briófitos no contemplados inicialmente.

Existen varios factores en los que se puede variar ciertos parámetros con el fin de comprobar en qué se puede haber fallado.

Las condiciones climatológicas de la ciudad de Burgos puede que no sean las más adecuadas para el desarrollo de los musgos. Además en el invierno en el que se ha experimentado, las precipitaciones acumuladas son menos de la mitad de la mediana de los últimos veinte años (Imagen 136). Sin embargo, sobre este fenómeno, no podemos actuar, aparte del incremento del riego.

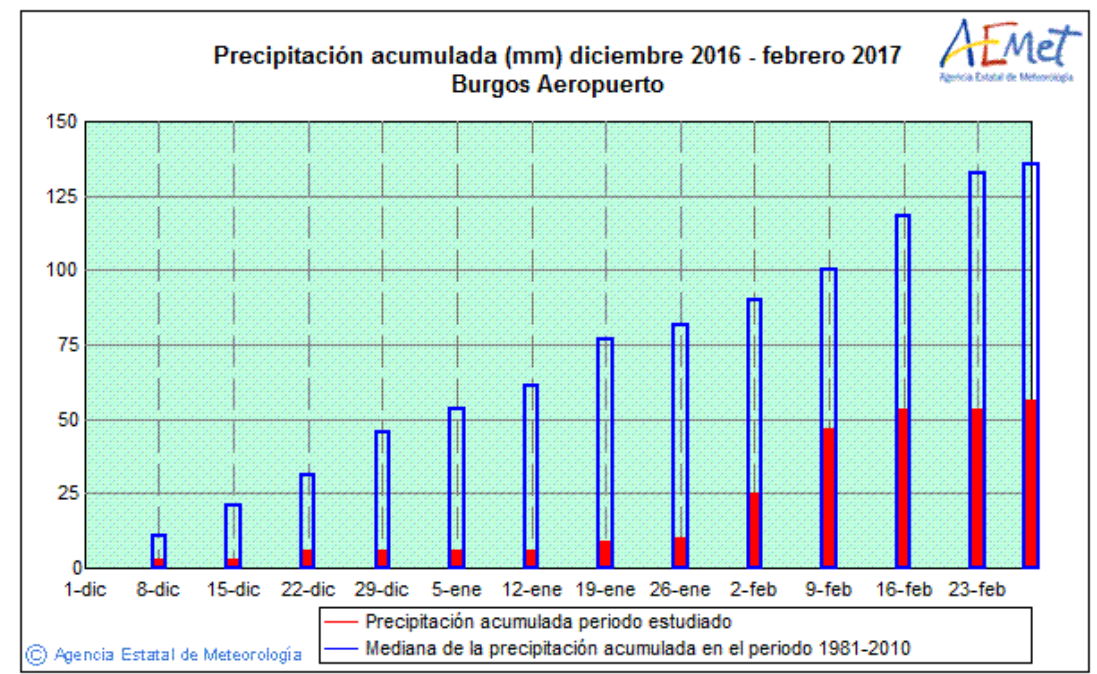

Imagen 136. Gráfico precipitación acumulada invierno 2016-2017 Burgos

Respecto a la solución nutritiva del "batido de musgo", esta se ha obtenido del proyecto "Bio-ceramic system", contemplado en el estado del arte, desarrollado por Luna, l. et al. Dado que esta solución obtuvo resultados positivos en ese sistema, se opta por no realizar variaciones sobre ella.

Un factor a tener en cuenta es la capacidad de adaptación de una especie a un hábitat diferente al suyo. En este caso los briófitos se han recolectado en el parque natural "Sierra Cebollera" de La Rioja. Los climas de Burgos ciudad y el parque natural difieren enormemente, por lo que cabe la posibilidad de que exista una incapacidad de la especie de musgo para adaptarse al nuevo medio.

Para determinar si esto está sucediendo o no, se opta por utilizar una especie de musgo obtenida dentro de la ciudad de Burgos, en un hábitat netamente urbano. Esta especie crece de forma espontanea en el patio de la Facultad de Ciencias de la Universidad de Burgos, junto al muro de fachada donde se han estado disponiendo las muestras en las experimentaciones anteriores. 

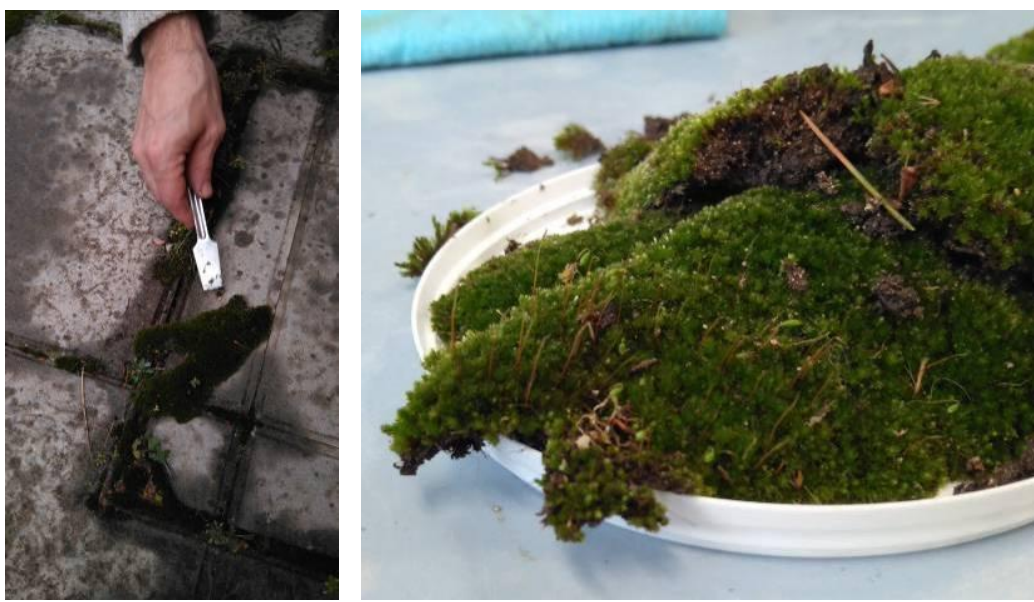

Imagen 137. Muestras del briófito empleado

Estas masas de musgo (Imagen 137) se identifican como dos especies diferentes: Tortula muralis Hedw y Bryum argenteum Hedw.

Tortula muralis Hedw. se trata de un briófito acrocárpico que aparece con frecuencia, formando céspedes almohadillados. Se trata de un musgo muy común que suele crecer en rocas y capaz de resistir la contaminación.

Bryum argenteum Hedw se trata de un briófito acrocárpico muy común de las zonas urbanas, creciendo en grietas en el pavimento, en suelos minerales, piedras, pero también en hábitats más naturales. La forma y color de la punta de sus hojas generan unos matices plateados y brillantes sobre el sustrato.

Ambas especies son acrocárpicas, es decir, que tienden a crecer perpendicularmente al sustrato y en longitud. Esto contrasta con Antitrichia Curtipendula, pleurocárpica, que forma un tapices sobre el terreno. La utilización de este tipo de briófitos se desvía del briófito buscado en capítulos anteriores, sin embargo esta experimentación busca contrastar la capacidad de adaptación de una especie autóctona y urbana frente a la previamente utilizada. De este modo, si la especie autóctona prospera en la superficie puede ser que los fracasos en las experimentaciones anteriores se deban a la incapacidad de adaptación, al tratarse de especies silvestres.

Una vez identificado el briófito se procede a reproducir dos de los ensayos realizados en las anteriores experimentaciones con Antitrichia Curtipendula.

\section{Ensayo 1. Batido de musgo}

Para la elaboración de este nuevo "batido de musgo" se replica la solución nutritiva y la metodología empleada en los anteriores ensayos, sustituyendo una especie de musgo por otra.

El "batido de musgo" elaborado en esta ocasión, incluye parte del sustrato sobre el que se asentaba. Esto se debe a que los rizoides se adhieren al suelo, formando un conjunto, que no se puede separar sin desmenuzar el briófito.

Las placas de mortero MPC empleadas para el ensayo son las que se relacionan en la Tabla 56. 


\begin{tabular}{|c|c|c|c|c|c|}
\hline \multicolumn{6}{|c|}{ Placas utilizadas } \\
\hline & $\mathrm{pH}$ & Dosificación & EAFS & Ubicación & Oscurecimiento \\
\hline PL3 & & 12 & No & 1 & No \\
\hline PL4 & & 13 & No & 1 & No \\
\hline PL5 & 9,88 & 14 & No & 1 & No \\
\hline
\end{tabular}

Tabla 56. Placas utilizadas en el ensayo

Las placas se introducen en los recipientes de plástico transparente utilizados en los anteriores ensayos.

Para este ensayo se opta únicamente por un único emplazamiento: se escoge de nuevo el laboratorio de Edafología y Química Agrícola de la Facultad de Ciencia. Los recipientes se disponen junto a las ventanas, situadas en una fachada con orientación a $18^{\circ}$ del norte exacto. Este emplazamiento es análogo, a escasos metros, de donde se ha recolectado el musgo utilizado.

Para el riego se vuelven a combinar el riego por lámina de agua y rociado por pulverización. De este modo se trata evitar la desecación del musgo.
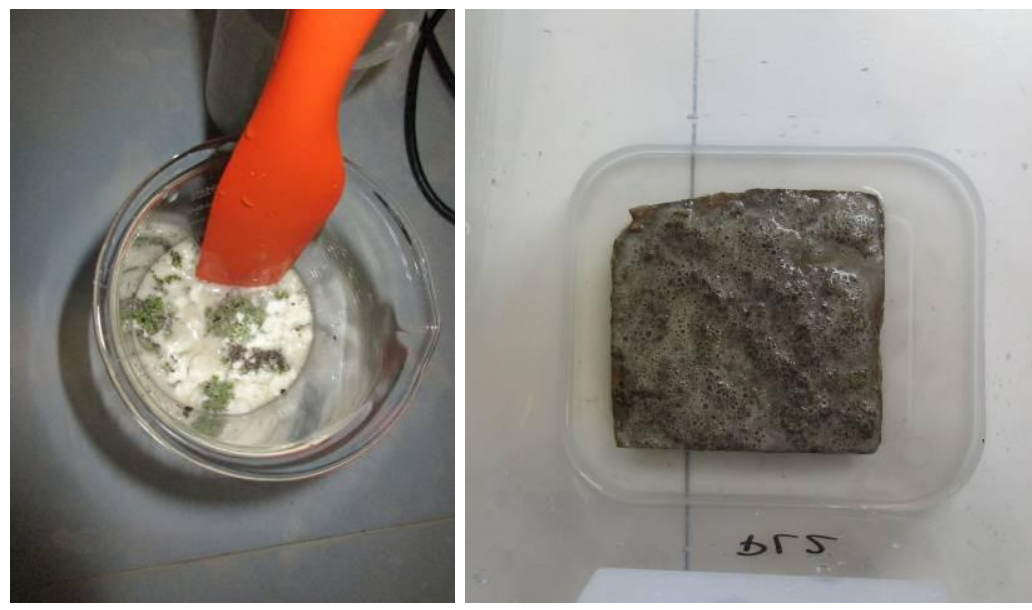

Imagen 138. Elaboración del batido de musgo

\section{Resultados}

Pasados siete días desde el batido de musgo se procede a un control del estado de las muestras. Las muestras han perdido humedad muy rápidamente. El calor de los días en los que se realiza el ensayo propicia la rápida evaporación del agua dispuesto en la lámina y el rociado sobre la superficie.

Pasados dieciocho días las muestras, completamente secas, claramente no prosperan. Sin embargo se intenta alargar el cultivo otros días más para comprobar si se puede revertir la situación, dado que las condiciones climatológicas vuelven a ser más propicias. El día 28 , visto que las muestras no han prosperado pese al riego y a la menor temperatura y mayor humedad ambiental, tiene que darse por fracasado el experimento.

\section{Conclusiones}

Las condiciones climáticas durante el experimento no han sido propicias para conseguir que el ensayo prospere. Las altas temperaturas y la muy baja humedad ambiental han contribuido a que la lámina de agua y el riego por rociado realizado sobre las muestras 
se evaporase muy rápidamente no permitiendo que el briófito tuviera un entorno adecuado para prosperar.

Día 7

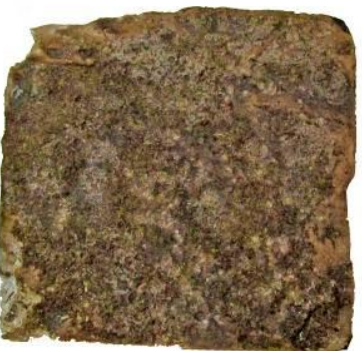

PL3

PL4
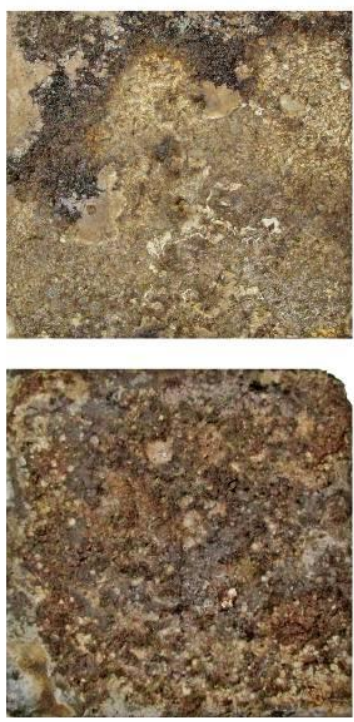

Día 18
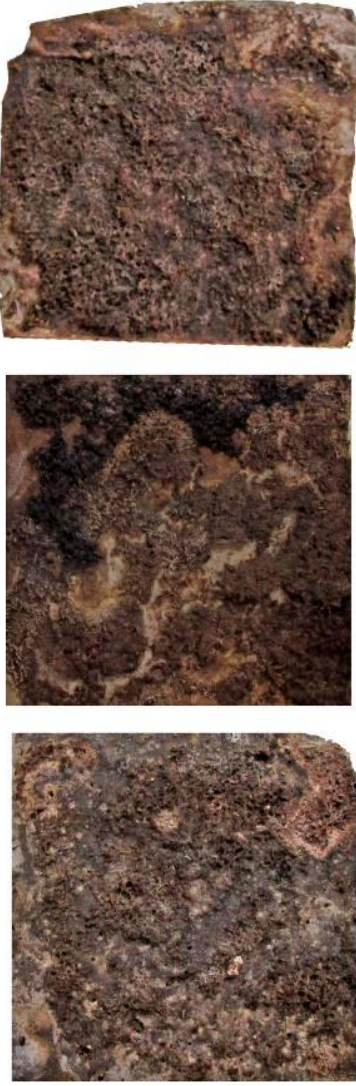

Día 28
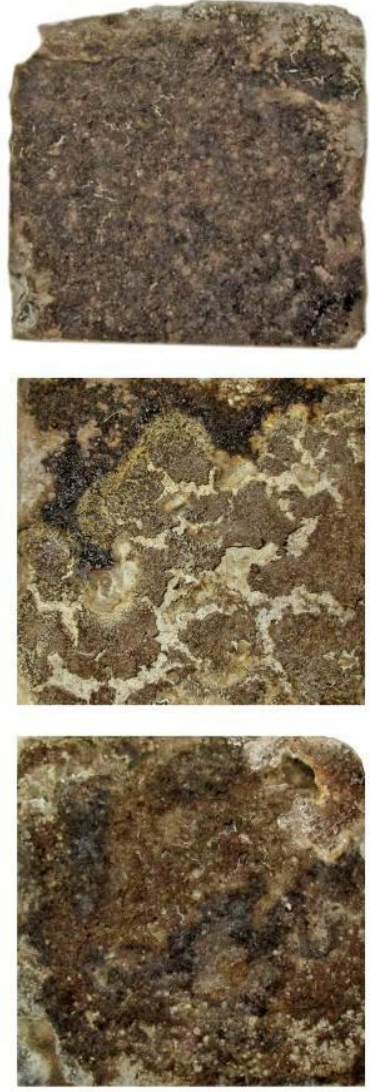

Imagen 139. Análisis fotográfico muestras

\section{Ensayo 2. Ejemplares adultos en superficie}

El ensayo se desarrolla paralelamente al ensayo 1 de la fase experimental 2. Este consiste en disponer el ejemplar de musgo adulto directamente sobre la placa.

Sin embargo, en vez de replicar exactamente el proceso, se opta por hacer un híbrido entre ambos ensayos. El tapiz se dispone sobre la superficie de la placa, que previamente se ha recubierto de una película de "batido de musgo". Esto se realiza para intentar acidificar la superficie e intentar aportar nutrientes al tapiz con el fin de que este prospere.

En esta ocasión se utiliza la placa PL8 (Tabla 57). Los brotes no se disponen sobre una red, ya que el briófito no se trata de una especie con tanto volumen como puede ser Antitrichia Curtipendula. Una vez dispuesto, se riega y presiona con los dedos fuertemente el musgo, tal y como recomienda Martin, $A$. con el fin de que se adhiera al soporte. 


\begin{tabular}{cccccc} 
& \multicolumn{4}{c}{ Placas utilizadas } \\
& $\mathrm{pH}$ & Dosificación & EAFS & Ubicación & Oscurecimiento \\
PL8 & 6,31 & 16 & Sí & 1 & No
\end{tabular}

Tabla 57. Placa utilizada en el ensayo
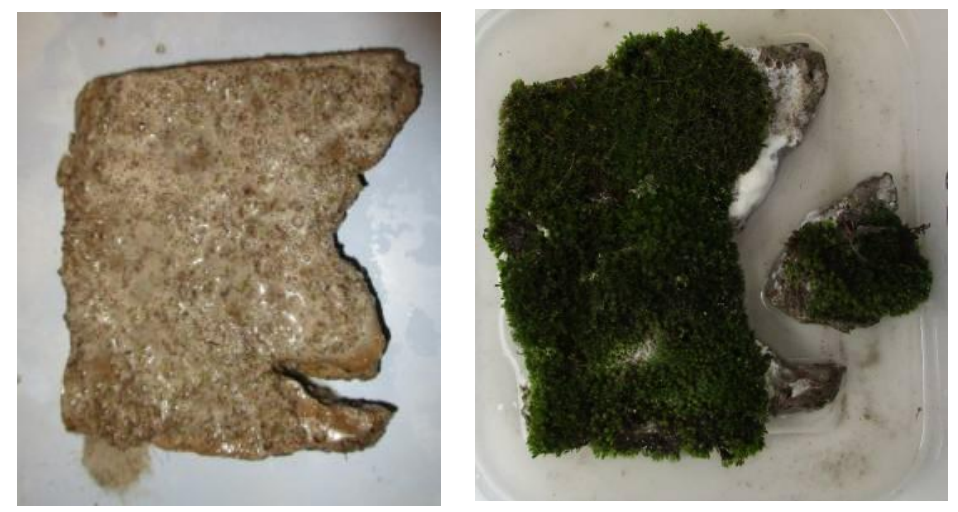

Imagen 140. Elaboración de las muestras.

\section{Resultado}

Día 1

Día 7

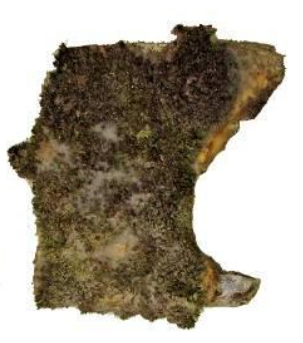

Día 18

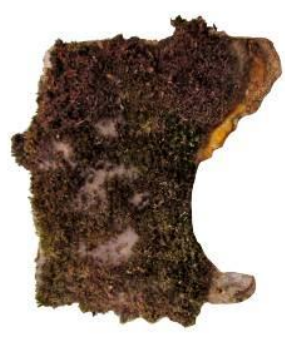

Día 28

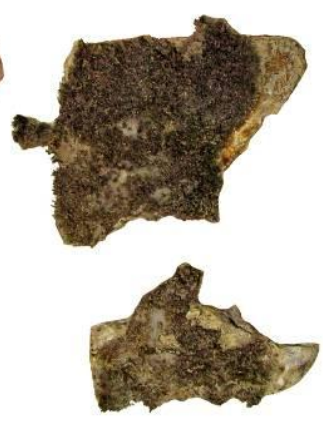

Imagen 141. Análisis fotográfico muestra

El ensayo se desarrolla durante 28 días. Pasados siete días, pese a que brotes del musgo siguen vivos, en general ha perdido mucha humedad y verdor. La aportación de agua no parece mitigar el continuado secado de las muestras, dándose por finalizado el ensayo. Al igual que en el ensayo anterior, las condiciones meteorológicas han sido adversas durante los 28 días. Es por ello que el desecado acelerado ha afectado negativamente al correcto desarrollo de las muestras (Imagen 141)

\section{Conclusiones}

No se ha conseguido que la muestra prospere, en gran medida por la rápida pérdida de humedad de la muestra debida al calor de los días en los que se realizó en experimento.

\section{Ensayo 3. Otras superficies}

El ensayo se desarrolla paralelamente a los anteriores ensayos. Aprovechando el acceso a un material similar al utilizado por Martin, $A$. en su sistema, descrito en la revisión del estado del arte, se intenta ver si este material puede ser compatible con las dos especies 
caracterizadas en esta fase experimental: Tortula muralis Hedw y Bryum argenteum Hedw.

Para ello se utiliza un material geosintético que dispone de una gran malla tridimensional de nylon, muy similar al que utilizaba Martin, $A$. Sobre su superficie se disgrega con los dedos los briófitos encontrados, con el fin de que se inserten en la malla. Cabe destacar que el briófito dispone de parte de suelo.

Una vez insertado en la malla se procede a regarse mediante rociado intenso con frecuencia diaria. El fin es intentar evitar la desecación rápida del musgo, como ha sucedido en los anteriores ensayos. La ubicación escogida es la número 3 de las anteriores fases experimentales.

\section{Resultado}

Pasados 23 días, el briófito sigue en perfectas condiciones e incluso se estar desarrollando numerosos brotes verdes nuevos (Imagen 142). Sin embargo esta demostración empírica no puede obviar que el briófito va acompañado de restos de suelo que pueden haber favorecido este proceso.

No obstante, dando por buenos estos resultados se decide trasladar parte de los brotes a una probeta elaborada con el mortero MPC caracterizado con escorias negras. Esta probeta está vacía interiormente, con forma similar a un macetero.
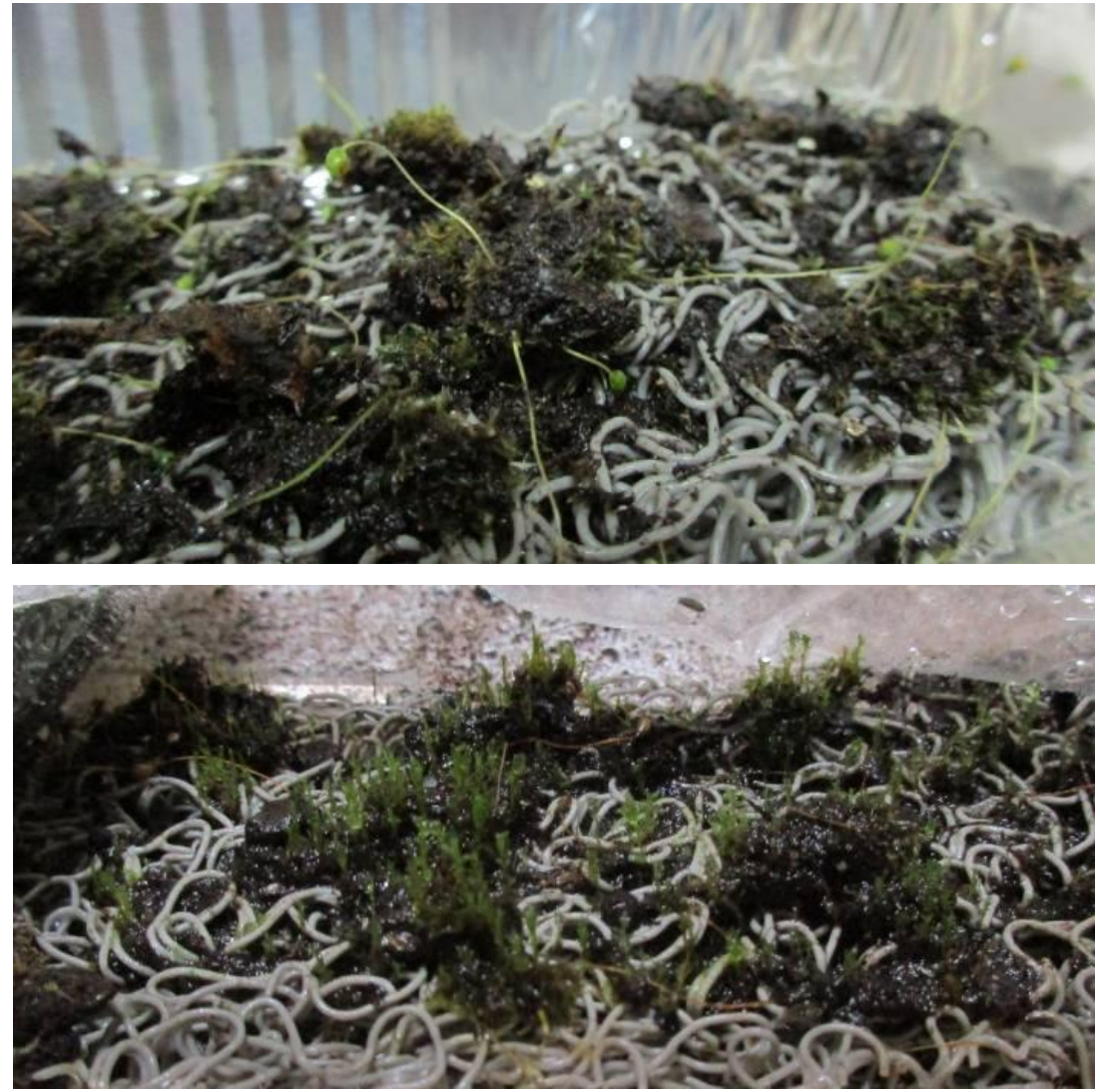

Imagen 142. (Arriba) Briófito día 1. (Abajo) Briófito día 23

El patrón seguido para el mantenimiento de los briófitos en esta nueva superficie es el mismo que con la anterior sintética, replicando riego y ubicación. 

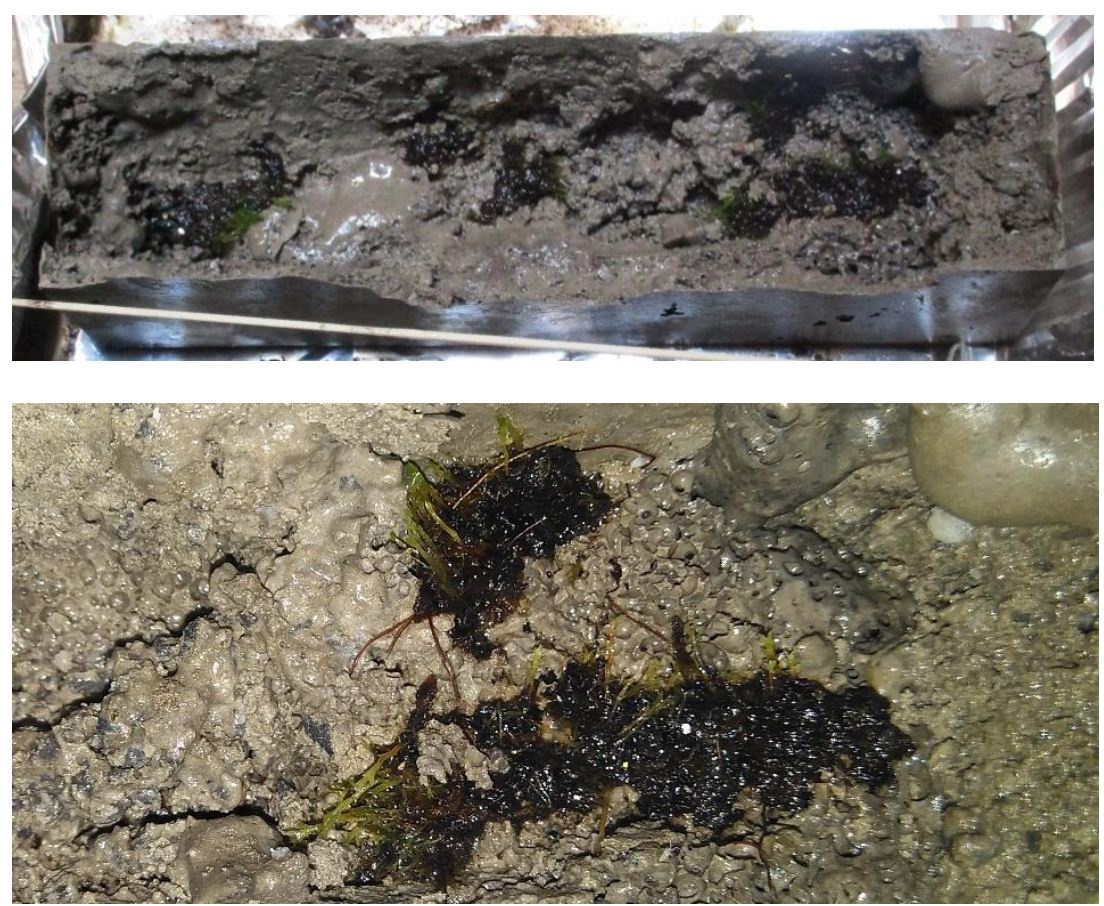

Imagen 143. (Arriba) Briófito día 1. (Abajo) Briófito día 14

Debido a imposibilidad de alargar el procedimiento, el día 14 se comprueba el estado de las muestras. El briófito aparentemente no se ha desarrollado más allá de donde ya estaba, sin embargo los brotes siguen verdes y vivos (Imagen 143).

\section{Conclusiones}

Aparentemente se han conseguido mejores resultados cuando se varía la superficie sobre la que se actúa, aunque esto viene condicionado también por la especie de musgo.

Por otro lado mientras que los 23 días que duró sobre el geosintético el briófito se desarrolló y generó nuevos brotes, el briófito sobre el MPC no prosperó. Esto confirmaría que la conductividad eléctrica es muy elevada en el MPC, y condiciona la proliferación del musgo, aunque en este tiempo, solo se ha visto que ralentice el crecimiento, no la vida vegetal.

De este modo, con las cautelas que deben tenerse debido a la escasa experimentación llevada a cabo con estos soportes, parece haberse dado con un briófito más urbano y que tiene más visos de conseguir prosperar en la superficie investigada.

\subsection{Fase experimental 4. Utilización de microalgas}

Durante las primeras fases experimentales no se han obtenido resultados positivos. Todas las muestras se han ido secando paulatinamente y los briófitos no han prosperado sobre el mortero MPC.

En este punto, se opta por diversificar el estudio que evalúa la bioreceptividad del soporte, dado que los briófitos son especies primitivas cuyo cultivo no es sencillo y depende de múltiples variables: la especie, que ha sido recolectada en un medio silvestre; el método de cultivo; la 
ubicación geográfica... pueden no ser adecuadas para que los briófitos prosperen.

Aprovechando que el proyecto LIFE+ Integral Carbon "Desarrollo en implementación integrada de fotobioreactores para la Reducción de Gases de Efecto Invernadero en la agroindustria" se está desarrollado por la Universidad de Burgos y cuyo objetivo es devolver al suelo los nutrientes que de él se han extraído en la producción de alimentos mediante la generación de algas que pueden actuar como biofertilizante. De este modo se decide emplear algas como medio para comprobar la bio-receptividad del mortero.

La idea es disponer las muestras en un canal de agua recirculada que se utiliza para la generación de microalgas. Estas algas actualmente crecen en este canal sobre una malla plástica de recolección, por biocolonización. El fin es simular este proceso con las placas de mortero MPC.

De este modo ya se ha evaluado previamente la bio-receptividad de un soporte por Manso, S. el al, en un producto similar [7].

Para ello se utiliza el canal de agua desarrollado por Miñón, J. et al en el contexto del proyecto citado [8] y descrito en la metodología experimental.

La placa utilizada es la PL9, (Tabla 58).

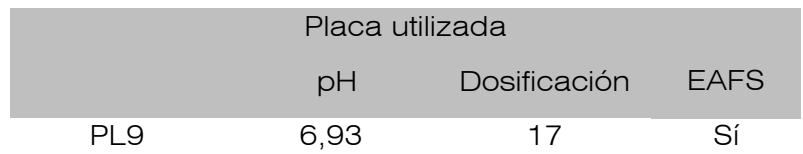

Tabla 58. Placa utilizada en el ensayo

Así mismo se dispone una placa de cemento Portland convencional, para poder comparar el proceso de crecimiento de microalgas respecto al mortero MPC.

\section{Caracterización de las microalgas}

La caracterización de las micro-algas presentes en el canal, está definida en la Tesis Doctoral de Miñón, J. [9]. Estas se obtienen en las costras de suelo de viñedos en el municipio conquense de Fuente de Pedro Naharro.

El procedimiento para la obtención del inoculo de microalgas, según indica Miñón, J. es el siguiente:

- Se toman $10 \mathrm{~g}$ de costra de suelo y se diluyen en $100 \mathrm{~mL}$ de medio de cultivo BG11 esterilizado.

- Se agita el contenido durante 30 min en agitación orbital a 150 rpms hasta lograr una buena dispersión del suelo.

- La solución se sónica con un pulso de un minuto de duración e intervalos de 5 pulsos/segundo y con una amplitud de salida de $90 \mathrm{~Hz}$.

- Se toma una alícuota de $100 \mu$ que se cultiva en una placa de Petri con medio de cultivo BG11 y agar al $2 \%$.

- Se incuban las placas en una cámara climática, invertidas y cubiertas con un papel de filtro para permitir una iluminación difusa e impedir la inhibición por exceso de luz. 
Pasados 20 días, se identifican de forma visual las colonias de algas diferentes, realizando una repica en una nueva placa Petri con medio de cultivo BG11. Pasados 12 días las colonias aisladas se inoculan en $10 \mathrm{~mL}$ medio de cultivo BG11 líquido.

Las cinco especies inicialmente identificadas por Miñón, J. fueron del género Chlorella. Con el objeto de conseguir una mayor variedad de especies de algas del suelo se repitió el proceso de extracción al que se le modificó su composición para incrementar su capacidad de selección.

La Tabla 59 recoge la identificación realizada por Miñón, J. [10] de las especies de algas y cianobacterias.

$\begin{array}{ll}\begin{array}{ll}\text { Nombre } & \multicolumn{1}{c}{\text { Identificación microalgas aisladas }} \\ \text { Observaciones }\end{array} \\ \begin{array}{l}\text { Klebsormidium flaccidum } \\ \text { Haslea spicula strain BA28 }\end{array} & \text { Crece bien sobre soporte sólido } \\ \text { Navicula pulchripora isolate UTEX 2604 } & \\ \text { Oocystis sp. FG2/8.5E } & \text { Crece bien en medio liquido } \\ \text { Microcoleus sp. E6 } & \begin{array}{l}\text { Cianobacteria filamentosa, crece bien en } \\ \text { soporte sólido }\end{array}\end{array}$

Tabla 59. Nombre, género y observación de las microalgas aisladas

\section{Resultado}

El ensayo se desarrolla durante 42 días. Pasados los primeros diez días se puede observar que la superficie ha sido colonizada por las microalgas que se adhieren a la placa.

Dado que no ha sido viable la disposición de la infraestructura necesaria para la monitorización de las algas con LabVIEW [11], se cuantifica el crecimiento biomásico mediante dos técnicas:

- Seguimiento fotográfico.

- Determinación de la cantidad de biomasa generada por unidad de superficie.

Día 10

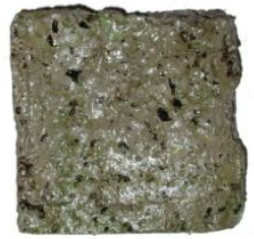

PL9

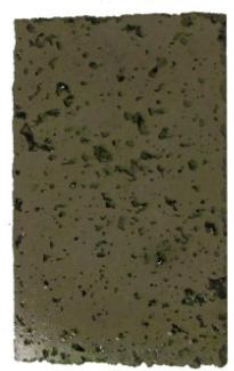

Día 20
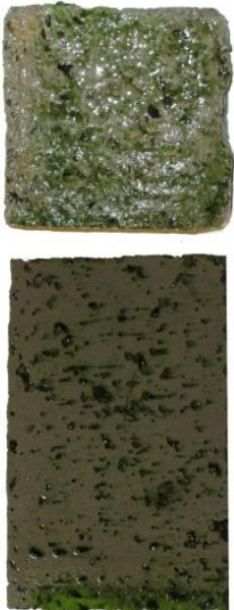

Día 28
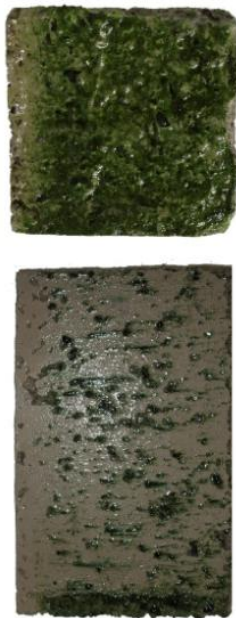

Día 42
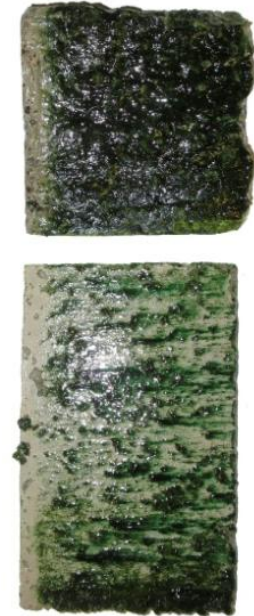

Imagen 144. Análisis fotográfico muestras 
El día 10 ya es patente que las algas están colonizando la superficie de la placa PL9 y también la placa de cemento portland. Sin embargo se puede comprobar que la colonización en este segundo medio es más lenta.

De este modo, parece determinarse que el mortero es bio-receptivo, aunque aplicando ciertas cautelas, debido al alcance del ensayo. El cultivo de algas en el canal de agua supone un continuo recirculado de agua, que arrastra las sales solubles que pudiera contener y evita que estas cristalicen en el propio mortero. De este modo, el material se hace más compatible.

Una medida de la bio-receptividad puede determinarse por la cantidad de biomasa generadas en la superficie en función de esta y comparándolas con las de otro material. Para ello se extraen las algas dispuestas en la superficie y se pesan, según se ha explicado en la metodología experimental. Esta biomasa se divide por la superficie de la placa y hayamos los ratios de biomasa generada por día y centímetro cuadrado. (Tabla 60)

\begin{tabular}{lllll} 
& \multicolumn{3}{c}{ Peso microalgas generadas } \\
Nombre & Biomasa & Superficie & Ratio & Ratio/día \\
\cline { 3 - 4 } & $\mathrm{gr}$ & $\mathrm{cm} 2$ & $\mathrm{gr} / \mathrm{m} 2$ & $\mathrm{gr} / \mathrm{día} \cdot \mathrm{m} 2$ \\
Portland & 0,2604 & 0,01 & 26,04 & 0,62 \\
& 0,0974 & 0,01425 & 6,835 & 0,1627
\end{tabular}

Tabla 60. Peso microalgas generadas

Los valores obtenidos para la placa PL9 son muy superiores a los de la de cemento Portland, siendo casi cuatro veces mayores.

Estos datos cabe compararlos con los valores óptimos, hayados en el canal de agua por Miñon, J. [12]. Según estos, la productividad diaria de materia seca, oscila entre 1,00 y 3,78 $\mathrm{gr} / \mathrm{día} \cdot \mathrm{m}^{2}$, dependiendo del ciclo y el tipo de residuo introducido en el líquido recirculado.

Aquí se podrían hacer dos comparaciones, ya que el ciclo menos productivo es el primero $\left(1,00 \mathrm{gr} / \mathrm{dí}^{\prime} \cdot \mathrm{m}^{2}\right)$ o con la media aritmética de todos los ciclos $\left(2,609 \mathrm{gr} /\right.$ día $\left.\cdot \mathrm{m}^{2}\right)$.

En ambos casos la productividad es más baja en las placas de mortero, tanto Portland como MPC, que en las muestras de referencia de Miñon, J., en las cuales el crecimiento debe ser óptimo.

\begin{tabular}{|c|c|c|c|c|c|}
\hline \multicolumn{6}{|c|}{ Peso microalgas generadas } \\
\hline Nombre & $\begin{array}{l}\text { Productividad } \\
\text { ensayo }\end{array}$ & $\begin{array}{l}\text { Referencia } \\
\text { ciclo } 1\end{array}$ & Diferencia & $\begin{array}{l}\text { Referencia } \\
\text { media }\end{array}$ & Diferencia \\
\hline & gr/día $\cdot \mathrm{m} 2$ & $\mathrm{gr} / \mathrm{dí} a \cdot \mathrm{m} 2$ & & $\mathrm{gr} / \mathrm{día} \cdot \mathrm{m} 2$ & \\
\hline PL9 & 0,62 & 1 & $-38 \%$ & & $-76,24 \%$ \\
\hline Portland & 0,1627 & 1,00 & $-83,73 \%$ & 2,600 & $-93,76 \%$ \\
\hline
\end{tabular}

Tabla 61. Comprarativa productividades biomasa seca

Con la cautela expuesta anteriormente y dado que el sistema requeriría de un mayor número de ensayos, lo cual no ha sido posible debido al 
tiempo disponible, cabe afirmar que el soporte es bio-compatible con la vida vegetal y que los ratios de producción de biomasa seca son aceptables, viendo los resultados de la Tabla 61.

\subsection{Conclusiones}

A lo largo del presente capitulo se han ensayado distintos métodos para evaluar la bio-receptividad del mortero MPC. Inicialmente estos ensayos se reducían a un programa experimental. Este consistía en un "batido de musgo" es decir una solución nutritiva mezclada con brotes de musgo dispuesto directamente sobre la superficie del mortero.

También, inicialmente se había planteado la utilización de una única especia de briófito Antitrichia curtipendula, recolectada en un medio natural y usada directamente para este fin como especie pionera que colonizase la superficie del mortero.

Sin embargo estos ensayos no han prosperado, debido a distintos factores, que se han ido justificando en cada fase experimental. Esta situación ha llevado a intentar experimentar con otros métodos de cultivos, otros briófitos y finalmente otras especies.

Se ha podido llegar a la conclusión que la elección de la especie Antitrichia curtipendula quizá no ha sido la más adecuada para el propósito buscado. Esta especie, tiene gran dificultad de adaptación al medio urbano en el que se ha intentado reproducir.

Sin embargo, el briófito autóctono de Tortula muralis Hedw y Bryum argenteum Hedw, si ha llegado a prosperar, tanto en el geosintético como en el MPC (con la cautela señalada en la fase experimental referida), aunque siempre diseminando los briófitos sobre la superficie y con el "batido de musgo".

Esto permite pensar que el "batido de musgo" no ha sido el método de cultivo preferible para este propósito, pese a las numerosas indicaciones en la bibliografía de sus bondades.

Esto ha llevado a la investigación al punto de investigar la biocompatibilidad del material con microalgas. El material, siempre teniendo en cuenta los escasos ensayos llevados a cabo, parece ser bio-receptivo ya que el crecimiento de las algas en la superficie es constatable. Sin embargo, tal y como se ha indicado anteriormente, el cultivo de algas en el canal de agua supone un continuo recirculado de agua, arrastrando las sales solubles que pudiera contener y evitando que estas cristalicen en el propio mortero. Por consiguiente se consigue mediante el ensayo reducir la salinidad, lo cual lo hace más tolerable. 
[1] Atherton, I.; Bosanquet, S.; Lawley M. Mosses and Liverworts of Britain and Ireland. A Field Guide. (2010) British Bryological Society. ISBN: 978-0-9561310-1-0.

[2] Martin, A. Moss gardening. (2015) ISBN 978-1-60469-560-1

[3] Prieto, B., Silva, B., Lantes, O. Biofilm quantification on stone surfaces: Comparison of various methods (2004) Science of the Total Environment, 333 (1-3), pp. 1-7

[4] Manso, S.; De Muynck, W.; Segura, I.; Aguado, A.; Steppe, K.; Boon, N.; De Belie, N. Bioreceptivity evaluation of cementitious materials designed to stimulate biological growth. (2014) Science of the Total Environment , 481, pp. 232-241

[5] Guillitte, O., Dreesen, R. Laboratory chamber studies and petrographical analysis as bioreceptivity assessment tools of building materials (1995) Science of the Total Environment, 167 (1-3), pp. 365374

[6] Institute for Advanced Architecture of Catalonia (laaC). Open Thesis Fabrication Program in 2013. https://iaac.net/research-projects/selfsufficiency/bio-ceramic-system/

[7] Manso, S.; De Muynck, W.; Segura, I.; Aguado, A.; Steppe, K.; Boon, N.; De Belie, N. Bioreceptivity evaluation of cementitious materials designed to stimulate biological growth. (2014) Science of the Total Environment , 481, pp. 232-241

[8] Miñón, J., Ruiz, G., Navas, L.M., Rad, C., Martínez, V. Sistema de monitorización del crecimiento de algas filamentosas basado en análisis de imagen (2014) I Symposium Nacional de Ingeniería Hortícola "La Agromótica en la Horticultura"

[9] Miñón, J. Desarrollo y análisis técnico-económico de la gestión de nutrientes residuales en la producción de biomasa de algas para fines agrícolas y ganaderos (2017) Universidad de Valladolid, PhD thesis

[10] Íbid.

[11] LabVIEW http://www.ni.com/labview/why/esa

[12] Miñón, J. Desarrollo y análisis técnico-económico de la gestión de nutrientes residuales en la producción de biomasa de algas para fines agrícolas y ganaderos (2017) Universidad de Valladolid, PhD thesis 



\section{Capítulo 8. Conclusiones y líneas de investigación}

El trabajo desarrollado en la presente investigación ha proporcionado una primera aproximación al uso de un material de revestimiento de fachadas con propiedades bio-receptivas para el crecimiento biológico en su superficie, dando lugar a la patente con solicitud P201730424.

Esta invención desarrollada a partir de la Tesis Doctoral, trata de un mortero con aglomerante de cemento de magnesio-fosfato y componentes procedentes de usos industriales, que puede usarse como soporte biológico. El fin es poderlo utilizar como revestimiento de fachadas en sustitución de los jardines verticales, mucho más complejos y de mantenimiento más costoso.

\section{Conclusiones generales}

La presente Tesis Doctoral surge con un triple enfoque: generar nuevas superficies verdes en las zonas urbanas; permitir la simplificación máxima de los sistemas de jardín vegetal actualmente existentes y favorecer la utilización de subproductos industriales que permitan acercarnos a una economía circular.

Dado que actualmente existen pocos materiales que permitan el crecimiento de especies biológicas en su superficie, y que la bioreceptividad, en sí, es una materia poco investigada, la investigación se afrontó como un primer paso para abordar los materiales biocompatibles.

El objetivo principal era desarrollar un producto que explorara esta capacidad de los materiales a ser colonizados por vegetales, mediante la modificación físico-química de un material.

De esta forma se buscó un material con un pH más reducido, y cuya superficie permitiese una bio-receptividad mejorada. En este punto se investigan los morteros químicos no procedentes del Cemento Portland, puesto que estos disponían de una alta alcalinidad lo que reducía drásticamente las posibilidades de prosperar de una gran mayoría de las especies vegetales. Esta investigación condujo a los cementos químicos de magnesio-fosfato (MPC), los cuales se generaban a través de una reacción química ácido base y cuyo resultado era un $\mathrm{pH}$ neutro óptimo para la proliferación vegetal.

En un proceso intermedio se investigó la posibilidad de sustituir productos de alta pureza, y por tanto de alto coste, tanto monetario como ambiental, empleando subproductos. 
Los resultados han mostraron que este triple enfoque propuesto es posible. El producto elaborado tiene características bio-receptivas mejoradas ( $\mathrm{pH}$, porosidad y rugosidad), y a su vez el coste ecológico del producto final desarrollado con agregados de escorias negras de horno eléctrico de arco (EAFS) es muy inferior al que pudiera darse con materiales de gran pureza.

\section{Conclusiones específicas}

En vista de los objetivos específicos marcados al comienzo de la tesis, a continuación se describen las conclusiones más relevantes. Estas se han dividido en dos aspectos diferenciales: los resultados obtenidos en el mortero MPC y la implantación o cultivo del briófito en la superficie del material.

\subsection{Mortero MPC}

La investigación se centró en un primer momento en una revisión de la literatura sobre los materiales más proclives a la colonización vegetal. Se descartaron todos aquellos que por su propia composición o especificaciones requirieran más de una capa.

En este punto el mortero de magnesio-fosfato con adición de escorias negras (EAFS) cumple todas las especificaciones requeridas, ya que se trata de un material autoportante que es propenso, gracias a su rugoso acabado superficial, a su porosidad, capacidad de absorción y $\mathrm{pH}$ a ser colonizado. El hecho de tener esta capacidad permite pensar que se podrá reducir al máximo el mantenimiento, ya que con las correctas condiciones de soleamiento y humedad la propia capa vegetal sería capaz de auto-regenerarse.

El mortero convencional con cemento Portland como soporte se descartó casi desde un punto inicial. El pH de losproductos derivados de éste es altamente alcalino.

La utilización del mortero MPC surge de esta necesidad. Inicialmente también se han investigado diferentes tipos de la magnesita, desde la más pura hasta el subproducto utilizado en la caracterización. Los resultados arrojados sitúan el $\mathrm{pH}$ entre 6 y 7 , valores cercanos a la neutralidad.

La adición de escorias negras de horno eléctrico de arco no ha supuesto una variación en los resultados de $\mathrm{pH}$.

Por otro lado el mortero MPC dispone de una capacidad de absorción de agua por capilaridad muy elevada. Solamente los morteros tradicionales que incorporan aireantes consiguen acercarse a estos valores. De esta manera se intuye una alta porosidad, y una red capilar interior que permite la circulación del agua retenido por el interior. La adición de escoria no hace más que disminuir ligeramente este indicador y mantenerlo más controlado.

Finalmente respecto al acabado superficial buscado, utilizando escorias negras de tamaño entre 1 y $4 \mathrm{~mm}$ se perseguía también el fin de conseguir una superficie totalmente rugosa sobre la que los rizoides pudieran anclarse.

El diseño global, orientado al objetivo de mejorar la bio-receptividad del conjunto parece haberse obtenido, aunque requerirá de mejoras. 
La utilización de subproductos industriales en la elaboración parece no haber tenido consecuencias en el resultado final. Si bien no se han llegado a caracterizar las dosificaciones que incluían magnesita de 83\% de pureza, si se ha caracterizado las que se realizaron con polvo de ciclón PC8 de 63\% de pureza. Los resultados, descontando la conductividad eléctrica, han sido mejores que los mínimos exigibles, que se establecieron al comienzo de la fase experimental. Por lo tanto, la utilización de este subproducto no ha supuesto un menoscabo en las propiedades buscadas, ya que estas cumplen con los parámetros de referencia

La inclusión de las escorias negras en la dosificación se ha planteado desde un primer momento como un agregado de doble función: mejorar la rugosidad superficial del mortero y reducir el coste ambiental del mismo.

Sin embargo la utilización de EAFS ha supuesto también una mejora importante en las resistencias a flexotracción. Esta adición, que se había consultado en otro tipo de materiales cementosos, ha supuesto un incremente entre el $100 \%$ y el 300\% en las resistencias mecánicas respecto al material que no lo agregaba.

La reutilización de las escorias negras de horno eléctrico de arco suponen un beneficio medioambiental importante, puesto que supone un 50\% del producto de mortero empleado, consiguiendo además un valor añadido frente al impacto ambiental que producen y la eliminación de residuos.

Se ha comprobado que las diferentes mezclas de cemento de magnesio-fosfato empleado disponen de unas características físicoquímicas que tienden a favorecer la presencia vegetal en su superficie.

\subsection{Colonización vegetal}

Para la evaluación de la bio-receptividad se ha utilizado como especie vegetal pionera un briófito recolectado en un hábitat silvestre: Antitrichia Curtipendula.

No se ha conseguido evaluar la bio-receptividad del mortero MPC utilizando esta especie briófita por dos razones. Por un lado se trató el cultivo mediante la disposición de la solución nutritiva "batido de musgo", el cual no ha ofrecido resultados favorables. Por otro lado, la conductividad eléctrica del mortero, que evalúa la presencia de iones salinos, ha resultado extremadamente alta, inhibiendo la posibilidad de desarrollo de esta especie silvestre.

Si que se han conseguido resultados positivos utilizando otra técnica y otra especie de briófito, en este caso autóctono, Tortula muralis Hedwy Bryum argenteum Hedw.

Los resultados obtenidos mediante la colonización a través de microalgas autóctonas, permiten afirmar que el material obtenido es biocompatible con la vida vegetal, sin embargo, este resultado debe considerarse con cautela, ya que la recirculación de agua puede variar el resultado de la salinidad presente en el mortero.

Por lo tanto, después de las fases experimentales llevadas a cabo, se muestra la necesidad de realizar algún tratamiento adicional que reduzca la conductividad eléctrica del material. 


\section{Futuras líneas de investigación}

La presente Tesis Doctoral ha mostrado que existe la posibilidad de utilizar un mortero químico con áridos reciclados como soporte bioreceptivo para la elaboración de envolventes verdes de edificaciones.

Sin embargo, la utilización de este tipo de mortero, dada su innovación, supone un reto para la industria de la construcción, más aún si incluye organismos vivos como son los briófitos. Por ello, durante el desarrollo de la investigación han ido surgiendo nuevas campos que permitirían desarrollar las siguientes líneas de investigación:

- Analizar la posibilidad de sustituir el resto de componentes por otros subproductos industriales con el fin de reducir costes y optimizar la sostenibilidad del mortero.

- Estudiar la mejora de la trababilidad del mortero, mediante la hidratación previa del PC8 u otras técnicas que permitan mejorarla.

- Otro de los problemas hallados durante la investigación ha sido la muy alta conductividad eléctrica (CE) del mortero. Para el mitigamiento de este problema cabe investigar dos líneas que pueden reducir la salinidad del conjunto: Por un lado se podría buscar otra fuente de magnesio, diferente al PC8, que no libere iones. La otra solución podría venir del lavado del producto hasta el que se eliminen parte de ellos o su totalidad.

- Sería interesante tanto ajustar la dosificación como completar la caracterización de los morteros MPC.

- Una vez colonizada la superficie, sería interesante evaluar el grado de aislamiento térmico que proporciona en los diferentes estados de la capa vegetal y estaciones climatológicas.

- Se debería estudiar la viabilidad técnica y económica de la fabricación a escala industrial de este tipo de morteros. No solamente por el mortero en sí, sino también por el "cultivo" de briófitos en su superficie. Para ello se requerirá un riguroso estudio de especies, modo de recolección, regeneración.... También se debería estudiar, debido al alto coste ecológico, la posibilidad de generar nuevos jardines de musgo, por ejemplo en cubiertas vegetales de edificios, que sirvan de nicho para la recolección controlada de estas especies.

- La fase experimental de crecimiento de briófitos no ha sido lo suficientemente extensa que se requeriría, por lo que es necesario ampliar este programa experimental, especialmente variando de localizaciones y ubicaciones; especies de briófitos; método de cultivo...

- Se han utilizado microalgas para evaluar la bio-receptividad del mortero MPC. Vistos los resultados positivos, podría evaluarse este producto como superficie duradera para la generación de mircroalgas en un canal de agua.

- Finalmente dado que no se ha podido investigar tales extremos, podría evaluarse y cuantificarse el mantenimiento necesario durante la vida del los briófitos y las alternativas de ubicación. De este modo habría un estudio que permitiera comparar el mantenimiento entre un jardín vertical normal y un mortero que explora la bio-receptividad. 


\section{Anexo. Producción científica}

\section{Patentes de invención}

Descripción: Mortero con aglomerante de cemento de magnesio-fosfato y componentes procedentes de usos industriales

Inventores: $\quad$ Daniel Garabito López y Roberto Vallejo Diez

Entidad depositaria: Universidad de Burgos.

No Solicitud: $\quad$ P201730424 (Marzo2017).

\section{Subvenciones}

$\checkmark$ Convocatoria de becas para el desarrollo de proyectos Programa Prototipo Comercializables

Proyecto: Diseño de un panel de fachada de una especie de briófito tapizante cuyo mantenimiento se nulo o casi nulo

Autores: Daniel Garabito López y Roberto Vallejo Diez

Convocante: Universidad de Burgos. Proyecto de Desarrollo de Actividades de Transferencia de Conocimiento desde la Universidad de Burgos hacia el tejido empresarial (proyecto TCUE)

Financiación: Fundación Universidad de Burgos, Fundación Caja de Burgos, Fundación Universidades y Enseñanzas Superiores de Castilla y León (FUESCYL), adscrita a la Consejería de Educación de la Junta de Castilla y León.

Lugar y fecha: $\quad$ Burgos, 2013-2014

\section{Artículos}

Título: Envolventes verdes con briófitos. Una revisión del estado del arte

Revista: Boletín sociedad española de briología (BSEB)

Autores:Daniel Garabito López, Roberto Vallejo Diez, Eduardo Montero García, Javier Garabito López y Javier Martínez-Abaigar

Estado: En revisión (Noviembre 2016) 


\section{Congresos nacionales e internacionales}

Título: Strategies to increase urban green areas: Comparative study between living wall systems and façade skins built with energy efficient bio-receptive materials

Autores:Daniel Garabito López, Roberto Vallejo Diez, Carlos Rad Moradillo, Eduardo Montero García y Javier Garabito López.

Evento: 30th International Conference on Efficiency, Cost, Optimisation, Simulation and Environmental Impact of Energy Systems

Lugar y fecha: San Diego, Estados Unidos, Julio 2017

Título: Use of bryophytes in the building envelope. A review of the state of the art.

Autores:Daniel Garabito López, Roberto Vallejo Diez y Javier Garabito López.

Evento: III International congress on construction and building research (COINVEDI 2015)

Lugar y fecha: Madrid, Diciembre 2015

Título: Sistemas constructivos de fachadas que incorporan vegetación para acondicionamiento energético y ambiental. Una revisión del estado del arte

Autores:Daniel Garabito López, Roberto Vallejo Diez y Eduardo Montero García.

Evento: $9^{\circ}$ Congreso Nacional de Ingeniería Termodinámica (9CNIT)

Lugar y fecha: Cartagena, Junio 2015 